\title{
PARADOSIS
}

Études de littérature et de théologie anciennes

XXXIX

CHARLES MUNIER

SAINT JUSTIN APOLOGIE

POUR LES CHRÉTIENS

Édition et traduction 
PARADOSIS

Etudes de littérature et de théologie anciennes

XXXIX

FONDÉE PAR

Othmar Perler

ÉDITÉE PAR

Dirk van Damme - Otto Wermelinger 


\section{CHARLES MUNIER}

\section{SAINT JUSTIN \\ APOLOGIE \\ POUR LES CHRÉTIENS}

Édition et traduction 
Publié avec l'aide du Conseil de l'Université de Fribourg Suisse

(c) 1995 by Editions Universitaires Fribourg Suisse Imprimerie Saint-Paul Fribourg Suisse

ISBN 2-8271-0682-5 


\section{AVANT-PROPOS}

Offrir aux lecteurs de langue française une édition de l'Apologie de Justin qui reflète le plus exactement possible l'état des recherches concernant cet ouvrage majeur du IIe siècle, tel a été notre souci constant au cours des longues anées de sa préparation.

Pour le texte, en attendant l'édition de CGS, toujours "à paraître", malgré les travaux de W. Schmid et de ses émules, il a semblé que le meilleur parti était de reproduire l'édition de A.W.F. Blunt (Cambridge 1911). Cette édition présente, entre autres avantages, celui de respecter l'ordre du manuscrit en Apol. II,3-9, ordre malencontreusement abandonné en 1742 par Dom Prudent Maran, et par la plupart des éditeurs et traducteurs après lui.

Afin de souligner l'unité de l'œuvre, il a semblé utile de proposer une numérotation continue des chapitres, de 1 à 83 . Cette numérotation nouvelle n'affecte, en fait, que les quinze chapitres d'Apol. II; elle devrait permettre de simplifier et d'harmoniser le mode de citation, qui deviendrait désormais: Justin, Apol. (suivi du numéro du chapitre - de 1 à 83). Cependant, afin de ne point dépayser les lecteurs accoutumés à l'ancien mode de citation, nous avons conservé, pour la présente introduction, l'ancienne numérotation de la "Deuxième Apologie".

Nous avons tenu le plus grand compte des traductions en langue française, qu'il s'agisse de l'excellente traduction de L. Pautigny, Paris 1904, reprise et améliorée par endroits par les soins d'A. Hamman, Paris 1958 (La philosophie passe au Christ. L'œuvre de Justin), ou de celle de A. Wartelle, Paris 1987, sans négliger celles qui ont paru en langue étrangère. Qu'il nous soit permis de dire que celle de $\mathrm{H}$. Veil, parue à Strasbourg en 1894, demeure l'une des toutes meilleures.

En présence de l'abondant commentaire suivi de l'édition d'A. Wartelle, il n'a pas semblé nécessaire de répéter cette opération présentement. Il n'était pas question non plus de reproduire les excellents Index: des noms propres, et des mots grecs, joints à cet ouvrage. Par contre, l'Index scripturaire a pu bénéficier des travaux du Centre d'analyse et de documentation patristiques de Strasbourg (CADP) et des recherches d'O. Skarsaune, The proof of prophecy, Leiden 1987. On y a joint un Index des auteurs modernes qui pourra aider le lecteur à s'orienter dans la bibliographie récente.

Celle-ci a été réduite à l'essentiel et assignée aux questions envisagées dans l'introduction. Le lecteur trouvera des indications bibliographiques 
plus fournies dans notre étude: L'Apologie de saint Justin, philosophe et martyr, parue dans la collection Paradosis 38, Fribourg Suisse, 1994. A Monsieur le Professeur Otto Wermelinger, maître d'œuvre de l'édition de ces deux ouvrages consacrés à l'Apologie de Justin, au Conseil de l'Université de Fribourg Suisse qui en a permis la publication, à Madame Silvia Wurst et à Monsieur Gregor Wurst, assistant au Séminaire de patristique de l'Université de Fribourg qui en ont assuré la composition et la mise en page, j'adresse mes vifs remerciements.

Charles Munier, Strasbourg 
TABLE DE MATIÈRES

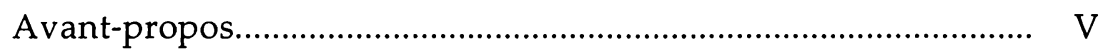

Introduction .......................................................................... 1

Conspectus siglorum ………………………………….......... 39

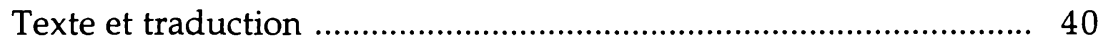

Index

I. Citations et allusions bibliques ......................................................... 147

II. Auteurs modernes ………………………………………............. 150 



\section{INTRODUCTION}

1. L'expansion du christianisme dans le monde romain, plus vigoureuse au IIe siècle, provoqua non seulement des persécutions de la part des autorités politiques, attentives à maintenir le lien étroit qui unissait alors la croyance aux dieux et la prospérité de l'État, mais aussi les réactions hostiles de certains milieux juifs et la haine tenace des populations païennes. Nourrie par les calomnies les plus extravagantes (repas de Thyeste, mœurs d'Oedipe, autant dire infanticide, anthropophagie, inceste), cette antipathie du vulgaire fut bientôt relayée par les attaques directes des lettrés et des philosophes (Fronton de Cirta, Lucien de Samosate, Celse).

La tâche des apologistes chrétiens du IIe siècle fut de répondre à ces critiques, et de dissiper ces préjugés. Aux Juifs, qui exaltent le privilège d'Israël et l'intangibilité de la Loi, ils opposent la vocation des Gentils, le rôle pédagogique de la Loi, la condition messianique et sotériologique de Jésus. A l'empereur ils remontrent l'iniquité de la procédure criminelle engagée contre les chrétiens, dont le loyalisme est sans faille et la conduite morale irréprochable. Aux masses païennes et aux philosophes ils présentent diverses preuves de la vérité du christianisme, s'attachant à réfuter les calomnies, dénonçant les absurdités et les immoralités de la mythologie; ils n'hésitent pas à exalter le christianisme comme la seule philosophie digne de foi et profitable et défendent avec fermeté les dogmes chrétiens, notamment le monothéisme, le libre arbitre, la résurrection.

J. Geffcken, Zwei Apologeten, Leipzig 1907; du même, Das Christentum im Kampf und Ausgleich mit der römischen Welt, Leipzig - Berlin 21920; A. Puech, Les apologistes grecs du IIe siècle, Paris 1912; P. de Labriolle, La réaction païenne. Etude sur la polémique antichrétienne du Ier au VIe siècle, Paris 1934, 1948; M. Pellegrino, Gli apologeti greci del II secolo. Saggio sui rapporti tra il cristianesimo primitivo e la cultura classica, Roma 1947; G. Bardy, art. Apologetik RAC I, 533-543 (1950); V. Monachino, Intento pratico e propagandistico nell'apologetica greca del II secolo, Gregorianum 32, 1951, 5-40; 107-222; R.M. Grant, The chronology of the Greek Apologists, VC 9, 1955, 23-33; R.L. Wilken, Toward a Social Interpretation of Early Christian Apologetic, Church History 39, 1970, 437-458; R. M. Grant, Forms and occasions of the Greek Apologists, Studi e materiali di scienze delle religioni 52, 1986, 213-226; Five Apologists and Marcus Aurelius, VC 42, 1988, 1-17.

2. Le plus important des apologistes grecs du Ile siècle fut saint Justin "philosophe et martyr" (Tertullien, Contre les Valentiniens, 5). Né à Flavia Neapolis (l'actuelle Nablus, en Israël), "fils de Priscus et petit-fils de Baccheios" (Apol. I,1), de naissance libre, il était issu d'une famille de colons installée dans la ville nouvelle fondée par Vespasien au lendemain de la Guerre juive (67-70), sur les ruines de l'antique Sichem en Samarie. 
Jeune homme avide de savoir, mais plus encore de vérité, Justin fréquenta diverses écoles de philosophie mais sans pouvoir trouver auprès de ses maîtres de réponse à ses aspirations profondes. Dans son Dialogue avec Tryphon (2-8), il évoque, non sans une pointe d'humour indulgent, les méandres de son cheminement philosophique, les limites méthodologiques et les faiblesses humaines de ses professeurs, la suffisance du stoïcien, l'âpreté au gain du péripatéticien, les prétentions encyclopédiques du pythagoricien. Seul trouve grâce à ses yeux le platonicien, qui avait "donné des ailes à son âme" (Dial. 2,6) et lui avait fait entrevoir la contemplation de Dieu comme but suprême de toute philosophie.

C'est alors que la rencontre fortuite d'un vieillard plein de sagesse, une sorte de "Socrate chrétien", décida de sa conversion: celui-ci lui fit comprendre, en effet, les déficiences de certaines thèses platoniciennes (Dial. 4-6) et lui révéla la vérité du christianisme, annoncée par les prophètes de l'Ancien Testament. L'exemple du courage des chrétiens devant les persécutions et la mort acheva de le convaincre (Apol. II,12,1). Le lieu et la date de cette conversion demeurent objet de conjecture; elle dut avoir lieu quelque part en Orient, aux alentours de la deuxième guerre juive (132135).

Désormais Justin parcourut le monde, "prêchant la parole de Dieu et combattant dans ses ouvrages en faveur de la foi" (Eusèbe, Histoire ecclésiastique IV,11,8). Le détail de son périple, depuis la Samarie natale jusqu'à Rome est inconnu. Nous savons seulement qu'il demeura quelque temps à Ephèse, où il place son entretien avec le Juif Tryphon (Dial. 1,1; Eusèbe, H.E. IV,18,6), et qu'il fit à Rome deux séjours, qui lui permirent de donner toute sa mesure comme didascale chrétien. Le futur apologiste Tatien compta parmi ses disciples. Ses controverses et débats publics lui valurent l'animosité du philosophe cynique Crescent. C'est à Rome que Justin présenta son Apologie à l'empereur Antonin le Pieux et à ses fils adoptifs. C'est à Rome enfin qu'il subit le martyre, sous la préfecture de Junius Rusticus, sans doute vers 165.

G. Bardy, art. Justin (saint), DTC VIII, 1925, 2228-2277; Les écoles romaines au IIe siècle; N. Hyldahl, Philosophie und Christentum. Eine Interpretation der Einleitung zum Dialog Justins, Kopenhagen 1966; L.W. Barnard, Justin Martyr. His Life and Thought, Cambridge 1967; J.C.M. van Winden, An Early Christian Philosopher. Justin Martyr's Dialogue with Tryphon, Chapters One to Nine. Introduction, Text and Commentary (PhP 1), Leiden 1971; E.F. Osborn, Justin Martyr, Tübingen 1973; Ch. Kannengiesser - A. Solignac, art. Justin (saint) Dict. de Spiritualité 8, 1972, 1640-1647; O. Skarsaune, art. Justin der Märtyrer, TRE 17 (1988) 471-478; The Conversion of Justin Martyr, STh 30, 1976, 337-350; R.L. Wilken, Kollegien, Philosophenschulen und Theologie, in: Zur Soziologie des Urchristentums. Ausgewählte Beiträge zum frühchristlichen Gemeinschaftsleben in seiner gesellschaftlichen Umwelt, hg. v. W.A. Meeks, München 1979, 165-193; G. Lüdemann, Zur Geschichte des ältesten Christentums in Rom. I: Valentin und Marcion; II: Ptolemäus und Justin, ZNW 70, 1979, 86-114; G.I. Gargano, L'anziano incontrato da Giustino: un amico del Logos o il Logos stesso?, in: Geist und Erkenntnis, Festschrift für Th. Spidlik, hg. von Prof. K. Macha, München 1985, 64-70; P. Lampe, Die stadtrömischen Christen in den ersten beiden Jahrhunderten, Tübingen 1987 (21990); G. Neymeyr, Die christlichen Lehrer im zweiten Jahrhundert (SVigChr IV), Leiden - New York, 1989. 
3. Eusèbe a dressé un catalogue imposant des ouvrages attribués à Justin (H.E. IV,18) mais son énumération ne paraît ni complète ni sûre. Plusieurs des écrits de Justin ne nous sont pas parvenus, tel le Traité contre toutes les hérésies (Syntagma), qu'il déclare avoir rédigé (Apol I,26,5). Irénée cite de lui un Traité contre Marcion (A.H. IV,6,2), qui n'était peut-être qu'une partie du précédent. Tatien (Or. 18) et Eusèbe citent un mot de Justin qui ne se retrouve pas dans les écrits conservés. Les traités $D e$ l'âme, et Le psalmiste, mentionnés par Eusèbe n'ont pas laissé de trace. Les Sacra Parallela de Jean Damascène contiennent des fragments d'un traité De la résurrection, où d'aucuns ont cru pouvoir reconnaître une œuvre authentique de Justin. La tradition manuscrite attribue à Justin plusieurs ouvrages d'apologétique et de controverse, qui ne sont pas de lui. En fait, seuls le Dialogue avec Tryphon et les écrits que l'on désigne communément comme ses deux Apologies sont certainement authentiques - à l'exception de leurs titres.

Clauis Patrum graecorum I (1983), nn.1073-1089; A. von Harnack, Die Überlieferung der griechischen Apologeten des zweiten Jahrhunderts in der alten Kirche und im Mittelalter (TU 1-2), Leipzig 1882.

4. Les deux apologies de Justin nous sont parvenus dans un unique manuscrit, le Parisinus graecus 450 de la Bibliothèque nationale de Paris, daté de 1364. La seconde Apologie (Apol. II), la plus courte, y est transcrite avant la première (Apol. I), la plus longue. Malgré la disposition du manuscrit, il est certain que la petite Apologie (Apol. II) a été composée avant la grande (Apol. I), à laquelle elle renvoie à plusieurs reprises (Apol. II,4,2; 6,5; 8,1; 9,1). Comme la formule utilisée par Justin à cet effet lui sert aussi pour effectuer les renvois au sein de la Première Apologie (cf. Apol. I,12,5; 216; 22,2; 32,11...), il est évident qu'aux yeux de l'auteur, les deux apologies forment une œuvre unique.

Plusieurs autres indices, tous convergents, confirment l'unité de composition, de rédaction et de publication de l'ouvrage, composé selon les règles de la rhétorique antique. Formellement, l'Apologie de Justin était un

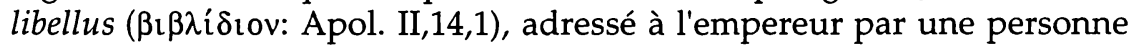
privée. Ces requêtes étaient déposées à Rome au bureau impérial commis à cet effet, le scrinium a rescriptis. Après en avoir pris connaissance, l'empereur émettait son avis au bas de la requête, et y apposait sa signature (cf. Apol. II,14,1). Les réponses impériales (rescripta) étaient consignés par ledit bureau sur des rouleaux (libri libellorum rescriptorum et propositorum), régulièrement affichés pour que chacun pût en prendre copie (cf. Apol. II,14,1: $\pi \rho 0 \theta \varepsilon i ́ v \alpha \mathrm{l})$.

Considérée du point de vue de la rhétorique antique, l'Apologie de Justin relevait du genre judiciaire; les auteurs assignaient à ce genre de discours une composition en cinq parties: l'exorde, la narration, la preuve, la réfutation, la péroraison. "Quelques-uns y ont ajouté la division, la pro- 
position, la digression. Cela me paraît surabondant; les deux premières ne sont que des dépendances de la preuve", écrit à ce propos Quintilien (III,9,2).

Il est aisé de repérer ces parties essentielles d'une apologie dans l'ouvrage de Justin: l'exorde (Apol. I,1-3); la péroraison (Apol. II,13-15); la narration (Apol. II,2,1-20). L'argumentation (Apol. I,4-II,12,6) se développe à travers tout le discours, suivant le plan annoncé dans la diuisio (Apol. I,3,2): afin que l'empereur puisse rendre une juste sentence en la cause des chrétiens, Justin lui fera un compte-rendu exact et rigoureux de leur conduite et de leur doctrine. De fait, l'exposé de la conduite des chrétiens (Apol. I,4-12; 61-68,2; II,12,1-6) et de leur doctrine (Apol. I,1360; II,10-11) répond à ce propos. En Apol. I,58,3, s'ouvre la digression, qui s'achève en Apol. $\Pi, 9,5$.

L'unité de l'Apologie ressort également de la mise en œuvre du thème:

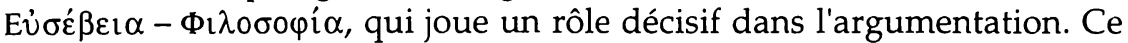
thème, qui reprend les éléments les plus marquants de la titulature impériale, la piété d'Antonin, l'amour de la philosophie et de la culture de ses fils adoptifs, reparaît a sept reprises, savamment distribuées à des endroits "stratégiques" du discours; à savoir: en I,1 (adresse); I,2,1 et 2 (captatio beneuolentiae); I,3,2 (requête: $\alpha \dot{\xi} \hat{i} \omega \sigma \mathrm{\iota} \varsigma) ; \mathrm{I}, 12,5$ (fin de la refutatio); II,2,16 (fin de la narratio); II,15,5 (fin de la péroraison).

L'unité de l'Apologie ressort enfin de l'agencement des inclusions, faisant se répondre des éléments placés en Apol. I et II, et soulignant que le discours s'étend bien d'Apol. I,1 à Apol. II,15,5. Qu'il suffise d'indiquer ici

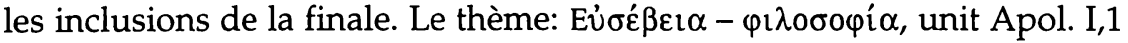
et Apol. II,15,5; il en va de même pour celui du juste jugement; quant au thème: "agissez dans votre intérêt", il unit Apol. I,8,1 et II,15,5 par-delà II,1,1.

Il résulte de toutes ces observations, semble-t-il, que les deux écrits de Justin, que la tradition manuscrite nous a conservés sous le nom Apologies I et II, constituent en réalité un ouvrage unique, composé d'un seul jet, et présenté à Rome comme une requête personnellement adressée à l'empereur Antonin le Pieux et à ses fils adoptifs, sous la forme d'un libellus déposé au bureau impérial des rescrits, afin d'obtenir un changement radical de la politique impériale envers les chrétiens.

U. Wilcken, Zu den Kaiserreskripten, Hermes 55, 1920, 1-42; W. Hüttl, Antoninus Pius, I et

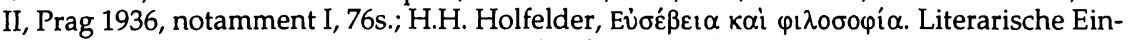
heit und politischer Kontext von Justins Apologie, ZNTW 68, 1977, 48-66; 231-251; Ch. Munier, A propos des Apologies de Justin, Revue des sciences religieuses 61, 1987, 177 186; L'Apologie de saint Justin, philosophe et martyr (Paradosis 38), Fribourg/Suisse, $1994,152-156$.

5. L'unité de l'Apologie de Justin étant ainsi établie, plusieurs questions, apparemment inextricables, peuvent être écartées sans plus. Point n'est besoin de s'interroger indéfiniment sur la nature d'Apol. II, sur les motifs 
qui ont pu décider Justin à la rédiger, ni de vouloir supputer le laps de temps qui a pu séparer la rédaction d'Apol. II de celle d'Apol. I. Point n'est besoin non plus d'imaginer des destinataires différents pour les deux écrits; les tituli du manuscrit, qui sont d'origine rédactionnelle et le fait de copistes, ne sauraient être déterminants à cet égard. Enfin, on n'a plus à s'évertuer à vouloir accorder à tout prix les indications extrêmement confuses données par Eusèbe au sujet de plusieurs apologies de Justin, adressées à des destinataires différents (H.E. IV,11,11; IV,16,1; IV,17,1).

Pour identifier les destinataires de l'Apologie et déterminer la date de sa rédaction, il suffit donc de s'en tenir aux données de la critique interne. Il convient, à ce propos, de rappeler les principaux événements relatifs à l'adoption des membres de la dynastie des Antonins. Ayant perdu les deux fils qu'il avait eus de Faustine, Hadrien adopta, au cours de l'année 136, L. Ceionus Commodus Verus et le fit César. Celui-ci (devenu L. Aelius Verus Caesar), étant mort le 1er janvier 138, Hadrien adopta, le 25 février 138, T. Aurelius Fulvius Boionius Antoninus, qu'il fit César (= Antonin le Pieux).

Sur l'ordre d'Hadrien, Antonin, adopta, ce même 25 février 138, M. Annius Verus (ou Verissimus), né en 121 (qui devint M. Aelius Aurelius Verus = Marc-Aurèle), ainsi que le fils de L. Verus, né en 130, (qui devint L. Aelius Aurelius Commodus). A la mort d'Hadrien, le 10 juillet 138, Antonin devint empereur (Augustus); sa titulature officielle est désormais: Imperator Caesar T. Aelius Antoninus Aug. Pius. En 139, Marc-Aurèle reçut le titre de César, il est appelé désormais M. Aurelius Caesar Aug. Pii filius, princeps iuuentutis. Le 1er décembre 147, il est investi de la tribunicia potestas, de l'imperium proconsulaire et du ius quintae relationis; il devint ainsi co-régent de l'empereur. L. Verus fut agrégé au Sénat, en 153, en qualité de questeur. A la mort d'Antonin, Marc-Aurèle devint empereur; il éleva aussitôt L. Verus au rang d'Augustus et de Princeps. Celui-ci est nommé désormais Caesar L. Aurelius Verus Aug.

L'Apologie de Justin étant une requête déposée au bureau impérial des rescrits, l'impétrant se devait de respecter la titulature officielle. De fait, l'identité des destinataires ne saurait être mise en doute: il s'agit d'Antonin le Pieux et des ses deux fils adoptifs, Marc-Aurèle et Lucius Verus. Les difficultés se multiplient toutefois, lorsque l'on cherche à préciser la date de composition de l'ouvrage à partir des seules données du manuscrit. Si l'on s'en tient à la lettre du texte, il faudrait admettre une date antérieure à 139, puisque Marc-Aurèle n'y est pas salué du titre de César. Or, une date aussi haute ne paraît pas admissible. Si le terme de philosophe, attribué à Marc-Aurèle, peut convenir à un jeune homme de dixhuit ans, comment croire que Justin l'ait donné à Lucius, qui n'avait alors que huit ans? Il est vrai qu'en retenant la leçon d'Eusèbe (H.E. IV,12: $\varphi 1$ $\lambda \circ \sigma o ́ \varphi o v)$, on lèverait cette difficulté, car Lucius serait alors désigné comme fils du César L. Aelius Verus, philosophe. 
Pour séduisante qu'elle soit, cette correction ne permet pas de résoudre tous les problèmes; plusieurs passsages de l'Apologie supposent, en effet, une date de composition plus récente, voisine de 150. En I,46,1, Justin dit qu'il écrit environ cent cinquante ans après la naissance du Christ; si l'on admet qu'il suit la chronologie lucanienne, cela revient à situer l'Apologie entre 147 et 154. En Apol. I,26,8 et 58,1, Justin parle de Marcion comme d'un hérétique confirmé, ce qui implique aussi une date proche de 150, de toute manière postérieure à 144. En Apol. I,29,2, Justin fait allusion à la requête adressée par un chrétien au préfet d'Égypte, alors en fonction. Deux papyrus, datés respectivement du 17 avril 150 (P. Ryl. II,75) et du 13 septembre 151 (P. Oxy. II,237) attestent la préfecture de Félix. Quant aux événements relatés en Apol. II,2, ils eurent lieu alors que Q. Lollius Urbicus était préfet de Rome, c'est-à-dire approximativement entre 150 et 161. Enfin, dans la mesure où la mention de Lucius Verus, en Apol. I,1 et en Apol. II,2,16, implique que ce personnage (tenu à l'écart des affaires publiques sous le principat d'Antonin) était, pour le moins, entré dans le cursus honorum, il faudrait assigner à l'Apologie une date voisine de 153. C'est, en effet, cette année-là que Lucius Verus, devenu questeur, fut agrégé au Sénat (Hist. Aug., Iulius Capitolinus, Verus 3).

Compte tenu de toutes ces données, il semble légitime d'admettre que l'Apologie de Justin fut composée à Rome même et présentée au scrinium impérial, en 153 ou peu après. Cette datation se trouve, du reste, confirmée par le témoignage d'Eusèbe. Dans sa Chronique, celui-ci indique, en effet, que Crescent, l'adversaire de Justin, commença à se signaler à Rome au cours de la deuxième année de la 233 e Olympiade, ce qui correspond à l'année 153/154.

H. Veil, Justinus des Philosophen und Märtyrers Rechtfertigung des Christentums (Apologie I\&II), Strasbourg 1894, p.xxviii-xxxii; A.W.F. Blunt, The Apologies of Justin Martyr, Cambridge 1911, p.xlvii-lii; D. Kienast, Römische Kaisertabelle. Grundzüge einer römischen Chronologie, Darmstadt 1990.

6. Aux dires de Justin lui-même (Apol. II,1,1), le procès inique intenté par le préfet Urbicus au didascale romain Ptolémée, fut l'événement déterminant qui le décida à intervenir en la cause des chrétiens. Les motivations sordides de l'accusateur, débauché notoire, les procédés sommaires employés lors de l'arrestation et de la détention du prévenu, le caractère expéditif de la sentence qui frappa non seulement Ptolémée, "convaincu ni d'adultère, ni de débauche, ni de meurtre, ni de vol, ni de rapt, ni du moindre délit" (Apol. II,2,16), mais ses compagnons, Lucius et le martyr anonyme qui s'étaient déclarés chrétiens, lui semblèrent justifier une protestation vigoureuse en faveur de ces hommes "de toute race, injustement haïs et persécutés" (Apol. I,1), car ce n'était pas seulement à Rome, sous les yeux mêmes de l'empereur, mais en tout lieu, que des magistrats prévenus ou hostiles prononçaient des jugements de ce genre (Apol. II,1,2). 
Si l'on en croit les déclarations de Justin, le règne d'Antonin aurait donc connu, vers 150-153, une recrudescence des persécutions contre les chrétiens, à tout le moins une dégradation sensible de leur situation, alors qu'ils n'avaient guère été inquiétés sous le règne d'Hadrien. Mais le principat d'Antonin marque-t-il vraiment un revirement de la politique impériale en la question chrétienne?

L'historien ne dispose que de rares témoignages pour apprécier la politique religieuse d'Antonin. Certes, l'empereur se veut le conservateur des vieux cultes et l'observateur minutieux des rites, ce qui lui valut d'être appelé le "Numa" de l'empire (Fronton, Princ. Hist., éd. Naber, p.206), d'être proposé comme idéal et de mériter le surnom de Pius (M. Aurèle, Pensées $6,30)$. Pareil contexte n'était guère favorable aux chrétiens qui, désormais distingués des Juifs, apparaissaient de plus en plus comme des déserteurs et des apostats de la religion nationale et comme les contempteurs des dieux à qui l'Empire devait sa felicitas. Or, en 147, le neuvième centenaire de la fondation de Rome avait été célébré avec magnificence et avait ranimé partout l'orgueil romain.

Plusieurs passages du Pasteur d'Hermas, sensiblement contemporain de l'Apologie de Justin, permettent de revivre les épreuves auxquelles la communauté chrétienne de Rome fut soumise à cette époque. "Ou bien obéis à mes lois, ou bien sors de mon pays", proclame le maître de la cité (Sim. I,3): opposition tragique, plus d'une fois sanctionnée par le martyre. "A ceux qui ont souffert à cause du Nom, qui ont connu les coups, la prison, de grandes tribulations, la croix, les fauves, à cause du Nom, le côté droit du saint lieu a été réservé", assure le Pasteur, qui déplore non seulement de nombreuses défections (Sim. IX,21,3), mais la lâcheté des indécis $(\delta i q u \chi 0 \imath)$, qui sympathisent avec l'Église, mais n'osent s'y adjoindre (Sim. I,10; VIII,8,1-2; 9,1; IX,20,1-2), d'autant que la menace de nouvelles persécutions demeure imminente (Vis. II,2).

Prospères, loyales, superstitieuses, les provinces asiates témoignaient de la même animosité contre les chrétiens. Une série de tremblements de terre, qui ravagea ces régions sensibles sous le règne d'Antonin (en 144, 151-152 et 155), fut attribuée à la colère des dieux. Des pogroms éclatèrent; la foule réclamait le châtiment des "athées". Les gouverneurs eurent sans doute recours à la méthode habituelle; pour calmer la fureur populaire ils procédèrent à quelques exécutions, puis ils demandèrent des instructions à l'empereur.

Les rescrits d'Antonin sont perdus, mais leur sens général apparaît en filigrane sous le témoignage de Méliton de Sardes, conservé par Eusèbe (H.E. IV,26,10). Antonin demeure attaché à la politique religieuse de son prédécesseur. En ce domaine sa devise est de n'innover en rien $(\mu \eta \delta \dot{\varepsilon} v v \varepsilon \omega-$ $\tau \varepsilon \rho i ́ \zeta \varepsilon(v)$; c'est dans ce sens qu'il répondit aux villes de Larissa, de Thessalonique et d'Athènes qui l'avaient consulté, entre 147 et 161. Quant au prétendu rescrit d'Antonin, adressé au conseil (кoıvóv) de la province sé- 
natoriale d'Asie, son caractère apocryphe, communément reconnu, ne permet pas d'en faire état (Eusèbe, H.E. IV,13).

C.H. Dodd, The Cognomen of the Emperor Antoninus Pius, Num.Chron. 11, 1911, 6-41; W. Hüttl, Antoninus Pius, t.1 \& 2, Prag 1931, 1936; H.E. Stier, art. Antoninus Pius, RAC I, 1950, 477-480; L. Cerfaux et J. Tondriau, Le culte des souverains dans la civilisation romaine, Paris. Tournai, 1957, 357-365; A. Hermann, art. Erdbeben, RAC V (1962) 10701113 (s.1105); L.W. Barnard, Hadrian and Christianity, CQR 165, 1964, 277-289; J. Colin, Les exigences de la populace païenne au Ile siècle, Revue des études grecques 78, 1965, 330335; R. Freudenberger, Christenreskript. Ein umstrittenes Reskript des Antoninus Pius, ZKG 78, 1967, 1-14; J. Speigl, Der römische Staat und die Christen. Staat und Kirche von Domitian bis Kommodus, Amsterdam 1970.

7. Les principes de la législation les concernant n'ayant pas été modifiés par Antonin, la condition des chrétiens continuait d'être régie par les rescrits de Trajan et d'Hadrien.

On se souvient que Pline le Jeune, alors gouverneur de Bithynie (vers 112), avait demandé à Trajan de bien vouloir lui préciser ce qui était punissable en cas d'incrimination de chrétiens: le nom lui-même en l'absence de forfaits ou les forfaits attachés à ce nom (nomen ipsum si flagitiis careat, an flagitia nomini cohaerentia puniantur; epist. X,96).

Trajan n'avait pas répondu à cette question, mais interdit de rechercher d'office les chrétiens, condamné les dénonciations anonymes, exigé une accusation en bonne et due forme, prescrit la relaxe pure et simple de ceux qui se rétractaient; par contre, il avait ordonné de sévir (puniendi sunt) ceux qui s'obstineraient dans leur attachement au Christ et leur refus de rendre aux dieux de Rome le culte qui leur est dû.

Loin de reconnaître aux chrétiens une existence légale, comme d'aucuns l'ont prétendu, le rescrit d'Hadrien à Minucius Fundanus (Apol. I,68,3-10; Eusèbe, H.E. IV,9) ne réglemente que certaines modalités de la procédure. D'une part, il interdit tout recours à des pétitions ( $\left.\dot{\alpha} \xi_{\imath} \omega \dot{\sigma \varepsilon} \iota \varsigma\right)$ ou à de simples clameurs ( $\mu$ óv $\alpha \mathrm{\imath} \beta 0 \alpha i$ ) en vue d'arracher aux magistrats la condamnation à mort des chrétiens; d'autre part, explicitant les termes: si deferantur du rescrit de Trajan, il exige l'application stricte des règles de la procédure accusatoire: l'accusation doit être soutenue individuellement et plaidée pro tribunali; la formulation du grief doit être précise et se référer aux lois en vigueur; la preuve de l'assertion incombe à l'accusation; si celle-ci n'est pas en mesure de l'apporter, des peines de rétorsion des plus sévères frapperont les accusateurs qui seraient convaincus d'avoir agi par pure malveillance. En multipliant ces exigences, l'empereur entend bien intimider les sycophantes, il rappelle gravement que l'appareil de la justice doit être au service de l'ordre public et de la vérité. Mais il ne change en rien le statut légal des chrétiens, dont le nomen demeure proscrit. Il en résulte que la profession de christianisme, faite publiquement, lorsque le prévenu est requis par le magistrat d'avoir à poser un acte du culte officiel (sacrifice, libation, serment par le Génie ou la Fortune (Tú ұ) de l'empereur), suffit à établir sa culpabilité et à lui valoir la sentence capitale. 
C. Callewaert, Le rescrit d'Hadrien à Minucius Fundanus, RHLR 8, 1903, 152-159; B. Capelle, Le rescrit d'Hadrien et S. Justin, RB 39, 1927, 365-368; M. Sordi, I rescritti di Traiano e di Adriano sui cristiani, Rivista di storia della Chiesa in Italia 14, 1960, 39-57; P. Keresztes, The Emperor Hadrian's Rescript to Minucius Fundanus, Phoenix 21, 1967, 120-129; Th. Mommsen, Der Religionsfrevel nach römischem Recht, HZ 64, 1890, 384-427; Gesammelte Schriften III,3, 1907, 389-422; H. Last, Christenverfolgungen (juristisch), RAC II (1954), 1208-1228 (Bibliographie); G.E.M. De Ste Croix, Why were the Early Christians Persecuted? Past and Present 26, 1963, 6-38, B.S. Eastwood, Causes of the Early Persecutions, History today 16, 1966, 555-563; Ch. Munier, L'Eglise dans l'Empire romain (IIeIIle siècles), Paris 1979, 218-240; R. Freudenberger, Das Verhalten der römischen Behörden gegen die Christen im zweiten Jahrhundert dargestellt am Brief des Plinius an Trajan und den Reskripten Trajans und Hadrians (MBPF 52), München 1967 (21969)

8. Justin sait parfaitement que le nomen christianum constitue un motif suffisant d'incrimination et de condamnation, mais il se garde bien d'aborder directement ce point crucial. S'appuyant sur le rescrit d'Hadrien, il l'interprète à son avantage, comme s'il requérait la preuve formelle que les chrétiens se livrent à des activités criminelles ( $\tau 1 \pi \alpha \rho \dot{\alpha} \tau o u ̀ \varsigma$

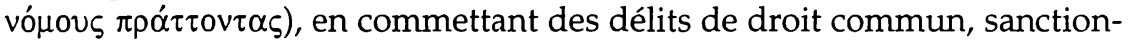
nés par les lois (Apol. I,68,3; II,2,16). Quant au nomen christianum, qui sert à accuser et à condamner les disciples du Christ, il les désigne, en réalité, comme étant des hommes excellents à tous égards ( $\chi \rho \eta \sigma \tau o ́ \tau \alpha \tau o 1)$, observe-t-il (Apol. I,4,1). Ce laborieux jeu de mots, fondé sur l'iotacisme de la prononciation populaire, sera repris inlassablement par les apologistes. S'il révèle tragiquement l'impuissance du christianisme naissant à prouver son innocence, il indique aussi l'orientation générale des apologies: protester contre la haine aveugle, les préjugés, la rumeur perfide, les motivations inavouables qui entretiennent l'hostilité populaire et raniment les accusations, mais surtout repousser inlassablement les calomnies concernant les flagitia prêtés aux chrétiens.

Il est remarquable que Justin ne s'attarde pas à réfuter en détail les accusations dites "vulgaires", dont l'énormité fait éclater l'invraisemblance, voire l'absurdité, aux yeux de quiconque prend en considération le courage des chrétiens devant la mort (Apol. II,12,1-2).

Les griefs d'ordre politique retiennent davantage son attention: sous les Antonins, les chrétiens passent pour être des marginaux, des rebelles dangereux, hostiles à la chose romaine et conspirant à sa perte. C'est pourquoi l'apologiste, dans un plaidoyer extrêmement soigné, fait ressortir le parfait loyalisme des chrétiens et expose les principes qui inspirent leur attitude politique. Loin de contester la légitimité de l'Etat, les disciples du Christ le servent sans arrière-pensée et ils s'acquittent scrupuleusement de tous leurs devoirs civiques; aussi attendent-ils de l'empereur qu'il reconnaisse le caractère irréprochable de leur conduite. Loin de pousser à la subversion, la religion chrétienne invite ses membres à s'engager résolument dans la construction de la cité terrestre et à se dévouer pour le bien commun (Apol. I,12,1-5). S'ils sont soupçonnés d'être les ennemis de l'État, c'est parce que, croit-on, ils attendent l'avènement d'un 
royaume qui doit assurer leur triomphe. Ce royaume n'est pas de ce monde, corrige Justin; s'ils attendaient un royaume terrestre et visaient à l'établir, il choisiraient certainement de vivre, pour y prospérer, et ils n'accepteraient pas la mort sans broncher, lors qu'il leur suffirait de renier leur foi pour avoir la vie sauve (Apol. I,11; 39,5; 57,3; II,11,8; 12).

Justin reprend aussi et développe l'argument des tranformations morales opérées par le christianisme, qui avait servi déjà à l'apologiste Aristide (Apol. 15-17), afin de prouver la vérité et la sainteté de la religion chrétienne. Fondé sur la volonté de Dieu lui-même et sur la crainte de son jugement, le civisme des chrétiens leur inspire un loyalisme sans faille (Apol. I,17) et leur fait pratiquer les vertus les plus utiles à la cité: le désintéressement, l'hospitalité, l'amour de la paix et de la concorde, le pardon des injures (Apol. I,14,2; 17,1-4). Point n'est besoin de dire qu'en réaction contre la licence des mœurs du monde gréco-romain, Justin souligne l'idéal de dignité, de maîtrise de soi ( $(\dot{\gamma \kappa \rho \alpha ́} \tau \varepsilon \imath \alpha)$ cultivé par les chrétiens (Apol. I,15,1-7; 29,1-4). Alors que le refus de l'enfant et le divorce continuent de sévir dans la haute société impériale, Justin exalte le devoir de fidélité des époux et le respect des fins du mariage, qui commandent l'union des chrétiens (Apol. I,15,5; 29,1). Quant au fléau de la prostitution, sous toutes ses formes, l'apologiste ne se contente pas d'en dénoncer les effets désastreux (Apol. I,27,1-3); il fait grief au pouvoir impérial de tirer profit de ce commerce abject, en le réglementant moyennant finances au lieu de l'extirper.

O. Sild, Das altchristliche Martyrium in Berücksichtigung der rechtlichen Grundlagen der Christenverfolgungen, Dorpat 1920; V. Vitale, Iniquità della procedura romana contro i cristiani. Tertulliano e Giustino filosofo e martire. Contributo alle fonti filologiche dell'apologetica, Musée belge 30, 1924, 35-46; J.P. Waltzing, Le crime rituel reproché aux chrétiens au Ile siècle, Musée belge 29, 1923, 209-238; G. Igino, La prima polemica cristiana: gli apologeti greci del secondo secolo, Torino-Roma 1930; F.J. Dölger, Sacramentum infanticidii, AC 4, 1934, 188-228; W. Nestle, Die Haupteinwände des antiken Denkens gegen das Christentum, ARW 37, 1941-42, 51-100; W. Schmid, The Christian re-interpretation of the rescript of Hadrian, Maia 7, 1955, 1-10; P. de Mouxy, Nomen christianorum. Ricerche sulle accuse e le difese relative al nome cristiano nella letteratura apologetica dei primi due secoli, Atti della Accademia delle Scienze di Torino, Classe di scienze morali storiche e filologiche 91, (1956-67), 204-236; P. Keresztes, Law and Arbitrariness in the Persecution of the Christians and Justin's First Apology, VC 18, 1964, 204-214; R. Freudenberger, Der Vorwurf ritueller Verbrechen gegen die Christen im 2. und 3. Jahrhundert, ThZ 23, 1967, 97-107; A. Henrichs, Pagan Ritual and the alleged Crime of the early Christians: A Reconsideration, Kyriakon I (Festschrift Johannes Quasten), 1973, 18-35.

9. A la différence des autres apologistes grecs du Ile siècle, qui rejettent catégoriquement l'accusation d'athéisme soulevée contre les chrétiens, Justin adopte une position complexe, dont Tertullien reprendra des éléments dans son Apologétique.

L'argumentation de Justin quant à ce grief se fonde sur l'exemple de Socrate, condamné comme "athée et impie", sous prétexte qu'il introduisait des divinités nouvelles et qu'il ne croyait pas aux dieux de la cité (Apol. 
I,5,3). En réalité, observe Justin, Socrate était un adorateur sincère du Père et Créateur de l'univers (Apol. II,10,5-6), mais ayant jugé la nature et l'origine de la religion polythéiste à la lumière de la raison, il crut de son devoir d'éclairer les hommes et de les détourner des cultes idolâtriques (Apol. I,5). Il provoqua ainsi la fureur des mauvais démons, instigateurs du polythéisme et encourut la vindicte des Athéniens, dont les puissances du mal se servirent pour assouvir leur haine (Apol. II,10,4; I,46,3). Or, l'exemple de Socrate illustre parfaitement le sort actuel des chrétiens, et tout particulièrement celui de leurs didascales, dont seuls des hommes perdus de mœurs complotent la mort (Apol. I,5,3-4; II,1,2; 10,5-6).

Justin lui-même s'attend à être l'objet d'une machination fatale de la part de Crescent, un chef d'école philosophique, dont il dévoilé l'ignorance et la duplicité. Ce Crescent, lui aussi, accuse publiquement les chrétiens d'être "athées et impies", mais que peuvent valoir les dires d'un individu qui se prétend philosophe, alors qu'il n'est qu'un ami du bruit et de l'emphase, l'esclave d'une opinion aveugle?

Aux accusations d'athéisme portées naguère contre eux, les Juifs de la Diaspora avaient répliqué en soulignant l'excellence du culte qu'ils rendaient à Yahvé, le seul Dieu véritable, Créateur du ciel et de la terre. Justin adopte la même ligne de défense dans son Apologie. Il confesse hautement sa foi au Dieu unique, le Père de tout bien, le seul qui mérite adoration; il espère donner ainsi une juste idée du culte que les chrétiens rendent aussi au Christ, le propre fils de Dieu, et à l'Esprit prophétique. Ayant ainsi placé la foi chrétienne à des sommets inaccessibles, il entreprend une critique radicale du polythéisme officiel; pour lui, comme pour les auteurs du judaïsme tardif, les dieux des nations ne méritent pas ce nom, de sorte que les vrais athées ne sont pas les chrétiens mais ceux qui les accusent. En effet, les dieux des païens ne sont que des vaines idoles et leur culte est le produit des machinations des mauvais démons (Apol. I,6,9; $13 ; 41,1$ etc.).

D'autres aspects, extérieurs et facilement vulnérables, des religions païennes font l'objet des critiques les plus sévères de Justin, notamment les rites sacrificiels et les légendes divines de la mythologie. Aux dépenses ostentatoires des cultes païens Justin oppose la simplicité de la religion chrétienne, toute spirituelle, et souligne la dimension caritative des assemblées eucharistiques (Apol. I,10,1; 13,1-2; 66,2; 67,1-2). Quant à la mythologie, qui sert de support culturel au paganisme gréco-romain, elle offre à l'apologiste une cible de choix: comment un homme sensé peut-il prêter foi à pareilles fables, qui attribuent aux dieux toutes les passions des hommes (Apol. I,21,5; 25,1-3)?

Non content de repousser l'accusation d'athéisme et d'impiété dirigée contre les chrétiens, Justin la rejette sur leurs adversaires. Cette rétorsion ne vise pas seulement les masses païennes dont la haine aveugle et la crainte superstitieuse suscitent les persécutions; en réalité, elle met en 
cause la religion païenne comme telle, et l'empereur lui-même, dont la charge de Pontifex maximus, depuis Auguste, consacre la nécessaire jonction du sacerdoce et du pouvoir. C'est dire combien elle est audacieuse, voire maladroite, du point de vue de l'apologétique; elle est même particulièrement injurieuse pour Antonin le Pieux, qui accomplit ses devoirs religieux avec un soin scrupuleux. Pour Justin, comme pour l'Apôtre (1 Thess. 1,9; cf. Eph. 2,12), les païens sont des athées, malgré tous leurs dieux et leurs déesses, puisqu'ils ne connaissent pas le Dieu vivant et véritable. Pire encore: les actes de leur culte n'ont d'autre effet que de vouer leurs auteurs aux mauvais démons, aux génies infernaux (Apol. I,12,5-8; $14,1 ; 25,3 ; 44,12)$. C'est pourquoi, non content d'adjurer le prince et ses fils, au nom de la raison et de la vérité, d'abandonner des opinions erronées, héritées du passé (Apol. I,2,1-3), Justin les exhorte instamment à mettre fin à l'usage d'offrir des sacrifices, dont nul effet heureux ne peut être espéré (Apol. I,12,7).

A. von Harnack, Der Vorwurf des Atheismus in den ersten drei Jahrhunderten, TU 28,4, 1905; M. Carena, La critica della mitologia pagana negli apologisti greci del secondo secolo, Didaskaleion 1, 1923, fasc.2, 23-55, fasc.3, 1-42; G. Melinossi, Socrate nella tradizione cristiana dei primi secoli, Didaskaleion 9, 1930, 125-176; W. Nestle, art. Asebieprozess, RAC I (1950), 735-740; Atheismus, ibid., 866-870; F. Benz, Christus und Sokrates in der Alten Kirche. Ein Beitrag zum altchristlichen Verständnis des Märtyrers und des Martyriums, ZNTW 43, 1950-51, 195-223; E. Fascher, Der Vorwurf der Gottlosigkeit in der Auseinandersetzung bei Juden, Griechen und Christen, Festschrift O. Michel (Abraham unser Vater), 1963, 78-105; J. Speigl, Der römische Staat und die Christen. Staat und Kirche von Domitian bis Kommodus, Amsterdam 1970, 143-156; P.G. van der Nat, art. Geister (Dämonen), III Apologeten, RAC IX, 1976, 715-761; J. Pépin, Christianisme et mythologie. Jugements chrétiens sur les analogies du paganisme et du christianisme, in: Dictionnaire des mythologies et des religions des sociétés traditionnelles et du monde antique, Paris 1981, 161-171; T. Baumeister, "Anytos und Meletos können mich zwar töten, schaden jedoch können sie mir nicht". Platon's Apologie des Sokrates 30CD bei Plutarch, Epiktet, Justin Martyr und Clemens Alexandrinus, in: Platonismus und Christentum, Festschrift für $\mathrm{H}$. Dörrie, JbAC 10, 1983, 58-63; L. Alfonsi, L'accusa di ateismo ai cristiani in Atenagora e Giustino, in: Sodalitas. Scritti in onore di O. Guarino, Napoli, 1984-85, vol. III, 1477-1481; R.P.C. Hanson, The Christian Attitude to Pagan Religions up to the Time of Constantine, in: Idem, Studies in Christian Antiquity, Edinburgh 1985, 144-220; J. Ries, Cultes païens et démons dans l'apologétique chrétienne de Justin à Augustin, in: J. Ries - H. Limet (ed.), Anges et démons. Actes du Colloque de Liège et de Louvain-la-Neuve, 25-26 novembre 1987 (Homo Religiosus 14), Liège-Louvain-la-Neuve 1989, 337-352.

10. Justin ne s'est pas contenté de clamer l'innocence des chrétiens et de demander que les règles élémentaires de la justice soient respectées dans les procès engagés contre eux (Apol. I,2,3; 3,1; 5,1; 7,1-2; 26,7; II,1,2; 2; 3 ?,2; 4,$4 ; 15,5)$. Ce qui importait plus que tout à sa conviction profonde, à son enthousiasme de converti, à son tempérament de dialecticien, c'était de convaincre ses interlocuteurs de la vérité de la doctrine chrétienne et de sa supériorité sur toute philosophie. Cette entreprise n'était pas noins ardue que sa démarche apologétique. En effet, les philosophes du IIe siècle nourrissent de multiples griefs contre les dogmes chrétiens. Ils dénient par principe toute valeur à une doctrine récente et barbare, dont les 
croyances leur paraissent déraisonnables, notamment la foi en JésusChrist le Crucifié, en l'Incarnation et en la Résurrection.

Justin consacre une grande partie de l'Apologie à réfuter les critiques qui visent les aspects doctrinaux du christianisme. Sa défense comporte deux lignes complémentaires: d'une part, il souligne les points communs, qui font de la philosophie et du christianisme des alliés dans la lutte de la raison et de la vérité contre le polythéisme traditionnel; d'autre part, il tend à prouver que la doctrine chrétienne est supérieure à toutes les philosophies profanes.

Ces deux thèmes apparaissent, étroitement liés, dès la première occasion qui s'offre à Justin d'évoquer la philosophie, en Apol. I,5. Pour l'apologiste romain, Socrate et les chrétiens livrent un même combat pour la justice et la vérité: il s'agit de faire éclater la vérité sur Dieu, créateur de l'univers, et sur l'homme, appelé à le contempler au terme d'une vie respectueuse de la loi morale, dont il est l'auteur et le garant. La raison humaine $(\log o s)$, qui anime la philosophie, est capable d'atteindre ces sublimes vérités; l'exemple de Socrate et des grands penseurs de l'antiquité grecque, philosophes et poètes (Apol. I,20,3; 44,6?; 59,6; II,8,1; 10,1; $13,2)$ en fait foi. Mais l'extrême faiblesse de la nature humaine laisse prise aux mauvais démons, qui font obstacle à la vérité; ceux-ci trouvent en l'homme des alliés puissants, les passions perverses qui l'entraînent vers l'erreur et le vice, et débauchent son libre arbitre (cf. Rom. 1,18-22; Act. 17,16).

Quant aux chrétiens, qui reçoivent leur doctrine du Logos incarné luimême, il ont accès à la vérité plénière, que le Fils de Dieu est venu apporter aux hommes; ils voient en Jésus-Christ le Maître divin, dont les enseignements les ont arrachés à l'emprise des démons, pour mener désormais une vie irréprochable, et proclament leur croyance en la survie bienheureuse, qui leur donne force et courage dans l'épreuve, car elle se fonde sur la justice et la puissance de Dieu (Apol. I,8,2-4; 13,2; 18-19; II,9).

On le voit: la vérité qui importe à Justin concerne au premier chef le salut de l'homme, la sanction par Dieu de sa conduite morale. Le didascale romain se plaît néanmoins à relever les points de rencontre du christianisme et de ses enseignements avec nombre de doctrines de la philosophie profane, agréées de l'empereur et du public cultivé de son temps. C'est ainsi, dit-il, que Platon concorde avec les dogmes chrétiens au sujet de la transcendance de Dieu (Apol. II,10,6), de la création du monde à partir de la matière informe (Apol. I,20,4; 59,4), de la liberté et de la responsabilité de l'homme devant Dieu (Apol. I,44,8) du jugement et des sanctions à venir (Apol. I,8,4; 18,5; 20,4); il est même persuadé que Platon a enseigné la présence du Fils de Dieu en l'univers (Apol. I,60,1 et 5), voire celle de l'Esprit (Apol. I,60,7).

S'il ne témoigne que mépris à l'égard des philosophes cyniques (Apol. II,3,7), épicuriens (Âpol. II,7,3; 12,5; 15,3); s'il exprime ses réserves à l'é- 
gard des disciples d'Aristote et de Pythagore (Dial. 3), en revanche il marque son estime pour l'admirable doctrine morale des stoïciens (Apol. II $, 8,1)$ et souligne leur accord avec la doctrine chrétienne quant à la future destruction du monde par le feu (Apol. II,7,3). Cependant il s'empresse de distinguer soigneusement ce qui distingue la conception stoïcienne, qui

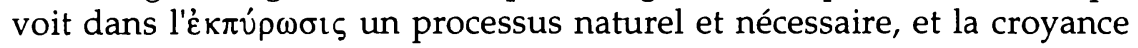
des chrétiens en un acte divin de jugement (Apol. I,20,2; II,7,2-3). Il exprime aussi les plus graves réserves à l'égard du matérialisme du Portique et de sa doctrine d'un destin fatal, qui lui paraît devoir ruiner toute responsabilité morale et abolir toute différence entre le vice et la vertu (Apol. II,7-9).

Dans le Dialogue avec Tryphon Justin soulève aussi des critiques contre plusieurs doctrines platoniciennes: la préexistence des âmes, leur immortalité naturelle, la limitation temporelle des sanctions qui frapperont les méchants (Dial. 4-6). Malgré tout, sa préférence va incontestablement à Platon et au platonisme, dont il a acquis une connaissance satisfaisante en fréquentant les maîtres éclectiques du moyen-platonisme de son temps. Depuis plusieurs décennies, les travaux de C. Andresen, de W. Schmid, de H. Waszink, de H. Chadwick, d'E. des Places, d'autres encore, ont précisé les influences qui se sont exercées sur Justin et fait ressortir combien ses propres conceptions philosophiques sont elles-mêmes éclectiques. L'ouverture d'esprit du didascale romain, sa volonté d'accueillir et de reconnaître toutes les parcelles de vérité disséminées dans les systèmes de la philosophie grecque et les écrits des poètes classiques ont été maintes fois soulignées. Mais a-t-on toujours discerné les raisons profondes de cet optimisme, et la visée apologétique qui le commande?

Lorsqu'il s'était converti au christianisme, Justin n'avait pas abandonné le $\tau$ í $\beta \omega v$, le manteau des philosophes; il signifiait par là son intime conviction: en devenant chrétien, il n'avait fait que passer d'une philosophie à une autre, mais "la meilleure de toutes, supérieure à toute humaine philosophie" (Apol. II,15,3). Cette conviction commande tout l'argumentaire de l'Apologie.

Tout d'abord, en associant les enseignements chrétiens avec les doctrines philosophiques de l'époque, Justin vise à placer le christianisme sous la protection de l'antique et prestigieuse tradition philosophique des Grecs. Puis, en présentant la religion chrétienne comme une philosophie parmi d'autres, qui constituent autant de rameaux de l'unique philosophie, vouée à la recherche et à l'enseignement de la sagesse et de la vertu, il escompte pour elle la même tolérance que le public cultivé accorde aux diverses écoles philosophiques rivales (Apol. I,4,7-9; 68,1; II,13,2; 15,3); il en appelle à la conscience philosophique du prince dans ce sens (Apol. I,7,2-5). Enfin, en faisant reconnaître à la doctrine chrétienne le statut d'une philosophie parmi d'autres, il se donne le moyen d'instaurer avec celles-ci une comparaison qu'il conduira jusqu'à sa pleine justification. 
Pour cette comparaison Justin recourt à deux critères complémentaires: d'une part, il reprend à l'apologétique juive la théorie bien connue des emprunts, selon laquelle les maîtres à penser grecs ne furent jamais que d'habiles imitateurs de l'antique sagesse des Juifs; d'autre part, il souligne les contradictions qui opposent les diverses écoles de la philosophie profane et en conclut que toutes ont échoué dans leur recherche de la vérité intellectuelle et morale. Certes, dans la mesure où chacun des écrivains de la Grèce (philosophes, poètes ou prosateurs) "en vertu d'une participation au divin logos séminal ( $\Lambda$ ó $о \varsigma$ $\sigma \pi \varepsilon \rho \mu \alpha \tau \iota$ кós), a contemplé ce qui lui était connaturel, il en a parlé excellement" (Apol. II,13,3); mais du fait que ces auteurs se sont contredits sur des points essentiels, il est évident qu'ils ne possèdent ni une science infaillible ni une connaissance $(\gamma v \omega \bar{\sigma} \iota \varsigma)$ irréfutable. Celles-ci n'appartiennent qu'aux chrétiens qui, par pure grâce, possèdent l'objet même de la Gnose parfaite en la personne du Logos divin, le fils de Dieu, incarné en Jésus-Christ. Certes encore, grâce à la semence du Logos, implantée en eux, les maîtres de l'Antiquité, législateurs, poètes et philosophes, ont pu entrevoir la réalité ( $\tau \dot{\alpha}$ óv $\tau \alpha)$, mais ce ne fut jamais que d'une manière partielle et indistincte. En effet "une semence, une ressemblance, accordées aux hommes à la mesure de leur capacité, est une chose; c'en est une autre que l'Être même, dont la participation et l'imitation procèdent en vertu de la grâce qui vient de lui" (Apol. II,13,6).

La notion du "logos séminal" ( $\sigma \pi \varepsilon \rho \mu \alpha \tau \iota \kappa o s)$, développée par Justin pour entrer en dialogue avec la philosophie de son temps lui appartient en propre; il est le premier écrivain chrétien qui l'ait utilisée, ouvrant ainsi à la religion du Christ de vastes perspectives missionnaires non seulement vers la philosophie antique, mais plus généralement vers les cultures les plus diverses, s'il est vrai que toutes participent à l'unique Logos divin. Conscients de l'importance de cette notion, nombre d'historiens se sont interrogés sur ses origines, qui sont multiples, assurément. En effet, les recherches les plus récentes ont permis d'établir que, si on peut la rattacher à la tradition philosophique éclectique de l'époque, à dominante stoïcienne et médio-platonienne, elle s'inscrit également dans la tradition judéo-alexandrine, illustrée par Philon. Mais il convient aussi de prendre en compte la tradition chrétienne ancienne; celle-ci reconnaît le double chemin qui conduit tout homme raisonnable à une connaissance de Dieu, obscure, certes, imparfaite, tant qu'on voudra, mais néanmoins réelle: le spectacle de la création et la loi morale gravée dans nos cœurs (Rom. 1-2; Act. 17). Par ailleurs, la parabole matthéenne du Semeur (Matth. 13) a pu inspirer la pensée de Justin; elle décrit l'activité universelle de l'unique Semeur; elle implique l'image des semences de vérité répandues par lui dans tout le genre humain, depuis les origines.

W. Bousset, Jüdisch-christlicher Schulbetrieb in Alexandria und Rom, Göttingen 1915; G. Bardy, Les écoles romaines au second siècle, RHE 28, 1932, 501-522; Saint Justin et la philosophie stoïcienne, RSR 13, 1923, 491-510; 24, 1924, 33-45; "Philosophie" et "philosophe" dans le vocabulaire chrétien des premiers siècles, RAM? 25, 1949, 97-108; L. Alfonsi, 
Giustino nella tradizione platonica-aristotelica, RStPh 1, 1946, 229-234; C. Andresen, Justin und der mittlere Platonismus, ZNTW 44, 1952-53, 157-195; W. Schmid, Frühe Apologetik und Platonismus, Hermeneia, Festschrift O. Regenbogen, Heidelberg 1952, 163-183; M. Spanneut, Le stoïcisme des Pères de l'Eglise, de Clément de Rome à Clément d'Alexandrie, Paris 1957; H. Wey, Die Funktionen der bösen Geister bei den griechischen Apologeten des zweiten Jahrhunderts nach Christus, Winterthur 1957; R. Holte, Logos spermatikos. Christianity and Ancient Philosophy according to St. Justin's Apologies, StTh 12, 1958, 109-169; H. Kraft, Der mittlere Platonismus und das Christentum, ThLZ 83, 1958, 330-340; M. Pellegrino, Cristianesimo e filosofia in San Giustino martire, Scuola cattolica 57, 1959, 301-303; A.-M. Malingrey, "Philosophia". Étude d'un groupe de mots dans la littérature grecque, des Présocratiques au IVe siècle après J.-C. (Etudes et Commentaires XL), Paris 1961; J. Sikora, Philosophy and Christian Wisdom according to Saint Justin Martyr, Franciscan Studies 23, 1963, 244-256; H. Waszink, Bemerkungen zu Justins Lehre vom Logos Spermatikos, Mullus. Festschrift Th. Klauser, JbAC, Erg.band 1, 1964, 380-390; Bemerkungen zum Einfluss des Platonismus im frühen Christentum, VC 19, 1965, 129-162; H. Chadwick, Early Christian Thought and the Classical Tradition. Studies in Justin, Clement and Origen, London 1966; R. Joly, Christianisme et philosophie. Études sur Justin et les apologistes grecs du deuxième siècle, Bruxelles 1973; J. de Vogel, Problems concerning Justin Martyr. Did Justin find a certain Continuity between Greek Philosophy and Christian Faith? Mnemosyne 31, 1978, 360-388; A. Stötzel, Warum Christus so spät erschien? Die apologetische Argumentation des frühen Christentums, ZKG 92, 1981, 147-160; D. Bourgeois, La sagesse des anciens dans le mystère du Verbe. Évangile et philosophie chez saint Justin, Paris 1981; E. des Places, Platonisme moyen et apologétique chrétienne au Ile siècle après J.C. Numénius, Atticus, Justin, StPatr 15, 1984, 432-441; A.J. Droge, Justin Martyr and the Restoration of Philosophy, Church History 56, 1987, 303-319; R. Price, Helleniza-

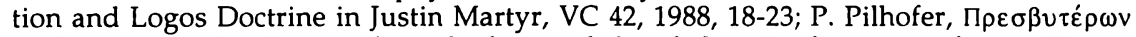

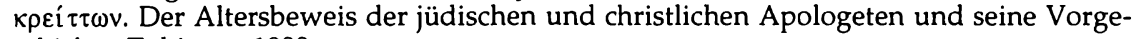
schichte, Tübingen 1990.

M. Pellegrino, Gli apologeti greci del II secolo. Saggio sui rapporti fra il cristianesimo primitivo e la cultura classica, Roma 1947; J. Pépin, Le challenge "Homère-Mö̈se" aux premiers siècles chrétiens, RScR 29, 1955, 105-122; J. Buffière, Les mythes d'Homère et la pensée grecque, Paris 1956; W. Krause, Die Stellung der frühchristlichen Autoren zur heidnischen Literatur, Wien 1958; J. Daniélou, Message évangélique et culture hellénistique aux Ile et IIIe siècles, Paris 1961; G. Glockmann, Homer in der frühchristlichen Literatur bis Justinus, TU 105, Berlin 1965; N. Zeegers-Van der Vorst, Les citations des poètes grecs chez les apologistes chrétiens du IIe siècle, Louvain 1972.

11. Les vues de Justin sur la philosophie antique ne présentent pas seulement un intérêt apologétique immédiat pour lui-même, dans la mesure où sa doctrine du Logos séminal lui permet de tendre la main à ses adversaires intellectuels en signe de réconciliation; elles contiennent en germe une théologie de l'histoire de portée universelle, promise à une longue fortune. De fait Justin considère toute l'histoire de l'humanité, celle d'Israël comme celle des Grecs, comme une histoire sainte, puisque Dieu la dirige pour le salut de l'humanité et que chaque homme est invité par sa raison et sa conscience à penser et à vivre selon le Logos et à découvrir son message de sagesse et de vérité. Pour les individus comme pour les peuples, Grecs ou Barbares, c'est bien dans l'histoire que se réalise le plan divin de salut. Aux yeux de Justin cette histoire sainte est unique, car le Dieu unique l'accomplit une fois pour toutes par son fils unique Jésus-Christ, "devenu homme pour nous, afin de prendre part à nos misères et nous en guérir" (Apol. II,13,4). 
L'apologiste romain élargit à l'histoire de tous les peuples la vision salvifique que l'Épître aux Hébreux présente de l'histoire d'Israël. Depuis toujours Dieu a parlé aux hommes, aux Pères par les prophètes (cf. Hebr. 1,1-3), aux Grecs - autant dire à toutes les nations - en les faisant participer à son Logos, Maître de sagesse et de vérité. Dès lors, la philosophie grecque, non moins que l'Ancien Testament, se révèlent comme "deux courants convergents qui confluent providentiellement dans le Christ et son évangile universel" (H. Chadwick, Justin Martyr's Defence of Christianity, p.287).

B. Seeberg, Die Geschichtstheologie Justins des Märtyrers, ZKG 58, 1939, 1-81; A. Quacquarelli, La storia nella concezione di S. Giustino, Rassegna di scienza filosofica 6, 1953, 323-339; L. Scipioni, Alle origini di una concezione della storia nei Padri della Chiesa, Sacra dottrina 2, 1957, 171-192; G. Jossa, La teologia della storia nel pensiero cristiano del secondo secolo, Napoli 1965; L.G. Patterson, God and history in early Christian thought. A study of themes from Justin Martyr to Gregory the Great, London 1967; H. von Campenhausen, Die Entstehung des christlichen Geschichtsbildes in der Theologie des ersten und zweiten Jahrhunderts, Saeculum 21, 1970, 189-212; L.W. Barnard, Justin Martyr, 27-39; E. Osborn, Justin Martyr, 154-171.

12. S'il est une idée, une démarche, chère à Justin, c'est bien que la vérité des croyances des chrétiens et la légitimité de leurs usages sont susceptibles d'une démonstration rationnelle $\left(\dot{\alpha} \pi o ́ \delta \varepsilon 1 \xi_{1 \varsigma}\right)$. L'apologiste se montre extrêmement préoccupé de réfuter l'objection selon laquelle les chrétiens se borneraient à exiger une foi aveugle en leurs dogmes, sans apporter de preuves de leur doctrine (Apol. II,9,1). Aux adversaires de la foi chrétienne, il se fait fort de fournir une démonstration en bonne et due forme ( $\dot{\alpha} \pi \delta ́ \delta \varepsilon 1 \xi 1 \varsigma)$ de la dignité et de la vérité du culte chrétien (Apol. I,13,1-3) et de la patience héroïque des disciples du Christ (Apol. I,16,4; II,12,1-4). Il en va de même pour leurs dogmes majeurs: la responsabilité morale de l'homme, fondée sur son libre arbitre (Apol. I,43,4; II,9,4), la sanction du jugement suprême (Apol. I,17,4), la résurrection corporelle (Apol. I,19). Par contre Justin accuse les mythologues (Apol. I,54,1) et les hérétiques (Apol. I,58,1) de ne pas offrir de démonstration de leurs dires, à la différence des chrétiens qui, non seulement prouvent la supériorité du Christ sur tous les fils de Zeus (Apol. I,22,4), mais possèdent, dans l'argument prophétique, le mode de démonstration "le plus convaincant et le plus véridique" qui soit, pour établir la vérité du christianisme (Apol. I,30), vainement contrefaite par les démons (Apol. I,23,3; 46,6). Et si ses interlocuteurs récusaient toutes ces démonstrations, Justin, avec une amère ironie, leur propose de démontrer, par l'absurde, que le christianisme est une "philosophie divine" (Apol. II,12,5), puisque les forfaits supposés de ses adeptes imitent les mœurs de Zeus et des autres dieux.

Pour Justin, la certitude de l'origine divine du christianisme, la garantie de sa vérité reposent sur des preuves de fait, tangibles, inscrites dans les réalisations de l'histoire. Il est fermement convaincu que l'accomplissement des prophéties de l'Ancien Testament, énoncées "cinq mille, trois 
mille, deux mille, mille et huit cent ans" (Apol. I,31,8) avant les événements, constitue une preuve irréfragable, de nature à convaincre obligatoirement du caractère divin de la religion chrétienne tous ceux qui en ont connaissance: puisque des événements précis ont pu être annoncés tant de siècles à l'avance, c'est qu'ils sont la réalisation d'un dessein de Dieu et non point des épisodes erratiques dénués de signification; en d'autres termes, l'argument prophétique révèle que Dieu est le maître de l'histoire et que cette histoire est sainte, dirigée par Dieu pour le salut de l'humanité (Apol. I,12,10; 42,1-2; 52,1).

S'il reconnaît à l'argument prophétique la valeur d'une démonstration rationnelle, Justin ne laisse pas de fonder l'autorité des prophètes euxmêmes sur leur inspiration divine, confirmée par les miracles qu'ils ont accomplis par la vertu de l'Esprit saint (Apol. I,33,9; Dial. 7,1 et 3). Par ailleurs, quelle que soit la confiance qu'il accorde à la force contraignante de cet argument, il n'en souligne pas moins la nécessité des dispositions morales dans l'approche de la foi (Apol. I,12,1; 53,1 et 12), et rappelle que la grâce de Dieu est indispensable pour comprendre les prophètes à la lumière de l'histoire évangélique (Dial. 7,3; 30,1; 58,1; 93,1; 108,1-3).

En Apol. I,31,7, Justin énumère les points essentiels de sa démonstration par les prophéties. Il est facile d'y reconnaitre plusieurs articles d'une profession de foi paléochrétienne, semblable à celle de la Ière Épître de Pierre $(3,18.22)$ ou d'Ignace d'Antioche (Eph. 18,2; Trall, 9; Smyrn. 1): la venue du Christ, sa naissance virginale, sa mort en croix, sa résurrection, son ascension. Ces articles figurent aussi régulièrement dans les propres "symboles de foi" de Justin (Apol. I,21,1; 46,5; 63,16; Dial. 85,2). D'autres propositions se retrouvent ailleurs moins régulièrement, telle la mention des miracles de Jésus (cf. Act. 2,22) ou celle des sévices qu'il eut à subir sous Ponce-Pilate (cf. Ignace, Trall. 9,1). D'autres, enfin, semblent n'avoir jamais fait partie intégrante d'une profession de foi paléochrétienne, telle la mention de l'incognito du Messie avant sa manifestation publique

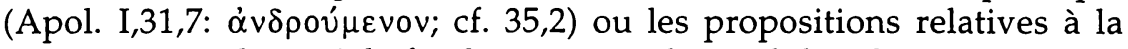
mission apostolique, à la foi des païens, à l'incrédulité du peuple juif et au châtiment national que subit Israël.

La diversité de ces éléments suggère que Justin a puisé à des sources diverses les testimonia qu'il a fait entrer dans le canevas de sa démonstration: si l'apport majeur provient du kérygme primitif, d'autres recueils ou centons de textes bibliques ont pu être constitués en vue de la catéchèse missionnaire auprès des païens ou de l'apologétique et de la polémique à l'adresse des Juifs. La nature particulière des citations vétéro-testamentaires alléguées en Apol. I,30-53 milite en faveur de la multiplicité de ces organisations antérieures de testimonia, semble-t-il. Exception faite des emprunts directs à la Septante touchant Is. 53 et le Ps. 110(109), il apparaît, en effet, que les citations de l'Ancien Testament de cette section ne sont pas des citations libres faites de mémoire par Justin ni des emprunts 
tardifs à des manuscrits déviants, mais qu'il s'agit là de matériaux provenant de sources paléochrétiennes écrites, auxquelles Justin doit aussi l'essentiel de ses commentaires. Ces recueils lui ont transmis des traditions particulières à des écoles théologiques, dont les tendances sont encore discernables. Oskar Skarsaune observe à ce propos, que les documents les plus étroitement apparentés à la tradition paléochrétienne qui inspire Justin dans cette section sont, d'une part, les 'Av $\alpha \beta \alpha \theta \mu$ oi 'I $\alpha$ kóßou I insérés dans les Reconnaissances Pseudo-Clémentines (I,33-71), les Testaments des Douze Patriarches, d'autre part. L'indication est intéressante; elle suggère que Justin, parmi les milieux judéo-chrétiens de son temps, privilégiait ceux dont les tendances apocalyptiques étaient les plus prononcées: on s'explique mieux, dès lors, l'importance qu'il accorde à certains thèmes comme la démonologie, le martyre, voire le millénarisme.

A plusieurs endroits de la section en cause (Apol. I,30-53) affleurent des séries de testimonia, dont la visée "missionnaire" en direction de la nation juive au lendemain de la révolte de Bar Kochba paraît assurée (Apol. I,36,3; 37,1-8; cf Dial. 13-15; Apol. I,39-46; cf. Dial. 16-17; 106110). La perspective missionnaire de ces sections explique apparemment l'excursus consacré à la responsabilité personnelle et au libre arbitre d'Apol. I,43-44; il est significatif qu'une part des testimonia bibliques produits par Justin à ce propos (Is. 16-20; Deut. 30,15-19) ait été reprise par Clément d'Alexandrie dans un contexte baptismal (Strom. VI,48-49; Protr. 95,2).

L'apologiste a réservé pour la fin de son développement les "prophéties" qui lui paraissent les plus démonstratives. En Apol. I,47-49, il revient sur l'actualité toute proche, la deuxième Guerre juive (132-135), l'échec de la rébellion, sa répression impitoyable, le Décret d'Hadrien qui, pour faire d'Aelia Capitolina une ville toute païenne, en avait interdit l'accès aux Juifs sous peine de mort. Il allègue dans ce sens Is. 64,9-11, comme annonçant la dévastation de la Judée; Is. 1,7 et Jer. 50,3, celle de Jérusalem, et voit dans la circoncision le signe relatif au Décret d'Hadrien. Dans le Dialogue avec Tryphon, une dizaine d'années après l'Apologie, il attribuera les malheurs qui se sont abattus sur la nation juive à la responsabilité qu'elle a encourue en rejetant le Christ Jésus et en persécutant ses disciples (Dial. 16,4; 108,2; 117,3; 131,1; 136,2); dans l'Apologie (I,4749), il se contente de rappeler que cette attitude hostile au Messie avait été annoncée par les prophètes et qu'elle avait eu pour conséquence la réussite extraodinaire de la mission chrétienne auprès des Gentils (Apol. I,49,5; cf. 53,3-11). Cette dernière prophétie (Is. 54,1; 1,9) s'accomplit sous les yeux mêmes des contemporains; sa réalisation garantit celle des événements prophétisés qui restent encore en suspens: le retour glorieux du Christ, le jugement dernier (Apol. I,52,3-9).

On le voit: aussi paradoxal que cela puisse paraître, l'argument prophétique constitue une pièce maîtresse du dispositif apologétique de Jus- 
tin à l'adresse des ses interlocuteurs païens eux-mêmes. Faute de pouvoir les renvoyer à des "annales" chrétiennes retraçant la vie de Jésus, il avait invoqué les documents officiels de l'administration romaine: le recensement de Quirinius (Apol. I,34,2; 46,1), les actes de la procuratèle de Ponce-Pilate (Apol. I,35,9; 46,1; 48,3). C'étaient là, pensait-il, des documents irrécusables, attestant que les événements de la vie de Jésus, annoncés par les prophètes, s'étaient effectivement réalisés. Force est pourtant de reconnaître que l'existence des documents allégués par Justin est des plus problématique; s'il la postule, c'est parce qu'il lui paraît impossible que les événements majeurs de la vie du Christ, que sa foi place au cœur de l'histoire du salut, n'aient pas été inscrits dans les archives de l'Empire romain.

J. Gervais, L'argument apologétique des prophéties messianiques selon saint Justin, Revue de l'Université d'Ottawa 13, 1943, 129-146; 193-208; I. Posnoff, Les prophètes dans la synthèse chrétienne de saint Justin (Diss.), Louvain 1949; H. Bacht, Die Lehre des hlg. Justinus Martyr von der prophetischen Inspiration, Scholastik 26, 1951, 481-495; 27, 1952, 12-33; H. Köster, Septuaginta und synoptischer Erzählungsstoff im Schriftbeweis Justins des Märtyrers, Heidelberg 1956; L.W. Barnard, The Old Testament and Judaism in the Writings of Justin Martyr, VT 14, 1964, 395-406; P. Prigent, Justin et l'Ancien Testament. L'argumentation scripturaire du traité de Justin contre toutes les hérésies comme source principale du Dialogue avec Tryphon et de la Première Apologie, Paris 1964; W.A. Shotwell, The biblical exegesis of Justin Martyr, London 1965; D.E. Aune, Justin Martyr's use of the Old Testament, Bulletin of the Evangelical Theological Society 9, 1966, 179-197; R.P.C. Hanson, Biblical Exegesis in the Early Church, Cambridge 1970, I, 412-453; L. Kline, Harmonized Sayings of Jesus in the Pseudo-Clementines and Justin Martyr, ZNTW 66, 1975, 223-241; W.S. Kurz, The Function of Christological Proof from Prophecy for Luke and Justin (Diss.), Yale 1976; J. Morales, Fé y demostración en el método teológico de san Justino, Scripta teologica 17, 1985, 213-225; J.L. Marshall, Some Observations on Justin Martyr's Use of Testimonies, TU 129, 1987, 197-200; O. Skarsaune, The Proof from Prophecy. A Study in Justin Martyr's Proof-text Tradition (NT.S 56), Leiden 1987.

13. L'examen des citations de l'Ancien Testament alléguées par Justin a permis à la critique de préciser toujours mieux l'origine et la nature des documents dont l'apologiste disposait en vue d'étayer son argumentation par les prophéties. La collecte et la mise en œuvre de testimonia bibliques, illustrant tel ou tel aspect du kérygme ou de la parénèse, s'inscrit dans la tradition paléochrétienne la plus ancienne, attestée dès l'époque apostolique. Le travail anonyme de générations de didascales chrétiens œuvrant individuellement ou en "écoles" dans les divers centres de la chrétienté permit de constituer une riche documentation, dont les éléments affleurent, d'Asie mineure et d'Alexandrie à Rome et à Carthage, au Ile et au IIIe siècle. Il est notoire que les premiers didascales chrétiens adaptèrent aux besoins de leurs communautés les méthodes exégétiques pratiquées dans le judaïsme tardif, mises en lumière par les découvertes de Qumran, notamment sous la forme du commentaire biblique du midrash pesher.

Le plus important des écrits qumraniens de cette veine est le commentaire d'Habacuc (QpHab), qui s'attache aux deux premiers chapitres de cet ouvrage. Le midrash pesher applique à des événements contemporains 
ou d'un passé récent des textes de l'Ancien Testament, qui sont censés les annoncer. C'est ainsi que l'auteur de 1QpHab applique les paroles du prophète aux tribulations subies par la communauté du fait du prêtre impie de Jérusalem, et à la persécution dont fut victime le Maître de Justice; dans le fragment du pesher sur Nahum (4QpNah), les allusions à des faits contemporains sont encore plus nettes: on y reconnaît les événements survenus depuis le règne de Démétrios III (96-98 avant J.C.) jusqu'à l'arrivée des Romains.

La manière dont Justin interprète la défaite de Bar Kochba, la dévastation de la Judée et le Décret d'Hadrien relève manifestement de cette méthode. Le fait qu'il utilise à cet effet des séries de testimonia constituées en milieu judéo-chrétien révèle à quel point l'apologiste romain est tributaire de traditions paléochrétiennes issus du judaïsme palestinien lui-même, mais aussi à quel point les événements de la récente guerre juive (132135) continuaient d'agiter les communautés chrétiennes d'Occident et d'influencer leurs relations avec les communautés juives avec lesquelles elles demeuraient en dialogue.

Certes, bien des points restent encore à élucider dans l'itinéraire chrétien de Justin. A-t-il reçu sa formation biblique en Palestine même ou bien en Asie mineure, dans un centre où l'influence judéo-chrétienne était nettement prononcée? Fut-il, d'emblée, associé à une école de didascales responsables de l'enseignement des recrues venues du paganisme? et/ou du dialogue avec les rabbins? Où a-t-il appris à scruter et à interpréter à cet effet les Écritures (cf. Dial. 58,1; 78,10; ?7?,3)? S'il revendique une grâce, un charisme personnel pour comprendre les Écritures, cette grâce s'exerce dans un cadre tracé d'avance. En réalité, Justin se sait dépositaire, responsable de traditions exégétiques transmises par l'Église comme venant des apôtres et, par eux, du Christ lui-même.

D. Barthélémy, Redécouverte d'un chaînon manquant de l'histoire de la Septante, Revue biblique 60, 1953, 18-29 (=Études d'histoire du texte de l'Ancien Testament, OBO 21, Fribourg/Suisse 1978, 38-50); Les devanciers d'Aquila. Première publication intégrale du texte des fragments du Dodécapropheton trouvés dans le désert de Juda. Supplement to Vetus Testamentum 10, Leiden 1963, 201-212; P. Katz, Justin's Old Testament Quotations and the Greek Dodekapropheton Scroll, StPatr 1 (TU 63), Berlin 1957, 343-353; H. Chadwick, Justin Martyr's Defence of Christianity, BJRL 47, 1964/1965, 275-297 (=History an Thought of the Early Church, Variorum Reprints, London 1982, Nr. VII); L.W. Barnard, The Old Testament and Judaism in the Writings of Justin Martyr, VT 14, 1964, 395-406; C.H. Dodd, According to the Scriptures. The Substructures of New Testament Theology, London 1965; K. Stendahl, The School of St. Matthew and its Use of the Old Testament, Lund 1969; R. Le Déaut, Un phénomène de l'herméneutique juive ancienne: le "targumisme", Biblica 52, 1971, 505-525; H. Köster, Einführung in das Neue Testament, Berlin-New York 1980, p.270s.; O. Skarsaune, The Proof from Prophecy, Leiden 1987; E.R. Goodenough, The Theology of Justin Martyr, 33-57; L.W. Barnard, Justin Martyr, 39-53; E.F. Osborn, Justin Martyr, 87-99; 111-120. 
14. Justin a conscience d'appartenir à une tradition vivante et d'enseigner une doctrine véridique, d'origine divine. Ce qu'il enseigne, c'est ce qu'il a appris, ce que tous les chrétiens apprennent (Apol. I,6,2; 13,1; 17,1; 46,2; $61,9 ; 66,2: \dot{\omega} \varsigma \dot{\varepsilon} \delta 1 \delta \alpha \dot{\alpha} \chi \theta \eta \mu \varepsilon v)$, c'est à dire l'enseignement des prophètes, du Christ et des apôtres, "envoyés pour enseigner à tous la parole de Dieu" (Apol. I,39,3; 61,9; 66,3). La tradition qu'il entend transmettre à son tour lui vient des apôtres, mais elle a pour garant le didascale par excellence, le Maître divin, qui est le Logos (le Verbe) et premier-né de Dieu (Apol. I,10,6; 13,3; 14,4; Dial. 58,9).

Quand on analyse de plus près le contenu de l'enseignement traditionnel, dont Justin se réclame constamment (I,14,4;15,16,8;40,1;46,1; II, 2,$13 ; 10,8 \ldots)$, on constate qu'il embrasse non seulement le domaine purement doctrinal, mais aussi les préceptes de la morale et les règles du comportement chrétien, voire certains traits essentiels des institutions ecclésiales, de la liturgie aux structures des communautés.

Parmi les articles de la foi chrétienne inscrits dans la tradition, Justin mentionne explicitement la croyance au Dieu très vrai, "Père de la justice, de la chasteté et des autres vertus" (Apol. I,6,1), Créateur de l'univers (Apol. I,10,2-3). Il souligne aussi que la création, que le Père, dans sa bonté, a réalisée par son Logos, a été effectuée "à cause des hommes" (Apol. II,12,1; 15,3). Bien entendu, les propositions fondamentales relatives à la nature et à l'œuvre du Christ, le Fils premier-né de Dieu, son Logos devenu homme, enfanté par une vierge, mort sur la croix, ressuscité et monté au ciel (Apol. I,46,2-5), font partie intégrante de cette tradition, signalée par Justin à travers les verbes: $\pi \alpha \rho \alpha \lambda \alpha \mu \beta \alpha_{\alpha} v \omega, \pi \alpha \rho \alpha \delta i \delta \delta \nu \alpha \iota, \delta 1 \delta \alpha \dot{\alpha} \sigma \omega$, $\pi \varepsilon i \theta \omega, \mu \alpha v \theta \alpha \dot{v} v \omega)$, ainsi que la vertu salvifique de son œuvre (Apol. $I, 13,3)$. Les enseignements relatifs à l'eschatologie: la rétribution individuelle, le bonheur des justes, le châtiment des impies (Apol. I,10,2; 21,6; 43,2), la résurrection occupent aussi une place de choix dans la doctrine traditionnelle rappelée par Justin.

Dans le domaine moral, l'apologiste insiste sur plusieurs préceptes que le Christ lui-même a inculqués (Apol. I,66,1). Ces préceptes marquent, aux yeux de Justin, toute la distance qui sépare le comportement des païens de celui des disciples du Christ; ils devraient impressionner favorablement tout observateur de bonne foi (Apol. II,12,1; 15,3). Les chrétiens ont appris de leur Maître à demeurer intrépides quand ils sont appelés à rendre raison de leur foi $(I, 4,7)$; ils professent un respect scrupuleux de la vie $(I, 27,1)$, une pureté sans défaillance $(I, 15)$, une patience à toute épreuve (I,16,1-4), un loyalisme sincère $(I, 17,1-3)$, un amour indéfectible de la vérité (I,16,5; II,2,11-14).

Dans le domaine liturgique, Justin souligne que la tradition chrétienne prône un culte spirituel, car Dieu n'a pas besoin des offrandes matérielles des hommes $(I, 10,1)$. Le baptême et l'eucharistie répondent à cette exigence. Par les engagements du baptême, les néophytes promettent de me- 
ner une vie digne de Dieu $(\mathrm{I}, 61,2)$. L'eucharistie, qui couronne les cérémonies impressionnantes de l'initiation chrétienne, intègre les néophytes à l'assemblée des frères qui les accueille par le baiser de paix; ils y participent au mystère de la chair et du sang du Logos divin, Jésus Christ le Sauveur; ils se savent incorporés désormais à une communauté de prière et d'entraide fraternelle, dont le président, dûment secondé, tient à cœur de leur faire vivre l'unité, la foi, le partage (Apol. I,67).

Qu'il s'agisse de points de doctrine, de règles de vie, de la structure hiérarchique des communautés, du déroulement correct de la liturgie et de l'assistance aux frères dans le besoin, Justin atteste donc que les "fraternités" chrétiennes possèdent des usages, des traditions, dont elles entendent ne point dévier et qu'elles respectent d'autant plus religieusement que leur origine apostolique leur paraît assurée. Bien qu'il n'utilise pas l'expression de "tradition apostolique", Justin en connaît parfaitement la réalité et il s'y réfère à mainte reprise. Il déclare explicitement que non seulement la doctrine chrétienne a été répandue par leur parole puissante (Apol. I,45,5; 49,5;50,12) et s'est imposée malgré les traditions juives (Apol. I,53,3; cf. Dial 38,2), mais que la substance de la parénèse dominicale des assemblées chrétiennes s'y rattache (Apol. I,67,3; cf. 42,4), ainsi que la liturgie eucharistique (Apol. $I, 66,3)$ et même les éléments essentiels de la catéchèse prébaptismale (Apol. I,61,9).

Ailleurs il précise qu'en fait la tradition doctrinale des églises se ratache par les apôtres au Christ en personne (Apol. I,39,3; 42,4; 67,1) et, par le

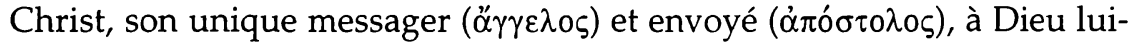
même (Apol. I,63,5.10.14; 12,9; cf. 6,2; 13,3; 21,1; 23,1; 67,8; cf. Clément de Rome, Ep. aux Corinthiens 42,1-4). Dès lors, l'enseignement des vérités "divines" (Apol. II,2,13; 4,3; 13,1) et des préceptes enjoignant de mener "une vie digne de Dieu" (Apol. I,10,2; 13,1) permet à la religion chrétienne de revendiquer le titre d"'école de la vertu divine" (Apol. II,2,13; cf. 12,5; $13,1 ; 15,3)$. Si Justin rend justice à certaines doctrines de la philosophie profane, il n'en réserve pas moins son adhésion intime aux seules vérités que lui transmet la tradition qui lui vient du Christ et des prophètes (Apol. I,23,1; cf. Dial. 7,1-8,2), car elles se fondent sur la vérité de Dieu lui-même. "La religion à laquelle Justin a adhéré de toute son âme est une religion révélée; c'est parce q'elle vient de Dieu et non des hommes qu'il y croit" (A. Puech, Les apologistes grecs, p.40).

A. Deneffe, Der Traditionsbegriff, Münster 1931; J. Ranft, Der Ursprung des katholischen Traditionsprinzips, Würzburg 1931; D. van den Eynde, Les normes de l'enseignement chrétien dans la littérature patristique des trois premiers siècles, Gembloux, Paris 1933; Ph. Carrington, The Primitive Christian Catechism: A Study in the Epistles, Cambridge 1940; O. Cullmann, Die Tradition als exegetisches, historisches und theologisches Problem, Zürich 1954; E. Flesseman-van Leer, Tradition and Scripture in the Early Church, 1954; R.P.C. Hanson, Tradition in the Early Church, 1962; G. Widengren, Tradition and Literature in Early Judaism and in the Early Church, 1963; C. Mondésert, La tradition apostolique chez saint Justin, L'année canonique 23, 1979, 145-158; G.I. Gargano, L'anziano incontrato da Giustino. Un amico del Logos o il Logos stesso, in: Geist und Erkenntnis. Festschrift für Th. 
Spidlik, München 1985, 64-75; P. Grech, Le tradizioni neotestamentarie e la "traditio catholica", Studia ephemeridis "Augustinianum" 31, 1990, 31-38; M. Tabet, I testi paolini sulla paradosis nei commenti patristici (secoli I-III), ibid., 39-54; J. Irmscher, Der Terminus paradosis, ibid., 55-62; J. Maier, Rivelazione, tradizione e autorità religiosa nel giudaismo palestinese e babilonese, ibid., 73-93; M. Dujarier, L'Eglise fraternité 1, Les origines de l'expression: adelphotès - fraternitas aux trois premiers siècles du christianisme, Paris 1991. - W.A. Curtis, Jesus Christ the Teacher, 1943; E. Fascher, Jesus der Lehrer, Sokrates und Christus, 1959; F. Roloff, Apostolat - Verkündigung - Kirche, 1965; F. Normann, Christos Didaskalos. Die Vorstellung von Christus als Lehrer in der christlichen Literatur des ersten und zweiten Jahrhunderts, MBTh 32, 1967; U. Neymeyr, Die christlichen Lehrer im zweiten Jahrhundert (SVigChr IV), Leiden -New York 1989.

15. L'Apologie de Justin atteste la richesse de la tradition vivante des églises. Celle-ci s'exprime principalement dans le cadre de l'assemblée liturgique, sous la forme de la lecture des livres saints, "les Mémoires des Apôtres ou les ouvrages des prophètes" (Apol. I,67,3), accompagnée d'exhortations appropriées (Apol. I,67,4); elle trouve aussi un champ d'application illimité dans la catéchèse des néo-convertis (Apol. I,61,10), l'apologétique (Apol. I,12-17), le dialogue ou la polémique avec les Juifs et les hérétiques.

Justin est le témoin d'une époque de transition. Certes, la tradition orale demeure encore vive dans les grands centres de la chrétienté, mais la prépondérance des documents écrits s'affirme de plus en plus nettement. Pratiquement contemporain de l'Apologie de Justin, l'Evangile de vérité atteste cette prépondérance; cet écrit puise, en effet aux quatre évangiles canoniques, aux épîtres pauliniennes, à l'Epître aux Hébreux, à l'Apocalypse, mais ignore les épîtres pastorales. Qu'en est-il de Justin?

S'il est difficile de déterminer la nature exacte des sources intermédiaires auxquelles l'apologiste romain doit nombre de ses citations de l'Ancien Testament, par contre la critique paraît être parvenue à un certain consensus au sujet de ses sources néotestamentaires. Elle admet que la plupart des allégations de Justin concordent avec le libellé des évangiles synoptiques pour le récit de la vie de Jésus et la substance de son enseignement. S'il retient parfois des détails infimes rapportés par les Synoptiques, il s'interdit les additions légendaires dont s'encombraient les évangiles apocryphes de l'époque.

Le matériau synoptique utilisé par Justin dans l'Apologie comprend, d'une part, les logia de Jésus allégués pour illustrer sa fonction de Didascale divin (Apol. I,14-20), d'autre part, les éléments narratifs produits en vue de prouver que les prophéties de l'Ancien Testament le concernant se sont effectivement réalisées (Apol. I,30-53). En ce qui concerne les logia de Jésus, la critique paraît avoir établi que Justin s'est servi de documents écrits, qui avaient rassemblé et parfois "harmonisé" le matériau synoptique. Elle a repéré en Apol. I,15-17 (cf. Dial. 35,3) un vade-mecum contre les hérésies, utilisé aussi par les Homélies pseudo-clémentines, Clément d'Alexandrie et Origène. Pour les regroupements partiels de logia en Apol. I,19,6-7, (cf. Dial. 17,3-4; 76,4-6; 98-106...), il est probable que Justin en 
soit l'auteur. Comment exclure que l'apologiste ait contribué à la formation de la tradition catéchétique romaine, qui semble avoir influencé celle d'Alexandrie dans la seconde moitié du Ile siècle? Les citations qui figurent en Apol. I,15-17 illustrent les enseignements de Jésus sur des sujets traditionnels de la catéchèse paléochrétienne; le Sermon sur la montagne en forme la substance. Dans plusieurs cas, le texte de Matthieu est enrichi d'éléments parallèles tirés de Luc ou d'autres sections de Matthieu.

Le matériau narratif des évangiles utilisé par Justin présente les mêmes caractéristiques que les logia de Jésus; il provient exclusivement des synoptiques, parfois le texte est cité ad litteram, plus souvent il offre une recension harmonisée de passages parallèles. Justin est le premier écrivain chrétien qui ait allégué systématiquement les évangiles synoptiques. Certes, il ne les commente pas encore de manière continue et pour euxmêmes; il se contente de les citer afin d'éclairer l'Ancien Testament qui seul est Écriture à ses yeux. A dire vrai, les évangiles, pour lui, ne sont pas Écriture, au sens technique du terme, mais des documents dignes de foi, relatant les événements de la vie du Christ et de l'Église. C'est pourquoi, à la différence de l'Ancien Testament, dont le texte lui paraît définitivement arrêté, le texte évangélique demeure "libre" et Justin ne se préoccupe pas d'en reproduire scrupuleusement la lettre; c'est seulement aux endroits où les synoptiques rapportent des citations de l'Ancien Testament qu'il s'astreint à citer exactement.

Aussi paradoxal que cela puisse paraître, compte tenu de la place que tient le Logos dans la christologie de Justin, celui-ci ne cite jamais expressément le Quatrième évangile. Toutefois les points de rencontre ne manquent pas de l'un à l'autre et ils sont assez nombreux et précis pour que l'on puisse admettre que, malgré les réticences manifestées alors en Occident à l'égard de l'évangile johannique, Justin lui reconnaissait une véritable autorité. A l'encontre de Philon, qui demeure en deçà, Justin s'accorde avec Jean pour dire que le Logos est Dieu, au sens propre du terme, et qu'au commencement Dieu a tout créé et ordonné par lui (Apol. II,5; In 1,1.10). Le fait que depuis les origines le genre humain tout entier participe au Logos correspond à Jn 1,4 et 9; Justin évoque à plusieurs reprises l'incarnation du Logos (Apol. I,32,11; 66,2; cf. Jn 1,14). Philon ignore le

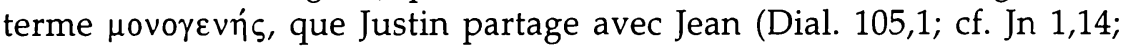
3,16.18; 1 Jn 4,9).

La tradition littéraire des Églises ne se limite pas pour Justin à la transmission des testimonia bibliques et des évangiles qui permettent de les illustrer. Dès l'Apologie il a recours au Livre de Actes pour exalter la mission des Apôtres (Apol. I,40,6; 49,5; 50,12; II,10,6). Le Dialogue avec Tryphon atteste de son côté la connaissance qu'il a du corpus paulinien: les allusions à l'Epître aux Romains sont nombreuses et nettes; plus clairsemées mais parfaitement repérables sont les références à la Première aux 
Corinthiens, à l'Épître aux Galates, à l'Épître aux Colossiens. Malgré tout, cette influence paulinienne demeure limitée; elle ne touche aucun des points essentiels de la théologie de Justin. Faut-il voir dans cette réserve de l'apologiste le reflet de la controverse qui agitait alors les milieux romains? N'est-ce pas au nom de Paul que Marcion combattait l'Ancien Testament?

A l'instar de l'Évangile de vérité, attribué à l'école de Valentin, Justin ignore les Épîtres pastorales. Quant aux traditions extracanoniques elles n'ont laissé que des traces infimes dans son œuvre (Dial. 35,3; 47,6). Dans l'Apologie, les quelques détails que l'on ne trouve pas dans les évangiles synoptiques sont vraiment insignifiants (Apol. I,32,6; 34,2; $38,6 ; 38,8)$. Quoi qu'il en soit de leur provenance, le fait est que Justin ne s'appuie que sur les Mémoires des Apôtres, les évangiles, dont l'autorité repose sur la tradition apostolique qu'ils incarnent (Apol. I,66,3).

W. Bousset, Die Evangeliencitate Justins des Märtyrers in ihrem Wert für die Evangelienkritik von neuem untersucht, Göttingen 1891; E.R. Buckley, Justin Martyr's Quotations from the Synoptic Tradition, JThS 36, 1935, 173-176; E. Massaux, Influence de l'Evangile de saint Matthieu sur la littérature chrétienne avant Irénée, Louvain-Gembloux 1950; Le texte du sermon sur la montagne de Matthieu utilisé par saint Justin, EThL 28, 1952, 411438; H. Köster, Septuaginta und synoptischer Erzählungsstoff im Schriftbeweis Justin des Märtyrers, Heidelberg 1956; Synoptische Überlieferung bei den apostolischen Vätern, TU 65, Berlin 1957; J.S. Romanidès, Justin Martyr and the Fourth Gospel, The Greek orthodox theological review 3, 1958-1959, 115-134; O.A. Piper, The Nature of the Gospel according to Justin Martyr, The Journal of Religion 41, 1961, 155-168; D.M. Davey, Justin Martyr and the Fourth Gospel, Scripture 17, 1965, 117-122; A. Bellinzoni, The Sayings of Jesus in the Writings of Justin Martyr, Leiden 1967; T.E. Pollard, Johannine Christology and the Early Church, Cambridge 1960; L. Kline, Harmonized Sayings of Jesus in the Pseudo-Clementines Homilies and Justin Martyr, ZNTW 66, 1975, 223-241; M. Mees, Form und Komposition der Herrenworte in Justin Apol. 1,15-17, Augustinianum 17, 1977, 283-306; G. Strecker, Eine Evangelienharmonie bei Justin und Pseudo-Clemens? NTS 24, 1978, 297-316; E. Dassmann, Der Stachel im Fleisch. Paulus in der frühchristlichen Literatur bis Irenäus, Münster 1979; P. Prigent, Les citations des Evangiles chez Justin (Apol. I,14-17), Cahiers de Biblia Patristica 1, 1987, 137-152; B.S. Childs, The New Testament as Canon, London 1984; W.D. Köhler, Die Rezeption des Matthäusevangeliums in der Zeit vor Irenäus, Tübingen 1987, 161-265; P. Pilhofer, Justin und das Petrusevangelium, ZNTW 81, 1990, 60-78; $\mathrm{P}$. Grech, Le tradizioni neotestamentarie e la "Traditio catholica", Studia ephemeridis "Augustinianum" 31, 1990, 31-38; P. Hofrichter, Logoslehre und Christusbild bei Apologeten, Modalisten und Gnostikern, in: Monotheismus und Christologie. Zur Gottesfrage im hellenistischen Judentum und im Urchristentum, hg. von H.J. Klauck, Freiburg, Basel, Wien 1992, 186-217. - R. Heard, The Apomnemoneumata in Papias, Justin and Irenaeus, NTS 2, 195455, 122-129; L. Abramowski, Die "Erinnerungen der Apostel" bei Justin, in: Das Evangelium und die Evangelien, hg. bei P. Stuhlmacher, Tübingen 1983, 341-343; H. Köster, From the Kerygma-Gospel to written Gospels, NTS 35, 1989, 361-381; Ancient Christian Gospels. Their History and Development, London 1990. - L.W. Barnard, Justin Martyr, 53-74; E.F. Osborn, Justin Martyr, 120-139.

16. L'examen des traditions littéraires repérables dans l'Apologie fait appaître l'extrême diversité des sources auxquelles Justin a puisé, et des courants auxquels il est apparenté, qu'il s'agisse de philosophie, d'exégèse ou de théologie. Ce fait reflète bien le foisonnement intellectuel et religieux qui caractérise l'Empire au IIe siècle; il est particulièrement sensible à 
Rome même, où les communautés chrétiennes sont traversées de courants de toute tendance. Si Justin a toujours été considéré comme appartenant à la Grande Eglise, on aimerait pouvoir le situer aussi face aux mouvements plus ou moins marginaux, qui se disputent alors la faveur de la chrétienté romaine. De fait, s'il intervient "en faveur des hommes de toute race injustement haïs et persécutés" (Apol. I,1), s'il affirme que le nom des chrétiens est un gage d'excellence (Apol. I,4,5) il ne laisse pas de prendre ses distances à l'égard de certains groupes ou individus qui se disent chrétiens, mais dont la conduite mauvaise fournit des prétextes "à ceux qui, de toute façon sont enclins à accuser injustement tous les chrétiens" (Apol. I,4,7).

Le critère d'une bonne conduite est décisif aux yeux de Justin, qui précise: "Ceux dont la vie ne se trouve pas être conforme aux enseignements de Jésus-Christ ne sauraient être tenus pour chrétiens, même si en parole ils professent la doctrine du Christ" (Apol. I,16,8). Qui vise-t-il ainsi? D'abord trois fondateurs de sectes appelées chrétiennes, Simon, Ménandre et Marcion, mais aussi "ceux qui se réclament de ces gens-là" (Apol. I,26,6). Manifestement l'apologiste cherche à les discréditer auprès des autorités romaines, afin que celles-ci prennent conscience que des distinctions s'imposent dans le traitement de la question chrétienne. S'il est vrai que Simon a égaré les Romains eux-mêmes par les prestiges de la magie, au point d'être considéré comme un dieu et d'être honoré d'une statue dans l'île du Tibre, il ne saurait prétendre au titre de disciple du Christ, ni ses adeptes qui "le reconnaissent comme leur premier dieu" et voient en sa comparse, Hélène, la mal-famée, sa première émanation (Apol. I,26,4). Cette fois l'accusation est double: magie et enseignement aberrant; Justin dénie à la secte le droit de revendiquer le titre de "philosophie", qu'il réclame hautement pour les (vrais) chrétiens. La même tactique est utilisée à l'égard de Marcion: "renier le Dieu créateur de cet univers" (Apol. I,26,5) n'est-ce pas le comble de l'absurde, face à l'enseignement unanime des grandes écoles de philosophie de l'Antiquité?

Si Justin ne formule aucun grief contre la conduite de Marcion, il n'épargne pas pour autant ses adeptes, car il les range implicitement parmi les prétendus chrétiens sur lesquels pèsent toute sorte de soupçons d'inconduite (Apol. I,26,6-7; cf. 4,7). Mais il y a plus: l'apologiste prétend que "tous ceux qui se réclament de ces gens-là" (Simon, Ménandre, Marcion) ne sont l'objet, de la part des autorités romaines ni de poursuites, $\mathrm{ni}$ de condamnations, "du moins à cause de leurs doctrines" (Apol. I,26,7). Le raisonnement de Justin apparaît en filigrane: si des sectes dites chrétiennes ne sont pas inquiétées, alors qu'elles rendent des honneurs divins à des magiciens (Simon, Ménandre) et à une ancienne prostituée; si les autorités romaines ne trouvent rien à redire à des affirmations manifestement "athées" (Marcion) ou absurdes (Ménandre, Simon), pourquoi s'en prennent-elles aux vrais chrétiens, dont les enseignements, reçus du 
Christ-Logos, incarnent la philosophie la plus sublime et la plus profitable au bonheur de la cité? L'Apologiste aimerait entraîner ses interlocuteurs vers l'examen des doctrines des différentes "écoles" chrétiennes; à cet effet, il propose la lecture de son Traité contre toutes les hérésies (Apol.

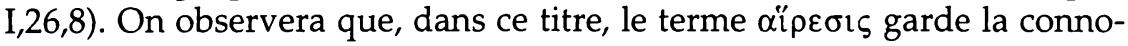
tation péjorative, qu'il possède déjà chez l'Apôtre (1 Cor. 11,18-19, cité en Dial. 35,3 et 51,2 ; cf. 17,$1 ; 62,3 ; 80,3.4 ; 108,2$ ).

Le fait que, dans l'Apologie, Justin ne fasse aucune allusion à Valentin, qui résidait alors à Rome, n'a pas manqué d'intriguer, d'autant plus que, dans le Dialogue avec Tryphon, une dizaine d'années plus tard, il range Marcionites, Valentiniens, Basilidiens et Saturniliens parmi les prétendus chrétiens qui "enseignent des discours et des pratiques impies et blasphématoires" (Dial. 35). Certains historiens ont imputé ce silence à un calcul de l'apologiste, soucieux de ménager un personnage qui jouissait d'un prestige certain jusque dans les milieux païens, à cause de sa culture littéraire et philosophique hors de pair, et dont l'entregent pouvait être précieux pour la chrétienté romaine. D'autres ont souligné les divergences profondes qui séparent le système mythique des Valentiniens, tel qu'il est décrit par Irénée, Tertullien et Épiphane, et l'enseignement de Valentin luimême, tel qu'il apparaît à travers les fragments de son œuvre que nous ont conservés Clément d'Alexandrie et Hippolyte. D'autres enfin observent que, selon Irénée, l'activité de Valentin à Rome s'étendit sur une vingtaine d'années seulement, s'il est vrai qu'il y arriva sous Hygin (136-140?), y prospéra sous Pie (140-155?) et y demeura sous Anicet (155-166?: A.H. IV,10; 11,1). Épiphane rapporte qu'il quitta Rome pour l'île de Chypre (Haer. 31,7,2), "où il abandonna la foi et s'écarta du bon sens". Que conclure de ces témoignages disparates? Qu'à l'époque de la rédaction de l'Apologie, Valentin n'était plus à Rome, déjà? Que, de toute façon, l'exégèse biblique de Valentin, respectueuse d'un strict monothéisme et accueillante à l'idée de la révélation, ne pouvait inquiéter les didascales et les responsables de la Grande Église, ni la coloration platonicienne dont il revêtait ses écrits, à l'instar de Philon et de Clément d'Alexandrie? Comme on le voit, le silence de Justin est difficile à interpréter; il est préférable, sans doute de s'en tenir à un prudent non liquet.

Mais qu'en est-il du didascale Ptolémée, dont le martyre décida Justin à présenter sa requête à l'empereur? S'il s'agit du chef d'école gnostique, classé par les hérésiologues parmi les représentants de la gnose valentinienne, cela signifie-t-il que Justin voyait en lui un allié (dans sa lutte contre Marcion) voire un collègue, dont l'enseignement ne lui était en rien suspect? Les partisans de l'identité font remarquer que les arguments favorables à cette hypothèse ne manquent pas: même nom, même lieu, même activité, même niveau culturel, même audience dans les milieux cultivés: en témoignent la belle facture littéraire de la Lettre de Ptolémée à Flora et le fait que le martyr Ptolémée fut accepté comme didascale par 
une dame romaine de la meilleure société; il est vrai aussi que le nom de Ptolémée est à peine attesté à Rome, au IIe siècle, au sein de la communauté chrétienne, encore modeste. "Tout cela ne saurait être le fait du hasard", estime G. Lüdemann (art.cit., p.110).

Bien que toutes ces concordances puissent, malgré tout, être le fait du hasard, il est possible aussi que les deux personnages soient un seul et même Ptolémée. Même dans ce cas, il est difficile de savoir en quels termes coexistaient les deux didascales romains. Dans le domaine de l'exégèse vétéro-testamentaire, Justin et Ptolémée professent des opinions similaires quant à la validité de la Loi. Cependant, si Justin avait à redire aux idées philosophiques de Ptolémée, il lui était difficile d'exposer ses griefs à ce sujet dans une Apologie adressée à l'empereur; en revanche, la manière dont le procès de Ptolémée avait été engagé, dirigé et conclu, lui offrait une parfaite illustration pour son plaidoyer en faveur des chrétiens "injustement haïs et persécutés" (Apol. I,1; II,1,2; 2,16). Il sut la saisir et plaça cet épisode au centre de sa démonstration, comme une antithèse inadmissible aux règles édictées naguère par Hadrien. Si Ptolémée était effectivement le didascale "qui avait instruit de la doctrine chrétienne" la noble dame Flora (Apol. II,2,9), le procès qui lui avait été intenté n'avait pas manqué de susciter des commentaires dans les quartiers résidentiels de la ville. L'Apologie de Justin se trouvait ainsi au cœur de l'actualité.

A. von Harnack, Analecta zur ältesten Geschichte des Christentums in Rom (TU 20,2: 1905), 1-5; G. Bardy, Les écoles romaines au second siècle, RHE 28, 1932, 501-532; W. Bauer, Rechtgläubigkeit und Ketzerei in ältesten Christentum, Tübingen 1934, 1964 ${ }^{2}, 269-$ 274; G. Quispel, Ptolémée. Lettre à Flora, Paris 1949, 1966²; H. Langerbeck, Zur Auseinandersetzung von Theologie und Gemeindeleben in der römischen Gemeinde in den Jahren 135-165. Idem, Aufsätze zur Gnosis, hg. v. H. Dörrie, Göttingen, 1967, 38-82; R.L. Wilken, Towards a Social Interpretation of Early Christian Apologetics: Church History 39, 1970, 437-458; du même, Kollegien, Philosophenschulen und Theologie, in: W.A. Meeks, Zur Soziologie des Urchristentums, München 1979, 165-193; G. Lüdemann, Zur Geschichte des ältesten Christentums in Rom, ZNTW 70, 1979, 86-114; T. Stylianopoulos, Justin Martyr and the Mosaic Law, Missoula 1975; K. Koschorke, Die Polemik der Gnostiker gegen das kirchliche Christentum (NHS 12), Leiden 1978; H. Cancik, Gnostiker in Rom. Zur Religionsgeschichte der Stadt Rom im 2.Jh.n.Chr., in: Gnosis und Politik. Religionstheorie und politische Theologie Bd.2, hg.v. J. Taubes, München, Paderborn, Wien, Zürich 1984, 163-184; A. Le Boulluec, La notion d'hérésie dans la littérature grecque IIe-IIIe siècle. T.I, De Justin à Irénée, Paris 1985; P. Lampe, Die stadtrömischen Christen in den ersten beiden Jahrhunderten. Untersuchungen zur Sozialgeschichte, Tübingen $1989^{2}$ (1ère éd.1987); C. Scholten, Gibt es Quellen zur Sozialgeschichte der Valentinianer Roms? ZNTW 79, 1988, 244-261; U. Neymeyr, Die christliche Lehre im zweiten Jahrhundert. Ihre Lehrtätigkeit, ihr Selbstverständnis und ihre Geschichte, Leiden 1989; M.J. Edwards, Gnostics and Valentinians in the Church Fathers, JThS 40, 1989, 26-47; Ch. Markschies, Valentinus Gnosticus? Tübingen 1992; M. Simonetti, Ortodossia ed eresia tra I e II secolo, Vetera christianorum 29, 1992, 359-390; C. Tibiletti, Nota in margine a idolatria, eresia e filosofia in Tertulliano, Augustinianum 32, 1992, 77-91; A. Chavasse, Sur le sol de Rome. Les Lieux anciens habités par les chrétiens, RScR 68, 1994, 2-4. 
17. S'il voulait prouver l'innocence des chrétiens, Justin se devait de décrire leurs rites d'initiation et leurs assemblées cultuelles. Pour précieuse qu'elle soit, cette description, faite à des fins apologétiques, demeure assez sommaire. Pour des raisons évidentes Justin n'avait pas à décrire en détail l'organisation hiérarchique ni les fonctions ministérielles des communautés chrétiennes. De fait il se borne à mentionner "celui qui préside" l'assemblée liturgique ( $\pi \rho \circ \varepsilon \sigma \tau \omega ́$ : Apol. I,65,3.5; 67,4.5.6) et ses assistants

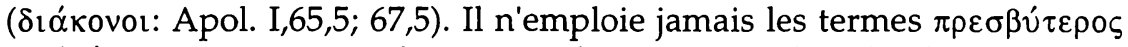
ou غ̇ $\pi$ í $\sigma \kappa о \pi \circ \varsigma$, au sens technique qu'ils ont revêtu dans l'Eglise ancienne pour désigner des ministères de direction.

L'exposé liturgique de Justin est centré sur l'initiation chrétienne (Apol. I,60-66). Pour être admis au baptême, il ne suffit pas que les candidats "croient à la vérité de nos enseignements et de notre doctrine", dit Justin; ils doivent "assurer qu'ils sont capables de vivre selon cette doctrine" (Apol. I,61,2). Alors "nous leur apprenons à prier et à demander à Dieu dans le jeûne la rémission de leurs péchés antérieurs et nous-mêmes nous prions et nous jeûnons avec eux". La description de Justin évoque une catéchèse prébaptismale, mais rien n'est dit de sa durée, de son objet, de ses responsables. Si l'éveil à la foi peut être suscité par des rencontres personnelles (Dial. 2-8; Apol. I,14,3), dans la mesure où tous les chrétiens, même les moins instruits, ont à cœur d'annoncer la Bonne Nouvelle (Apol. I,60,11; II,2,2), Justin ne cache pas que la prise en charge de l'instruction doctrinale et morale des candidats au baptême et des néophytes est assumée par des didascales de profession, comme lui-même (Apol. II,2,9; cf. I,6,2; Acta Iustini). Ces initiatives individuelles mériteront le nom de catéchuménat lorsqu'elles seront reconnues et ordonnées par la hiérarchie et que les candidats au baptême posséderont un statut particulier dans la communauté locale. La situation décrite par Justin annonce cette institution, dont les contours se préciseront de plus en plus nettement dans la deuxième moitié du IIe siècle.

Les sujets dont on a reconnu qu'ils possédaient les qualités requises sont admis au baptême de l'initiation; une période ultime de préparation, consacrée à la prière et au jeûne, témoigne de leur $\mu \varepsilon \tau \alpha \dot{v} v o \iota \alpha$, et leur fait découvrir la solidarité qui les unit dans cet effort avec leurs frères dans la foi. Justin ne précise pas les formes - étaient-elles aussi liturgiques? - du nécessaire examen d'admission. Il ne dit pas non plus quels étaient les représentants qualifiés de la communauté, habilités à décider de l'accueil, ni le rôle des garants de la foi des candidats, dont on connaît l'existence par ailleurs.

L'initiation proprement dite comporte deux temps forts, le baptême et l'eucharistie; elle se déroule sans solution de continuité. Justin ne précise pas la date du baptême; il est loisible de penser à la veillée pascale, dès son époque. Le baptême se fait en un lieu approprié, séparé de l'assemblée; il est administré au nom de la Trinité (Apol. I,61,3.10.13), mais Jus- 
tin ne décrit ni la forme du rite ni les fonctions respectives des ministres qui le confèrent ou y assistent. Il ne s'agit pas d'un bain symbolique, mais

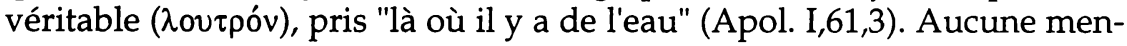
tion non plus d'une onction, précédant ou suivant le bain, d'une imposition de la main ou d'une signation.

L'intégration du néophyte à la communauté s'effectue aussitôt après le baptême, lorsqu'il est introduit dans l'assemblée des "frères" (Apol. I,65,1); il y participe aux prières des fidèles, récitées aux intentions de la communauté locale, de ses nouveaux membres et "des autres qui sont partout" - on reconnaît là ce qui deviendra plus tard la prière des fidèles ou prière universelle - et reçoit le baiser de paix mutuel (Apol. I,65,2).

Dans l'Apologie, Justin donne deux descriptions de la synaxe eucharistique. La première (Apol. I,65) s'inscrit dans le contexte baptismal, tout comme la Tradition apostolique (c.21), les Actes de Thomas (c.26s.; 50; 157), les Actes de Pierre (c.5), l'Evangile de Philippe (sent. 23; 68); la seconde (Apol. I,67,3-8) présente la synaxe dominicale, à l'instar de la Didachè (c.9 et 14), d'Ignace d'Antioche (Eph. 13,1; 20,1; Magn. 7,2; Trall. 7,2; Smyrn. 7,1 8,1) et d'Irénée (A.H. IV,18; V,2). Si l'intention apologétique a conduit Justin à mettre en relief certains aspects des rites chrétiens, notamment la parfaite décence de leur déroulement (Apol. I,65,3 et $5 ; 67,5)$, la noblesse morale des enseignements et des exhortations qui s'y trouvent dispensés (Apol. I,65,1; 67,4), l'importance des œuvres d'assistance gérées par la communauté (Apol. I,67,6-7), son témoignage n'en demeure pas moins parfaitement représentatif de la liturgie paléochrétienne.

Justin écrit à Rome mais sa description de l'eucharistie s'inscrit harmonieusement dans le cadre élargi des liturgies de l'aire hellénistique, qui diffère à certains égards de celles de l'aire syro-palestinienne. La synaxe a lieu le dimanche, en mémoire de la création du monde et de la résurrection du Sauveur (Apol. I,67,7). Après la lecture des prophètes ou (et) des Mémoires des apôtres Apol. I,67,3: première référence à un usage liturgique d'écrits chrétiens), le président ( $\pi \rho 0 \varepsilon \sigma \tau \omega \varsigma)$ prononce l'homélie. Après la prière des fidèles et le baiser de paix (qui ne sont pas mentionnés pour l'eucharistie dominicale, mais ne devaient pas y manquer; cf. Apol. I,65,1-2), vient la présentation des offrandes: pain, eau et vin trempé sont apportés à celui qui préside. "Il les prend, adresse louange et gloire au Père de l'univers par le nom du Fils et de l'Esprit saint et fait une

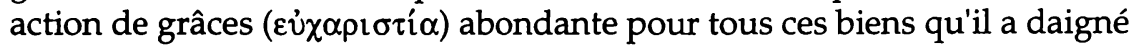
nous accorder; tout le peuple présent exprime son accord en répondant Amen" (Apol. I,65,3). Puis les éléments "eucharistiés" sont distribués aux assistants et apportés aux absents par les diacres (Apol. I,65,5; 67,5).

Il appartient enfin au président de l'assemblée de répartir le plus équitablement possible les dons (en nature; en espèces) collectés en vue de subvenir aux besoins des frères nécessiteux (Apol. I,67,6-7). Les services 
d'assistance décrits par Justin ne sont plus ceux de l'agape, plus ou moins improvisée, difficilement adaptée à des situations de dénuement extrême, prolongé, ou à des foules incompressibles d'indigents; dans les grandes cités, comme Rome, la prise en charge des orphelins, des veuves, malades, hôtes de passage, pauvres de toute nature (Apol. I,67,7) rend nécessaire une gestion rigoureuse des subsides des communautés chrétiennes. Nombre d'historiens se plaisent à souligner que Justin associe étroitement le culte chrétien et les institutions caritatives des églises locales.

Quant aux historiens de la liturgie, ils relèvent quelques détails significatifs du rite eucharistique: 1 . L'assemblée réunit en un même lieu tous les frères, ceux qui le sont de longue date et les néophytes, ceux de la ville et des campagnes (Apol. I,67,3), les indigents comme ceux qui sont dans l'abondance; la communauté des frères est une réalité vivante (V. Saxer, Les rites de l'initiation, p.61). 2. Dans l'assemblée se dessinent des distinctions fonctionnelles. Du peuple ( $\lambda \alpha o ́ \varsigma)$ est distingué le président $\left(\pi \rho \circ \varepsilon \sigma \tau \omega \omega^{\prime}\right)$. Si ce terme n'est pas technique, rien ne permet d'affirmer ou de nier du titulaire qu'il soit prêtre. En revanche, le diacre est désigné par un terme technique: la distribution de l'eucharistie aux frères absents (Apol. I,65,5; 67,5), notamment aux prisonniers, faisait connaître le diacre, sa fonction, son nom même, aux païens. Dès lors Justin n'avait plus aucune raison de l'appeler d'un nom plus compréhensible aux païens (V. Saxer, ibid.). 3. Justin ne fait aucune allusion au chant qui agrémentait les réunions liturgiques ni à une bénédiction qui en marquait la fin, bien que ces usages aient existé très vraisemblablement dès son époque (A.W.F. Blunt, The Apologies of Justin Martyr, p.xxxix, qui renvoie à Pline le Jeune, epist. X,96, et aux Constitutions Apostoliques, sans plus; cf. M. Metzger, Les C.Ap. II,69s.).

M.H. Shepherd, The Early Apologists and Christian Worship, The Journal of Religion 18, 1938, 60-79; A. Benoît, Le baptême chrétien au second siècle. La théologie des Pères, Paris 1963, 138-185; D. Van den Eynde, L'eucaristia in S. Ignazio, S. Giustino e S. Ireneo, in: Eucaristia. Il mistero dell'altare nel pensiero e nella vita della chiesa, ed. A. Piolanti, Brugge 1957, 115-127; T.G. Jalland, Justin Martyr and the President of the Eucharist, StPatr 5 (TU 80), Berlin 1962, 83-85; C.I.K. Story, Justin's Apology I, 62-64: Its Importance for the Author's Treatment of Christian Baptism, VC 16, 1962, 172-178; O. Heggelbacher, Die christliche Taufe als Rechtsakt nach dem Zeugnis der frühen Christenheit (Paradosis 8), Freiburg/Schweiz 1953; G. Kretschmar, Die Geschichte des Taufgottesdienstes in der alten Kirche, Leiturgia 5, 1970; E.C. Ratcliff, The Eucharistic Institution Narrative of Justin Martyr's First Apology, JEH 22, 1971, 97-102; K. Thraede, Ursprünge und Formeln des "Heiligen Kusses" im frühen Christentum, JbAC 11/12, 1968/69, 124-180; M. Jourjon, Justin, in: L'eucharistie des premiers chrétiens, Paris 1976, 76-88; G.H. Williams, Baptismal Theology and Practice in Rom as reflected in Justin Martyr, in: The Ecomenical World of Orthodox Civilisation, Essays in Honor of Georges Florovsky, vol.3, The Hague, Paris 1974, 9-34; J. Betz, Eucharistie in der Schrift und Patristik, Handbuch der Dogmengeschichte IV,4a, Freiburg 1979, 32-50; V. Saxer. Les rites de l'initiation chrétienne du IIe au Vle siècle, Spoleto 1988, 57-64; B. Kleinheyer, Sakramentalische Feiern I. Die Feiern der Eingliederung in die Kirche (GDK 7,1), Regensburg 1989; - E.R. Goodenough, The Theology of Justin Martyr, 271-278; L.W. Barnard, Justin Martyr, 126-151. - E. Baumgartner, Eucharistie und Agape im Urchristentum, Solothurn 1909; B. Reicke, Diakonie, Festfreude und Zelos in Verbindung mit der altchristlichen Agapenfeier, Uppsala 1951; A. Hamman, Quelle 
est l'origine de l'agape?, StPatr (TU 107) 1970, 351-354; Valeur et signification des renseignements liturgiques de Justin, St Patr 13, 1975, 364-374.

18. Les exposés d'ensemble sur la théologie de Justin ne manquent pas et les monographies qui abordent des points particuliers de sa pensée théologique sont innombrables, depuis Harnack jusqu'à nos jours. A. Davids offre une bibliographie de plus d'une centaine de titres pour les années 1923-1973. Le lecteur trouvera un status quaestionis relatif aux problèmes doctrinaux envisagés par Justin dans l'Apologie, ainsi que la bibliographie récente en ce domaine dans notre ouvrage: L'Apologie de saint Justin philosophe et martyr, Fribourg 1994. Mais il sait aussi qu'il tirera le plus grand profit des "classiques" en la matière, dont nous joignons ici la liste:

M. von Engelhardt, Das Christentum Justins des Märtyrers. Eine Untersuchung über die Anfänge der katholischen Glaubenslehre, Erlangen 1879; A. von Harnack, Lehrbuch der Dogmatik, 3 vol. Tübingen (5e éd., 1931-32); R. Seeberg, Grundriß der Dogmengeschichte, Erlangen (7e éd., 1921); J. Tixeront, Histoire des dogmes dans l'antiquité chrétienne, 3 vol. Paris (11e éd., 1930); A. Puech, Les apologistes chrétiens du Ile siècle de notre ère, Paris 1912; E.R. Goodenough, The Theology of Justin Martyr, Jena 1923 (repr. Amsterdam 1968); G. Bardy, art. Saint Justin, DTC 8, 1925, 2228-2277; L.W. Barnard, Justin Martyr. His life and thought, Cambridge 1967; E.F. Osborn, Justin Martyr (BHTh 47), Tübingen 1973; A. Wartelle, Saint Justin. Apologies, Paris 1987.

19. Le lecteur ne trouvera pas ici une nouvelle édition critique de l'Apologie de Justin. Comme l'établissement du texte repose sur un unique manuscrit et que la tradition indirecte (Eusèbe, Jean de Damas) est fort limitée et peu sûre, il a paru préférable, en attendant l'édition du GCS, de donner un status quaestionis de la critique philologique actuelle. Pour le texte, nous reproduisons l'édition de A.W.F. Blunt (Cambridge 1911); mais nous donnons dans l'apparat critique non seulement les leçons de Blunt, qu'il a tirées des principales éditions antérieures, de 1551 (R. Etienne) à G. Krüger (1904), mais celles d'Eusèbe de Césarée, d'après l'édition d'E. Schwartz (GCS 9,1-3, Leipzig 1903-1909) et celles des Sacra Parallela de Jean de Damas, d'après l'édition de K. Holl, Fragmente vornicänischer Kirchenväter aus den Sacra Parallela, Leipzig 1899, p.32s.

Nous indiquons aussi les conjectures proposées par W. Schmid, dans son important article: Die Textüberlieferung der Apologie des Justin, ZNTW 40, 1941, 87-138, ainsi que les variantes relevées par A. Wartelle et par P. Pilhofer sur le manuscrit de Paris, suivi de près par l'édition de E.J. Goodspeed, Göttingen 1914.

Pour un certain nombre de passages discutés, nous avons retenu des conjectures ignorées ou écartées par Blunt. En voici la liste, selon l'ordre du texte:

1. Apol. 1: L'abondance des noms propres et sans doute aussi la graphie particulière de l'adresse ont provoqué plusieurs erreurs ou omissions, qu'il est possible de corriger, en tenant compte de la titulature officielle des destinataires et de la date plus que probable de la rédaction de 
l'ouvrage, dégagée par la critique interne. En conséquence, nous restituons le texte grec comme suit:

Aủ

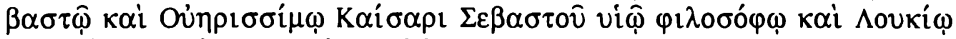

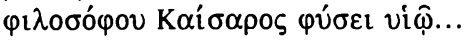

Pour une discussion détaillée, le lecteur voudra bien se reporter à l'ouvrage d'A. von Harnack, Geschichte der altchristlichen Literatur II,1 Leipzig 1897, p.274-284; cf. Blunt, p.xlviii s.; Wartelle, p.31-32.

2. Leçons de Blunt

12,10 rivónevov

15,13 Stкaíovs

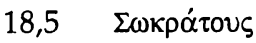

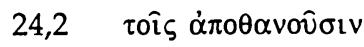
ह่v $\tau \alpha \varphi \alpha \hat{i} \varsigma$

26,3 $\pi \varepsilon \rho t v o \sigma \tau \eta \dot{\sigma} \sigma \alpha \sigma \alpha \nu$

$\sigma \tau \alpha \theta \varepsilon \hat{\tau} \sigma \alpha \nu$

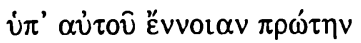

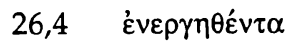

$\delta \alpha \iota \mu o v i \omega v$

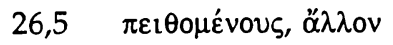

ồ $(\kappa \alpha \tau \dot{\alpha})$

$\tau \dot{\alpha} \mu \varepsilon \dot{\zeta}$ ov $\alpha$

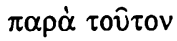

$\pi \varepsilon \pi \mathrm{o} \eta \bar{\kappa} \varepsilon \dot{v} \alpha \mathrm{l}$

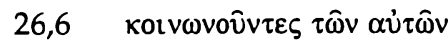

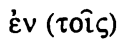

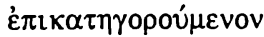

$31,6 \quad \gamma \varepsilon \gamma \varepsilon v \eta \mu \varepsilon ́ v \omega$

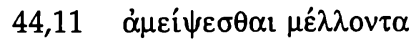

54,6 oîvov

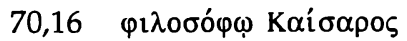

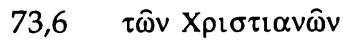

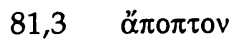

\section{Leçons retenues}

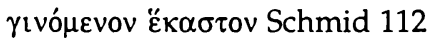

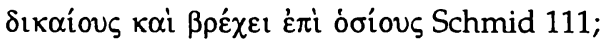

cf. Dial. 96,3

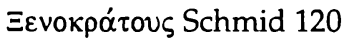

om. Schmid 108

om. Schmid 108

$\sigma \nu \mu \pi \varepsilon p \imath v o \sigma \tau \eta \dot{\sigma} \sigma \alpha \sigma \alpha v$ Eus. II,13,3; Schmid 108

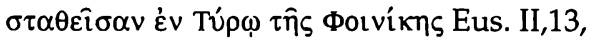
3; Schmid 103

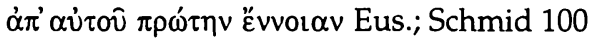
oi $\sigma \theta \rho \eta \theta \varepsilon ́ v \tau \alpha$ Eus. III,26,3; Schmid 100 $\delta \alpha \iota o^{\prime} \omega \omega v$ Eus.

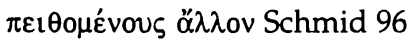

om. Schmid 98

om. Eus. IV,11,9

om. Schmid 99

om. Eus.; Schmid 99

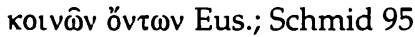

om. Eus.; Schmid 96

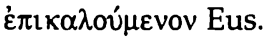

$\gamma \varepsilon v o \mu \varepsilon ́ v \varphi$ Eus. IV,8,4; cf. Dial. 1,3

$\dot{\alpha} \pi \alpha v \tau \eta \dot{\sigma} \sigma \varepsilon \sigma \theta \alpha \iota \mu \varepsilon^{\prime} \lambda \lambda \sigma v \tau \alpha$ transp. Schmid 115

övov Sylburg; Schmid 117; cf. Dial. 69,2



Koí $\sigma \alpha \rho \circ \varsigma$ Valesius

om. Schmid 110

ớ $\pi \omega \tau$ ov Paul; Pfättisch

A.W.F: Blunt, The Apologie of Justin Martyr, Cambridge Patristic texts, ed. A. J. Mason, Cambridge 1911; E.J. Goodspeed, Die ältesten Apologeten, Texte mit kurzen Einleitungen, Göttingen 1914; P. Pilhofer, Harnack and Goodspeed, The Second Century 5, 1985, 232242; A. Wartelle, Saint Justin. Apologies, Introduction, texte critique, traduction, commentaire et Index par A. Wartelle, Paris 1987. 
20. Analyse: EXORDE (1-3)

Justin adresse à l'empereur Antonin le Pieux et à ses fils adoptifs, ainsi qu'au Sénat et à tout le peuple romain, sa requête en faveur des chrétiens injustement haïs et persécutés.

Argumentation (4-80)

I. Réfutation des accusations communes (4-12)

1. Le seul nom de chrétien n'est pas un motif de condamnation; la justice et la raison exigent que l'on examine la conduite de chacun (4).

2. L'accusation d'athéisme est une machination des démons (5); en fait, les chrétiens honorent le Créateur de l'univers, son Fils, les bons anges et l'Esprit prophétique (6).

3. Leur conduite est innocente (7):

a) leur attitude devant le tribunal devrait leur valoir présomption d'innocence (8);

b) s'ils refusent de rendre un culte aux idoles (9), ils croient en Dieu et s'efforcent de mener une vie digne de Lui (10);

c) loin d'être des séditieux, ils aspirent à un royaume qui n'est pas de ce monde (11) et sont les artisans les plus zélés de la paix et de la vertu (12).

II. Exposé de la doctrine chrétienne (13-60)

A. Les chrétiens voient en Jésus-Christ le Maître divin (14), dont les enseignements prônent les vertus les plus utiles à la cité: pureté (15), charité, patience, non-violence (16-17). Leurs dogmes n'ont rien d'inouï ni d'absurde (18):

survie, résurrection (19), conflagration finale (20).

B. Ils croient aussi que Jésus-Christ est le Logos divin, le Fils premier-né de Dieu. Cette croyance n'a rien de déraisonnable, eu égard aux récits de la mythologie (21), mais la personnalité du Christ est incomparable, dans ses œuvres (22) et ses enseignements.

THĖSE (1 ̀̀re partie): la doctrine chrétienne est supérieure aux conceptions des païens (23-60; cf. 78-80); ceci résulte:

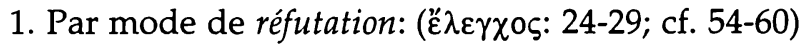

a) des vains efforts déployés par les démons pour la mettre en échec (24-27);

b) des mœurs détestables du paganisme (27-29).

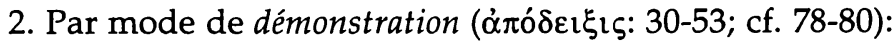

Le Christ est véritablement le Fils de Dieu fait homme; la preuve de cette assertion est administrée par les prophéties concernant sa personne et sa mission (30-53). 
3. Au contraire, les arguments avancés par les adversaires n'ont aucune force démonstrative:

a) les fables de la mythologie ne sont que des plagiats mensongers, répandus par les démons (54/55), qui n'ont pas compris les prophéties,

b) mais ont suscité nombre d'hérésies (56-58);

c) quant aux philosophes païens, qui furent attentifs au Logos, ils doivent aux prophètes les doctrines qu'ils partagent avec les chrétiens (59$60)$.

III. Exposé des rites essentiels de la religion chrétienne (61-68)

Ni le baptême (61-64), ni l'eucharistie (65-67) ne comportent rien de suspect ni de criminel.

Cet exposé prouve que la doctrine chrétienne mérite d'être prise en considération; dès lors la justice demande que l'on cesse de condamner des innocents (68,1-2), comme le demandait le rescrit d'Hadrien (68,3-10).

\section{INSTANCE et DIGRESSION (69-77)}

En effet, partout les chrétiens sont persécutés par des hommes perdus de mœurs, agissant sous l'emprise des démons (69), comme le prouve, à Rome même, le martyre de Ptolémée et de ses compagnons: NARRATION (70).

\section{HYPOTHESE (71-77):}

Justin répond brièvement à plusieurs objections:

1. Pourquoi les chrétiens rejettent-ils le suicide et ne renient-ils pas leur foi (71?)

2. Pourquoi leur Dieu permet-il les persécutions (72-76)?

3. Est-il possible d'admettre la doctrine chrétienne de la rétribution (77)?

THÈSE (2e partie 78-80):

Si la doctrine chrétienne l'emporte sur toutes les doctrines humaines, c'est parce qu'elle se fonde sur l'enseignement du Christ, le Logos intégral, auquel les philosophes païens eurent participation (78). Et c'est parce qu'ils ont accès à la vérité plénière, incarnée en Jésus-Christ, que les chrétiens affrontent avec courage l'opinion et la mort (79-80).

PÉRORAISON (81-82) et CONCLUSION (83).

H. Veil, Justins des Philosophen und Märtyrers Rechtfertigung des Christentums (Apologie I u. II), Strasbourg 1894; Th. Wehofer, Die Apologie Justins des Philosophen und Märtyrers in literarhistorischer Beziehung zum erstenmal untersucht, RQS, Suppl.6, 1897; K. Hubik, Die Apologien des hl. Justinus des Philosophen und Märtyrers. Literarhistorische Untersuchung, Wien 1912; U. Hüntemann, Zur Kompositionstechnik Justins. Analyse seiner ersten Apologie, ThGl 25, 1933, 410-428; P. Keresztes, Justins und Tertullians Apologien. Eine rhetorische Untersuchung, (Diss.) Graz 1963; The literary genre of Justin's First Apology, VC 19, 1965, 99-110; The so-called Second Apology of Justin, Latomus 24, 1965, 858-

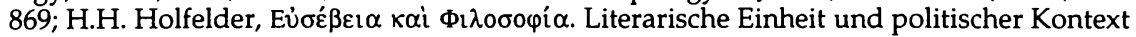


von Justins Apologie, ZNTW 68, 1977, 48-66; 231-251; Ch. Munier, La structure littéraire de l'Apologie de Justin, RvSR 60, 1986, 34-54; L'Apologie de saint Justin, philosophe et martyr (Paradosis 38), Fribourg/Suisse, 1994, 152-156. 



\section{CONSPECTUS SIGLORUM}

A cod. Parisinus gr. 450 (anno 1364)

B cod. Claromontanus 82 (anno 1541)

Ashton C. Ashton, ed. Cambridge 1768

Blunt

A.W.F. Blunt, ed. Cambridge 1911

Braun J.W.J. Braun, ed. Bonn 1839

Eus

Eusebius, Historia ecclesiastica I-V (ed. E. Schwartz, GCS 9,1) Leipzig 1903

Goez J.A. Goez, comment. Nüremberg-Altdorf 1796

Goodspeed E.J. Goodspeed, ed. Göttingen 1914

Grabius J.E. Grabe, ed. Oxford 1700

Maran P. Maran, ed. Paris 1742

Otto

J.C.T. Otto, ed. Iéna 1842 (1847, 1876)

Paul

L. Paul, Zur ersten Apologie des Justin Märtyrers, in: Jahrbuch für klassische Philologie (1880), 316-320.

Pautigny $\quad$ L. Pautigny, ed. Paris 1904

Perionius J. Périon, ed. Paris 1554

Pfättisch J.M. Pfättisch, ed. Münster i.W. 1912

Pilhofer P. Pilhofer, art.cit. 1990

SacrPar Iohannes Damascenus, Sacra Parallela, ed. K. Holl, 1899

Scaliger Notae in Eusebii Chronicon

Schmid W. Schmid, art.cit. 1941

Stephan R. Estienne, ed. Paris 1551

Sylburg F. Sylburg, ed. Heidelberg 1593

Thalemann G.G. Thalemann, ed. Leipzig 1755

Thirlby S. Thirlby, ed. London 1722

Trollope W. Trollope, ed. Cambridge 1845

Veil

H. Veil, comment. Strasbourg 1894

Wartelle A. Wartelle, ed. Paris 1987

Pour les titres complets des anciennes éditions, on voudra bien se reporter à la liste établie par E.R. Goodenough, The Theology of Justin Martyr, léna 1923, p.296s. 


\section{TOY AГIOY IOY

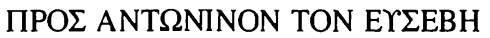

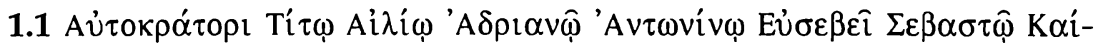

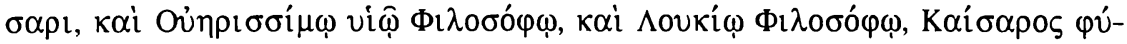

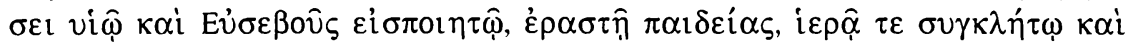

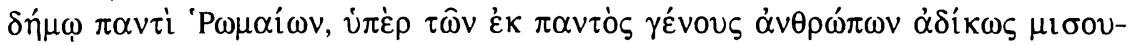

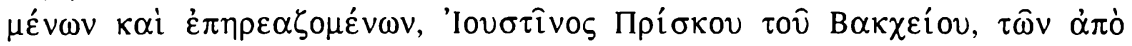

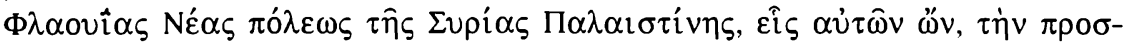

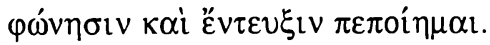

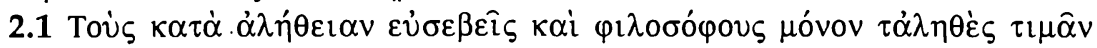

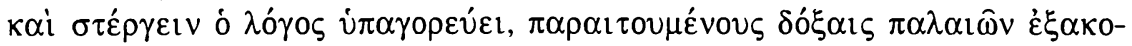

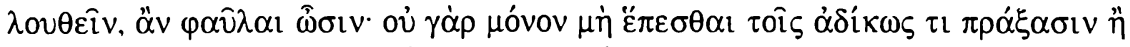

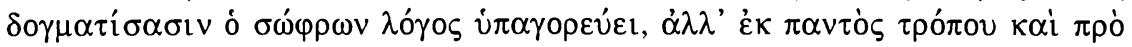

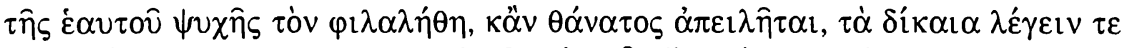

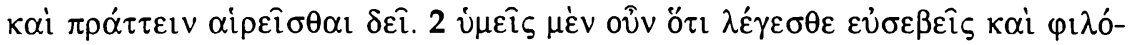

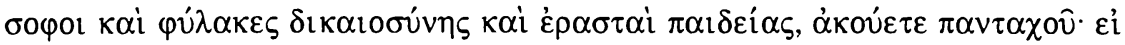

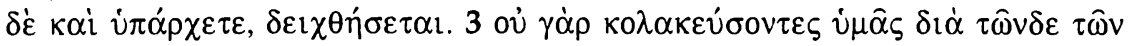

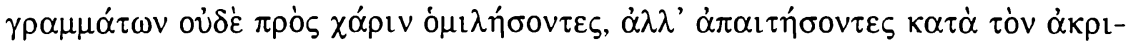

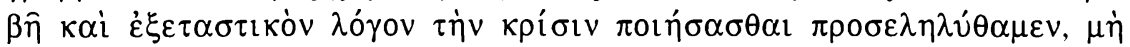

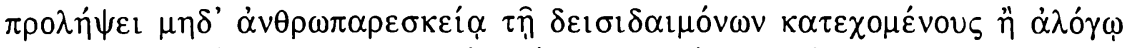

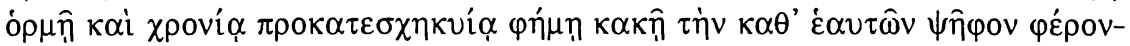

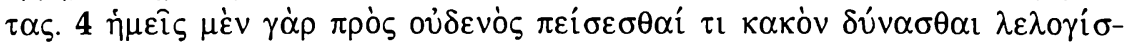

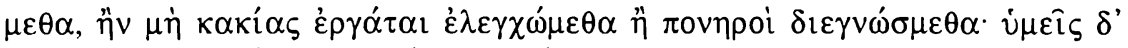

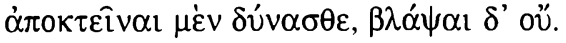

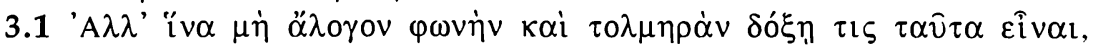

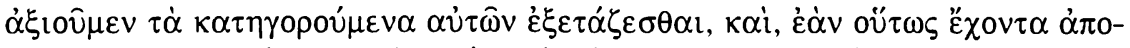

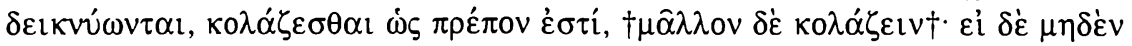

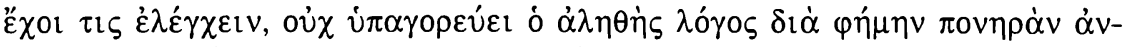

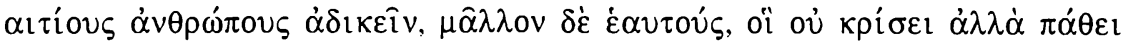

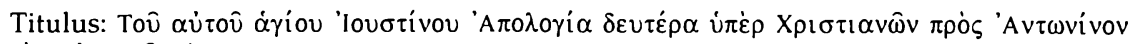

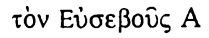

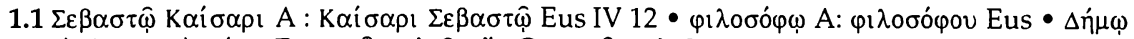

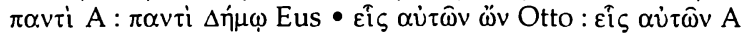

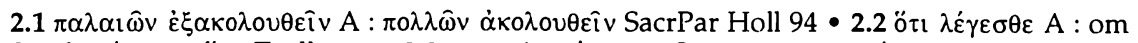

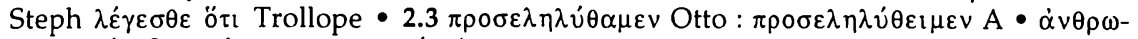
$\pi \alpha \rho \varepsilon \sigma \kappa \varepsilon i \not \alpha$ Otto : $\dot{\alpha} v \theta \rho \omega \pi 0 \pi \alpha \rho \varepsilon \sigma \kappa \varepsilon i ́ \alpha \mathrm{A}$

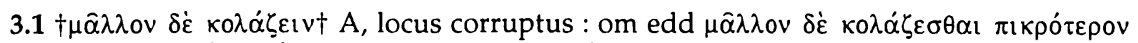

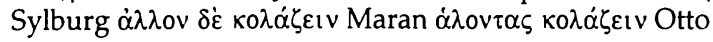

1.1 Eusèbe, H.E. IV,12 • 2.1 Platon, Apol. 28B • 2.3 Platon, Apol. 30C 
1.1 A l'empereur Titus Aelius Hadrianus Antoninus César Auguste et à Vérissimus César, fils d'Auguste, philosophe, et à Lucius, fils selon la nature de César philosophe, et de Pius par adoption, ami de la culture, au sacré Sénat et à tout le peuple romain, en faveur des hommes de toute race, injustement haïs et persécutés, moi, l'un d'eux, Justin, fils de Priscus, petit-fils de Baccheios, de Flavia Neapolis en Syrie de Palestine, j'adresse cet appel et cette requête.

2.1 Ceux qui sont véritablement pieux et philosophes, la raison leur ordonne de n'estimer et de n'aimer que la seule vérité, en refusant de suivre les opinions des anciens, si elles sont mauvaises; en effet, la saine raison ordonne de ne pas suivre ceux qui commettent ou enseignent ce qui est injuste, mais l'ami de la vérité doit, de toute manière et de préférence à sa propre vie, même quand la mort menace, choisir de dire et de faire ce qui est juste. 2 Vous donc, partout, vous vous entendez appeler pieux et philosophes, gardiens de la justice et amis de la culture; mais si vous l'êtes effectivement, l'avenir le montrera. 3 Car ce n'est pas pour vous flatter par cet écrit, ni pour vous tenir un discours agréable, que nous nous sommes adressé à vous, mais pour vous demander de prononcer votre jugement au terme d'une enquête exacte et rigoureuse, sans vous laisser dominer par des préjugés, par le désir de plaire à des hommes superstitieux, par une précipitation irréfléchie et de perfides rumeurs fortifiées par le temps, au risque de porter la condamnation contre vous-mêmes. 4 Pour nous, en effet, nous savons ne pouvoir subir de mal de la part de personne, si nous ne sommes pas convaincus d'avoir commis quelque action criminelle, ou reconnus coupables; quant à vous, vous pouvez nous tuer; nous nuire, non.

3.1 Pour que personne n'aille croire que ce sont là propos insensés et téméraires, nous demandons que l'on examine les accusations portées contre nous et, si elles sont reconnues fondées, que l'on nous punisse, comme de juste; mais si nul ne peut nous convaincre de quelque crime que ce soit, la droite raison vous interdit de léser des innocents sur de méchantes rumeurs, ou plutôt de vous léser vous-mêmes, si vous trouvez bon d'expédier les affaires au mépris de la justice, au gré de la passion. 


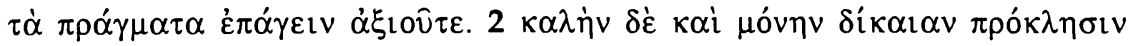

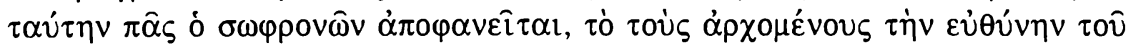

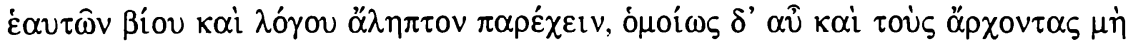

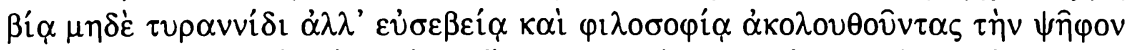

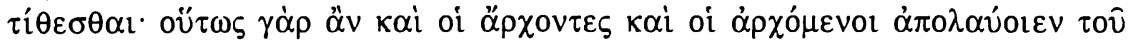

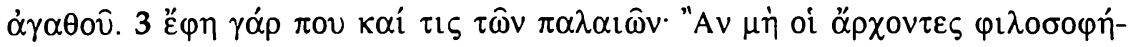

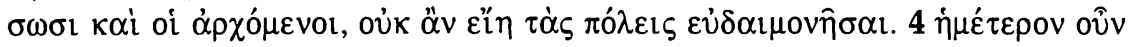

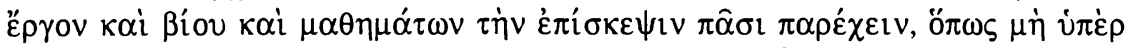

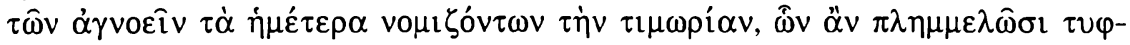

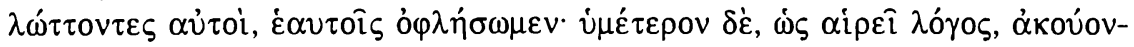

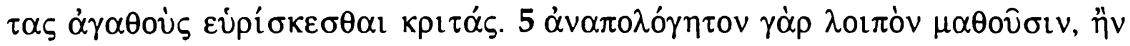

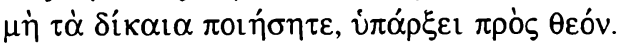

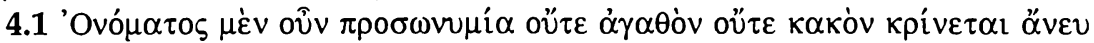

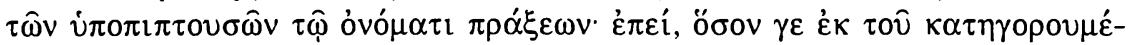

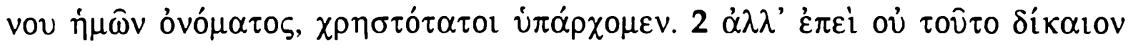

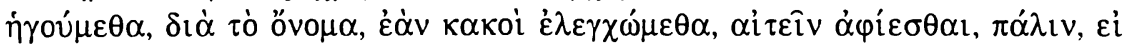

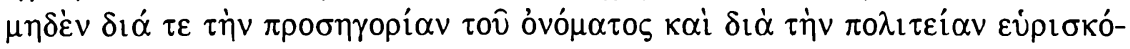

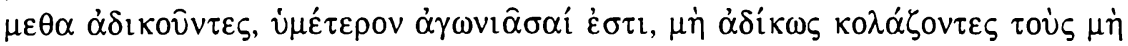

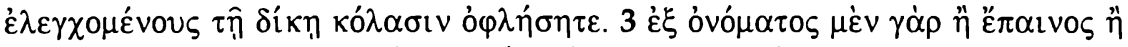

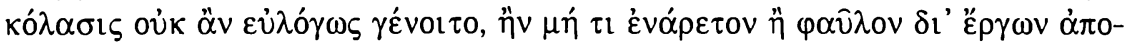

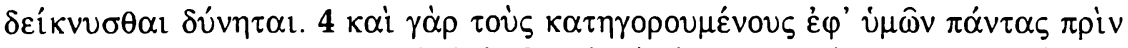

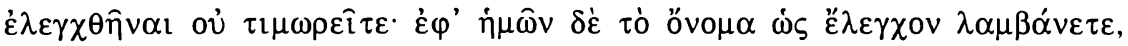

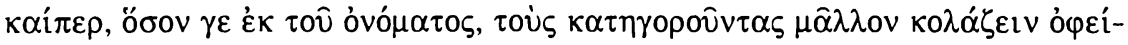

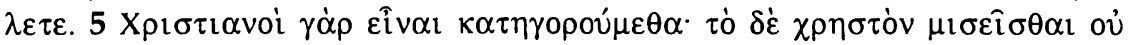

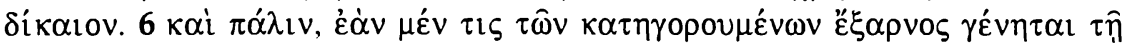

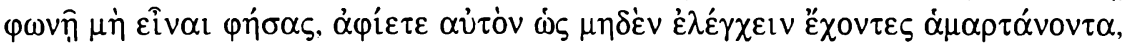

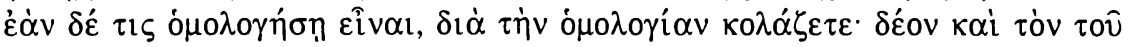

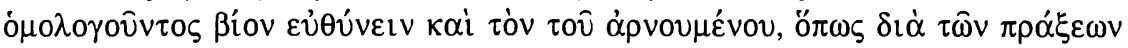

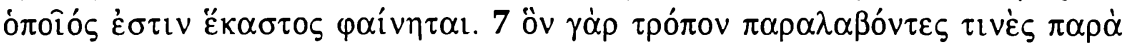

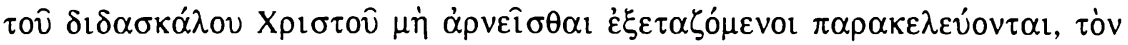

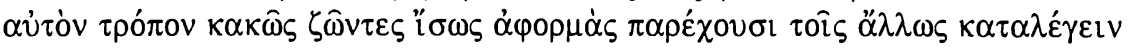

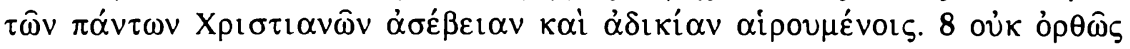

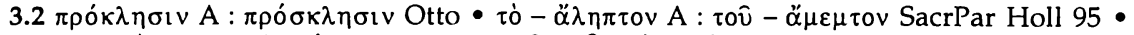

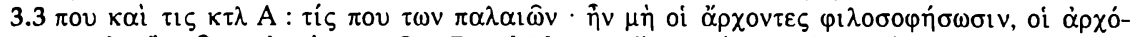

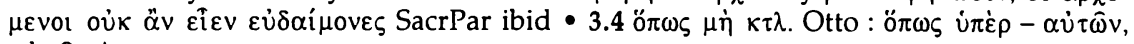

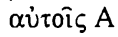

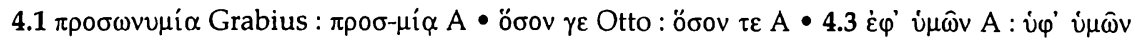

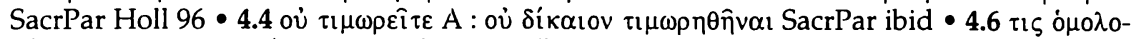

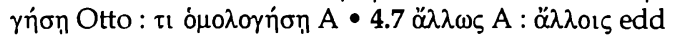

3.3 Platon, Resp. 473DE; Hist.Aug., Marcus 27,6-7

4.1 Suétone, Claud. 25; Athénagore, Leg. 2; Théophile d'Antioche, Autol. I,1; Tertullien, Nat. I,3,9; Lactance, Inst.diu. IV $7,5 \ldots$ 
2 Une pétition convenable, voire la seule juste, tout homme de bon sens la reconnaîtra en ceci: que les sujets fournissent un compte-rendu irrécusable de leur conduite et de leurs motivations, que pareillement les souverains rendent aussi leurs sentences en se laissant diriger non point par la violence et la tyrannie mais par la piété et la philosophie; car c'est ainsi que gouvernants et gouvernés pourront goûter le bonheur. 3 De fait, un ancien a dit quelque part: "Si les souverains et les sujets ne sont pas philosophes, il ne saurait y avoir de bonheur pour les cités". 4 A nous donc de permettre à tous l'examen de notre conduite et de nos enseignements, afin de ne point encourir nous-mêmes, par notre faute, à la place de ceux qui font profession d'ignorer ce qui nous concerne, le châtiment des fautes qu'ils commettent dans leur aveuglement; à vous de nous entendre, comme la raison l'exige, et de vous montrer de bons juges. $5 \mathrm{Car}$ si, une fois instruits, vous n'observez pas la justice, vous serez désormais sans excuse devant Dieu.

4.1 Le (seul) énoncé d'un nom n'autorise aucun jugement, ni en bien ni en mal, si l'on fait abstraction des actions qui tombent le coup de ce nom; or, si l'on s'en tient au nom dont on nous fait grief, nous sommes des gens excellents. 2 Mais puisque nous ne pensons pas qu'il soit juste de prétendre être absous à cause de notre nom, si nous sommes convaincus d'être des criminels, en revanche, s'il est établi que nous commettons aucun délit ni par l'appellation de notre nom ni par notre comportement dans la cité, il vous appartient de faire tous vos efforts afin de ne point encourir vousmêmes un juste châtiment pour avoir puni injustement des gens qui n'auraient pas été convaincus de crime. 3 En effet, un nom ne peut raisonnablement être un motif de louange ou de blâme, si l'on ne peut prouver, à partir des actes, rien de louable ou de mauvais. 4 Et de fait pour ce qui concerne ceux d'entre vous qui sont accusés, vous ne les punissez pas avant qu'ils aient été convaincus de crime; mais pour ce qui nous concerne, vous prenez notre nom comme une preuve à charge, alors que, du moins à en juger d'après notre nom, vous devriez bien plutôt punir ceux qui nous accusent. 5 En effet, nous sommes accusés d'être chrétiens; or il n'est pas juste de haïr ce qui est excellent. 6 Au contraire, si l'un des accusés vient à nier, ne serait-ce qu'en déclarant oralement ne pas être chrétien, vous prononcez sa relaxe, comme n'ayant plus aucun grief pour l'incriminer; mais si quelqu'un avoue être chrétien, vous le punissez à cause de cet aveu, alors qu'il faudrait examiner la conduite de celui qui avoue non moins que celle de celui qui nie, afin que, d'après ses actes, la nature de chacun apparaisse au grand jour. 7 En effet, de même que certains, qui ont appris à l'école du Christ à ne pas renier quand ils sont interrogés, donnent une belle leçon de courage, ainsi ceux qui ont une conduite mauvaise fournissent des prétextes à ceux qui de toute façon sont enclins à accuser injustement tous les chrétiens d'impiété et d'injustice. 


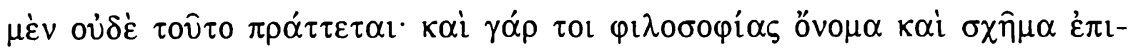

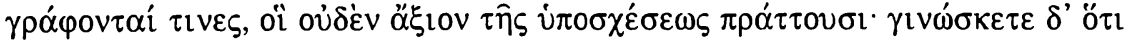

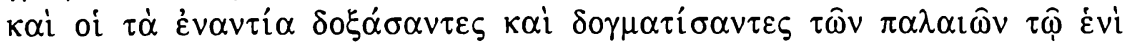

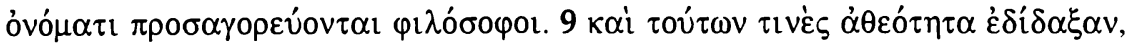

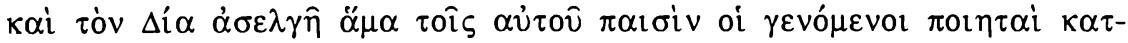

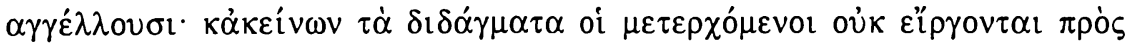

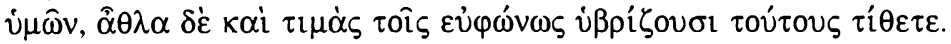

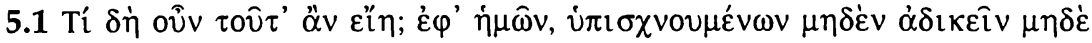

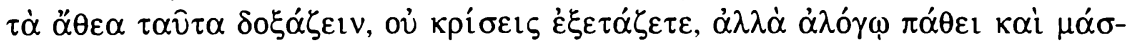

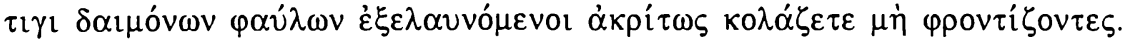

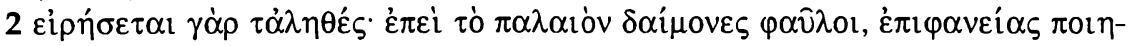

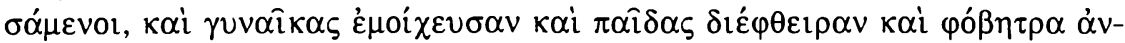

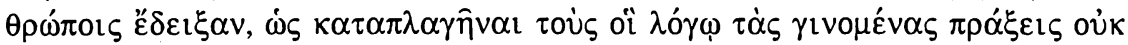

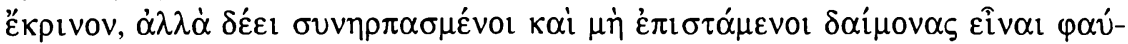

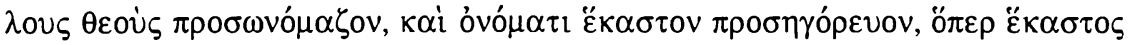

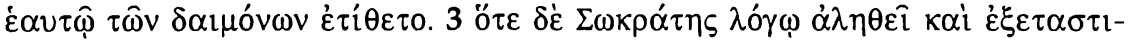

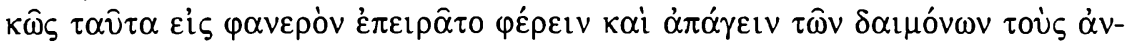

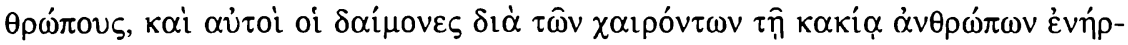

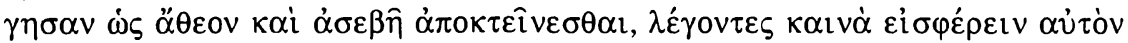

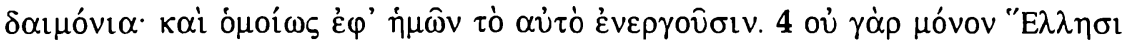

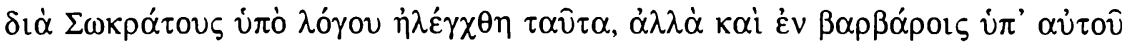

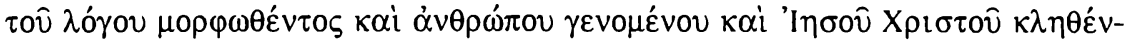

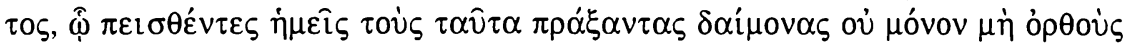

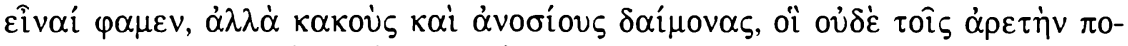

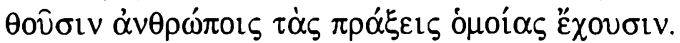

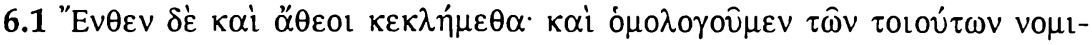

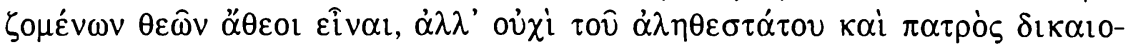

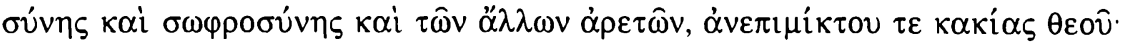

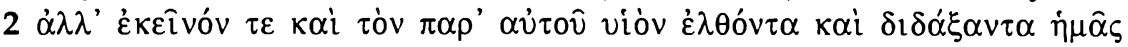

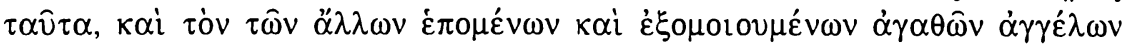

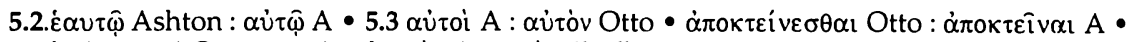

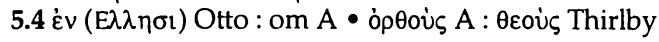

5.3 Xénophon, Memor. 1,1; Platon, Apol. 24B 
8 Mais agir de la sorte n'est pas non plus équitable. Car enfin d'aucuns s'arrogent le nom de philosophes et en adoptent le maintien, sans que leur conduite corresponde en rien à cette profession; vous savez aussi que, parmi les anciens, des gens qui ont enseigné des opinions et des doctrines opposées sont désignés par le seul nom de philosophes. 9. Parmi eux certains ont enseigné l'athéisme; il s'est trouvé aussi des poètes pour traiter de débauchés Zeus ainsi que ses enfants; or ceux qui recherchent ces enseignements, vous ne les rejetez pas, mais vous accordez honneurs et récompenses à des gens qui outragent les dieux dans leurs discours harmonieux.

5.1 Qu'est-ce à dire? alors que nous nous engageons par serment à ne commettre aucun méfait et à ne pas enseigner ces doctrines impies, vous n'examinez pas sérieusement nos mises en accusations, mais poussés par une passion déraisonnable, et sous le fouet des mauvais démons, vous nous punissez, sans jugement, sans vous en faire scrupule. 2 Car il faut dire la vérité: autrefois de mauvais démons, multipliant leurs manifestations, violentèrent des femmes, corrompirent des enfants et produisirent aux yeux des hommes des phénomènes effrayants, au point que, frappés de terreur, ces gens ne jugeaient plus selon la raison les événements qui se produisaient, mais, saisis de crainte et ignorant qu'il s'agissait de mauvais démons, ils leur donnaient le nom de dieux et les invoquaient chacun par un nom, celui précisément que chacun des démons s'était attribué. 3 Mais lorsque Socrate, à la lumière de la raison véritable et après une enquête approfondie, tenta de tirer ces choses au clair et de détourner les hommes des démons, ces mêmes démons, par l'intermédiaire d'hommes pervers, qui prennent plaisir au mal, s'employèrent à le faire condamner à mort comme athée et impie, sous prétexte qu'il introduisait des divinités nouvelles; et pareillement ils emploient la même manœuvre contre nous. En effet, ce n'est pas seulement chez les Grecs, par la bouche de Socrate, que ces faits ont été dénoncés, à la lumière de la raison, mais aussi chez les Barbares, par le Verbe lui-même, revêtu d'une forme sensible, devenu homme et appelé Jésus-Christ; nous qui avons cru en lui nous déclarons que ceux qui ont agi de la sorte ne sont pas des démons bienfaisants mais des démons pervers et impies, puisqu'ils n'agissent même pas comme les hommes qui aiment la vertu.

6.1 De là vient qu'on nous appelle athées. Certes, nous l'avouons, nous sommes athées à l'égard des prétendus dieux de cette espèce, mais nous ne le sommes pas à l'égard du Dieu très vrai, père de la justice, de la pureté et des autres vertus, sans nul mélange de mal. 2 Au contraire nous le vénérons, nous l'adorons, nous l'honorons en raison et en vérité, ainsi que son Fils qui est venu d'auprès de Lui et qui nous a donné cet en- 


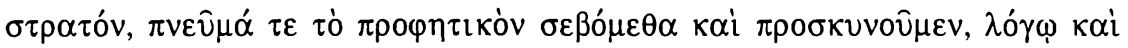

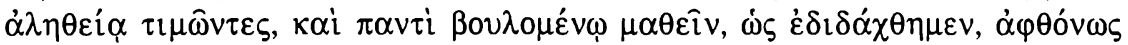
$\pi \alpha \rho \alpha \delta เ \delta o ́ v \tau \varepsilon \varsigma$.

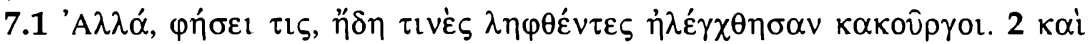

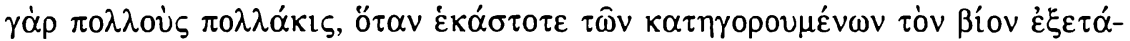

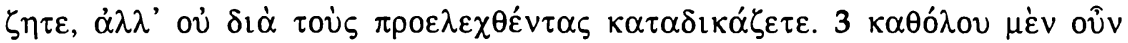

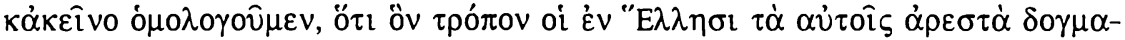

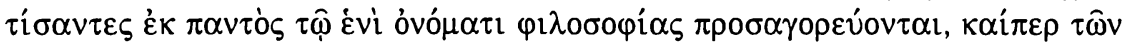

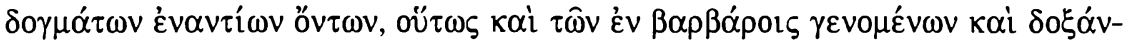

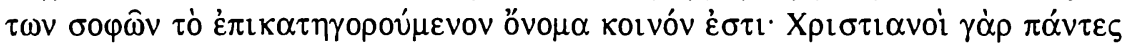

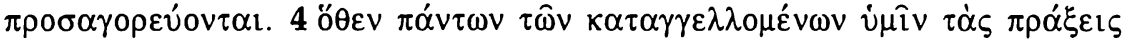

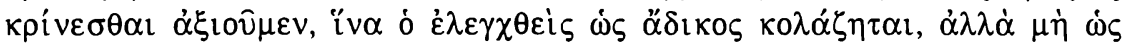

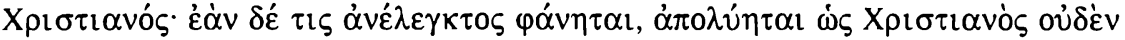

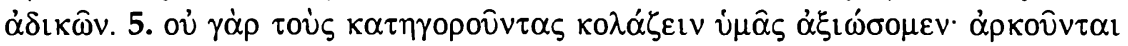

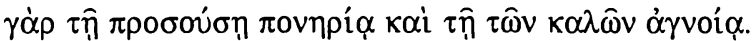

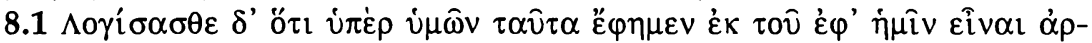

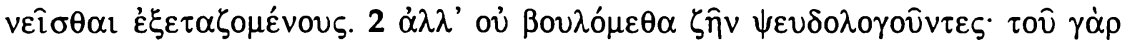

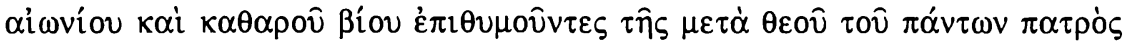

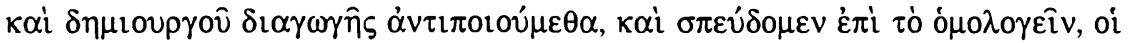

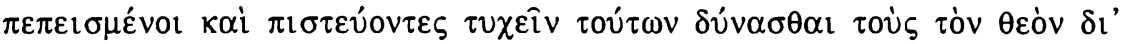

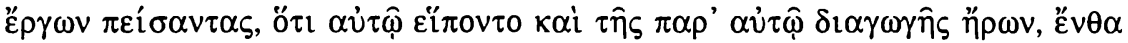

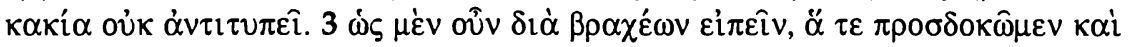

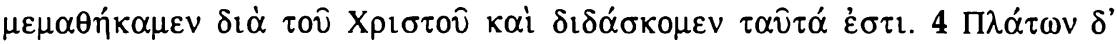

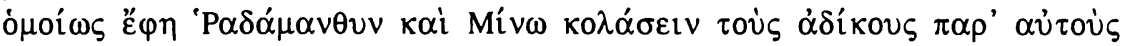

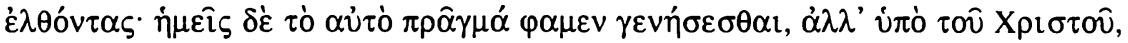

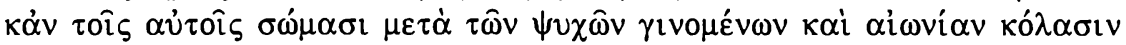

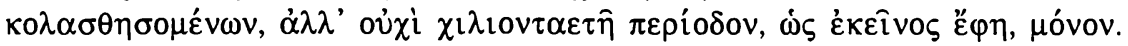

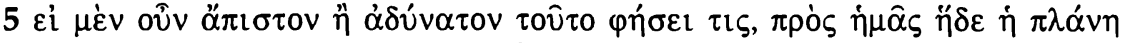

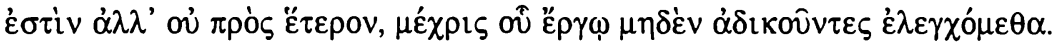

$7.2 \pi \rho \circ \varepsilon \lambda \varepsilon \chi \theta \varepsilon \dot{v} v \tau \alpha \varsigma$ Perionius, Maran : $\pi \rho 0 \lambda \varepsilon \chi \theta \varepsilon \dot{\varepsilon} v \tau \alpha \varsigma$ A, Otto

8.4 kỏv Otto : кai A

7.5 cf. infra; Apol. 68,10; Cod.Theod. IX,2,3 • 8.1 Platon, Apol. 30D • 8.4 Platon, Gorg. 523E; Phaedr. 249A; Resp. X,615A 
seignement, et l'armée des autres bons anges qui l'escortent et lui ressemblent, ainsi que l'Esprit prophétique; et à quiconque veut s'instruire nous transmettons la doctrine comme on nous l'a enseignée, sans réserve.

7.1 Mais, dira-t-on, déjà des chrétiens ont été arrêtés et convaincus d'être des malfaiteurs. 2 Assurément, lorsque vous examinez individuellement la conduite des accusés, il vous arrive souvent d'en condamner un grand nombre, mais vous ne le faites pas à cause de ceux qui ont été convaincus de crime antérieurement. 3 Or donc, d'un point de vue général, nous reconnaissons aussi le fait que voici: de même que, chez les Grecs, ceux qui ont soutenu les doctrines qui leur plaisaient, fussent-elles contradictoires entre elles, se voient désigner toujours et partout de l'unique nom de philosophes, de même chez les Barbares, ceux qui sont ou passent pour sages reçoivent une dénomination commune qui sert à les désigner: il sont tous appelés chrétiens. 4 C'est pourquoi nous demandons que l'on examine la conduite de tous ceux qui vous sont déférés, afin que celui qui aura été convaincu de crime soit puni en tant que coupable au regard de la loi mais non point en tant que chrétien, mais s'il est établi que quelqu'un ne peut être convaincu de crime, qu'il soit relaxé en tant que chrétien, étant donné qu'il ne commet aucun crime. 5 Nous ne vous demanderons pas de punir les accusateurs: ils sont assez punis par la méchanceté qui s'attache à eux et par leur ignorance du bien.

8.1 Ce que nous avons dit, c'est dans votre intérêt; reconnaissez-le au fait qu'il nous serait possible de nier quand nous sommes interrogés. 2 Mais nous ne voulons pas vivre au prix d'un mensonge, car animés du désir de la vie éternelle et pure, nous aspirons à vivre avec Dieu le père et créateur de l'univers et nous nous empressons de faire notre confession (judiciaire), car nous sommes persuadés et nous croyons que peuvent obtenir ces biens ceux qui auront persuadé Dieu par des actes qu'ils ont marché à sa suite et ont aspiré à vivre auprès de lui, là où nul mal ne rebute. 3 Voilà donc en peu de mots ce que nous attendons, ce que nous avons appris par le Christ et que nous enseignons. 4 Platon a dit pareillement que Rhadamante et Minos puniront les coupables quand ils se présenteront devant eux; quant à nous, nous disons que la même chose arrivera, mais par le Christ et que, dans leurs mêmes corps unis à leurs âmes, ils subiront un châtiment qui durera éternellement et non point seulement durant une période de mille ans, comme le prétendait Platon. $5 \mathrm{Si}$ donc quelqu'un déclare ceci incroyable ou impossible, cette erreur ne concerne que nous et personne d'autre, aussi longtemps que nous ne sommes pas convaincus d'être en fait coupables au regard de la loi. 


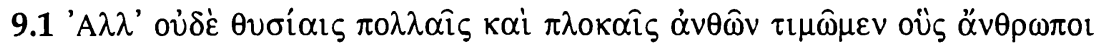

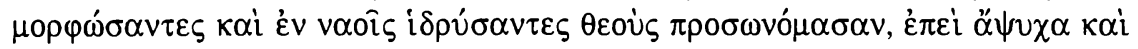

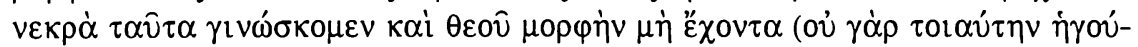

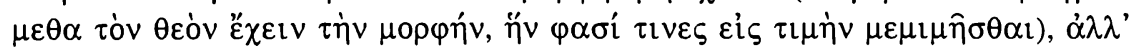

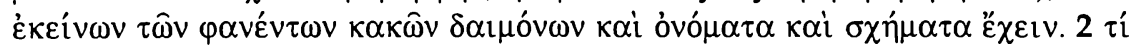

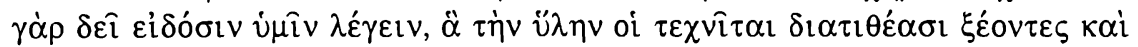

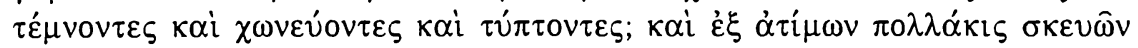

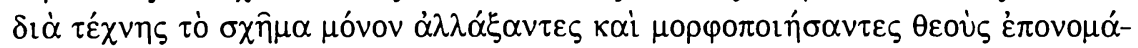

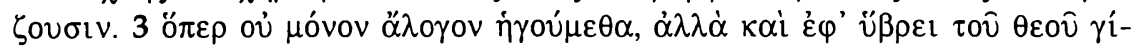

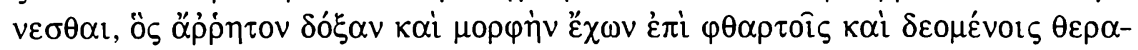

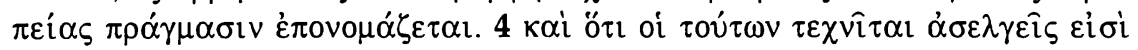

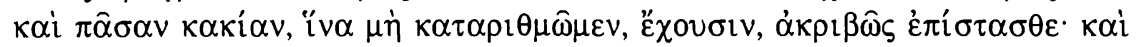

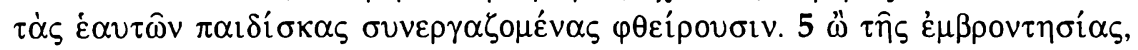

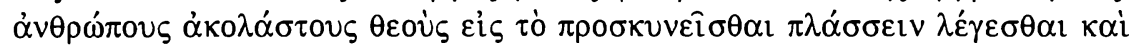

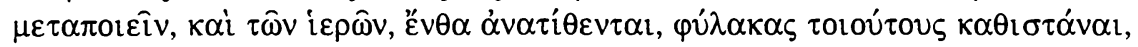

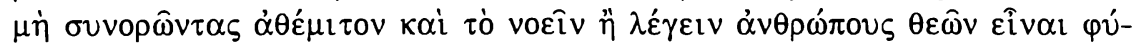
$\lambda \alpha \kappa \alpha \varsigma$.

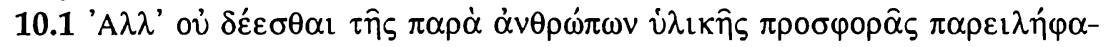

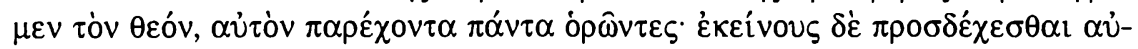

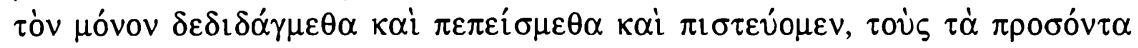

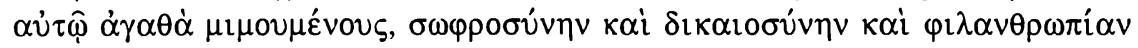

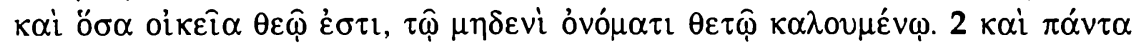

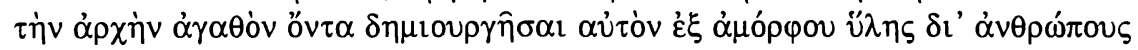

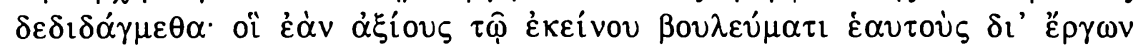

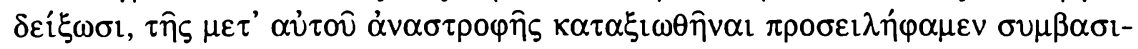

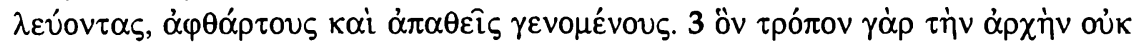

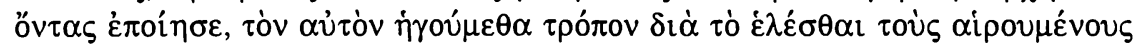

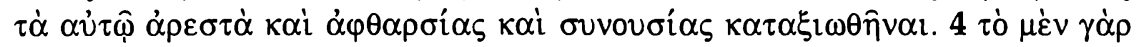

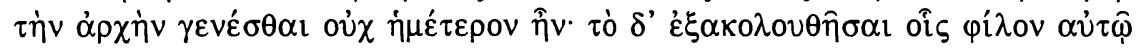

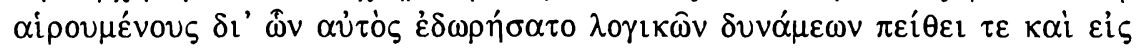

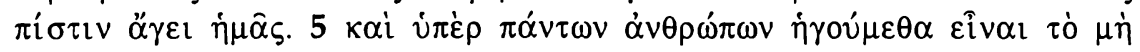

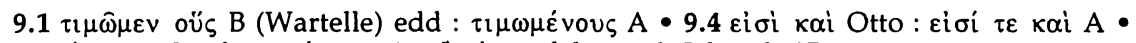
$9.5 \lambda \dot{\varepsilon} \gamma \varepsilon \sigma \theta \alpha \mathrm{l}$ Stephan : $\lambda \dot{\varepsilon} \gamma \varepsilon \sigma \theta \varepsilon \mathrm{A} \bullet \hat{\eta} \lambda \lambda^{\prime} \dot{\gamma} \varepsilon \iota v$ delere uult Schmid 107

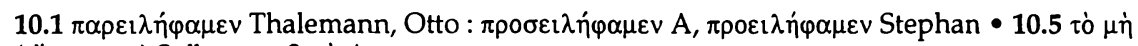

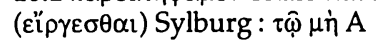

9.2 Hérodote, II,172; Horace, Sat. I,8 • 9.3 Platon, Tim. 28C • 10.2 Platon, Tim. 29E 
9.1 Nous n'honorons pas non plus par de nombreux sacrifices et des guirlandes de fleurs ceux que des hommes ont façonnés, et placés dans les temples en leur donnant le nom de dieux, car nous savons que ce sont là des objets inanimés et sans vie, qui ne possèdent pas de forme divine nous ne croyons pas, en effet, que Dieu ait une forme semblable à celle que d'aucuns prétendent avoir imitée afin de l'honorer, mais que les dieux portent les noms et offrent les apparences de ces mauvais démons qui se sont manifestés autrefois. 2 Qu'est-il besoin de vous dire, puisque vous le savez, en quels objets les artistes transforment la matière, quand ils la polissent, la taillent, la fondent, la martellent; souvent, à partir de matériaux sans valeur, en se bornant à modifier habilement leur apparence et à leur donner une forme, ils fabriquent ce qu'ensuite ils appellent des dieux? 3 C'est là, croyons-nous, non seulement une absurdité mais une insulte à la divinité qui, possédant une gloire et une beauté indicibles, voit son nom attribué à des œuvres corruptibles, qui requièrent des soins attentifs. 4 Et que les artisans de ces dieux sont des débauchés, livrés à tous les vices, vous le savez trop bien, pour que nous n'ayons pas à les énumérer; ils vont jusqu'à violer les jeunes servantes qui les assistent dans leur travail. 5 Quelle stupidité: on prétend que des hommes sans retenue façonnent et remodèlent des dieux pour qu'ils soient adorés; on établit des gens de cette espèce gardiens des temples où ces dieux sont érigés; on ne comprend pas que c'est une impiété de penser ou de dire que des hommes soient les gardiens des dieux.

10.1 Tout au contraire nous avons appris que Dieu n'a pas besoin d'offrandes matérielles de la part des hommes, car nous voyons que c'est lui qui donne tout, nous avons appris aussi et nous sommes fermement convaincus que ceux-là seuls lui agréent qui imitent ses perfections essentielles: la pureté, la justice, l'amour des hommes et les autres attributs qui sont propres à Dieu, lui que l'on ne saurait désigner en lui imposant un nom. 2 Nous avons appris aussi qu'au commencement, parce qu'il est bon, d'une matière informe Il a créé toutes choses, à cause des hommes; s'ils se montrent dignes de ses desseins, par leurs œuvres, nous savons qu'ils seront jugés dignes de demeurer avec Lui et, devenus incorruptibles et impassibles de règner avec Lui. 3 De même qu'il a créé, au commencement, des êtres qui n'existaient pas, de même, croyons-nous, ceux qui auront choisi ce qui lui est agréable, seront, à cause de leur libre choix, jugés dignes de l'immortalité et de la société divine. 4 Le fait de venir à l'existence ne dépendait pas de nous, mais de rechercher ce qui lui est agréable, en le choisissant grâce aux facultés rationnelles que lui-même nous a données, c'est lui qui nous en persuade et, dans ce but, il nous conduit à la foi. 5 Nous croyons aussi qu'il est dans l'intérêt de tous 


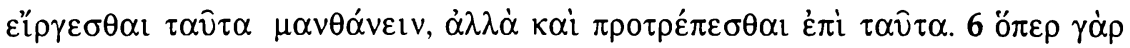

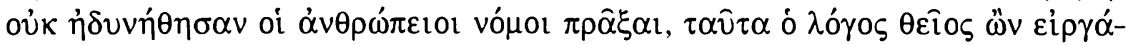

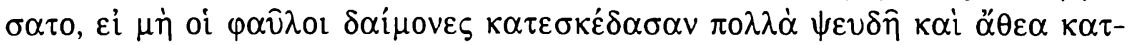

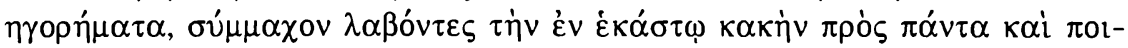

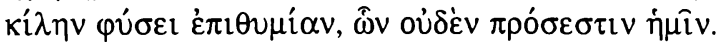

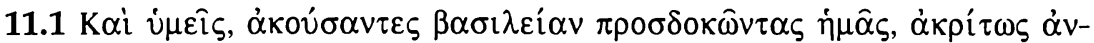

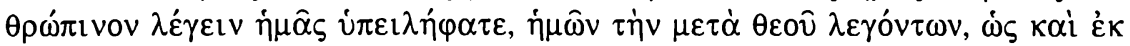

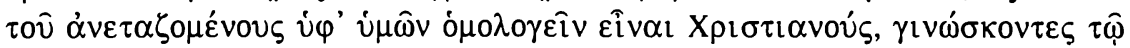

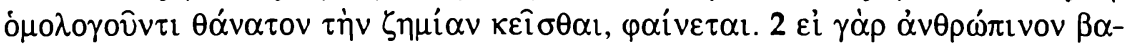

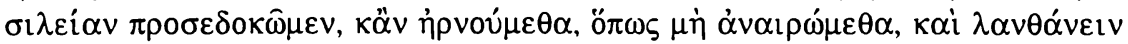

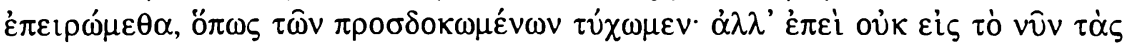

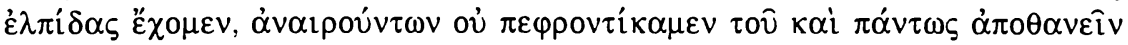

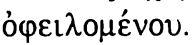

12.1 'A

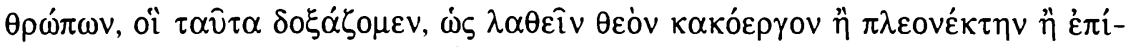

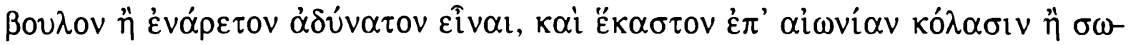

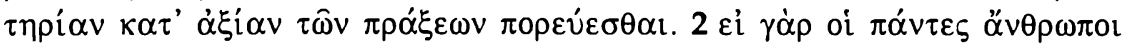

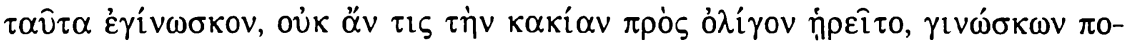

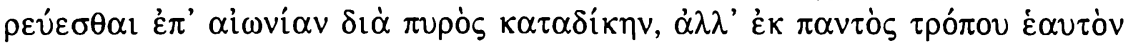

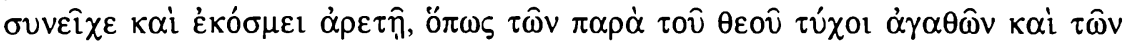

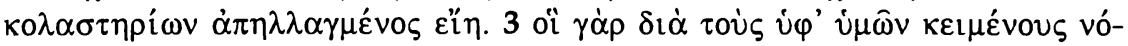

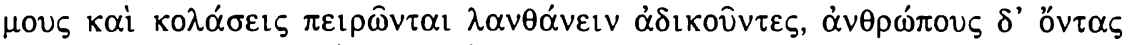

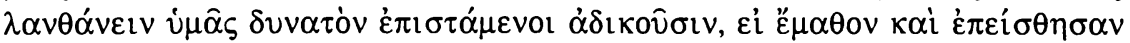

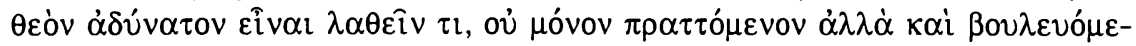

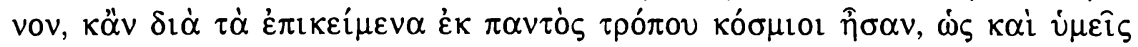

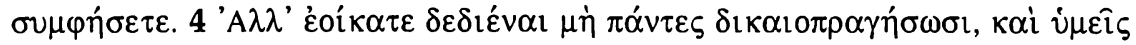

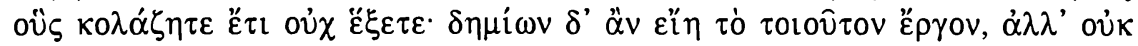

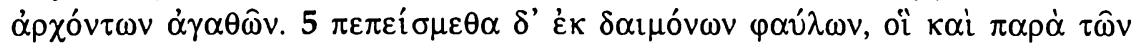

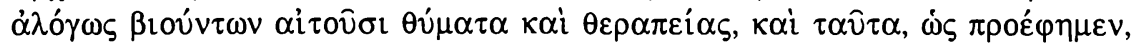

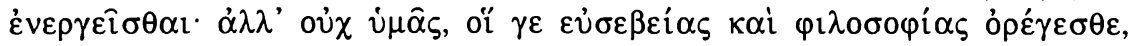

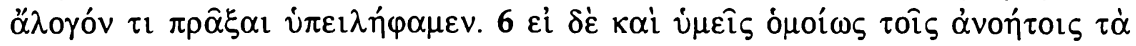

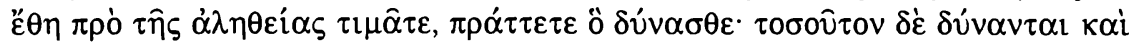

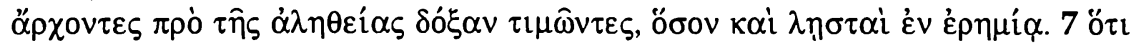

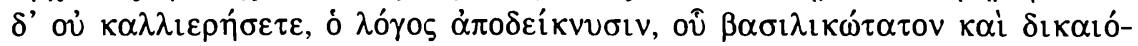

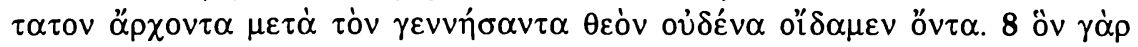

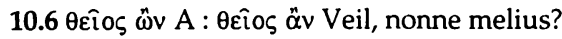

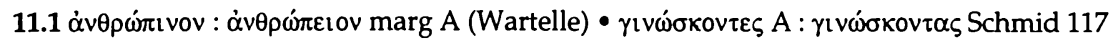

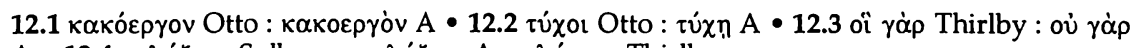

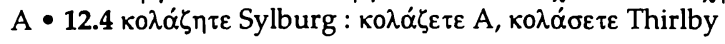

10.6 Tacite, Ann. XV,44; Suétone, Nero 16 • 11.2 Euripide, Alc. 417.782; Androm. 1272 • 12.5 Apulée, De Deo Socratis, 148 
les hommes de ne pas être détournés de la connaissance de ces vérités, mais au contraire d'y être vivement encouragés. 6 Car ce que les lois humaines ne purent réaliser, le Logos, parce qu'il est divin, l'eût accompli, si les mauvais démons n'avaient répandu nombre d'accusations mensongères et impies, en prenant pour allié le désir pervers, multiforme, qui habite en chaque homme; mais aucune de ces accusations ne nous atteint.

11.1 Aussi bien, quand vous avez entendu dire que nous attendons un royaume, vous avez admis sans discernement que nous parlons d'un royaume humain, alors que nous parlons de celui qui est auprès de Dieu, comme il apparaît aussi par le fait, qu'interrogés par vous, nous avouons être chrétiens, alors que nous savons bien que pour celui qui fait cet aveu la peine de mort est instituée. 2 En effet, si nous attendions un royaume humain, nous nierions (être chrétiens), afin de n'être point mis à mort et nous chercherions à demeurer cachés, afin de parvenir à ce que nous attendons, mais parce que nous ne plaçons pas nos espoirs dans le présent, nous n'avons cure de nos bourreaux, d'autant que, de toute façon, il faut mourir.

12.1 Nous sommes pour vous, plus que tous les hommes, des auxiliaires et des alliés en vue de promouvoir la paix, nous qui enseignons que nul pervers, avare, perfide ne peut échapper à Dieu, non plus qu'un homme de bien, et que chacun va au châtiment ou au salut éternel, selon la qualité de ses actes. 2 En effet, si tous les hommes avaient cette conviction, personne ne choisirait de faire le mal, fût-ce un instant, sachant qu'il va au devant d'un supplice éternel par le feu, mais il se contiendrait de toute manière et se parerait de vertu, afin d'obtenir le bonheur qui vient de Dieu et de demeurer exempt des châtiments. 3 Les malfaiteurs qui, à cause des lois et des peines que vous avez établis, cherchent à se cacher, font le mal, en sachant qu'il est possible de vous échapper, car vous n'êtes que des hommes, mais s'ils avaient appris et s'ils étaient convaincus qu'il est impossible de rien cacher à Dieu, ni action ni intention, ils se conduiraient honnêtement de toute manière, ne fût-ce qu'à cause des châtiments qui menacent, - vous en conviendrez vous-mêmes. 4 Cependant vous paraissez craindre que tout le monde pratique la justice et que vous ne trouviez plus personne à punir; pareille attitude conviendrait à des bourreaux mais nullement à de bons princes. 5 Tout cela, nous en sommes convaincus, est l'œuvre des mauvais démons, qui exigent des sacrifices et des adorations de la part de ceux qui ne vivent pas selon la raison, comme dit; mais nous ne pouvons supposer que vous, qui aspirez à la piété et à la philosophie, agissiez au mépris de la raison. 6 Toutefois, si vous aussi, à l'instar des insensés, préférez la coutume à la vérité, agissez selon votre pouvoir; quand ils sacrifient la vérité à l'opinion, le pouvoir des princes équivaut à celui de brigands dans un désert. 7 Mais ce n'est pas sous des auspices favorables que vous immolerez les victimes, déclare le Logos, le prince le plus puissant et le plus juste que 


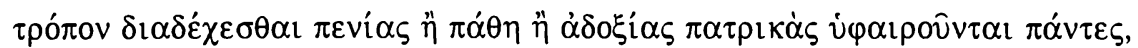

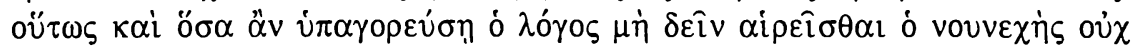

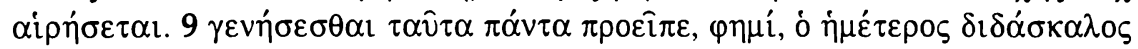

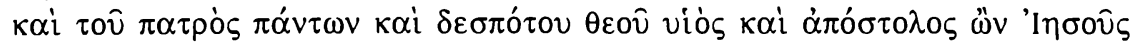

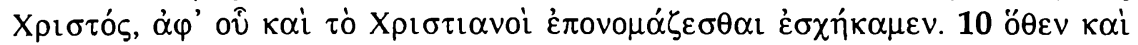

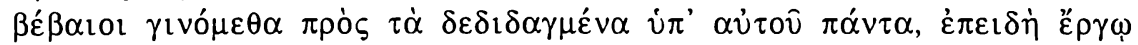

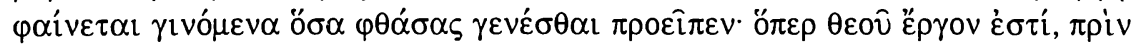

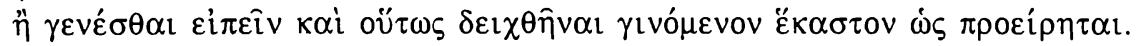

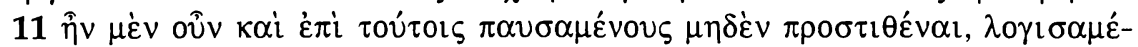

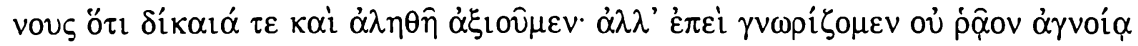

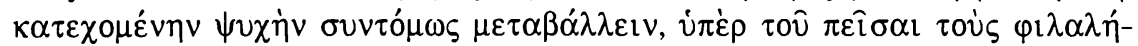

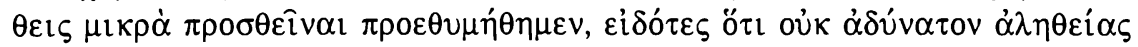

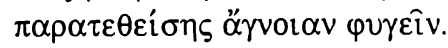

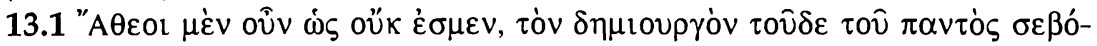

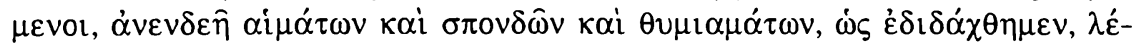

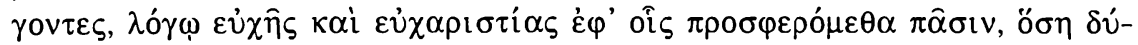

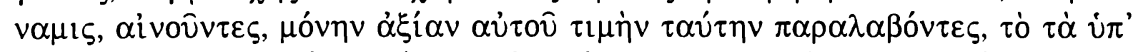

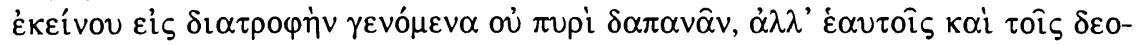

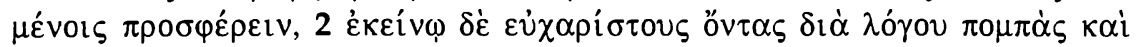

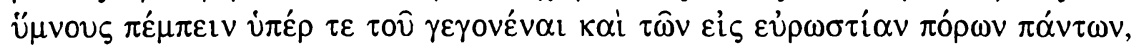

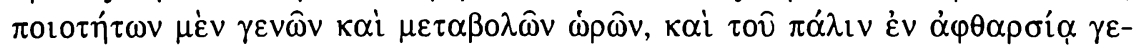

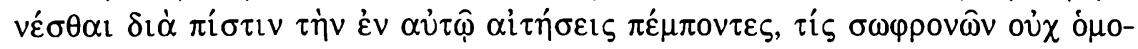

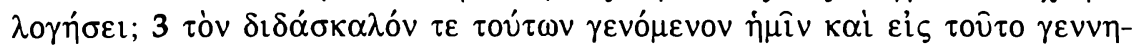

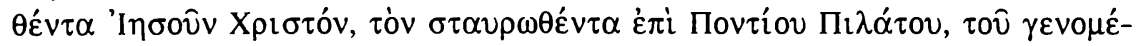

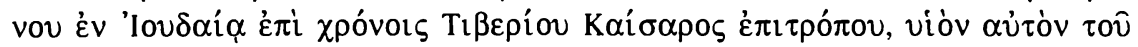

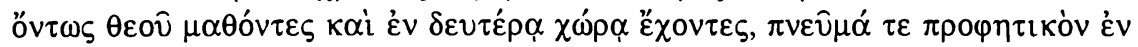

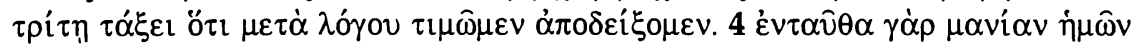

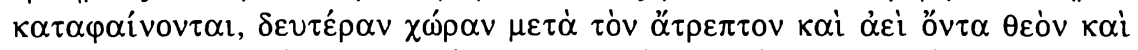

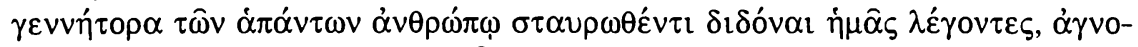

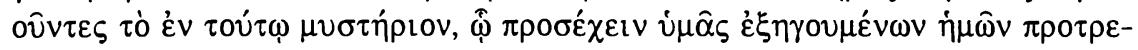
$\pi$ ó $\mu \varepsilon \theta \alpha$.

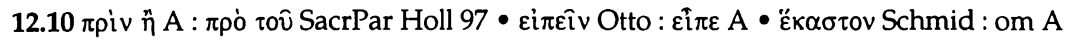

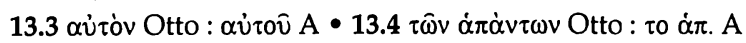

12.11 Irénée, A.H. II, 2,3 • 13.1 Euripide, H.F. 1348; Platon, Tim. 33D 
nous connaissions, après Dieu qui l'a engendré. 8 Car de même que tous les hommes renâclent à recueillir de leurs parents un héritage de pauvreté, de souffrance, de déshonneur, de même l'homme de bon sens refusera de choisir ce que le Logos lui interdit de choisir. 9 La réalisation de tous ces événements a, je l'affirme, été prédite par notre maître, Jésus-Christ, le fils et l'envoyé de Dieu, qui est le Père et le Seigneur de l'univers; c'est de lui que nous avons reçu le nom de chrétiens. 10 Si nous avons une ferme confiance en tous ses enseignements, c'est parce qu'effectivement se réalisent tous les événements dont il a prédit la réalisation; c'est bien là une œuvre divine que de prédire chaque événement avant sa réalisation et qu'il apparaisse réalisé comme il avait été prédit. 11 Nous pourrions donc nous en tenir là, sans rien ajouter, conscients de demander justice et vérité, mais comme nous savons bien qu'il n'est pas facile à une âme possédée par l'ignorance de changer subitement, afin de convaincre les amis de la vérité, nous nous sommes résolu à insister quelque peu, sachant qu'il n'est pas impossible que l'ignorance s'enfuie quand on expose la vérité.

13.1 Nous ne sommes pas des athées, nous qui adorons le créateur de cet univers, nous qui disons, comme nous l'avons appris, qu'il n'a besoin ni de sang ni de libations ni d'encens, nous qui le louons, selon notre pouvoir, pour toute nourriture que nous prenons, en un discours de prière et d'action de grâces, nous qui avons appris que la seule manière digne de l'honorer est celle-ci: ne point consumer inutilement par le feu les choses qu'il a créées pour notre subsistance mais d'en disposer pour notre bien et celui de ceux qui sont dans le besoin, 2 cependant que, pénétrés de reconnaissance envers lui, nous lui adressons en hommage solennel nos prières et nos chants, pour avoir été appelés à l'existence, pour tous les moyens qu'il nous donne d'être vigoureux, pour les qualités des êtres de toute espèce, et pour les changements des saisons; nous qui lui adressons aussi nos requêtes afin qu'il nous fasse revivre dans l'immortalité, à cause de la foi que nous plaçons en lui - quel homme sensé ne l'accordera? 3 Nous vous démontrerons aussi que nous honorons celui qui nous a donné ces enseignements et qui a été engendré pour cela, Jésus-Christ, qui fut crucifié sous Ponce-Pilate, procurateur en Judée au temps de Tibère César, parce que nous savons qu'il est le fils du vrai Dieu et nous le plaçons au second rang, et l'Esprit prophétique au troisième. 4 C'est sur ce point, en effet, que l'on nous accuse de folie en disant que nous accordons le second rang, après le Dieu immuable et éternel, créateur de l'univers, à un homme qui fut crucifié, mais il y a là un mystère que l'on méconnaît. Veuillez y appliquer votre esprit, tandis que nous vous l'exposerons, nous vous y invitons. 


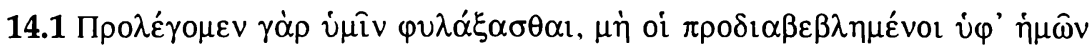

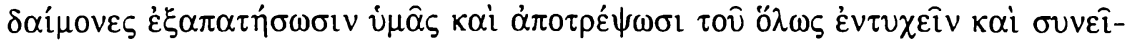

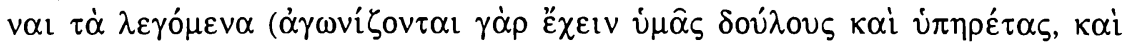

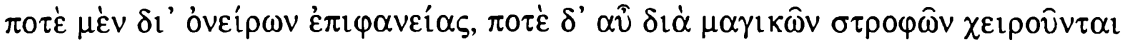

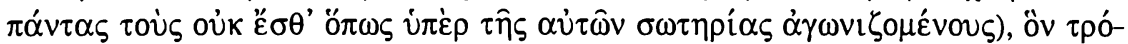

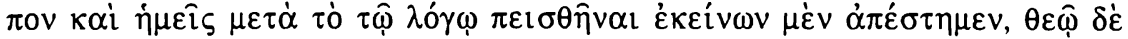

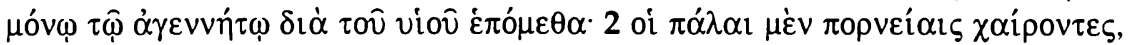

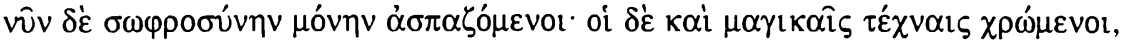

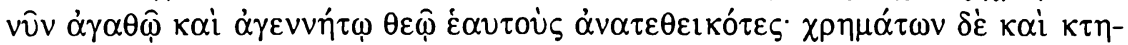

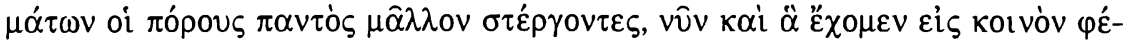

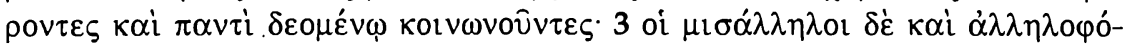

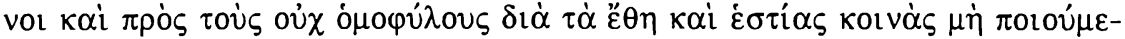

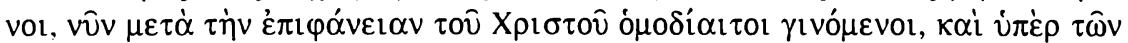

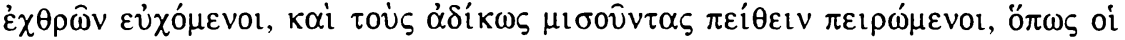

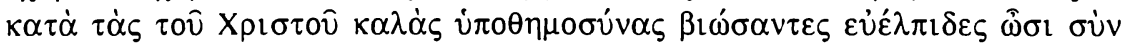

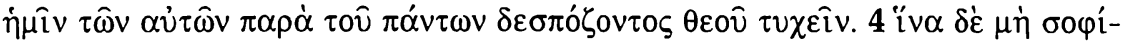

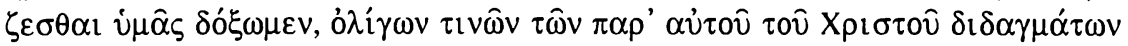

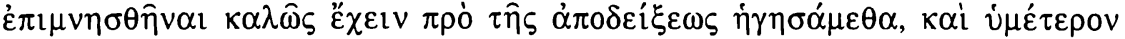

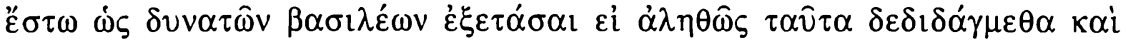

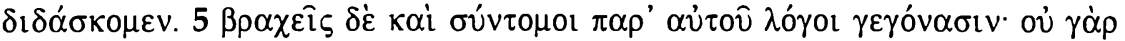

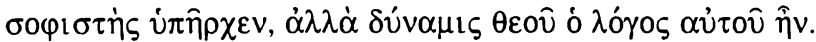

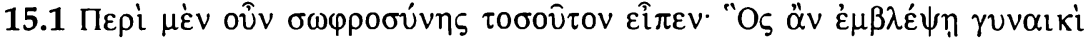

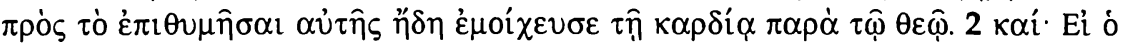

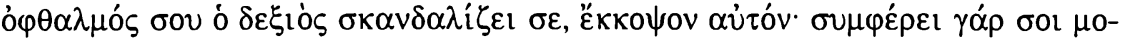

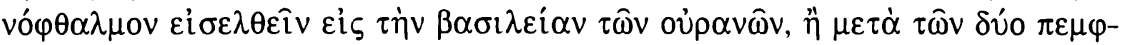

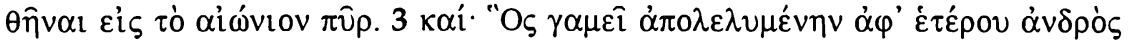

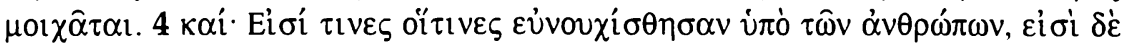

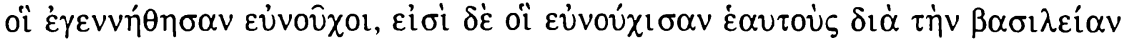

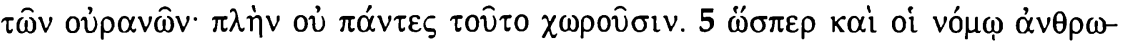

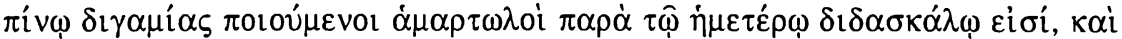

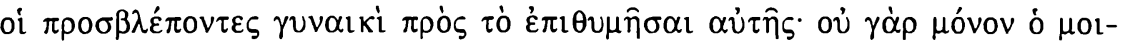

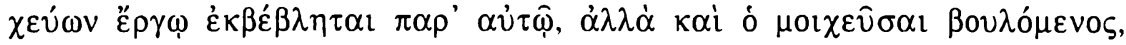

14.2 vîv $(\dot{\alpha} \gamma \alpha \theta \hat{\varphi})$ Otto : om A • $14.4 \dot{\omega} \varsigma \delta v v \alpha \tau \hat{\omega} v \mathrm{~A}: \dot{\omega} \zeta \delta \dot{\eta} \sigma u v \varepsilon \tau \hat{\omega} v$ Stephan

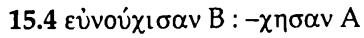

14.2 cf. Const.Apost. VIII,6 
14.1 Prenez garde, en effet, nous vous en prévenons, de peur que les démons, que nous accusons, ne vous dupent et ne vous détournent de nous lire jusqu'au bout et de comprendre ce que nous disons (ils s'efforcent de faire de vous leurs esclaves et leurs serviteurs et, tantôt par les visions des songes, tantôt par des tours de magie, ils mettent sous leur pouvoir tous ceux qui ne font aucun effort pour assurer leur salut; prenez garde, comme nous-mêmes: après avoir cru au Logos nous nous sommes éloignés des démons, pour nous attacher seulement, par son Fils, à Dieu inengendré. 2 Nous qui autrefois prenions plaisir à la débauche, maintenant nous ne chérissons plus que la chasteté; nous qui recourions aux artifices de la magie, maintenant nous sommes tout entiers consacrés au Dieu bon et inengendré; nous qui estimions par-dessus tout l'argent et les propriétés, maintenant nous mettons en commun ce que nous possédons et nous le partageons avec quiconque est dans le besoin; 3 nous qui nous haïssions et nous égorgions les uns les autres, nous qui, à cause de leurs coutumes, n'admettions pas d'étrangers à notre foyer, maintenant, après la manifestation du Christ, nous partageons avec eux le gîte et le couvert, nous prions pour nos ennemis et nous nous efforçons de persuader ceux qui nous haïssent injustement, afin que ceux qui vivront selon les beaux préceptes du Christ, partagent avec nous l'espoir de recevoir les mêmes biens de la part de Dieu, le maître du monde. 4 Mais pour que vous n'ayez pas l'impression que nous voulons vous tromper, nous croyons bon, avant d'aborder la démonstration, de rappeler quelques-uns des enseignements qui nous viennent du Christ lui-même; il vous appartiendra, en vertu de votre autorité impériale, d'examiner si telle est bien la vérité des enseignements que nous avons reçus et que nous transmettons. 5 Ses maximes sont brèves et concises, car il n'était pas un sophiste, mais sa parole était puissance de Dieu.

15.1 Or donc, en matière de chasteté, il est allé jusqu'à dire: "Celui qui regarde une femme pour la convoiter a déjà commis l'adultère dans son cœur devant Dieu", 2 et: "Si ton œil droit te scandalise, arrache-le, car il vaut mieux pour toi d'entrer avec un seul œil dans le royaume des cieux que d'être jeté avec les deux dans le feu éternel". 3 Et: "Celui qui épouse une femme répudiée par un autre homme commet un adultère". 4 Et: "Il y en a qui sont devenus eunuques par le fait des homes, il y en a qui sont nés eunuques et il y en a qui eux-mêmes se sont rendus tels à cause du royaume des cieux, mais cela tous ne le comprennent pas". 5 De même que ceux qui, grâce à une loi humaine, contractent un second mariage, sont pécheurs aux yeux de notre maître, de même aussi le sont ceux qui regardent une femme pour la convoiter; d'après lui ce n'est pas seulement celui qui commet effectivement l'adultère qui est réprouvé, mais égale-

14.3 Mt 5,44; Lc 6,27-28 • 15.1 Mt 5,28 • 15.2 Mt 5,29; 18,9; Mc 9,47 • 15.3 Mt 5,32; Mc 10,$11 ;$ Lc $16,18 \cdot 15.4$ Mt 19,12; 19,11 


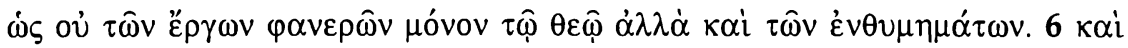

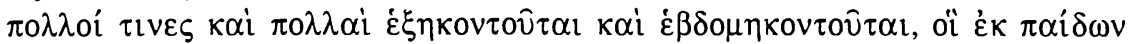

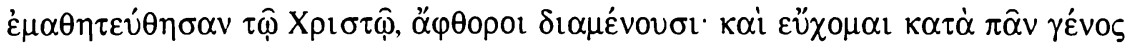

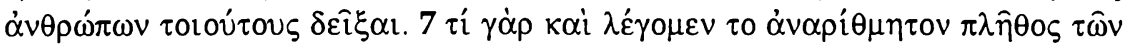

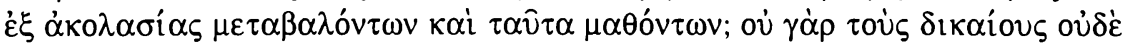

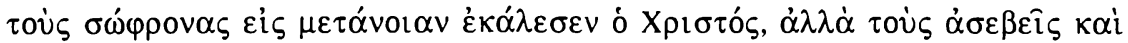

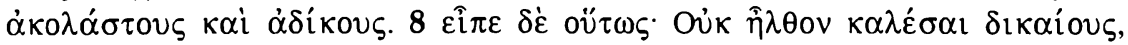

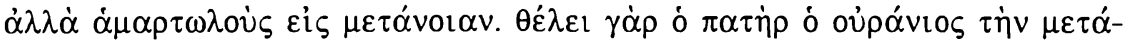

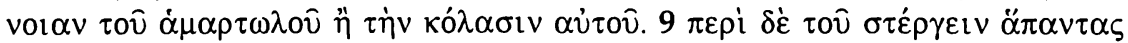

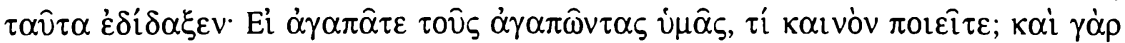

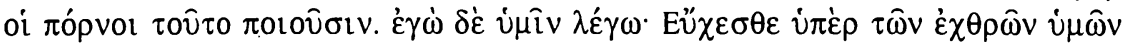

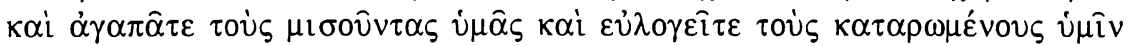

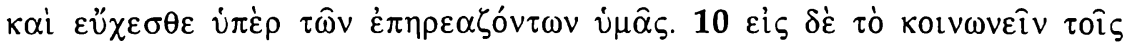

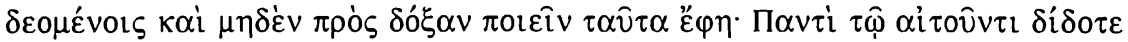

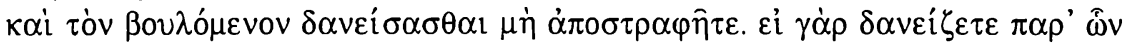

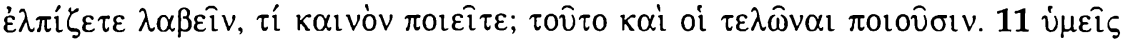

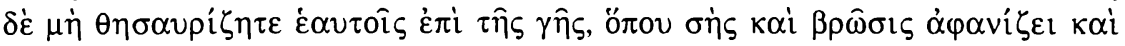

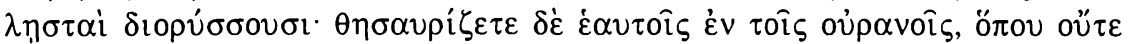

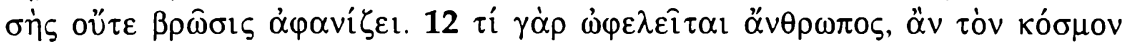

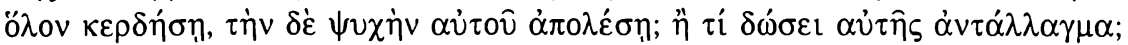

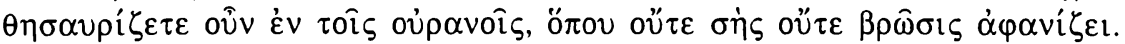

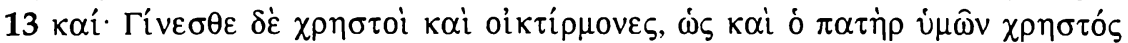

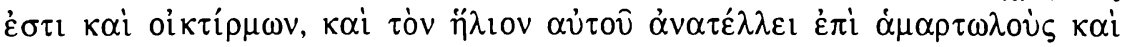

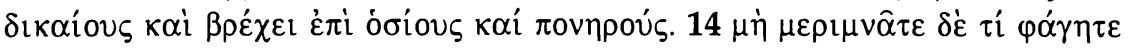

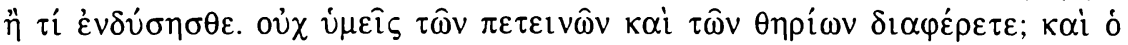

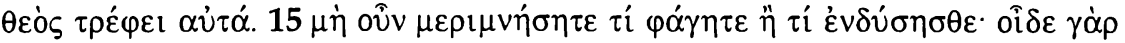

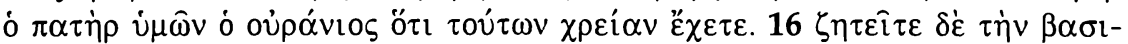

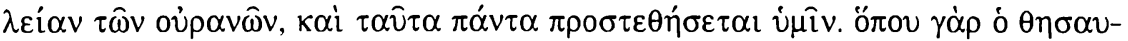

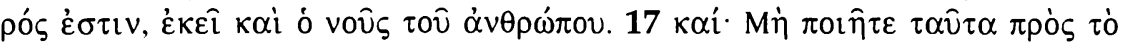

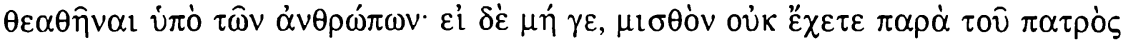

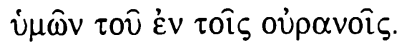

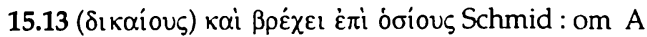

15.5 cf. Irénée, A.H. II,32,1 • 15.9 cf. Irénée, A.H. III,18,5 
ment celui qui a l'intention de le commettre, étant donné que ce ne sont pas seulement les actes qui apparaissent pour Dieu en pleine lumière, mais aussi les pensées. 6 De plus, un grand nombre d'hommes et de femmes qui, dès leur enfance se sont attachés à l'enseignement du Christ, persévèrent dans la virginité à l'âge de soixante ou de soixante-dix ans, et je me fais fort d'en montrer dans toutes les conditions, 7 sans parler de la foule innombrable de ceux qui, après une vie de débauche, se sont convertis et ont accepté ces principes, car ce ne sont pas les justes ni les sages que le Christ a appelés à la pénitence, mais les impies, les débauchés et les injustes. $8 \mathrm{Il}$ a dit, en effet: "Je ne suis pas venu appeler les justes mais les pécheurs à la pénitence, car le père céleste veut la pénitence du pécheur plutôt que son châtiment". Sur l'amour de tous les hommes il a enseigné ceci: "Si vous aimez ceux qui vous aiment, que faites-vous de nouveau? les impudiques en font autant. Quant à moi je vous dis: Priez pour vos ennemis; aimez ceux qui vous haïssent, bénissez ceux qui vous maudissent, priez pour ceux qui calomnient". 10 Sur le devoir de partager avec ceux qui sont dans le besoin et de ne rien faire par vaine gloire, il a dit ceci: " A quiconque vous sollicite, donnez et ne vous détournez pas de celui qui veut vous emprunter; car si vous prêtez à ceux dont vous espérez recevoir, que faites-vous de nouveau? les publicains en font autant. 11 Quant à vous, ne vous amassez pas de trésors sur la terre, où la teigne et le rouille détruisent, mais amassez vous des trésors dans les cieux, où ni la teigne ni la rouille ne détruisent. 12 Car que servira-t-il à l'homme de gagner le monde entier, s'il vient à perdre son âme, ou bien que donnera-t-il en échange de celle-ci? Amassez-vous donc des trésors dans les cieux, où ni la teigne ni la rouille ne détruisent". 13 Et: "Soyez bons et miséricordieux, comme votre Père est bon et miséricordieux et il fait lever son soleil sur les pécheurs et sur les justes et fait pleuvoir sur les saints et sur les méchants. $14 \mathrm{Ne}$ vous inquiétez pas de ce que vous mangerez ni de quoi vous vous vêtirez. Ne valez-vous pas mieux que les oiseaux et les bêtes? or Dieu les nourrit. $15 \mathrm{Ne}$ vous inquiétez donc pas de ce que vos mangerez ni de quoi vous vous vêtirez, car votre Père céleste sait que vous en avez besoin. 16 Cherchez le royaume des cieux et tout cela vous sera donné par surcroît. Car là où est son trésor, là est aussi le cœur de l'homme. 17 Et: "Ne faites pas ces choses pour être vus des hommes, sinon vous n'aurez pas de récompense auprès de votre Père dans les cieux".

15.8 Mt 9,13; Mc 2,17; Lc 5,32; Ez 33,11 - 15.9 Mt 5,46; Lc 6,32; Mt 5,44.45; Lc 6,27-28 • 15.10 Mt 5,42; Lc 6,30; Lc 6,34 -15.11 Lc 12,33; Mt 6,19-20 • 15.12 Mt 16,26; Mc 8,36; Lc 9,25; Mt 6,20 • 15.13 Mt 5,48; Lc 6,36; Mt 5,45 - 15.14 Mt 6,25; Lc 12,22; Mt 6,26; Lc $12,24 \cdot \mathbf{1 5 . 1 5}$ Mt 6,31-32; Lc 12,29-30 - 15.16 Mt 6,33; Lc 12,31; Lc 12,34; Mt 6,21 • 15.17 Mt 6,1 


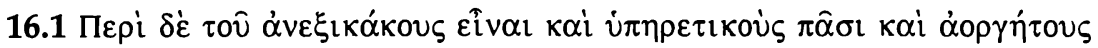

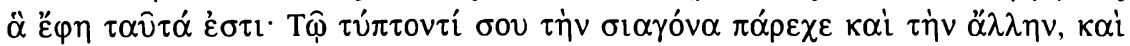

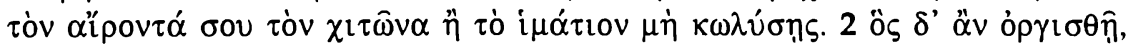

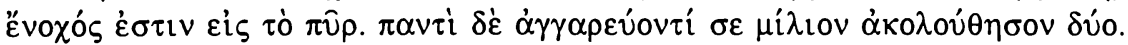

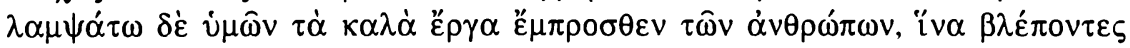

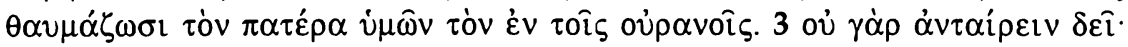

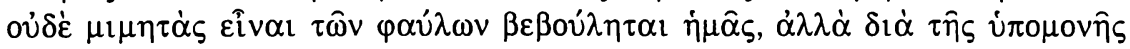

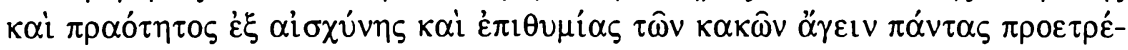

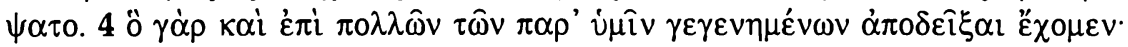

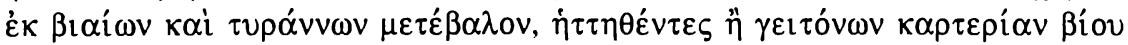

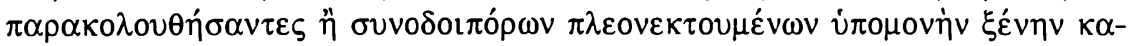

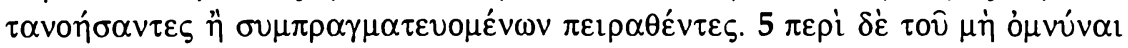

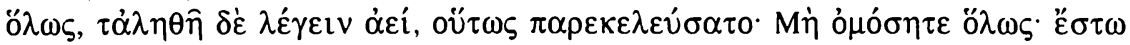

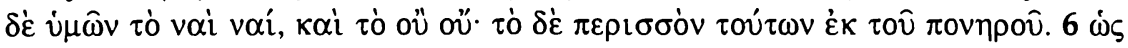

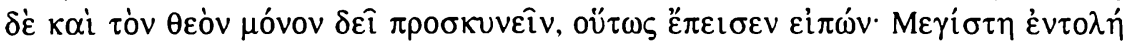

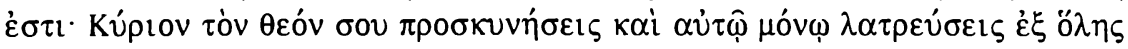

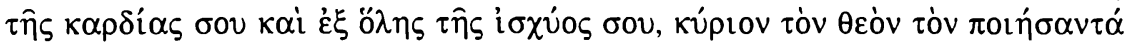

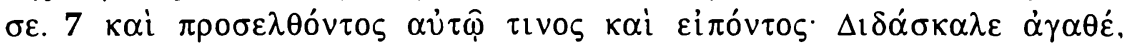

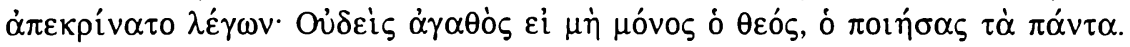

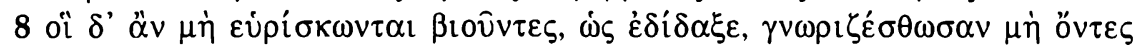

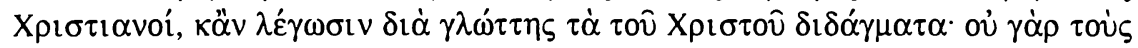

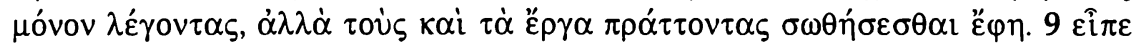

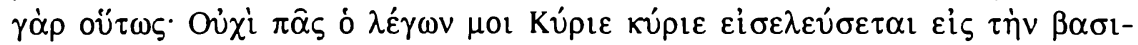

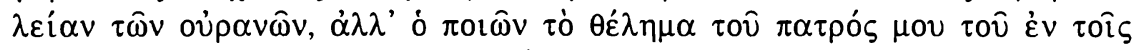

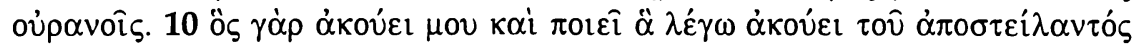

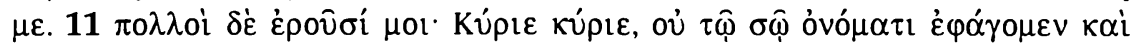

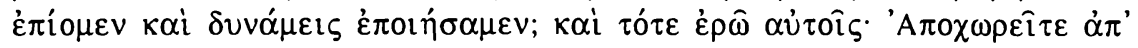

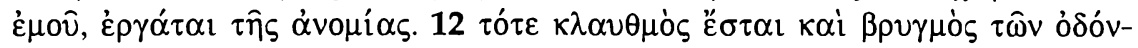

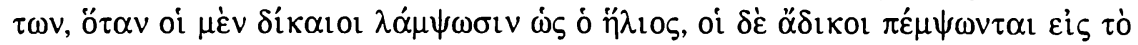

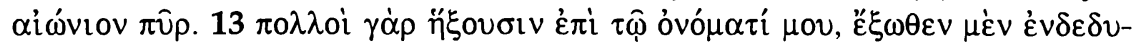

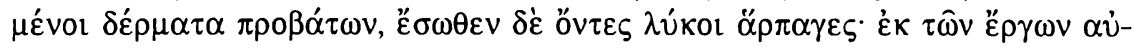

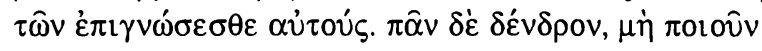

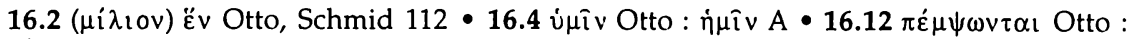
$\pi \dot{\varepsilon} \mu \pi \omega \nu \tau \alpha \mathrm{l} A$ 
16.1 Sur le devoir d'être patients, serviables envers tous et sans colère, voici ce qu'il dit: "A celui qui te frappe sur une joue, présente aussi l'autre, et celui qui te prend ta tunique ou ton manteau, ne l'empêche pas. 2 Celui qui se met en colère est passible du feu. Si quelqu'un te requiert pour un mille, fais-en deux avec lui. Que vos bonnes œuvres brillent devant les hommes, afin qu'ils les voient et admirent votre Père qui est dans les cieux". 3 Car il ne faut pas opposer de résistance. Il ne veut pas non plus que nous imitions les méchants; tout au contraire il nous a exhortés à user de patience et de douceur pour arracher les hommes à la honte et à la séduction du mal. 4 Cela aussi, assurément, nous pouvons le prouver, en citant nombre de gens qui ont vécu parmi vous: alors qu'ils étaient violents et tyranniques, ils ont changé de vie, s'étant laissé convaincre soit pour avoir observé la force d'âme que des voisins déployaient dans leur vie, soit pour avoir réfléchi à l'étrange patience dont témoignaient des compagnons de route, victimes d'injustices, soit pour l'avoir expérimentée eux-mêmes dans les affaires qu'ils traitaient avec eux. 5 Sur le devoir de ne jurer jamais et de dire toujours la vérité, il nous a donné ce commandement: "Ne jurez pas du tout; que votre oui soit oui, et votre non, non; le surplus vient du malin". 6 Quant au devoir de n'adorer que Dieu seul, il nous l'a persuadé en ces termes: "Le plus grand commandement est: Tu adoreras le Seigneur ton Dieu et tu le serviras lui seul, de tout ton cœur et de toute ta force, lui le Seigneur Dieu, qui t'a créé". 7 Comme quelqu'un s'était approché de lui et lui avait dit: "Bon maître", il répondit: "Personne n'est bon que Dieu seul, qui a créé l'univers." 8 Ceux dont la vie ne se trouve pas conforme à ses enseignements, que l'on reconnaisse qu'ils ne sont pas chrétiens, même si en parole ils professent la doctrine du Christ, car il a déclaré que seraient sauvés non point ceux qui se contentent de la réciter mais ceux qui en accomplissent les œuvres. $9 \mathrm{Il}$ a dit expressément: "Ce ne sont pas tous ceux qui disent: Seigneur, Seigneur, qui entreront dans le royaume des cieux, mais celui qui fait la volonté de mon Père qui est aux cieux. 10 Quiconque m'écoute et fait ce que je dis, écoute celui qui m'a envoyé. 11 Or, beaucoup me diront: Seigneur, Seigneur, n'est-ce pas en ton nom que nous avons mangé et bu et accompli des miracles? et alors je leur dirai: Eloignez-vous de moi, artisans d'iniquité. 12 Alors il y aura des pleurs et des grincements de dents, quand les justes resplendiront comme le soleil, tandis que les méchants seront envoyés au feu éternel. 13 Car beaucoup viendront en mon nom, revêtus à l'extérieur de peaux de brebis, mais qui au-dedans sont des loups ravisseurs. Tout

16.1 Lc 6,29; Mt 5,39-40 • 16.2 Mt 5,22; 5,41; 5,16 • 16.5 Mt 5,34; 5,37; cf. Jc 5,12 • 16.6 Mc 12,29-30; Mt 22,37; cf. Dt 6,5; Lc 10,27 • 16.7 Mc 10,17-18; Mt 19,16-17; Lc 18,18-19 • 16.9 Mt 7,21; Lc 6,46 - 16.10 Mt 7,24; Lc 6,47; 10,16; Mt 10,40 • 16.11 Mt 7,22; Lc 13,26; Mt 7,23; Lc 13,27; Mt 13,42-43 - 16.13 Mt 24,5; Mc 13,6; Lc 21,8; Mt 7,15-16; 7,19; Lc $6,43-44$ 


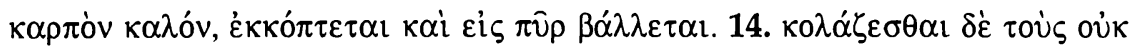

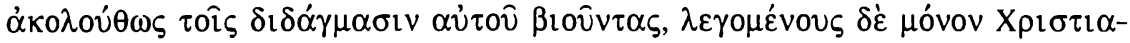

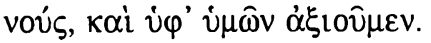

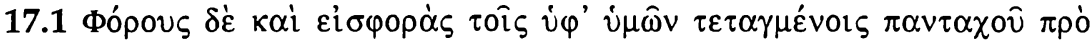

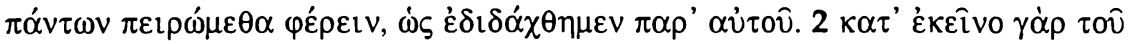

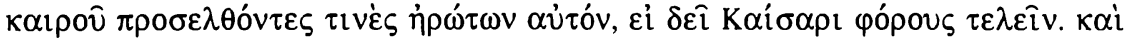

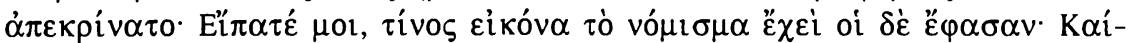

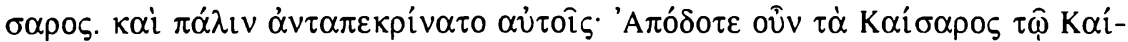

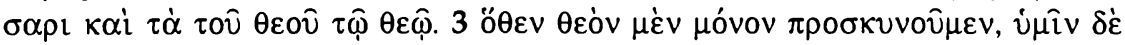

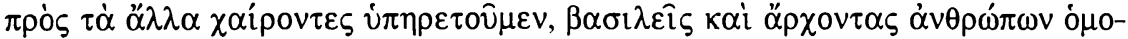

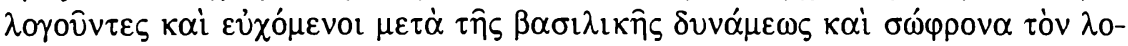

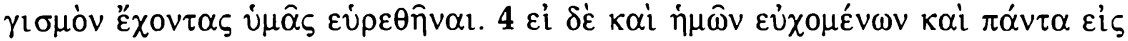

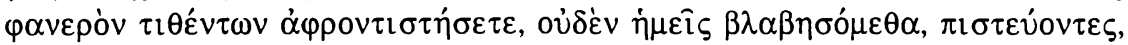

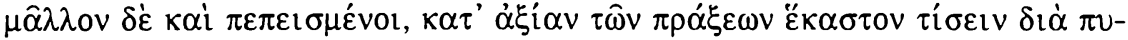

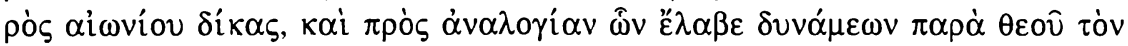

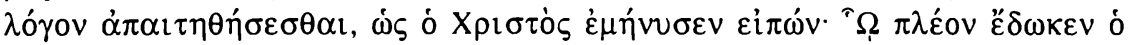

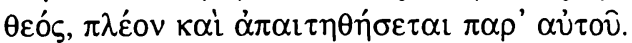

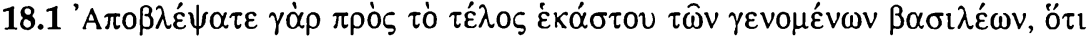

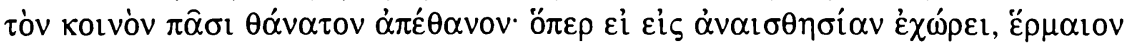

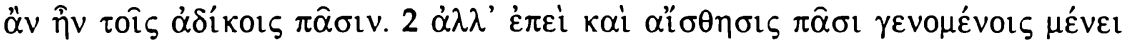

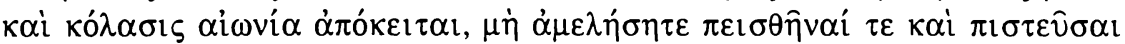

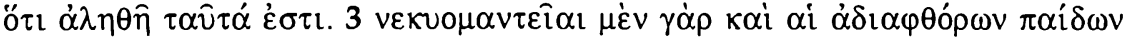

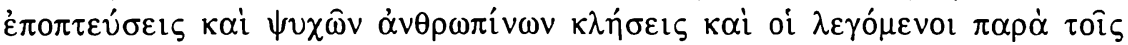

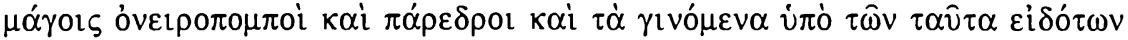

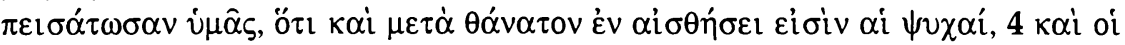

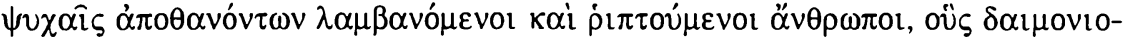

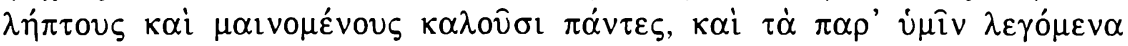

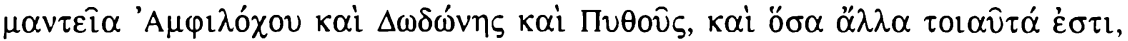

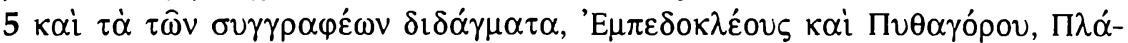

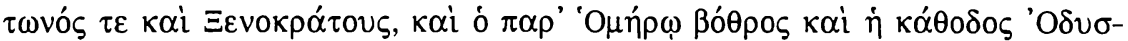

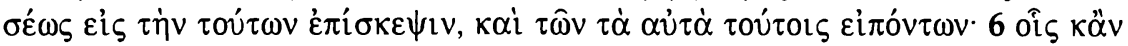

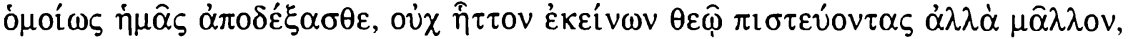

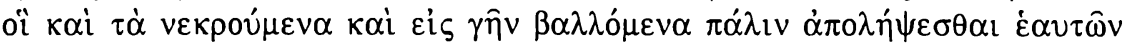

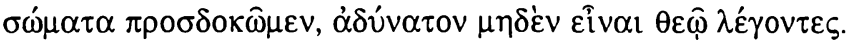

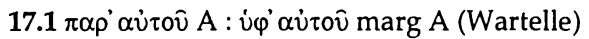

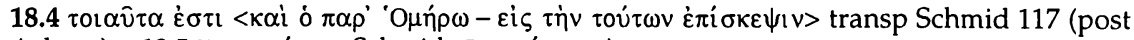

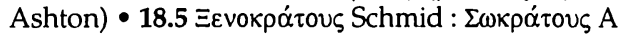

18.1 Platon, Phaedo 107C • 18.3 Cicéron, in Vatin. 6,14; Eusèbe, H.E. VII,10; VIII,14 • 18.4 Josèphe, B.J. VII,6,3 • 18.5 Homère, Od. XI,25; Suétone, Nero 34 
arbre qui ne produit pas de bon fruit sera coupé et jeté au feu". 14 Que soient donc punis ceux qui ne vivent pas conformément aux enseignements du Christ et qui ne sont chrétiens que de nom, cela aussi nous vous le demandons.

17.1 Tributs et impôts, nous nous efforçons partout de les payer, avant tout le monde, à ceux que vous chargez de les collecter, comme il nous en a instruits. 2 Car en ce temps-là certains vinrent lui demander s'il fallait payer le tribut à César, et il répondit: "Dites-moi: de qui la pièce de monnaie porte-t-elle l'effigie? - De César", dirent-ils, et il leur répondit: "Rendez donc à César ce qui est à César et à Dieu ce qui est à Dieu". 3 Voilà pourquoi nous n'adorons que Dieu seul, mais pour le reste nous vous obéissons avec joie, car nous vous reconnaissons comme rois et chefs des hommes et nous demandons dans nos prières qu'avec la puissance souveraine on puisse aussi trouver en vous la sagesse et la raison. 4 Mais si, en dépit de nos prières et malgré notre exposé au grand jour, vous n'avez pour nous que mépris, nous n'en éprouverons aucun dommage, car nous croyons ou plutôt nous sommes fermement convaincus que, selon la valeur de ses œuvres, chacun subira le châtiment dans un feu éternel et que, à proportion des pouvoirs qu'il aura reçus de Dieu, il devra rendre compte, comme le Christ l'a indiqué, en disant: "Celui à qui Dieu aura donné davantage, il lui sera aussi demandé davantage".

18.1 Considérez la fin de chacun des souverains qui vous ont précédés, ils sont morts, de la mort qui est le sort commun à tous les hommes; si cela conduisait à l'absence de tout sentiment, ce serait une bonne aubaine pour tous les méchants. 2 Mais puisque le sentiment demeure chez tous ceux qui ont cessé de vivre et qu'un châtiment éternel est tenu en réserve, ne négligez pas de vous laisser persuader et de croire que c'est bien là la vérité. $3 \mathrm{De}$ fait, la nécromancie, les divinations faites sur les entrailles d'enfants innocents, les évocations d'âmes humaines, les pratiques de ceux que la magie appelle envoyeurs de songes et assesseurs, ainsi que les opérations de ceux qui possèdent ces sciences, tout cela doit vous convaincre qu'après la mort les âmes conservent encore le sentiment. $4 \mathrm{Il}$ y a aussi les hommes qui sont saisis et jetés à terre par les âmes des morts, que l'on appelle communément démoniaques et possédés, et ce que vous appelez vos oracles, ceux d'Amphiloque, de Dodone, de la Pythie et tant d'autres du même genre, 5 et aussi les témoignages des écrivains, d'Empédocle, de Pythagore, de Platon, de Xénocrate, la fosse d'Homère, la descente d'Ulysse pour la visite des enfers, et les récits des auteurs qui ont rapporté des faits analogues. 6 Pareillement au leur, veuillez recevoir notre témoignage, nous qui croyons en Dieu, pas moins qu'eux, mais bien davantage, puisque nous espérons recouvrer nos propres corps, même morts et jetés en terre car, disons nous, rien n'est impossible à Dieu. 


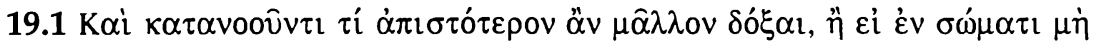

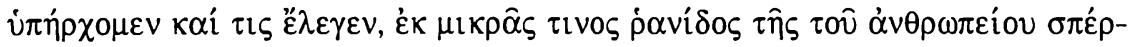

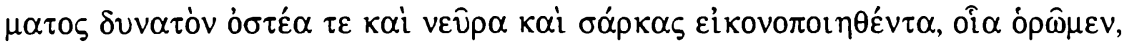

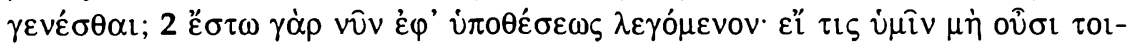

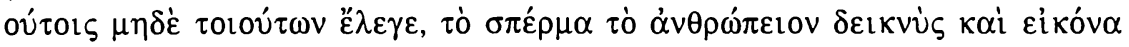

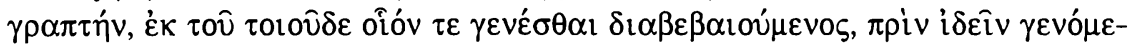

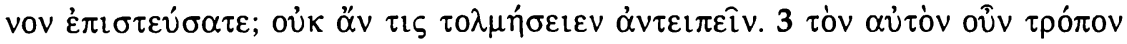

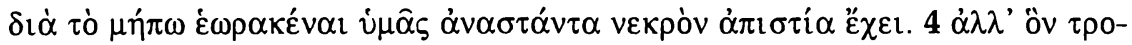

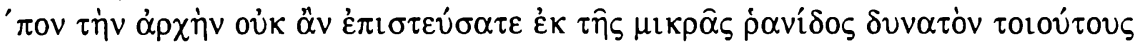

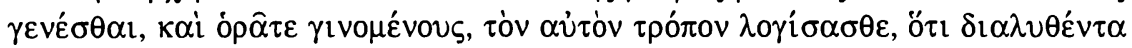

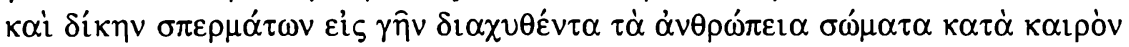

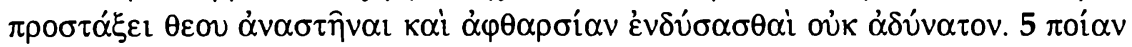

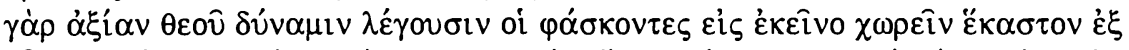

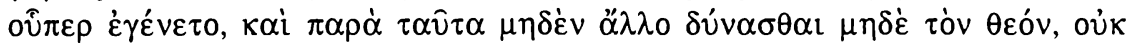

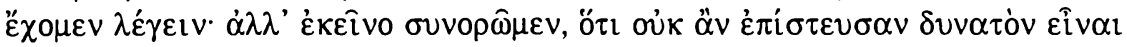

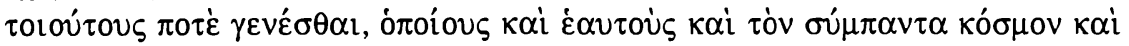

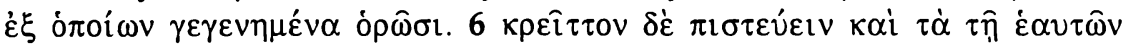

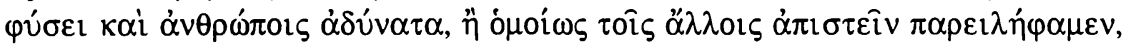

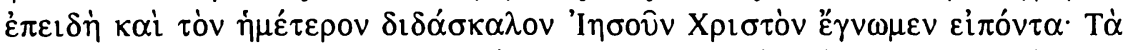

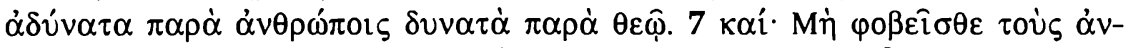

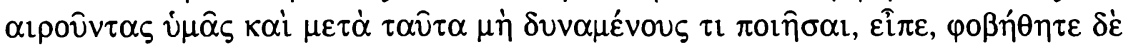

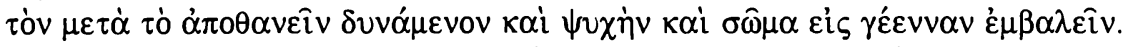

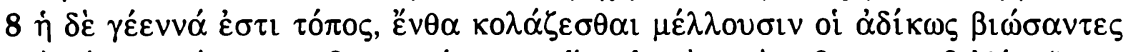

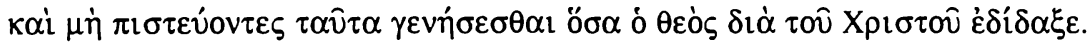

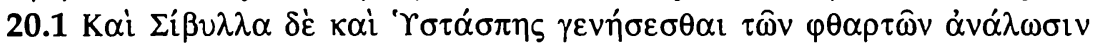

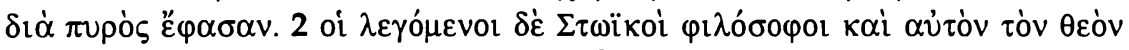

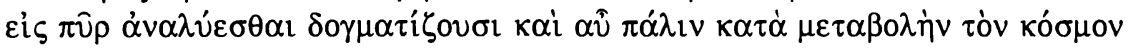

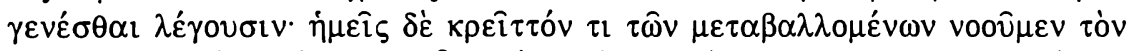

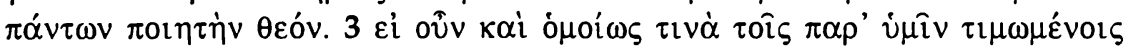

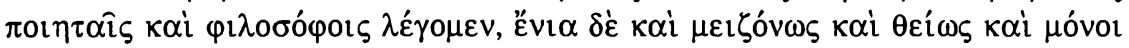

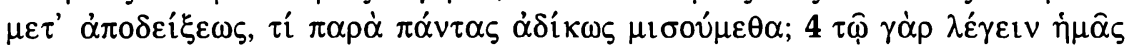

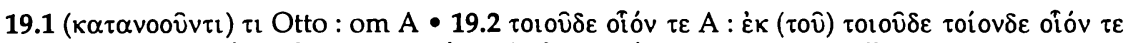

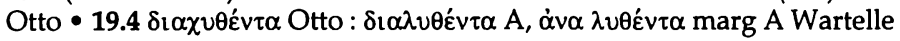

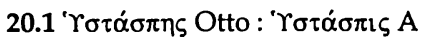

19.1 cf. Tatien, Or. 6; Athénagore, Res. 17 • 19.5 Virgile, Georg. IV,219; Aen. VI,724; Athénagore, Res. 2,5 • 20.1 Orac.Sibyll. II,196s. • 20.2 Ps.Plutarque, de Placit.Philos. I,6 
19.1 A y bien réfléchir, pourrait-il y avoir rien de plus incroyable, si nous ne vivions pas dans un corps, que d'entendre quelqu'un dire que d'une minuscule goutte de sperme il est possible de produire des os, des nerfs et des chairs, façonnés selon les formes que nous leur voyons. $2 \mathrm{De}$ fait, admettons pour l'instant l'hypothèse qui vient d'être énoncée: à suposer que vous ne soyez ni tels que vous êtes ni de telle origine, si quelqu'un, vous montrant d'un côté le sperme humain et de l'autre l'image peinte d'un homme vous assurait que ce dernier peut provenir de celui-là, le croiriez-vous, avant de le voir réalisé? Personne, assurément, n'oserait $y$ contredire. 3 Ainsi donc, parce que vous n'avez pas encore vu de mort ressuscité, vous demeurez incrédules.4 Mais de même qu'au départ vous n'auriez pas cru possible que d'une minuscule goutte de sperme naissent des êtres tels que nous, et pourtant vous voyez bien que c'est là leur origine, de même admettez qu'il n'est pas impossible que les corps humains, décomposés et dispersés en terre, comme des semences, ressuscitent au moment voulu, sur un ordre de Dieu, et revêtent l'immortalité. 5 De quelle puissance digne de Dieu peuvent parler ceux qui prétendent que chaque être retourne au lieu dont il est issu et que même Dieu ne peut s'y opposer, nous ne saurions le dire; par contre, ce que nous voyons bien, c'est qu'ils n'auraient pas cru possible de devenir un jour ce qu'ils sont, tels qu'ils se voient eux-mêmes, ainsi que le monde entier, créés à partir de tels éléments. $6 \mathrm{Il}$ vaut mieux croire ce qui est impossible à notre propre nature et aux hommes que d'être incrédules avec les autres; tel est l'enseignement que nous avons reçu de notre maître Jésus-Christ qui a dit: "Ce qui est impossible aux hommes, est possible à Dieu." 7 Et: "Ne craignez pas ceux qui vous tuent et qui ne peuvent rien faire au delà, mais craignez celui qui, après la mort, peut jeter l'âme et le corps dans la géhenne". $8 \mathrm{La}$ géhenne est le lieu où doivent être punis ceux qui ont vécu dans l'iniquité et qui ne croient pas que se réalisera tout ce que Dieu a enseigné par le Christ.

20.1 Du reste la Sibylle et Hystaspe ont annoncé une destruction des êtres corruptibles par le feu. 2 Et les philosophes qu'on appelle Stoïciens enseignent que Dieu lui-même se résout en feu et prétendent que le monde surgit de nouveau à l'existence par un processus de transformation. Quant à nous, nous pensons que le Dieu qui a créé l'univers est un être supérieur aux êtres corruptibles. $3 \mathrm{Si}$ donc nous sommes d'accord sur certains points avec les poètes et les philosophes que vous tenez en estime, si sur certains autres nous parlons mieux qu'eux et d'une manière plus digne de Dieu, si enfin nous sommes les seuls à offrir une démonstration, pourquoi sommes-nous l'objet d'une haine injuste et exceptionnelle? $4 \mathrm{Si}$ nous affirmons que l'univers reçoit de Dieu son ordonnance et son 


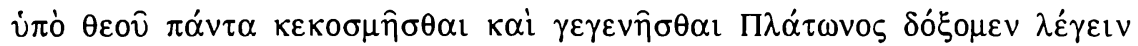

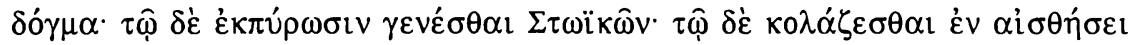

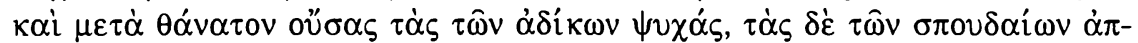

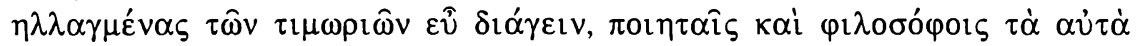

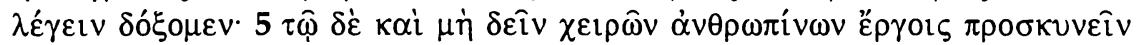

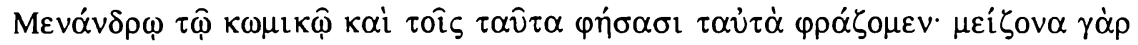

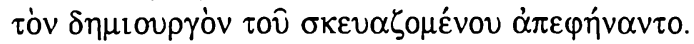

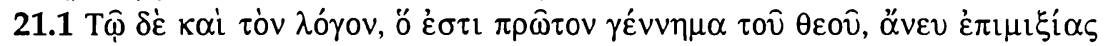

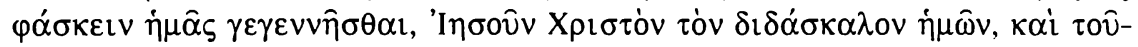

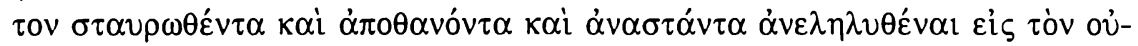

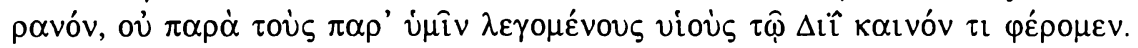

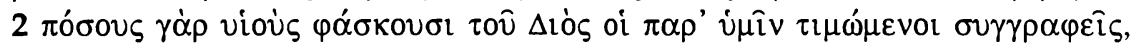

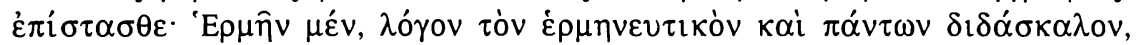

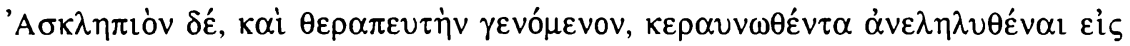

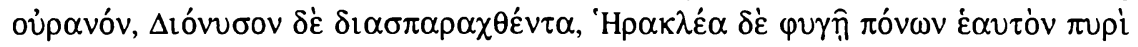

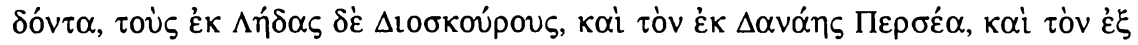

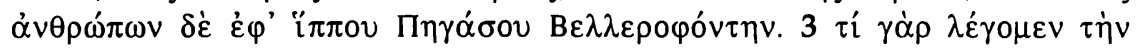

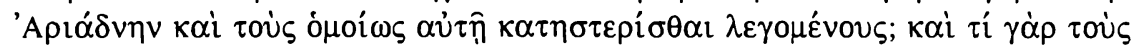

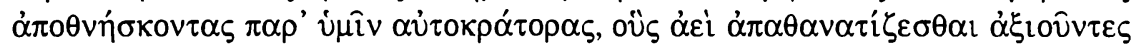

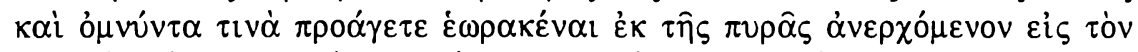

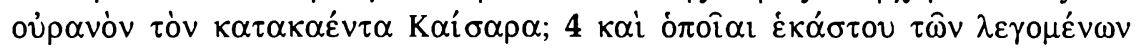

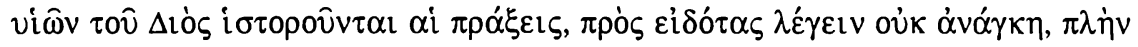

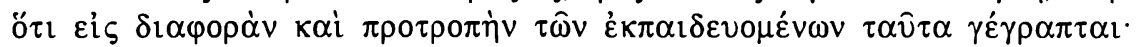

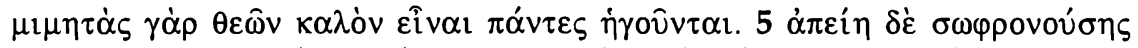

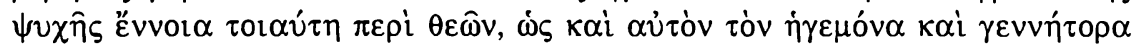

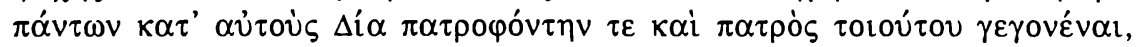

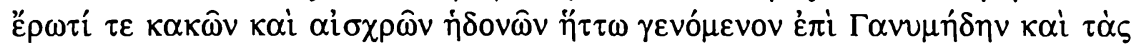

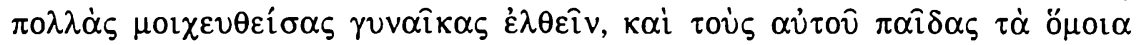

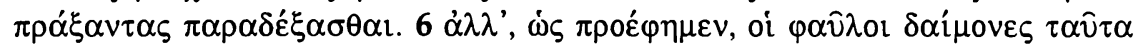

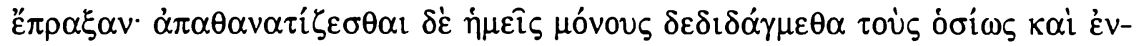

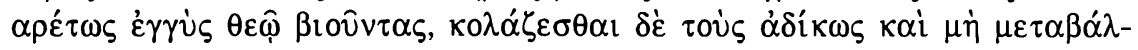

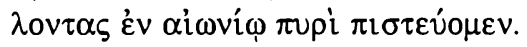

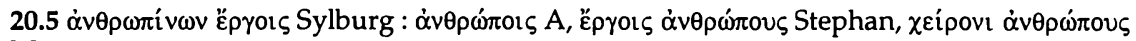
Maran

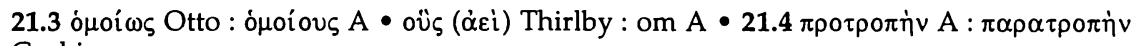
Grabius

20.5 Ps.Justin, Monarch. 5 • 21.2 Hermès: cf. Clément d'Alexandrie, Strom. VI,15. Asclépios: cf. Pindare, Pyth. III,55-58; Euripide, Alc. 3; Platon, Resp. 408B; Virgile, Aen. VII, 770. - Héraclès: cf. Sophocle, Trach. - Dioscures: cf. Aen. VI,121s. - Bellérophon: cf. Pindare, Isthm. VII,46; Horace, Od. IV,11,26 • 21.3 Suétone, Diuus Julius, 88; Diuus Augustus, 100; Sénèque, Apocoloquintosis, 1 • 21.4 Sénèque, De breu.uitae 16,5 
existence, on reconnaîtra que nous enseignons la doctrine de Platon; si nous affirmons l'embrasement universel, celle des Stoïciens; si nous disons que les âmes des méchants conservent le sentiment et sont châtiées, même après la mort, mais que celles des justes, libérées de toute peine, mènent une vie heureuse, on reconnaîtra que nous disons la même chose que les poètes et les philosophes. 5 En affirmant qu'il ne faut pas se prosterner devant des ouvrages faits de main d'homme, nous parlons comme le poète comique Ménandre et ceux qui se sont exprimés dans le même sens, car ils ont proclamé que l'ouvrier est supérieur à son ouvrage.

21.1 Quand nous disons que le Logos, le premier-né de Dieu, JésusChrist notre Maître, a été engendré sans union charnelle, qu'après avoir été crucifié, être mort et ressuscité, il est monté au ciel, nous n'annonçons rien d'inouï par rapport à ceux que vous appelez fils de Zeus. 2 Vous savez, en effet, combien de fils de Zeus énumèrent vos écrivains les plus estimés: Hermès, le verbe qui interprète et enseigne toutes choses; Asclépios, qui fut médecin et qui, frappé de la foudre, est monté au ciel, tout comme Dionysios, après avoir été mis en pièces; Héraclès, après s'être livré aux flammes pour échapper à ses douleurs; les Dioscures, fils de Léda; Persée, fils de Danaé, ainsi que, sur le cheval Pégase, Bellérophon, qui était d'origine humaine. 3 Que dire d'Ariadné et de ceux qui, comme elle, furent placés parmi les astres? et que dire de vos empereurs défunts, que toujours vous jugez dignes de mettre au rang des immortels, et vous produisez chaque fois un quidam pour jurer qu'il a vu le César s'élever du bûcher vers le ciel. 4 Quelles sortes d'actions les histoires attribuent à chacun des prétendus fils de Zeus, il n'est pas nécessaire de le rappeler à des gens qui en sont informés; qu'il suffise de dire qu'elles ont été écrites pour l'avantage et l'instruction des jeunes qui les apprennent, car tout le monde pense qu'il est beau d'imiter les dieux. 5 Qu'un esprit de bon sens se garde d'une pareille conception de la divinité selon laquelle Zeus luimême, le chef et le géniteur des dieux, a été un parricide et le fils d'un parricide, que, vaincu par l'attrait de plaisirs vils et honteux, il est descendu chez Ganymède et quantité de femmes, pour commettre l'adultère avec elles, et que ses enfants ont commis des actions semblables. 6 Par contre, comme nous l'avons dit précédemment, ce sont les mauvais démons qui furent ici à l'œuvre. Mais selon la doctrine que nous avons reçue, seuls sont mis au rang des immortels ceux qui vivent auprès de Dieu d'une vie sainte et vertueuse, mais ceux qui vivent dans l'iniquité et refusent de se convertir, nous croyons qu'ils sont punis dans un feu éternel. 


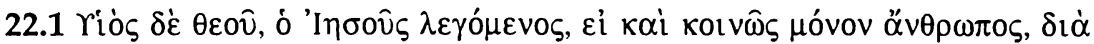

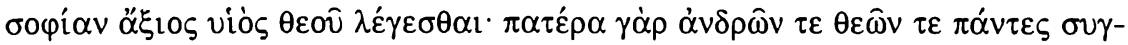

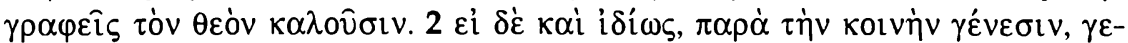

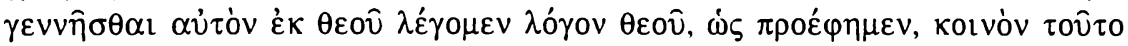

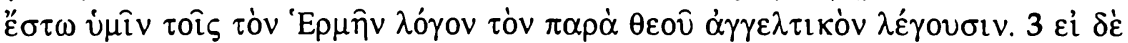

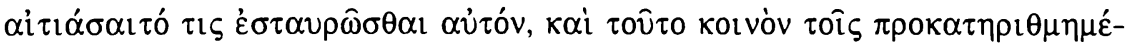

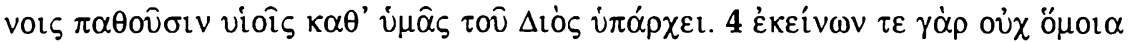

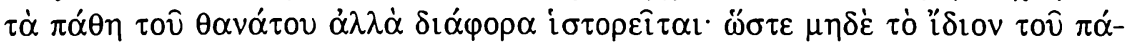

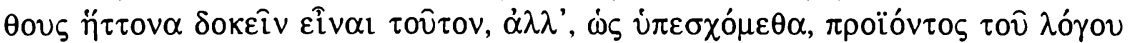

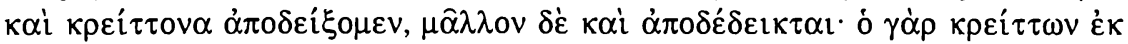

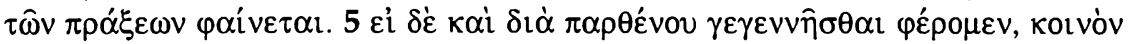

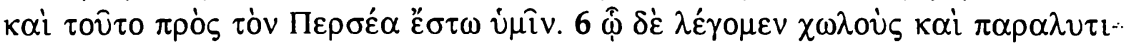

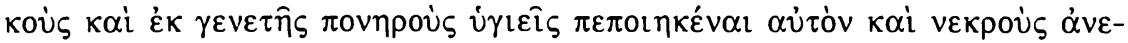

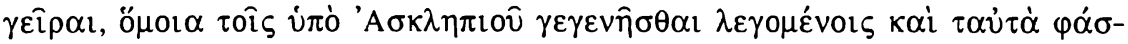

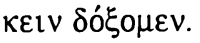

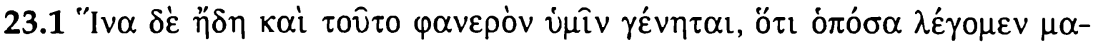

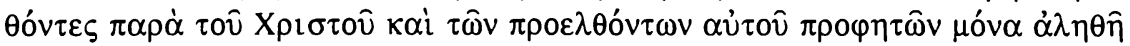

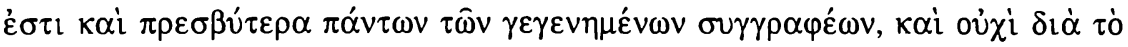

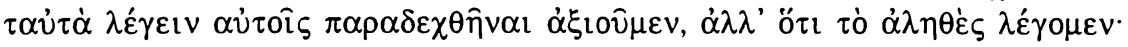

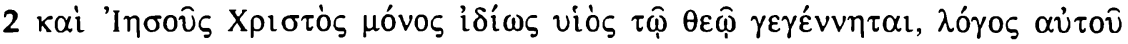

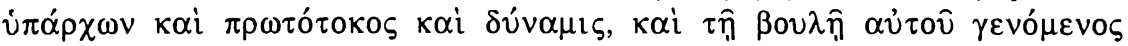

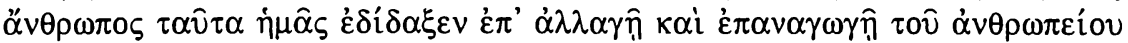

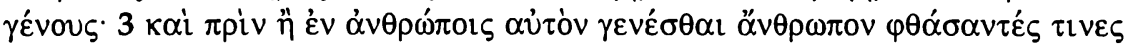

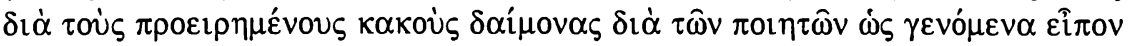

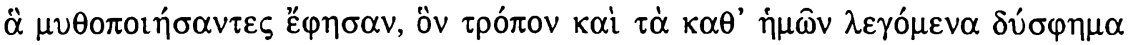

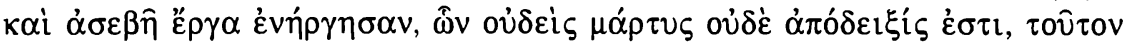

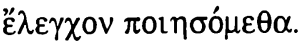

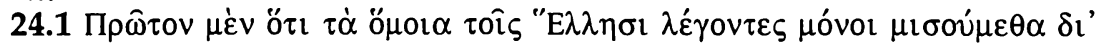

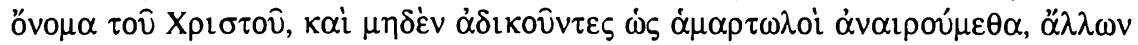

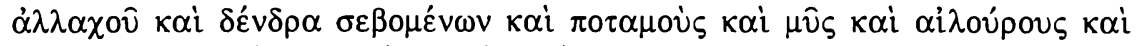

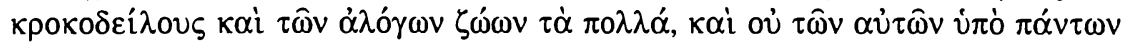

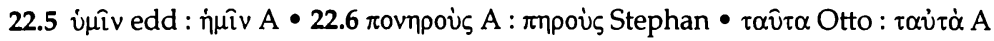

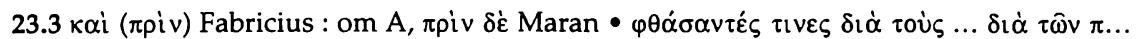

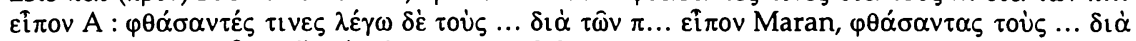

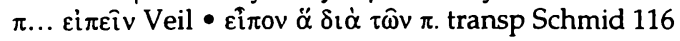

22.1 Homère, Il. I,544; IV,68; Cicéron, De nat.deorum II,2,4; Varron, De ling.latin. V,65 
22.1 Mais le fils de Dieu, qu'on appelle Jésus, quand bien même il ne serait qu'un homme ordinaire, est digne, pour sa sagesse, d'être appelé fils de Dieu, car tous les auteurs donnent à Dieu le nom de père des dieux et des hommes. 2 Si nous affirmons qu'il est né de Dieu, comme Logos de Dieu, selon un mode de génération qui lui est particulier, différent de la génération ordinaire, comme nous l'avons dit précédemment, admettez que ce point nous est commun avec vous, puisque vous appelez Hermès le Logos messager qui vient d'auprès de Dieu. $3 \mathrm{Si}$ quelqu'un venait à objecter qu'il a été crucifié, ce point aussi lui est commun avec les fils de Zeus, énumérés plus haut, qui eurent à souffrir, d'après vous; 4 en effet, on rapporte qu'ils subirent des genres de mort non point semblables mais différents, de sorte qu'il ne leur paraît pas inférieur pour ce qui concerne le genre de supplice qui lui fut particulier; au contraire, comme nous l'avons promis, dans la suite de notre discours nous démontrerons qu'il leur est supérieur, ou plutôt la démonstration a déjà été faite, car celui qui est supérieur se révèle tel par ses actes. 5 Si nous rapportons qu'il est né d'une vierge, admettez que ce point aussi vous est commun avec Persée. $6 \mathrm{Si}$ enfin nous disons qu'il a guéri des boîteux, des paralytiques et des infirmes de naissance, et qu'il a ressuscité des morts, nous paraîtrons là aussi parler de faits semblables à ceux que l'on attribue à l'action d'Asclépios.

23.1 Mais afin que maintenant vous apparaisse clairement: que tout ce que nous affirmons pour l'avoir appris du Christ et des prophètes qui l'ont précédé est la seule doctrine vraie, plus ancienne que celle de tous les écrivains du passé et que, si nous vous demandons de l'accepter, ce n'est pas parce qu'elle est en accord avec ceux-ci, mais parce que nous disons la vérité, 2 que Jésus-Christ seul a été engendré comme Fils de Dieu au sens propre du terme, lui qui est son Logos, son premier-né, sa puissance, que, devenu homme par sa volonté, il nous a donné cet enseignement pour le renouveau et la transformation du genre humain; 3 que, avant qu'il ne parût, homme parmi les hommes, certains, je veux dire les mauvais démons, dont on a parlé précédemment, ont pris les devants pour faire présenter par les poètes comme des réalités les fables qu'ils avaient imaginées et mises dans leur bouche, tout comme ils ont inventé les actions infâmes et impies dont on nous accuse, mais dont il n'existe ni témoin ni preuve - nous ferons la réfutation que voici.

24.1 Premièrement: alors que nous disons les mêmes choses que les Grecs, nous seuls sommes objet de haine à cause du nom du Christ, et alors que nous ne faisons rien de mal, on nous met à mort comme des scélérats, tandis que d'autres ailleurs adorent des arbres, des fleuves, des rats, des chats, des crocodiles et la plupart des animaux privés de raison, 


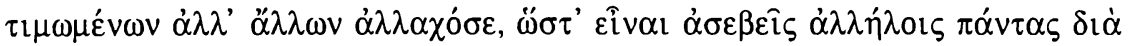

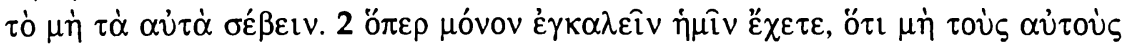

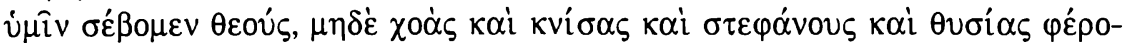

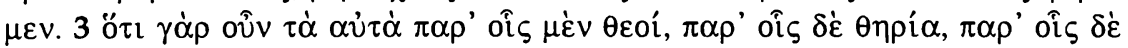

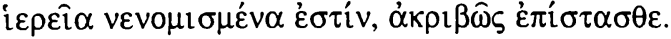

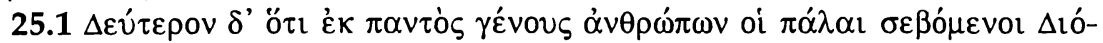

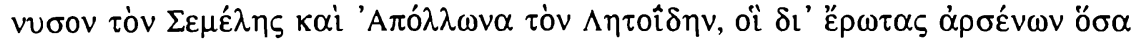

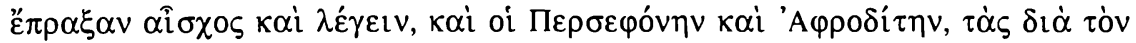

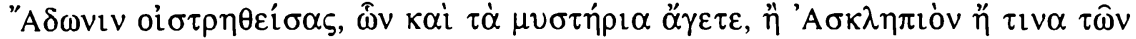

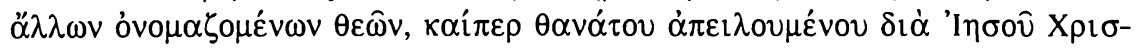

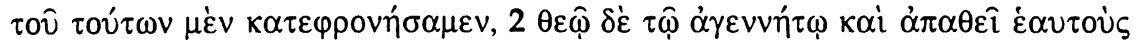

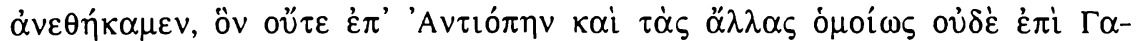

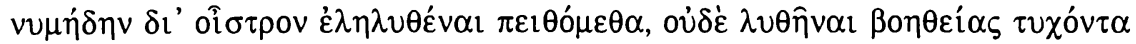

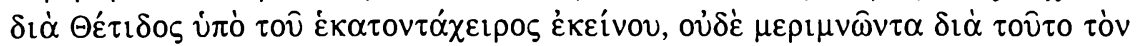

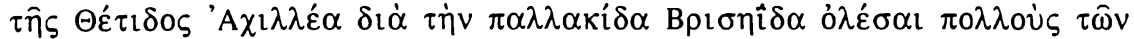

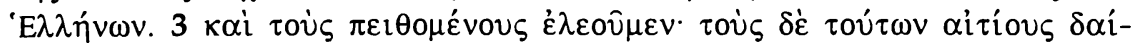
$\mu о v \alpha \varsigma \gamma v \omega \rho i \zeta o \mu \varepsilon v$.

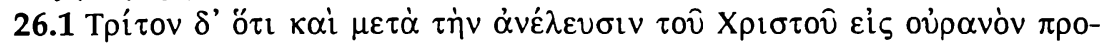

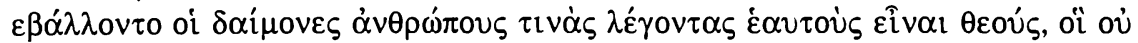

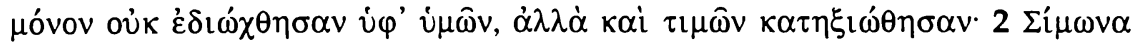

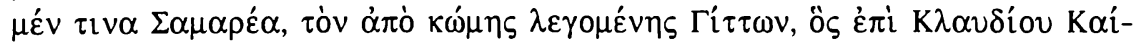

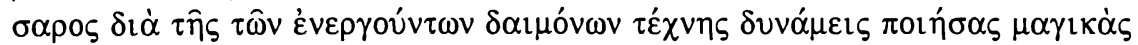

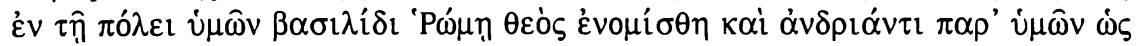

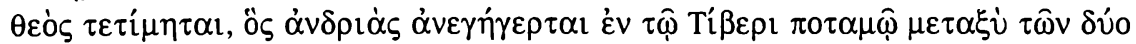

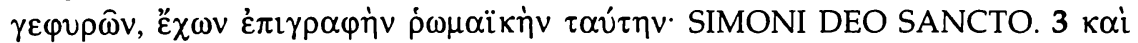

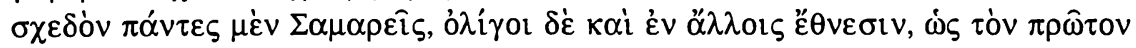

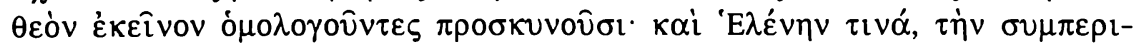

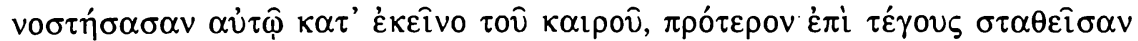

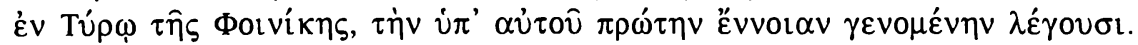

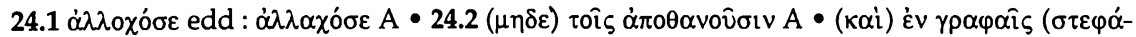

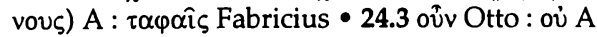

$25.1 \pi \alpha \dot{\alpha} \lambda \alpha_{1}$ Otto : $\pi \alpha \lambda \alpha$ loíA

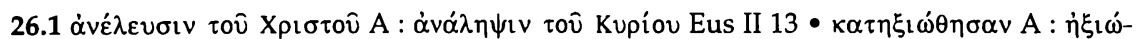

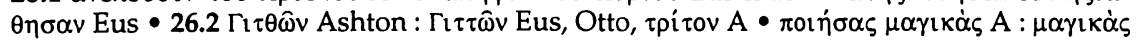

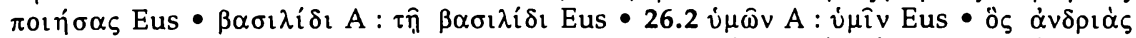

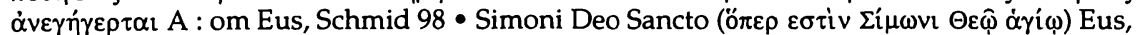

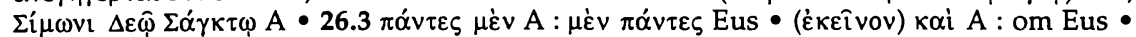

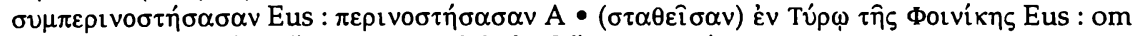

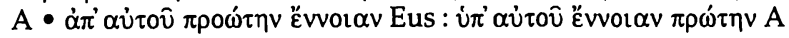

25.1 cf. Athénagore, leg.20 • 25.2 Briséis: cf. Homère, Il. II,3s. • 26.1-3 cf. Eusèbe, H.E. II,13,3-4 
et ce ne sont pas les mêmes qui sont honorés par tous mais les uns ici, d'autres ailleurs, si bien que tous sont des impies les uns aux yeux des autres, puisqu'ils ne vénèrent pas les mêmes objets. 2 Le seul reproche que vous puissiez nous faire, c'est précisément que nous ne vénérons pas les mêmes dieux que vous et que nous n'offrons pas non plus, comme vous, des libations, ni la graisse des victimes, ni couronnes, ni sacrifices. 3 Car vous savez parfaitement que les mêmes êtres sont considérés chez les uns comme des dieux, chez les autres comme des bêtes sauvages, chez d'autres enfin comme du bétail destiné à l'abattoir.

25.1 Deuxièmement: nous, hommes de toute race, qui vénérions jadis Dionysos, fils de Sémélé et d'Apollon, fils de Léto, dont il serait honteux de dire les actions qu'ils ont commises par amour des garçons, et aussi Perséphone et Aphrodite, qui furent dardées d'un fol amour pour Adonis et dont vous célébrez aussi les mystères, ou encore Asclépios ou tel autre de ceux qui sont appelés dieux, nous avons, malgré la mort dont on nous menace, appris à les mépriser à cause de Jésus-Christ, 2 et nous nous sommes consacrés au Dieu inengendré et impassible dont nous ne croyons pas qu'il soit jamais venu assouvir sa passion auprès d'Antiope ou d'autres femmes, ni auprès de Ganymède, ni qu'il ait été délivré grâce à l'aide de Thétys par le fameux géant aux cent bras, ni qu'il se soit soucié, en retour, de voir Achille, le fils de Thétys, faire périr quantité de Grecs, à cause de sa concubine Briséis. 3 Nous avons pitié de ceux qui croient ces choses et nous savons que les démons en sont les auteurs.

26.1 Troisièmement: après l'ascension du Christ au ciel, les démons poussèrent certains hommes à se faire passer pour des dieux; non seulement ces gens ne furent pas poursuivis par vous, mais vous les avez jugés dignes de recevoir des honneurs: 2 un certain Simon, Samaritain du bourg de Gitthon, qui sous le règne de Claude César accomplit dans votre ville impériale de Rome des prodiges de magie avec l'aide des démons qui agissaient par lui; considéré comme un dieu, il fut comme un dieu honoré d'une statue; cette statue se dresse dans l'île du Tibre, entre les deux ponts, avec cette inscription en latin: Simoni deo sancto. 3 Presque tous les Samaritains et un petit nombre d'hommes d'autres nations les reconnaissent et l'adorent comme leur premier dieu; ils disent aussi qu'une certaine Hélène, qui l'accompagnait à cette époque, après avoir vécu dans une maison de débauche, à Tyr, de Phénicie, serait sa première émanation. 


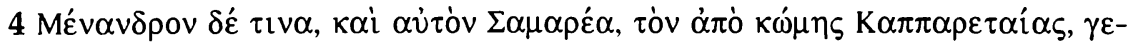

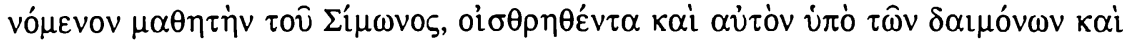

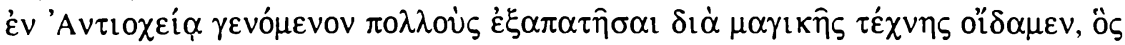

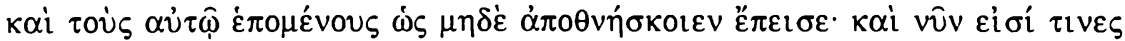

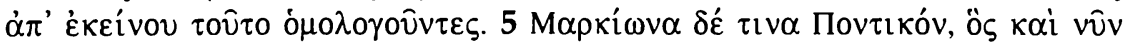

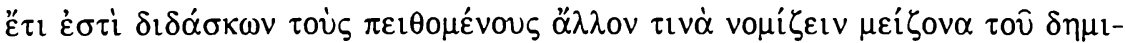

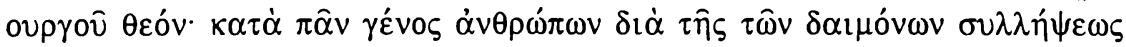

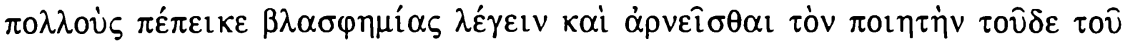

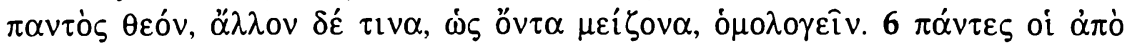

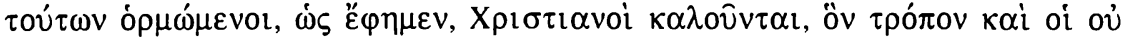

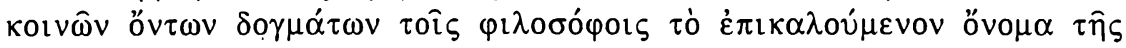

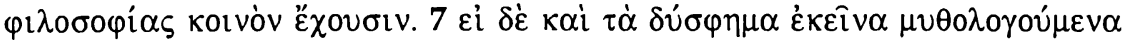

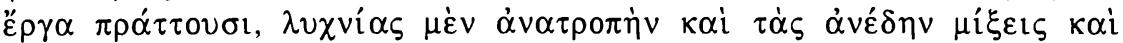

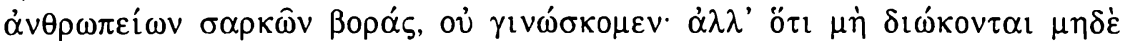

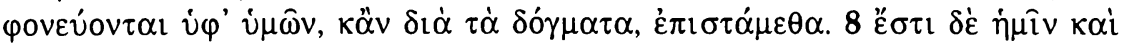

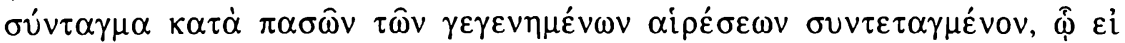

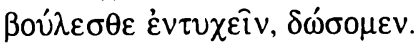

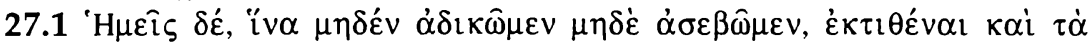

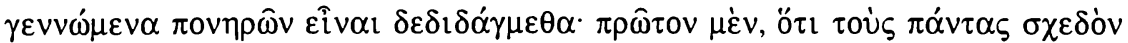

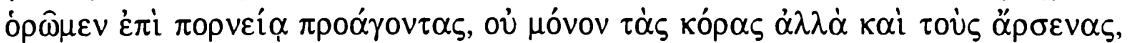

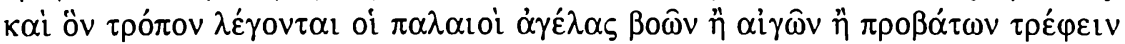

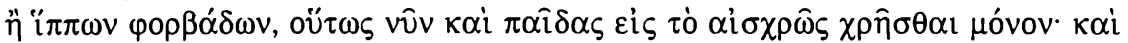

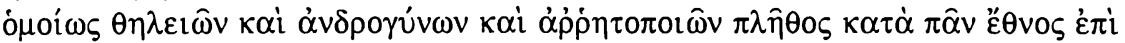

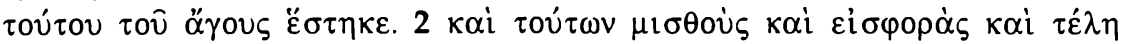

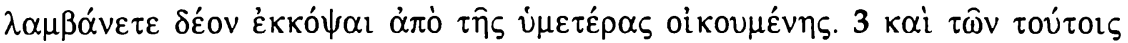

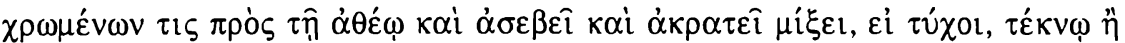

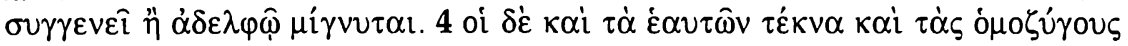

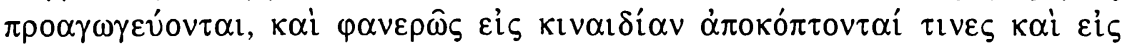

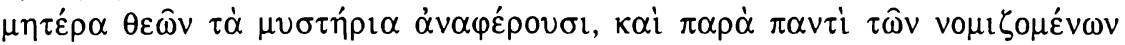

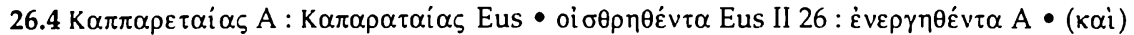

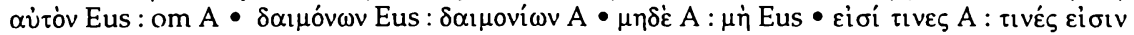

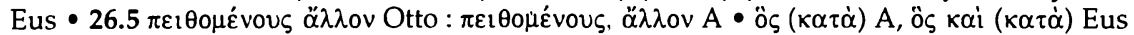

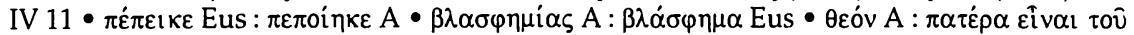

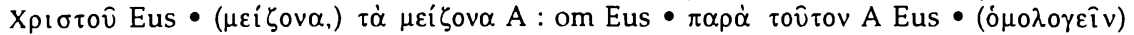

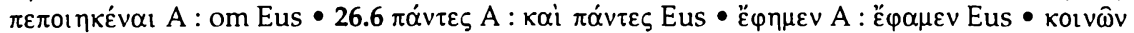

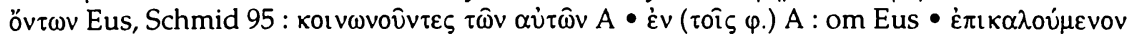

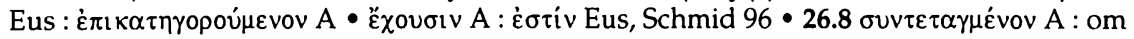
Eus

$27.1 \mu \eta \delta \dot{\varepsilon} v \dot{\alpha} \delta เ \kappa \hat{\omega} \mu \varepsilon v$ Stephan : $\mu \eta \delta \dot{\varepsilon} v \alpha \delta$ $\delta \omega \dot{\kappa} \omega \mu \varepsilon v \mathrm{~A}$

26.4 cf. Eusèbe, H.E. III,26,3; IV,7,3-4 • 26.5-6. 8 cf. Eusèbe H.E. IV,11,8-10 • 27.2 Suétone, Calig. 40-41; Dion Cassius, Hist.rom. 59,28 
4 Un certain Ménandre, lui aussi Samaritain, du bourg de Capparétée, qui fut disciple de Simon; aiguillonné lui aussi par les démons, il parut à Antioche et nous savons qu'il trompa beaucoup de gens par ses artifices magiques, au point de faire croire à ses adeptes qu'ils ne mourraient pas; encore aujourd'hui il y a de ses disciples qui professent cette croyance. 5 Un certain Marcion, originaire du Pont, qui encore aujourd'hui instruit ses sectateurs à croire qu'il existe un autre Dieu, supérieur au Créateur; avec l'assistance des démons il a mené un grand nombre de gens, à travers le monde entier, à proférer des blasphèmes et à renier le Dieu créateur de cet univers, pour confesser un autre Dieu, comme lui étant supérieur. 6 Tous ceux qui se réclament de ces gens là sont, comme nous l'avons dit, appelés chrétiens, de même que, malgré les différences de leurs doctrines, le nom de philosophes est attribué en commun à ceux qui font profession de philosophie. 7 Commettent-ils les infamies que l'on affabule, renversement du lucernaire, accouplements au hasard, repas de chair humaine, nous l'ignorons, mais ce que nous savons bien, c'est qu'ils ne sont ni poursuivis par vous, ni mis à mort, du moins à cause de leurs doctrines. $8 \mathrm{Du}$ reste, nous avons composé un Traité contre toutes les hérésies; si vous voulez le lire, nous vous le ferons tenir.

27.1 Quant à nous, afin de nous abstenir de toute injustice et de toute impiété, nous avons appris qu'il est criminel d'exposer les nouveau-nés, d'abord parce que nous voyons que presque tous, non seulement les filles mais aussi les garçons, s'avancent sur le chemin de la prostitution. Et de même que les Anciens, à ce que l'on dit, élevaient des troupeaux de bœufs, de chèvres, de moutons ou de chevaux, ainsi, de nos jours, on élève des enfants, uniquement pour les vouer à la débauche; de même on trouve dans toutes les nations quantité de femmes, d'androgynes et de débauchés, destinés à ce commerce. 2 Or vous percevez sur ces gens-là des rémunérations, des impôts et des taxes, alors qu'il faudrait les extirper de votre empire. 3 De plus, parmi ceux qui abusent de ces malheureux, outre le fait que ces unions sont sacrilèges, impies et abjectes, peut-être s'en trouve-t-il qui abusent d'un enfant, d'un parent, d'un frère. 4 Certains vont jusqu'à prostituer leurs propres enfants et leurs épouses, d'autres se font mutiler publiquement à des fins de débauche, et ils font remonter l'origine de ces mystères à la mère des dieux; de plus, à chacun 


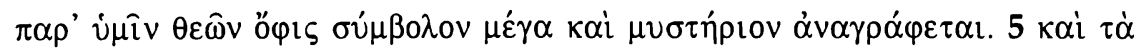

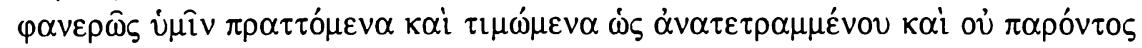

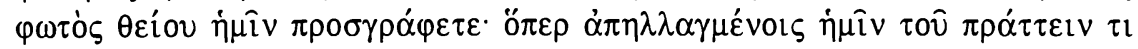

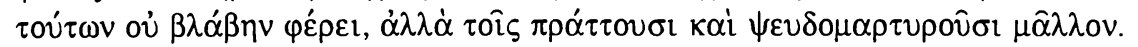

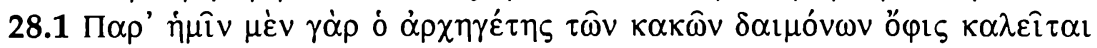

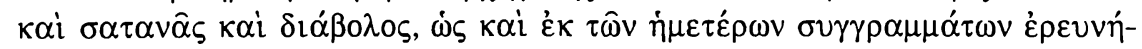

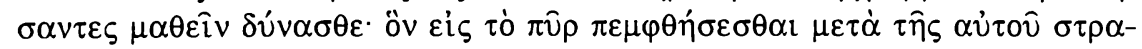

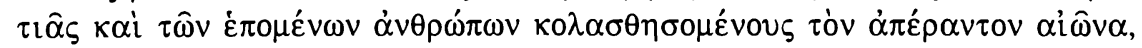

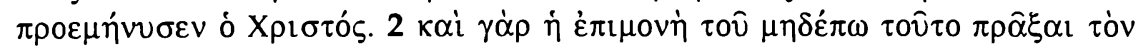

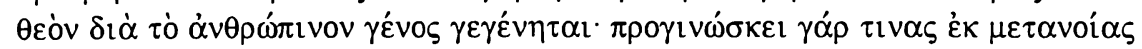

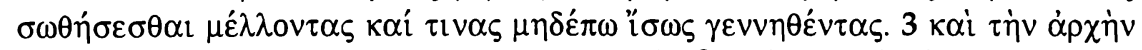

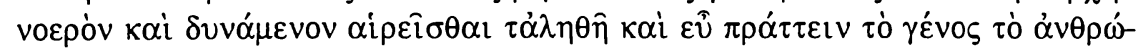

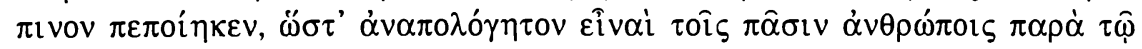

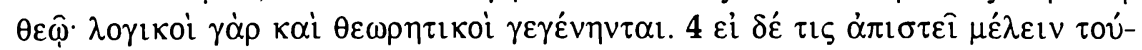

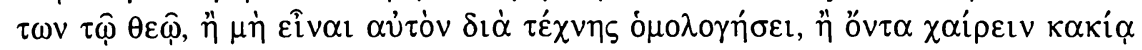

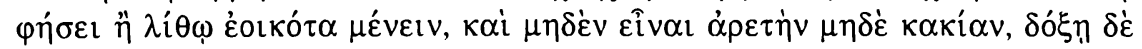

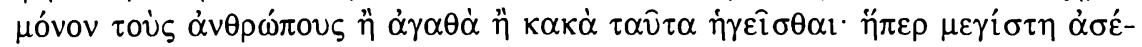

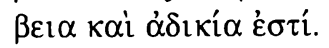

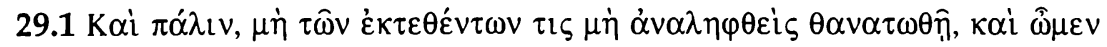

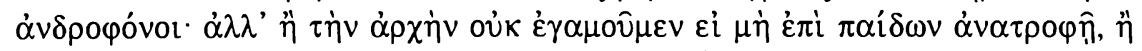

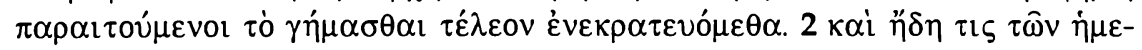

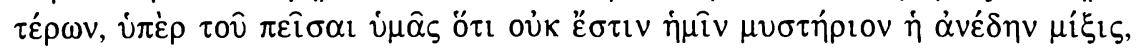

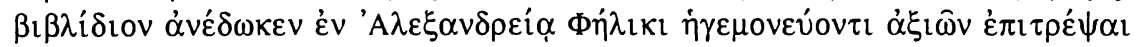

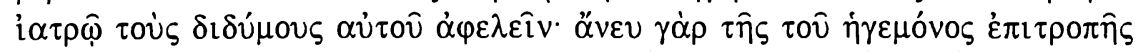

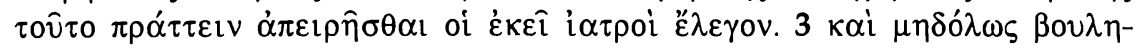

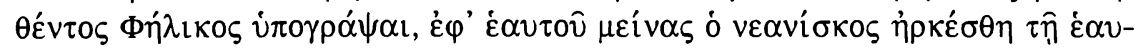

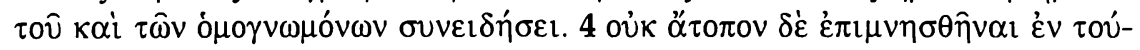

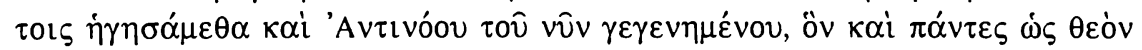

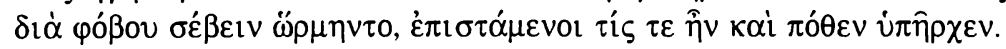

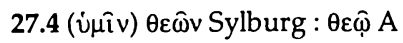

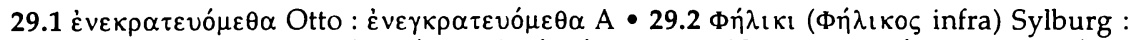

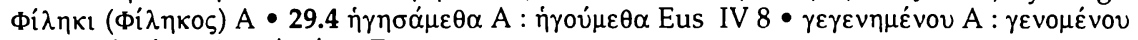

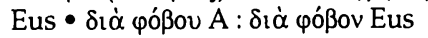

27.4 cf. Aristide, Apol. 11,5; Tatien, Or. 8,3 • 29.4 cf. Eusèbe, H.E. IV,8,3. - Antinoüs: cf. Hist.Aug., Hadr. 13-14; Dion Cassius, Hist.rom. 69,11 
de ceux que vous tenez pour des dieux vous adjoignez le serpent comme un symbole éminent et mystérieux. 5 Or, les actes que vous commettez au grand jour et dont vous vous faites honneur, après avoir renversé et éteint toute lumière divine, vous nous le imputez. Mais cette accusation ne nous cause aucun tort, car nous sommes bien loin de commettre quoi que ce soit de ce genre; tout au contraire elle retombe plutôt sur ceux qui agissent ainsi et rendent de faux témoignages.

28.1 Chez nous, c'est le chef des mauvais démons qui est appelé serpent, Satan, diable, comme vous pouvez l'apprendre en consultant nos écrits. Il sera jeté au feu avec son armée et les hommes qui le suivent, pour y subir un châtiment éternel: ainsi l'a prédit le Christ. 2 Si Dieu diffère ce châtiment, c'est dans l'intérêt du genre humain, car il sait d'avance que certains doivent être sauvés par la pénitence et que d'autres (qui doivent être sauvés) ne sont probablement pas encore nés. 3 A l'origine il a créé le genre humain intelligent et capable de choisir le vrai et de faire le bien, de sorte qu'il n'y a d'excuse pour personne devant Dieu, car les hommes sont nés doués de raison et d'entendement. 4 Mais si quelqu'un prétend que Dieu ne se soucie pas des hommes, il lui faudra soit admettre indirectement que Dieu n'existe pas, soit affirmer que, s'il existe, il prend plaisir au mal ou demeure insensible comme une pierre, que ni le bien ni le mal n'ont de consistance et que c'est seulement dans leur opinion que les hommes distinguent entre le bien et le mal, or, c'est bien là le comble de l'impiété et de l'iniquité.

29.1 Par ailleurs nous craignons que, faute d'être recueilli, l'un (des enfants) qui ont été exposés ne vienne à mourir et qu'ainsi nous ne nous rendions coupables d'homicide. Au contraire, ou bien nos mariages n'avaient absolument pas d'autre fin que d'élever nos enfants, ou bien, si nous renoncions au mariage, nous observions une chasteté parfaite. 2 Afin de vous convaincre que les unions licencieuses ne constituent pas nos mystères, l'un des nôtres a présenté naguère une supplique à Félix, gouverneur d'Alexandrie, pour lui demander l'autorisation de se faire castrer par un médecin, car les médecins du lieu prétendaient qu'il leur était interdit de pratiquer cette opération sans l'autorisation du gouverneur. $3 \mathrm{Et}$ comme Félix se refusa absolument à souscrire à cette requête, le jeune homme demeura célibataire, en paix avec sa conscience et avec celle des frères dans la foi. $4 \mathrm{~A}$ ce propos, il n'est pas déplacé, croyons-nous, de rappeler Antinoüs, qui vécut récemment et que tout le monde s'empressait, par crainte, de vénérer comme un dieu, alors que l'on savait bien qui il était et d'où il venait. 
30.1 “О

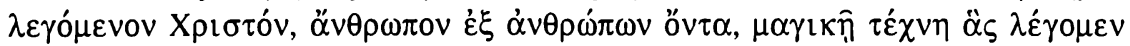

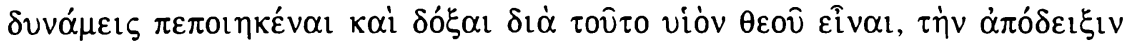

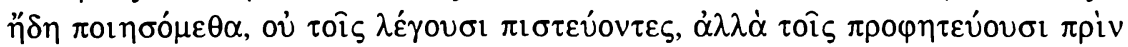

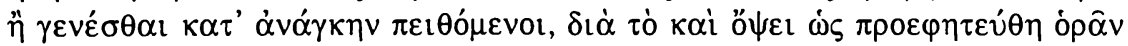

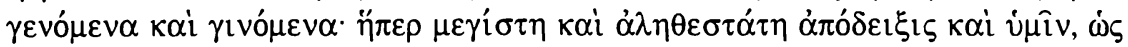

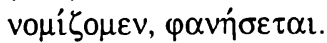

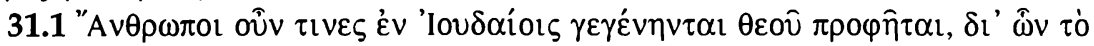

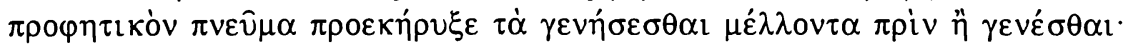

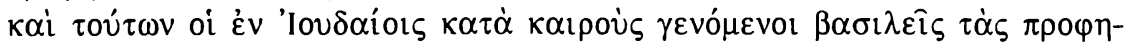

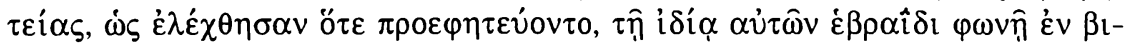

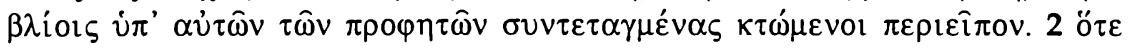

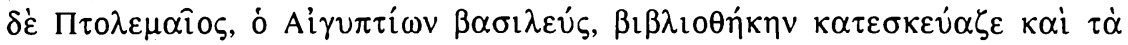

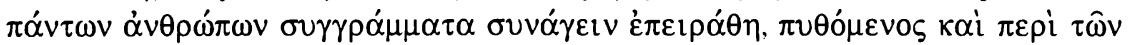

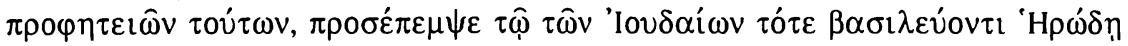

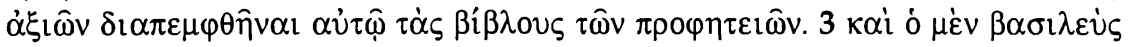

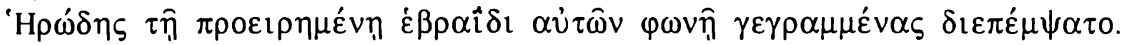

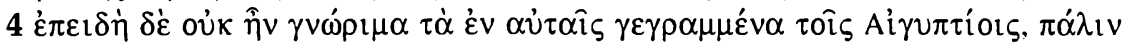

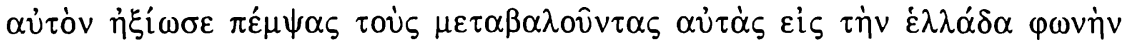

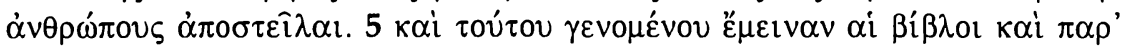

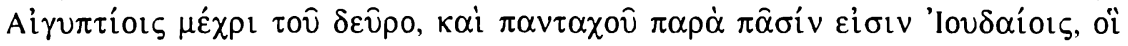

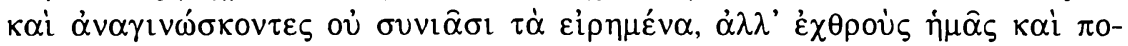

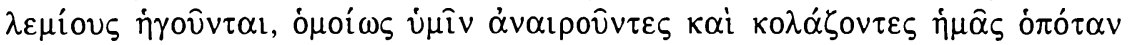

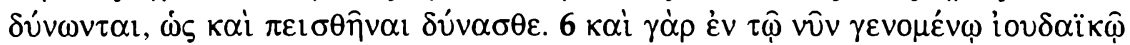

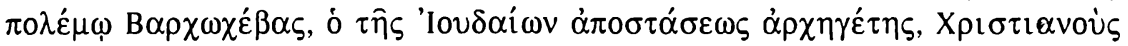

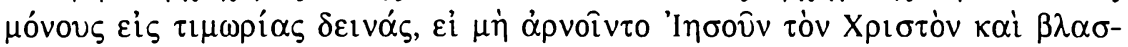

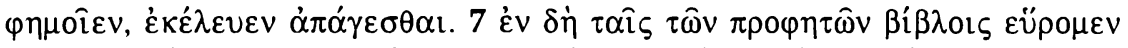

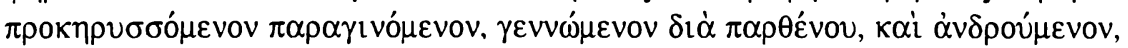

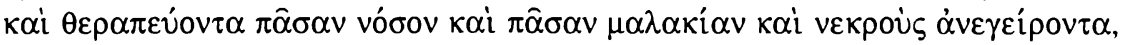

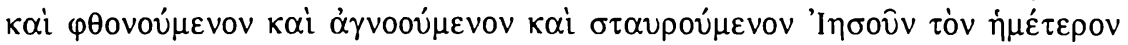

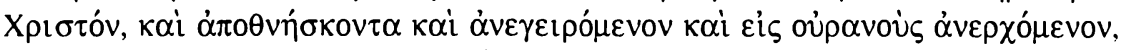

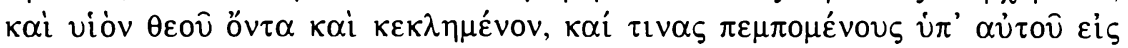

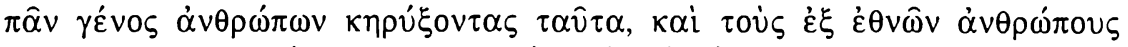

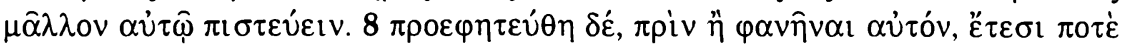

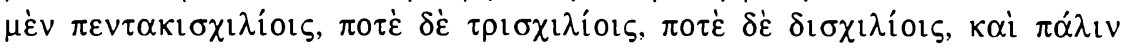

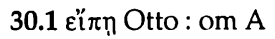

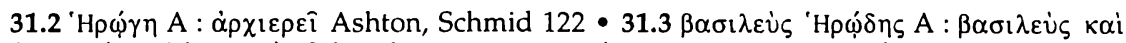

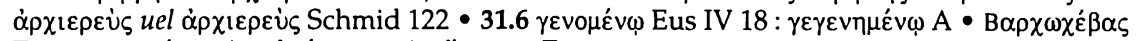

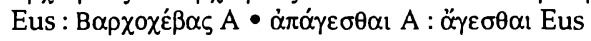

31.2-4 cf. Lettre d'Aristée, éd. A. Pelletier, SC 89 • 31.6 cf. Eusèbe, H.E. IV,8,4 
30.1 Mais pour que l'on ne vienne pas nous objecter que, celui que nous appelons Christ, rien n'empêche que, homme né d'un homme, il ait accompli par magie les prodiges que nous lui attribuons, et que pour cela l'on ait cru qu'il était fils de Dieu, nous allons maintenant effectuer la démonstration, sans nous appuyer sur des on-dit, mais sur la créance que l'on doit nécessairement à ceux qui annoncent les choses avant qu'elles n'aient lieu, car nous voyons de nos propres yeux que des événements se sont réalisés et se réalisent encore comme ils ont été prédits, c'est là la démonstration la plus convaincante et la plus véridique, qui vous apparaîtra à vous aussi comme telle, croyons-nous.

31.1 Il y eut donc chez les Juifs des hommes qui furent des prophètes de Dieu, par lesquels l'Esprit prophétique annonça par avance les événements à venir, avant leur réalisation; leurs prophéties furent recueillies et gardées soigneusement par les rois qui se succédèrent alors en Judée, telles qu'elles avaient été prononcées au moment de leur proclamation et telles qu'elles avaient été consignées par les prophètes eux-mêmes en des ouvrages rédigés en leur propre langue, en hébreu. 2 Mais lorsque Ptolémée, le roi d'Égypte, fonda une bibliothèque où il s'efforça de réunir les œuvres de tous les écrivains, ayant entendu parler aussi de ces prophéties, il fit demander au roi Hérode, qui régnait alors en Judée, de bien vouloir lui envoyer les livres des prophètes. 3 Le roi Hérode lui envoya ces écrits, rédigés, comme on l'a dit, en hébreu, leur langue originale. 4 Mais comme leur contenu était inintelligible aux Égyptiens, il lui adressa une nouvelle demande, en le priant de lui envoyer des gens capables de les traduire en grec. 5 Ceci fait, ces ouvrages sont conservés jusqu'à nos jours chez les Égyptiens; on les trouve aussi partout chez les Juifs, mais ceux-ci les lisent sans comprendre ce qui y est dit. Au contraire ils nous tiennent pour leurs adversaires et leurs ennemis et, comme vous, ils cherchent à nous mettre à mort ou à nous maltraiter, chaque fois qu'ils en ont la possibilité, ainsi que vous pouvez vous en convaincre. 6 En effet, dans la récente guerre juive, Barkocheba, le chef de la révolte des Juifs, faisait livrer aux plus cruels supplices les chrétiens et eux seuls, s'ils refusaient de renier et de blasphèmer Jésus-Christ. 7 Et pourtant, c'est dans les livres des prophètes que nous avons trouvé annoncé d'avance que Jésus, notre Christ, doit venir, qu'il doit naître d'une vierge, parvenir à l'âge d'homme, guérir toute maladie et toute infirmité, ressusciter des morts, être haï, méconnu, et mis en croix, mourir, être ressuscité et monter au ciel, qu'il est fils de Dieu et a reçu ce nom, que des messagers envoyés par lui à toutes les races d'hommes proclameront cette nouvelle et que ce sont surtout les hommes venus des nations paiennes qui doivent croire en lui. $8 \mathrm{Ces}$ prophéties furent faites avant qu'il ne parût, cinq mille, trois mille, 


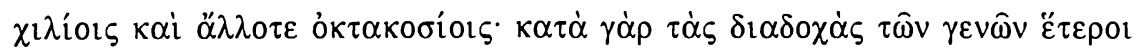

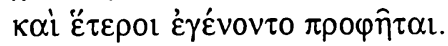

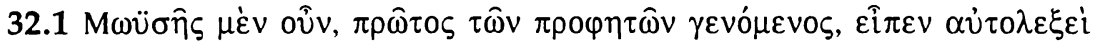

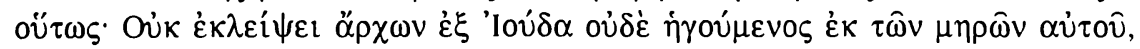

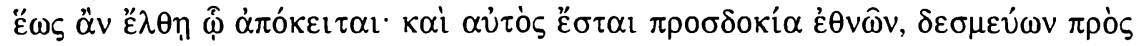

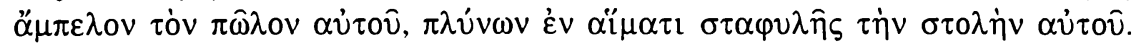

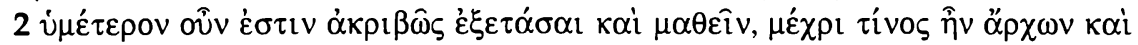

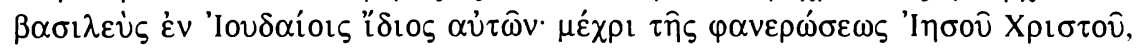

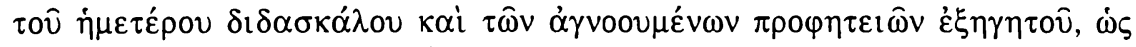

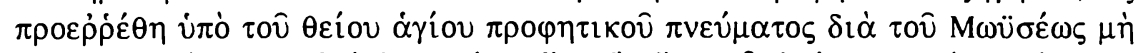

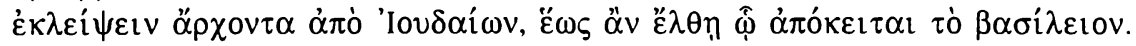

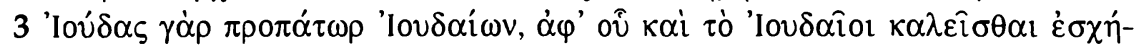

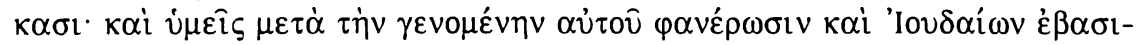

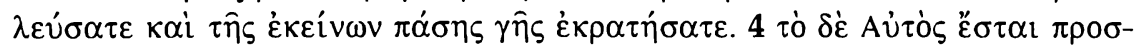

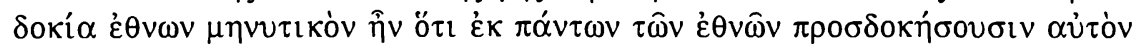

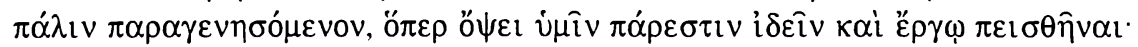

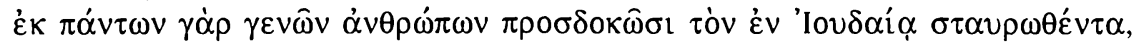

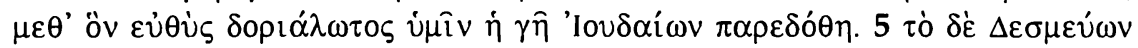

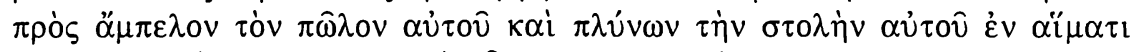

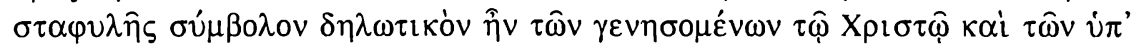

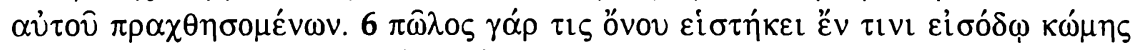

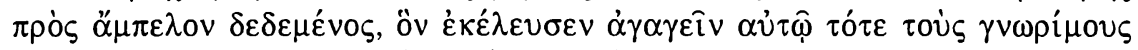

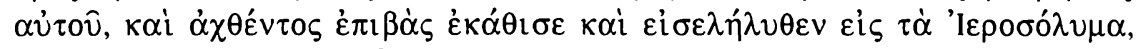

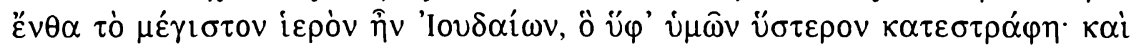

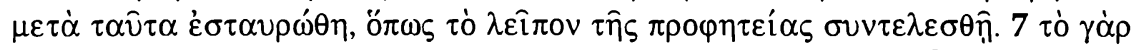

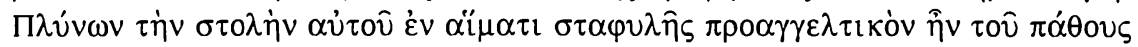

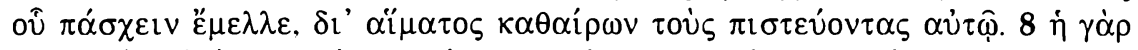

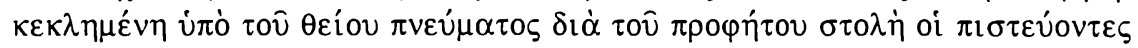

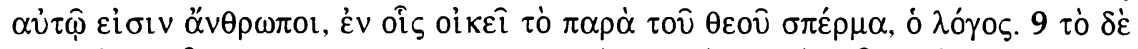

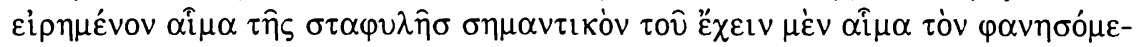

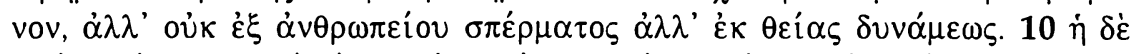

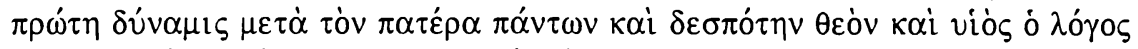

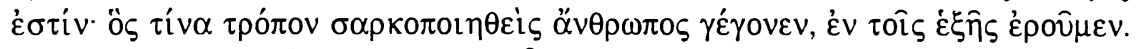

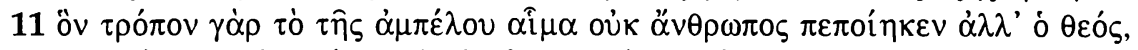

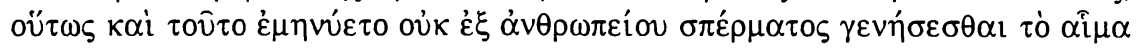

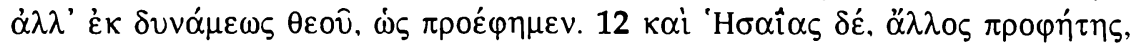

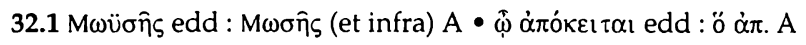


deux mille, mille ou huit cents ans auparavant; de fait, à mesure que se succédèrent les générations, toujours surgirent de nouveaux prophètes.

32.1 Moïse, le premier des prophètes, déclare expressément: "Il ne manquera pas de roi de la descendance de Juda, ni de chef de sa race, jusqu'à ce que vienne celui à qui est réservé <le royaume>; il sera l'attente des nations, attachera son poulain à une vigne et lavera sa robe dans le sang de la grappe". 2 Il vous appartient donc d'examiner soigneusement et de reconnaître jusques à quand les Juifs eurent un chef et un roi de leur nation; ce fut le cas jusqu'à l'apparition de Jésus-Christ, notre Maître et l'interprète des prophéties méconnues d'après lesquelles l'Esprit divin, saint, prophétique a prédit par la bouche de Moïse que le sceptre ne sortirait pas de Juda, jusqu'à ce que vînt celui à qui est réservé le royaume. 3 De fait, Juda est l'ancêtre des Juifs et c'est à lui qu'ils doivent d'être appelés Juifs. Or, après la manifestation du Christ, vous avez établi votre règne sur les Juifs et pris possession de tout leur territoire. 4 Quant à la parole: "Il sera l'attente des nations", elle signifiait que des hommes de toutes les nations attendraient son second avènement; c'est ce que vous pouvez voir de vos propres yeux, un fait dont vous pouvez vous convaincre, car des gens de toutes les nations on attend l'avènement de celui qui fut crucifié en Judée et dont la mort fut suivie de près par la conquête par les armes que vous avez faite du pays des Juifs. 5 La parole: "Il attachera son poulain à une vigne et lavera sa robe dans le sang de la grappe", signifiait symboliquement ce qui devait arriver au Christ et ce qu'il devait réaliser lui-même. 6 En effet, il y avait à l'entrée d'un village un ânon attaché à une vigne; il ordonna à ses disciples de le lui amener; quand on le lui eut amené, il s'assit dessus et fit son entrée à Jérusalem, où se trouvait le grand temple des Juifs, que vous avez détruit par la suite. Après cela il fut crucifié, et ainsi fut accompli le reste de la prophétie. 7 En effet, la parole: "Il lavera sa robe dans le sang de la grappe", annonçait par avance la passion qu'il devait soufrir, afin de purifier dans son sang ceux qui croient en lui. 8 Car la robe dont parle l'Esprit divin par la bouche du prophète, ce sont les hommes qui croient en lui, dans lesquels habite la semence qui vient de Dieu, le Logos. 9 L'expression: le sang de la grappe, signifie que celui qui devait se manifester aurait du sang provenant non point d'une semence humaine mais d'une puissance divine. $10 \mathrm{Or}$, la première puissance, après Dieu le Père et le Maître de l'univers, c'est le Logos, qui est aussi son Fils; de quelle manière, fait chair, il est devenu homme, nous le dirons dans la suite. 11 Car de même que ce n'est pas l'homme mais Dieu qui a fait le sang de la grappe, de même il était révélé que le sang du Christ tirerait son origine non d'une semence humaine, mais d'une puissance divine, comme nous l'avons dit. 12 Un 


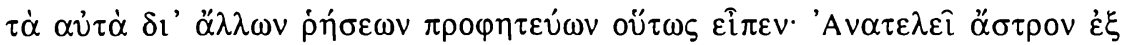

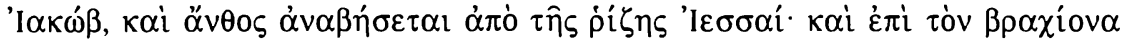

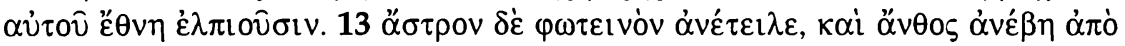

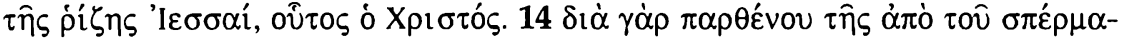

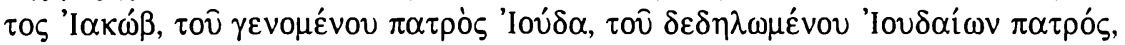

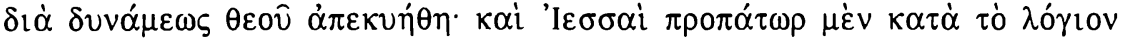

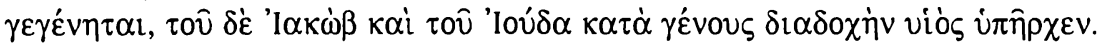

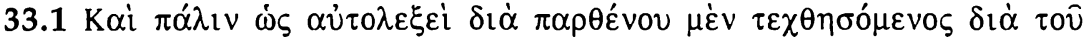

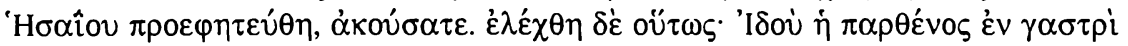

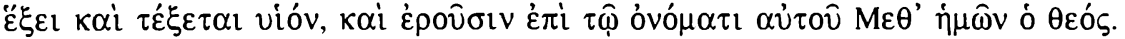

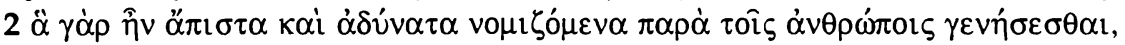

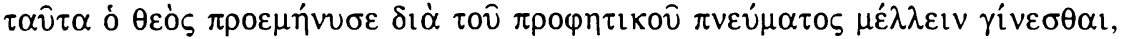

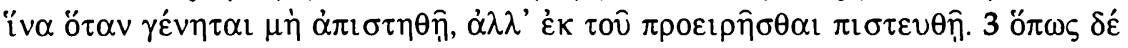

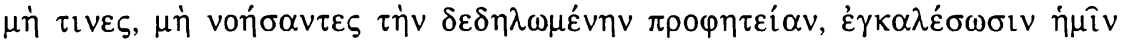

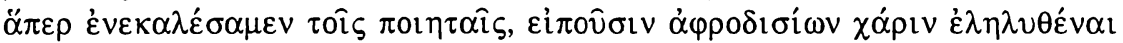

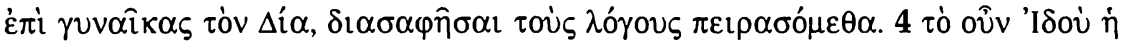

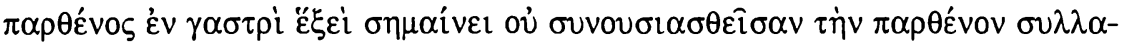

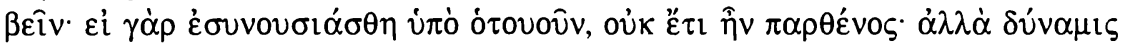

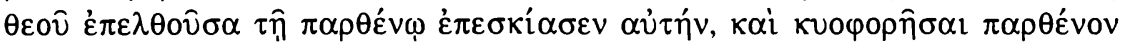

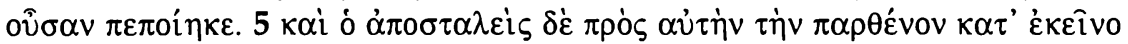

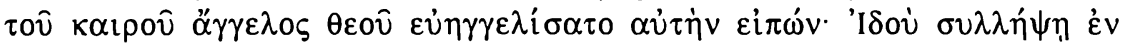

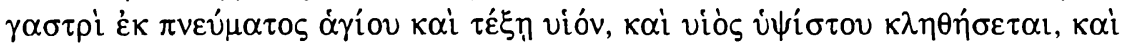

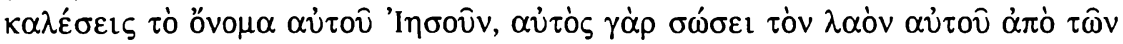

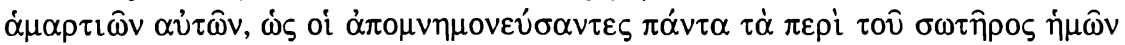

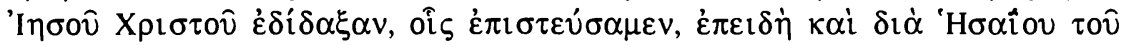

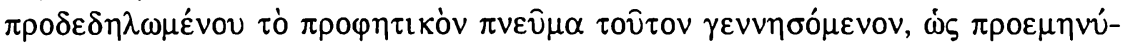

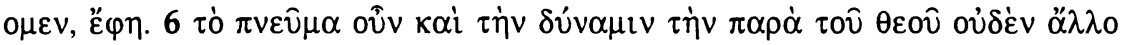

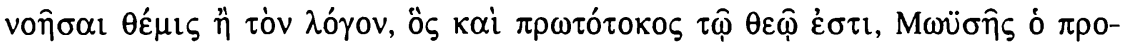

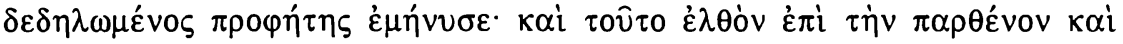

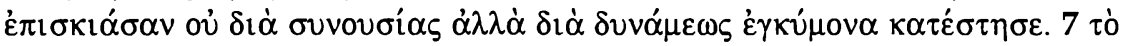

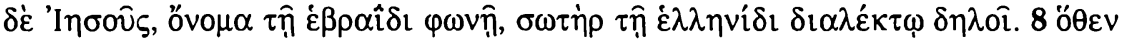

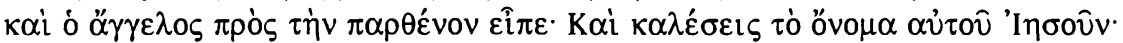

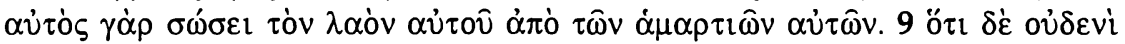

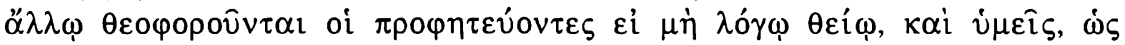
$\dot{v} \pi 0 \lambda \alpha \mu \beta \alpha \dot{\alpha} \omega \omega, \varphi \eta \dot{\sigma \varepsilon \tau \varepsilon . ~}$

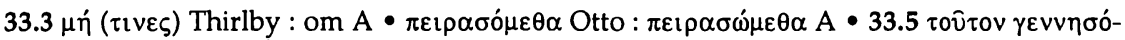

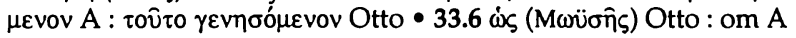


autre prophète, Isaïe, a fait la même annonce prophétique en d'autres termes: "Une étoile se lèvera de Jacob, dit-il, et une fleur poussera sur la racine de Jessé, et les nations espéreront en son bras". 13 Un astre lumineux s'est levé et une fleur a poussé sur la racine de Jessé; c'est le Christ. 14 Car il est né, par une puissance de Dieu, d'une vierge de la race de Jacob, le père de Juda, qui fut l'ancêtre des Juifs, comme nous l'avons montré; Jessé aussi, selon cet oracle, fut un ancêtre du Christ, lui qui fut fils de Jacob et de Juda selon la succession de leur descendance.

33.1 Ecoutez encore comment Isaïe a prophétisé expressément que le Christ naîtrait d'une vierge. Il s'exprime en ces termes: "Voici que la vierge sera enceinte et enfantera un fils et on dira à propos de son nom: Dieu avec nous". 2 En effet, des choses qui paraissaient incroyable et impossibles aux yeux des hommes, Dieu a révélé d'avance par son Esprit prophétique qu'elles se réaliseraient, afin qu'à leur réalisation on ne refusât pas de les croire mais qu'on les crût, pour avoir été prédites. 3 Mais pour éviter que certains, n'ayant pas compris la prophétie qui vient d'être évoquée, ne nous reprochent ce que précisément nous avons reproché aux poètes qui racontent les aventures amoureuses de Zeus avec des femmes, nous allons essayer d'expliquer ces paroles. 4 Les mots: "Voici que la vierge sera enceinte" signifient que la vierge a conçu sans relations charnelles; si, en effet, elle avait eu des relations charnelles avec qui que ce soit, elle ne serait plus vierge. Au contraire, une puissance de Dieu, descendant sur la vierge, l'a prise sous son ombre et l'a fait concevoir sans porter atteinte à sa virginité. 5 Or, l'ange de Dieu, envoyé à la vierge en ce temps-là, lui annonça la bonne nouvelle en ces termes: "Voici que tu concevras de l'Esprit Saint et tu enfanteras un fils; il sera appelé le Fils du Très-Haut, tu lui donneras le nom de Jésus, car c'est lui qui sauvera son peuple de ses péchés". C'est là ce que nous avons appris de ceux qui ont consigné par écrit tout ce qui concerne notre sauveur Jésus-Christ; nous les croyons parce que, comme nous l'avons dit, l'Esprit prophétique a annoncé sa future naissance par la bouche d'Isaïe, mentionné plus haut. 6 Par l'Esprit et la puissance venue d'auprès de Dieu, il n'est pas permis d'entendre rien d'autre que le Logos, qui est aussi le Premier-né de Dieu; Moïse, le prophète mentionné plus haut, l'a révélé, et lorsque cet Esprit, survint sur la vierge, et la couvrit de son ombre, il la fit concevoir, non par union charnelle, mais par l'effet de sa puissance. 7 Jésus est un nom hébreu, qui signifie en grec, Sôter, sauveur. 8 C'est pourquoi l'ange dit à la vierge: "Tu lui donneras le nom de Jésus, car c'est lui qui sauvera son peuple de ses péchés". 9 Que les prophètes ne reçoivent d'inspiration que d'un logos divin, et de nul autre, vous aussi vous l'admettrez, je suppose. 


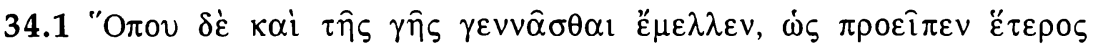

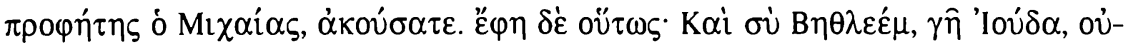

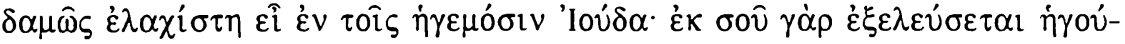

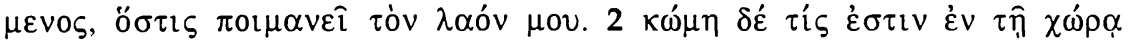

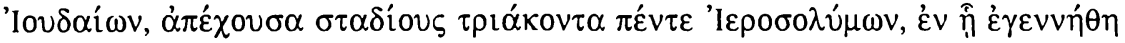

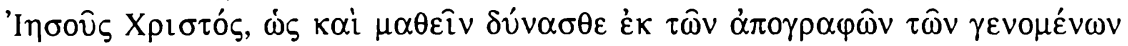

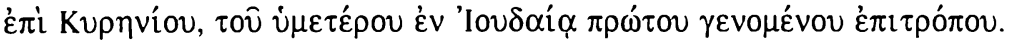

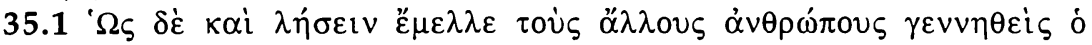

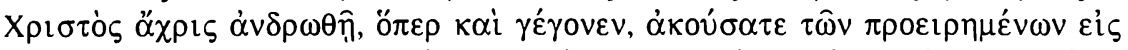

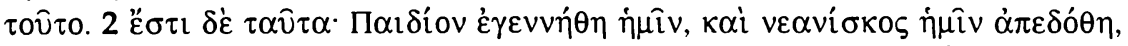

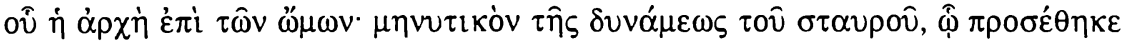

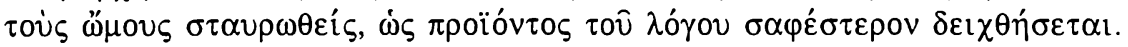

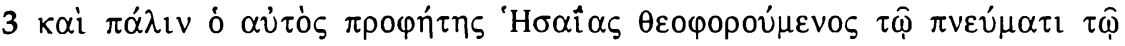

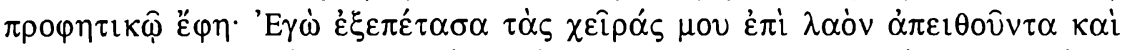

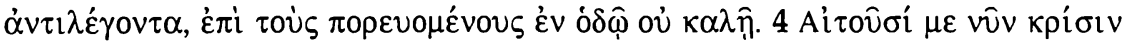

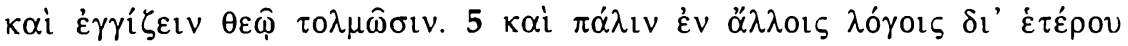

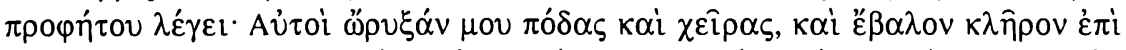

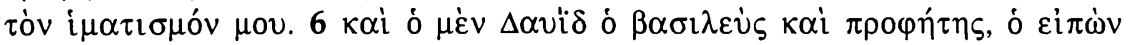

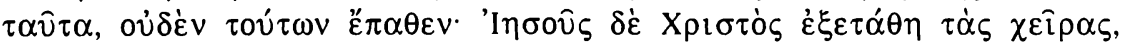

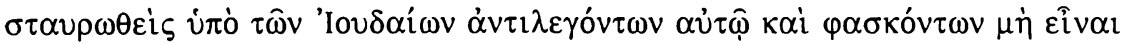

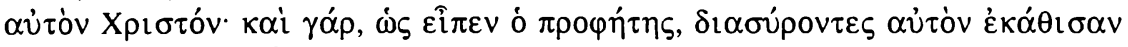

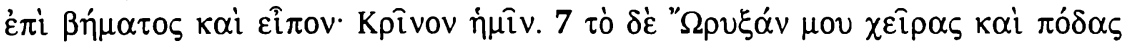

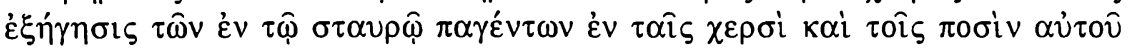

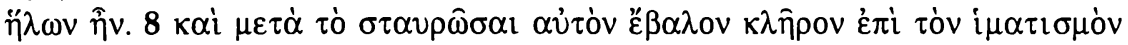

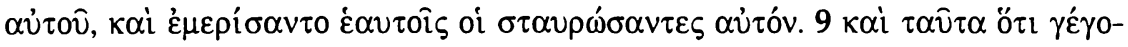

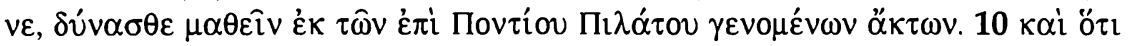

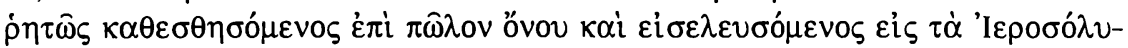

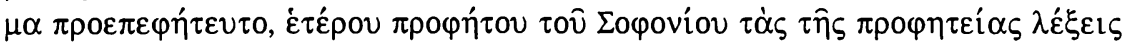

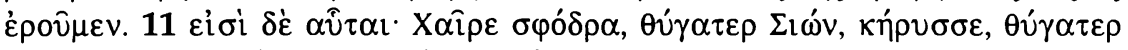

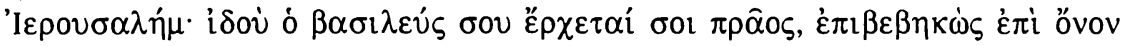

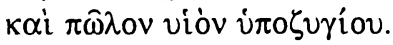

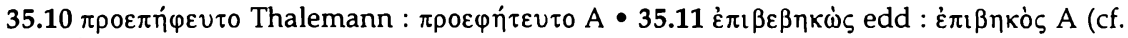
Pilhofer 241)

35.6 Evangile de Pierre 6-7 
34.1 Ecoutez encore comment le lieu de sa naissance fut prédit par Michée, un autre prophète. Il a parlé ainsi: "Et toi, Bethléem, terre de Juda, tu n'es certes pas la moindre parmi les principales cités de Juda, car de toi sortira un chef qui paîtra mon peuple". $2<$ Bethléem> est un bourg de Judée, à trente-cinq stades de Jérusalem; c'est là qu'est né Jésus-Christ, comme vous pouvez vous en assurer d'après les registres du recensement établis au temps de Quirinius,votre premier procurateur en Judée.

35.1 Le Christ devait rester inconnu aux autres hommes depuis sa naissance jusqu'à l'âge viril, ce qui est arrivé en effet; écoutez ce qui avait été prédit à ce sujet. 2 En voici les paroles: "Un petit enfant nous est né, un jeune homme nous a été donné, son pouvoir repose sur ses épaules"; ceci indique la puissance de la croix, sur laquelle il appliqua ses épaules quand il fut crucifié, comme on le montrera plus clairement dans la suite de ce discours. 3 Le même prophète Isaïe, inspiré par l'Esprit prophétique, dit encore: "J'ai tendu les mains vers un peuple incrédule et contradicteur, vers ceux qui s'avançaient sur une voie mauvaise. Ils me demandent maintenant de juger et ont l'audace de s'approcher de Dieu". 5 Et encore, dans un autre passage, il dit, par la bouche d'un autre prophète: "Ils ont percé mes pieds et mes mains; ils ont tiré au sort mes vêtements". 6 Or, David, le roi-prophète, qui a dit ces paroles, n'a rien souffert de cela, mais c'est Jésus-Christ qui a tendu ses mains lorsqu'il fut crucifié par les Juifs, qui le contredisaient et prétendaient qu'il n'était pas le Christ; en effet, comme l'avait annoncé le prophète, pour le tourner en dérision ils le firent asseoir sur un trône, et lui dirent: "Juge-nous". 7 Cette parole: "Ils ont percé mes mains et mes pieds" signifiait que, sur la croix, ses mains et ses pieds seraient percés de clous. 8 Et après l'avoir crucifié, ils tirèrent au sort ses vêtements et ceux qui l'avaient crucifié se les partagèrent. 9 Qu'il en fut bien ainsi, vous pouvez vous en assurer en lisant les Actes rédigés sous Ponce-Pilate. 10 De plus, il avait été annoncé littéralement qu'il serait assis sur un ânon pour faire son entrée à Jérusalem; nous citerons à ce propos les paroles prophétiques de Sophonie, un autre prophète. 11 Les voici: "Exulte de joie, fille de Sion; publie-le à haute voix, fille de Jérusalem. Voici ton roi qui vient à toi, plein de douceur, monté sur un âne et sur un ânon, le petit de celle qui porte le joug".

34.1 Mi 5,1; Mt 2,6 35.2 Is 9,5 - 35.3 Is 65,$2 ; 58,2 \bullet 35.5$ Ps 22,$17 ; 22,19 \bullet 35.7$ Ps $22,17 \bullet$

35.8 Ps 22,19 


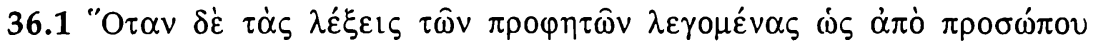

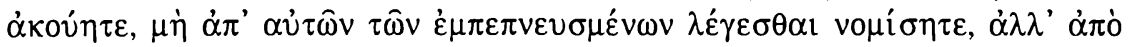

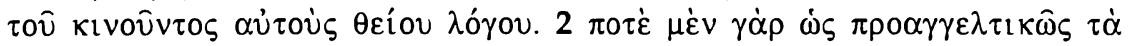

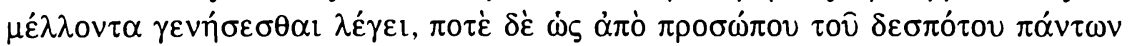

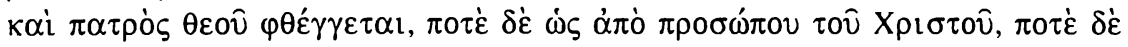

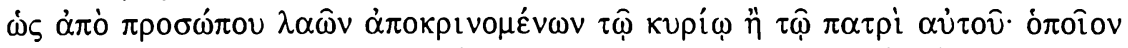

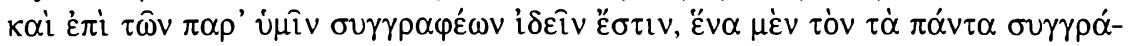

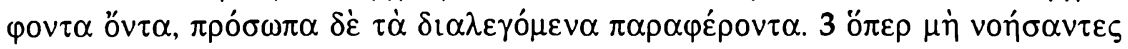

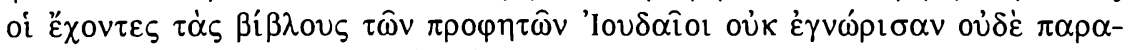

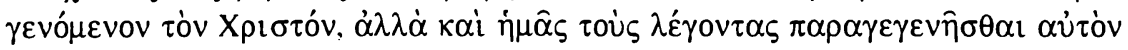

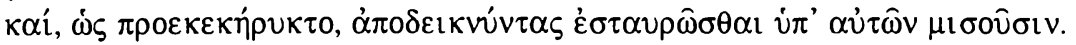

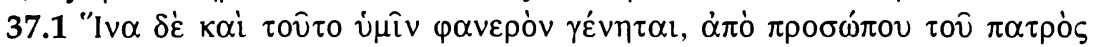

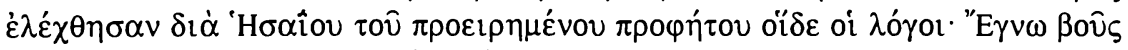

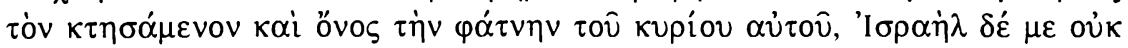

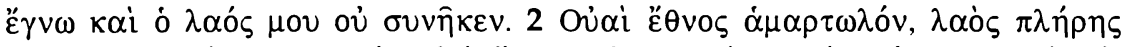

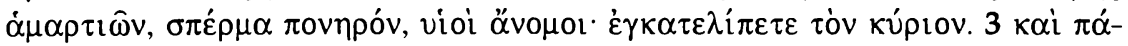

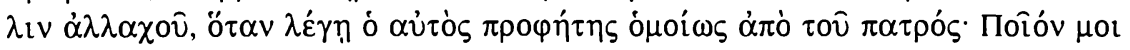

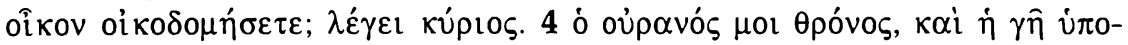

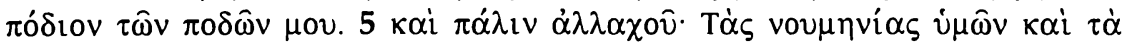

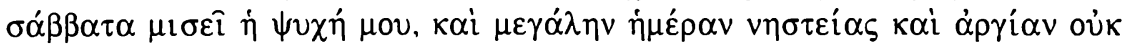

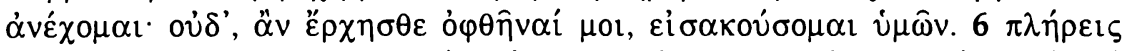

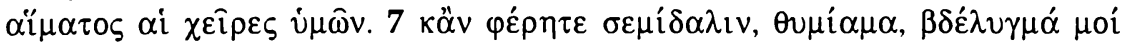

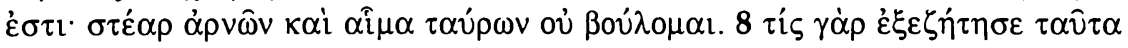

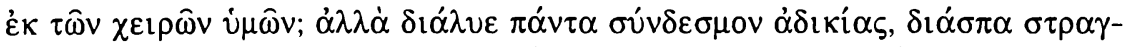

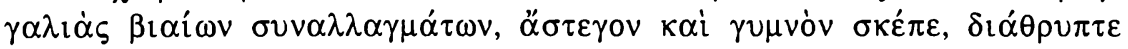

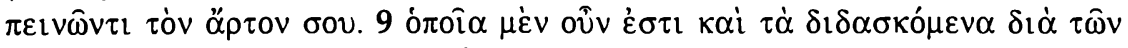

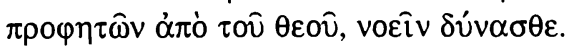

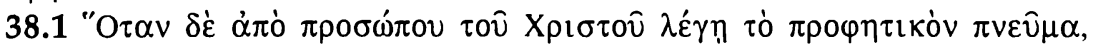

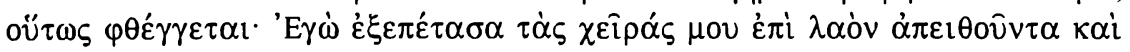

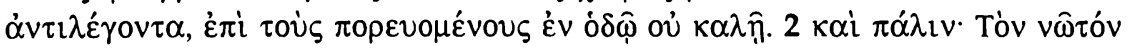

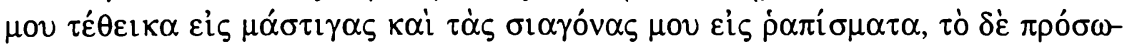

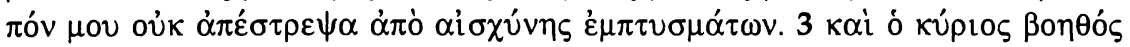

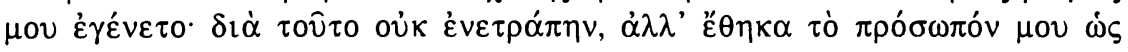

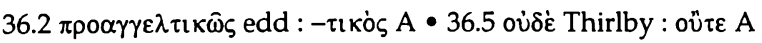

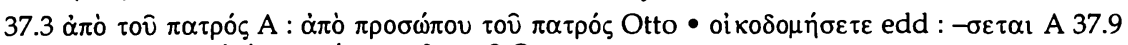

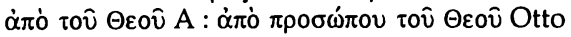


36.1 Quand vous entendez les paroles des prophètes exprimées comme si elles étaient dites au nom de quelque autre personnage, n'allez pas croire qu'elles viennent de ces hommes inspirés, elles viennent du Logos divin, qui les met en mouvement. 2 Parfois, en effet, celui-ci annonce les événements à venir comme par manière de prédiction, parfois il s'exprime comme s'il parlait au nom même de Dieu, le maître et le père de l'univers, ou encore au nom du Christ ou au nom des peuples qui répondent au Seigneur ou à son père. Vous pouvez constater quelque chose d'analogue chez vos écrivains: c'est un même auteur qui rédige l'œuvre entière mais il met en scène divers personnages qui dialoguent. 3 Parce que les Juifs, qui ont en mains les livres des prophètes, n'ont pas compris cela, ils n'ont pas reconnu le Christ, même après sa venue; mais ils nous poursuivent de leur haine, parce que nous affirmons qu'il est déjà venu et parce que nous prouvons qu'il a été crucifié par eux, comme cela avait été annoncé d'avance.

37.1 Afin que ce point aussi vous apparaisse clairement, voici les paroles qui ont été dites au nom du Père par la bouche du prophète Isaïe, mentionné plus haut. "Le bœuf connaît son possesseur et l'âne l'étable de son maître, mais Israël ne m'a pas connu et mon peuple ne m'a pas compris. 2 Malheur à toi, nation pécheresse, peuple rempli de crimes, race perverse, fils sans loi, vous avez abandonné le Seigneur". 3 Et ailleurs, dans un autre passage où le même prophète s'exprime pareillement au nom du Père: "Quelle maison voulez-vous me bâtir, dit le Seigneur. 4 Le ciel est mon trône et la terre l'escabeau de mes pieds". 5 Et ailleurs encore: "Vos néoménies et vos sabbats, mon âme les déteste; votre grand jour de jeûne et votre oisiveté, je ne puis les supporter, et même si vous venez pour paraître devant moi, je ne vous écouterai pas. 6 Vos mains sont pleines de sang. 7 Et même si vous m'apportez de la fleur de farine de froment ou de l'encens, c'est pour moi une abomination; la graisse des agneaux et le sang des taureaux, je n'en veux pas. 8 Car qui a exigé ces offrandes de vos mains? Par contre, délie tout lien d'iniquité, brise les chaînes des contrats fondés sur la violence; abrite celui qui est sans toit et couvre celui qui est nu; partage ton pain avec celui qui a faim". 9 Vous pouvez juger par là de quelle nature sont les enseignements donnés au nom du Père par la bouche des prophètes.

38.1 Lorsque l'Esprit prophètique parle en la personne du Christ, il s'exprime ainsi: "J'ai tenu les mains vers un peuple incrédule et contradicteur, vers ceux qui s'avançaient sur une voie mauvaise". 2 Et encore: "J'ai présenté mon dos aux fouets et mes joues aux soufflets, je n'ai pas détourné ma face de l'affront des crachats. 3 Le Seigneur s'est fait mon appui; c'est pourquoi je n'ai pas été confondu, mais j'ai rendu mon visage

37.1 Is $1,3-4 \cdot 37.3$ Is $66,1 \bullet 37.5$ Is $1,11-15 ; 58,6-7 \bullet 37.8$ Is $58,7 \bullet 38.1$ Is 58,$2 ; 65,2 \bullet \mathbf{3 8 . 2}$ Is $50,6-8$ 


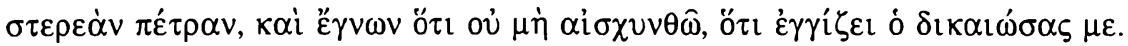

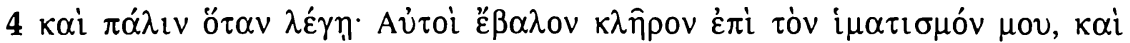

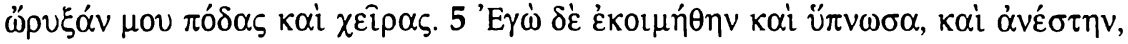

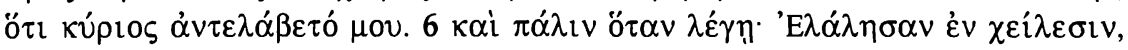

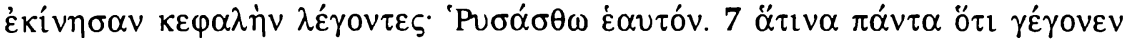

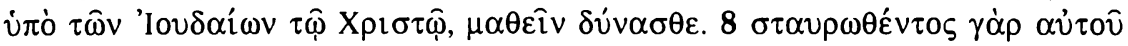

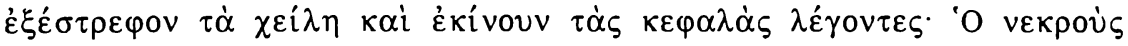

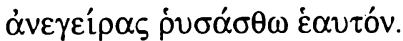

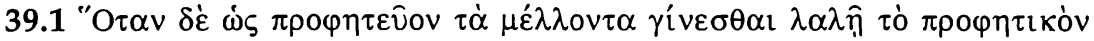

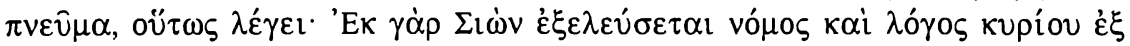

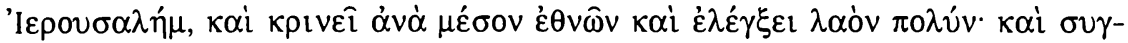

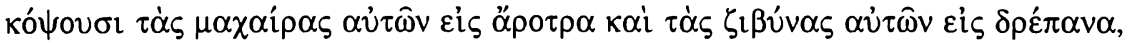

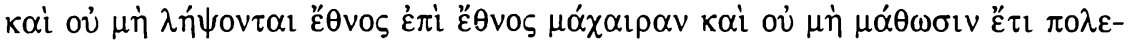

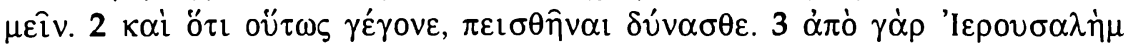

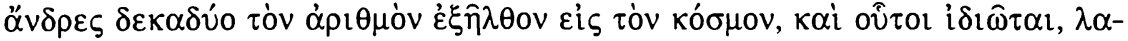

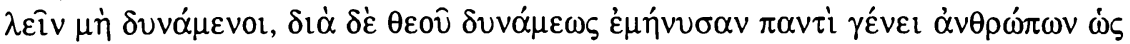

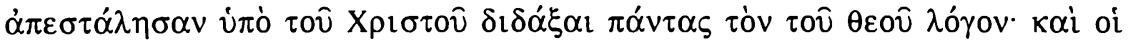

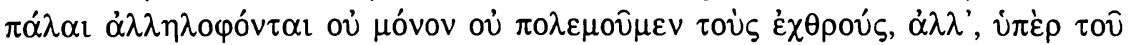

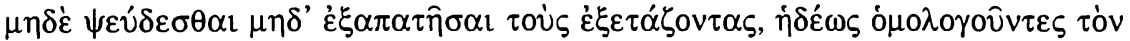

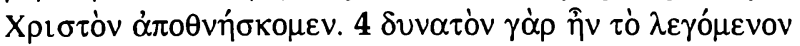

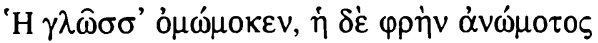

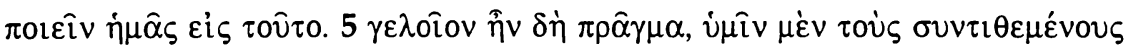

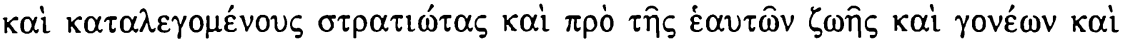

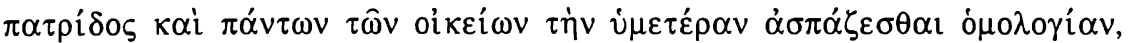

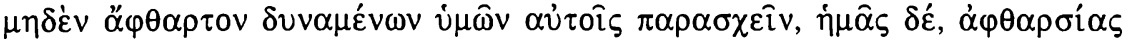

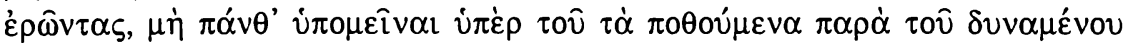
$\delta$ ธิv $\alpha \mathrm{l} \lambda \alpha \beta \varepsilon \hat{\varepsilon} v$.

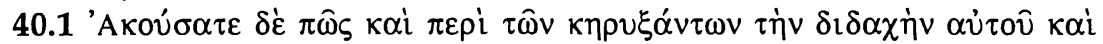

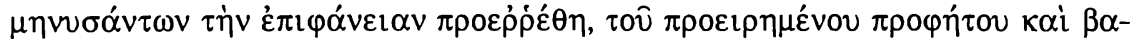

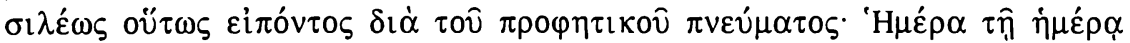

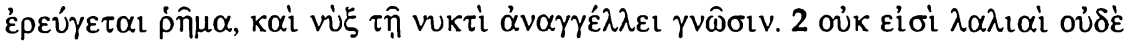

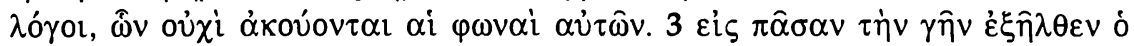

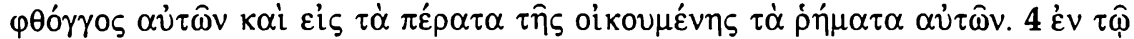

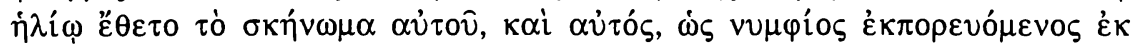

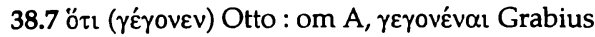

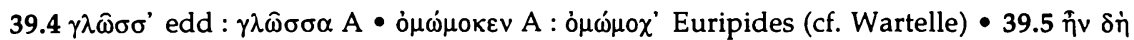
Otto : ท̌ $\delta \eta \mathrm{A}$

39.4 Euripide, Hippol. 612 - 39.5 Serment militaire: cf. Suétone, Calig. 15; Aulu-Gelle, N.A. 16,4; Tertullien, Cor. 11 
comme une pierre dure et j'ai su que je ne serais pas couvert de honte, car il est près de moi celui qui me justifie". 4 Et encore: "Ils ont tiré au sort mes vêtements, ils ont percé mes pieds et mes mains. 5 Mais moi je me suis endormi, j'ai pris mon sommeil et je me suis levé, parce que le Seigneur a pris soin de moi". 6 Et encore, quand il dit: "Ils ont marmonné des lèvres et hoché du chef, en disant: Qu'il se sauve lui-même". 7 Que tout cela est arrivé au Christ du fait des Juifs, vous pouvez vous en assurer. 8 Car quand il fut crucifié ils remuaient les lèvres et hochaient du chef, en disant: "Lui qui a ressuscité des morts, qu'il se sauve lui-même".

39.1 Lorsque l'Esprit prophétique parle pour prédire ce qui doit arriver, il s'exprime ainsi: "De Sion sortira une loi, et de Jérusalem une parole du Seigneur; il prononcera le jugement entre les nations et il convaincra un peuple nombreux. De leurs épées ils forgeront des socs de charrue et de leurs lances des faucilles; ils ne lèveront plus l'épée nation contre nation et ils n'apprendront plus à faire la guerre". 2 Or, cela s'est réalisé, vous pouvez vous en convaincre. 3 Car de Jérusalem des hommes au nombre de douze sont partis dans le monde, des hommes simples, inhabiles à discourir, mais ils ont, par la puissance de Dieu, annoncé à toute race d'homme qu'ils étaient envoyés par le Christ pour enseigner à tous la parole de Dieu. Et nous, qui autrefois nous égorgions les uns les autres, non seulement nous ne sommes plus en guerre avec nos ennemis, mais afin de ne point mentir ni tromper ceux qui nous interrogent, nous acceptons joyeusement la mort en confessant le Christ. 4 Il nous serait possible, en efffet, d'agir en cette circonstance selon l'adage: " La langue a juré, mais le cœur n'a pas juré". 5 Mais il serait ridicule, assurément, que les soldats recrutés et enrôlés par vous, fassent passer le serment qu'ils vous ont prêté, avant leur propre vie, leurs parents, leur patrie et toute leur parenté, alors que vous ne pouvez rien leur offrir d'incorruptible, tandis que nous, qui aspirons à l'incorruptibilité, nous ne saurions supporter tous les tourments, pour obtenir les biens que nous désirons de celui qui peut nous les accorder.

40.1 Ecoutez encore ce qui a été prédit au sujet de ceux qui devaient annoncer sa doctrine et publier sa manifestation, comment le roi prophète mentionné plus haut s'est exprimé sous la motion de l'Esprit prophétique: "Un jour instruit un autre jour, une nuit en donne connaissance à une autre nuit. 2 Il n'est pas de conversation ni de discours où l'on n'entende leurs paroles. 3 Sur toute la terre s'est répandu leur appel et leurs paroles jusqu'aux extrêmes limites du monde habité. 4 Dans le soleil il a établi sa tente et, comme un époux qui sort de sa chambre nuptiale, il se réjouira

38.4 Ps 22,19; 22,17 • 38.5 Ps 3,6 - 38.6 Ps 22,8-9 • 38.8 Mt 27,39-42; Mc 15,29-32; Lc $23,35-37 \bullet 39.1$ Is $2,3-4 \cdot 39.3$ Ac $4,13 \bullet 40.1$ Ps $19,3-6$ 


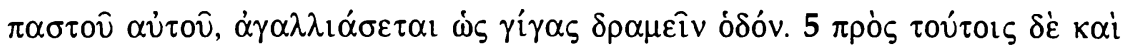

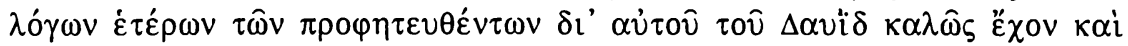

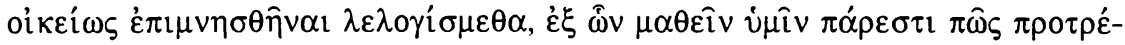

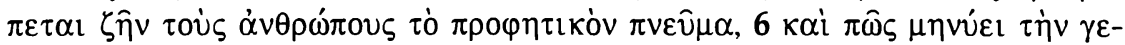

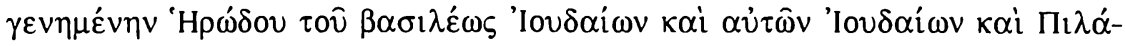

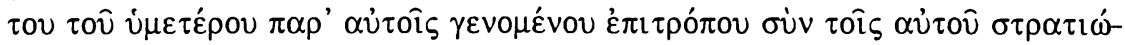

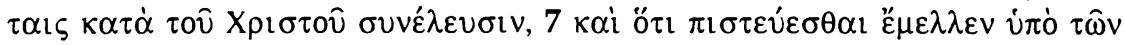

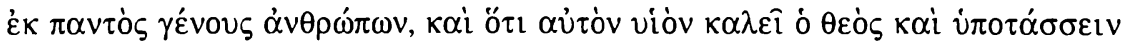

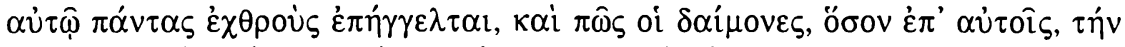

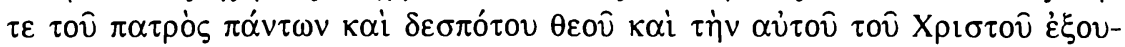

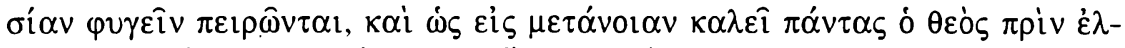

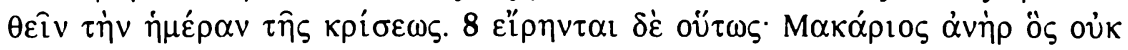

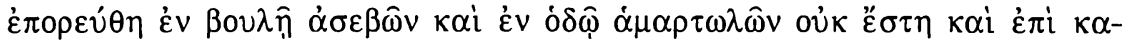

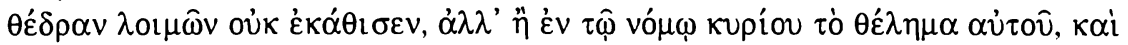

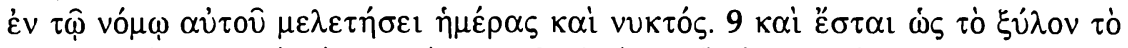

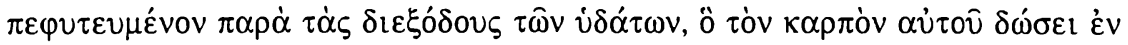

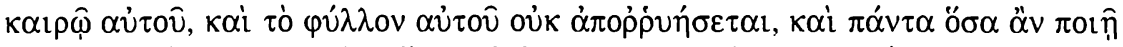

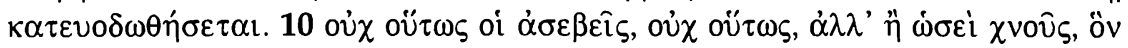

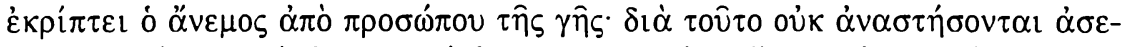

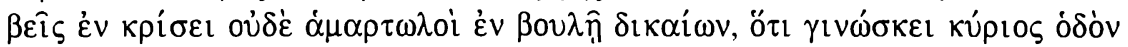

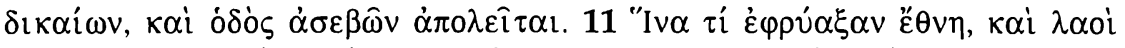

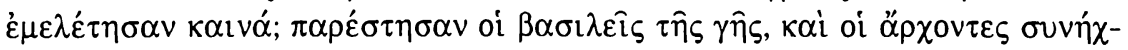

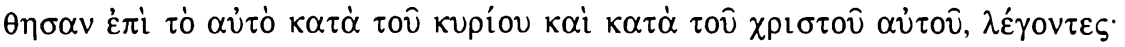

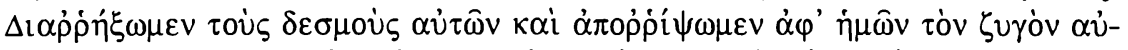

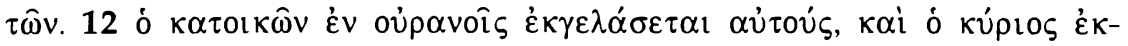

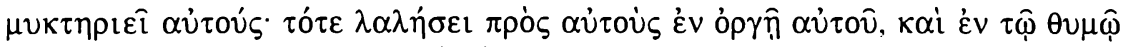

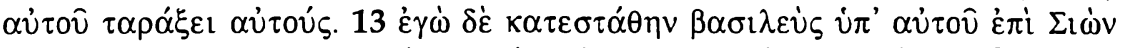

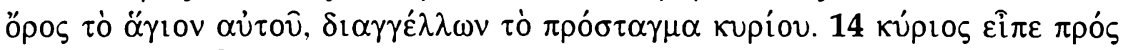

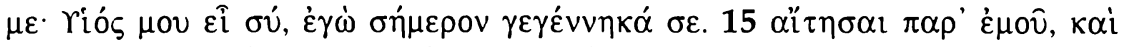

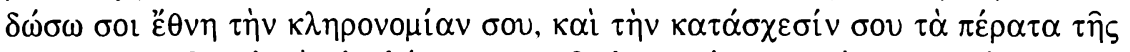

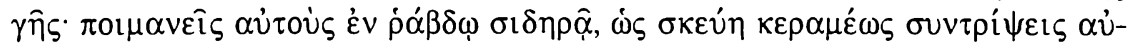

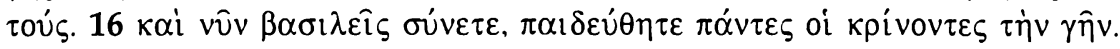

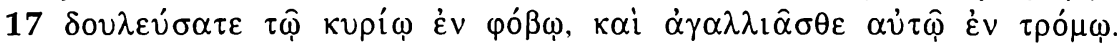

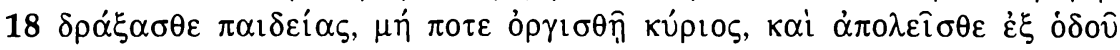

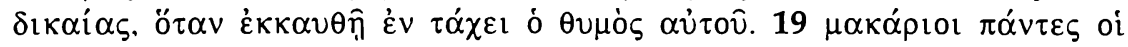

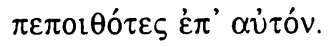


de parcourir sa carrière, comme un géant". 5 En outre, nous croyons qu'il est bien et à propos d'ajouter à ces paroles d'autres prophéties du même David, grâce auxquelles vous pourrez apprendre quelles règles de vie l'Esprit prophétique propose aux hommes; 6 et comment il annonce la coalition du roi des Juifs, Hérode, des Juifs eux-mêmes, et de Pilate, votre procurateur, dans leur contrée, avec ses soldats, contre le Christ; 7 et que des hommes de toute race devaient croire en lui, et que Dieu l'appelle son Fils et a promis de lui soumettre tous ses ennemis; comment les démons, autant qu'ils le peuvent, s'efforcent d'échapper au pouvoir de Dieu, le père et le maître de l'univers, et à celui du Christ; que Dieu appelle tous les hommes à la pénitence, avant que ne vienne le jour du jugement. 8 Elles sont formulées en ces termes: "Heureux l'homme qui n'a pas marché selon le conseil des impies, qui n'a pas suivi la voie des pécheurs et n'est pas assis dans la chaire de pestilence, mais qui prend plaisir à la loi du Seigneur et médite sa loi jour et nuit. $9 \mathrm{Il}$ sera comme l'arbre planté près du courant des eaux, qui donne du fruit en son temps; son feuillage ne se flétrit pas et toutes ses entreprises réussiront. $10 \mathrm{Il}$ n'en sera pas ainsi des impies, non, il n'en sera pas ainsi, mais ils seront comme la bale que le vent balaie de la surface de la terre. C'est pourquoi les impies ne subsisteront pas au jugement, ni les pécheurs au conseil des justes, parce que le Seigneur connaît la voie des justes, et la voie des impies se perdra. 11 Pourquoi ce tumulte parmi les nations, ces vaines pensées parmi les peuples? Les rois de la terre se sont dressés et les princes se sont ligués contre le Seigneur et contre son Christ, disant: Brisons leurs liens et rejetons loin de nous leur joug. 12 Celui qui habite dans les cieux rira d'eux et le Seigneur les tournera en dérision; alors il leur parlera dans la colère et dans sa fureur il les frappera d'épouvante. 13 Quant à moi, j'ai été établi par lui roi sur Sion, sa montagne sainte, pour publier le commandement du Seigneur. 14 Le Seigneur m'a dit: Tu es mon fils, je t'ai engendré aujourd'hui. 15 Demande-moi et je te donnerai les nations pour héritage et, pour ta possession, les confins de la terre. Tu les paîtras avec une houlette de fer et comme des vases de potier tu les briseras. 16 Et maintenant, rois, comprenez; intruisez-vous, juges de la terre. 17 Servez le Seigneur avec crainte; exaltez-le avec tremblement. 18 Soumettez-vous à ses leçons, de peur que le Seigneur ne s'irrite et que vous n'alliez vous perdre hors du droit chemin quand soudain s'enflammera sa colère. 19 Heureux tous ceux qui ont placé en lui leur confiance". 


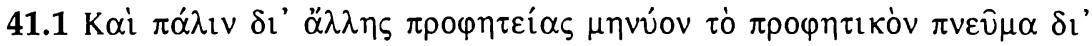

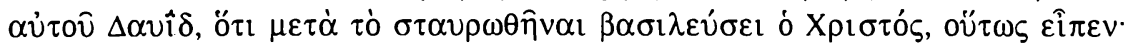

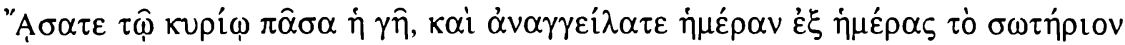

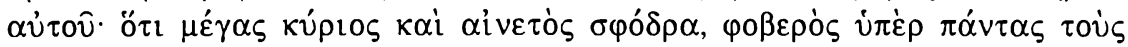

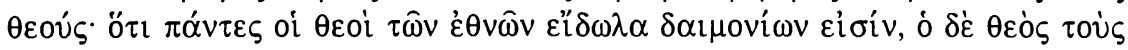

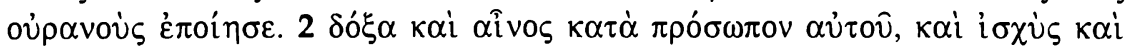

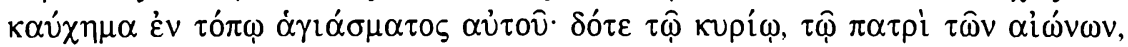

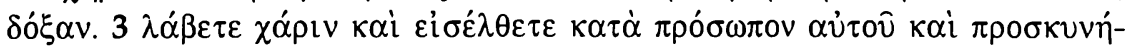

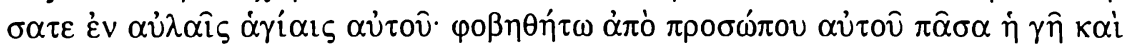

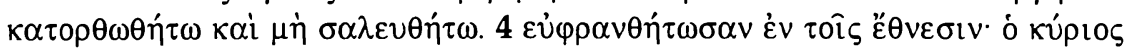

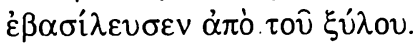

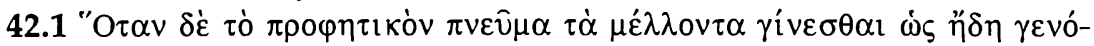

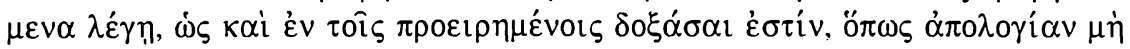

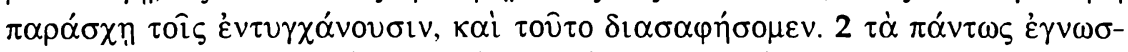

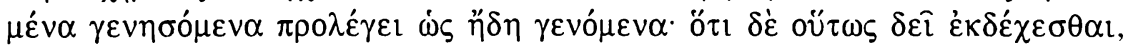

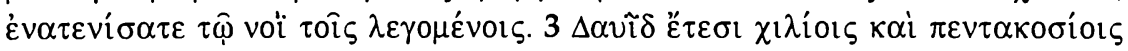

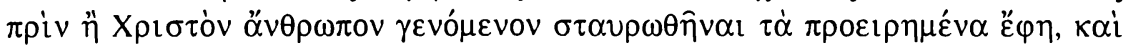

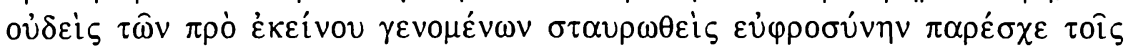

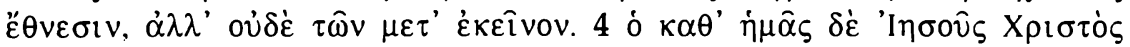

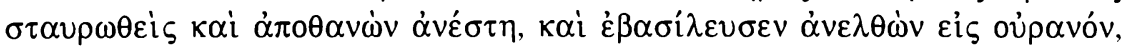

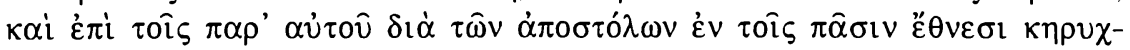

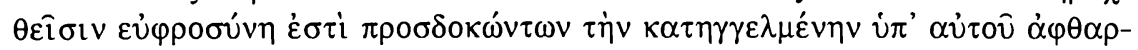

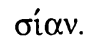

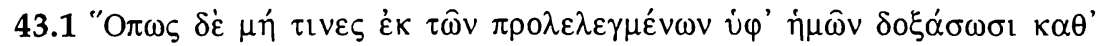

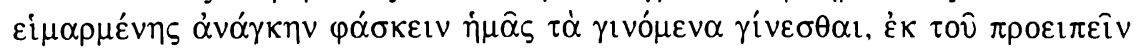

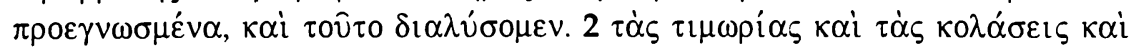

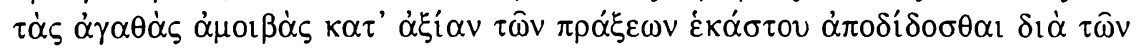

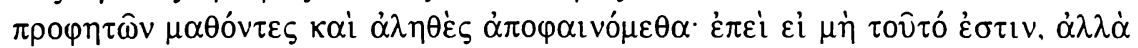

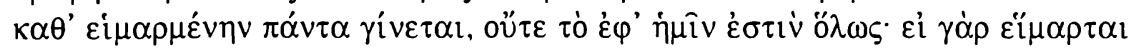

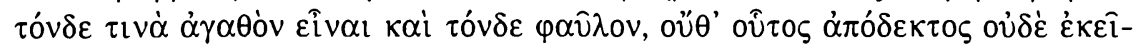

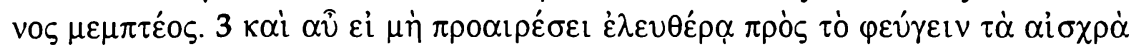

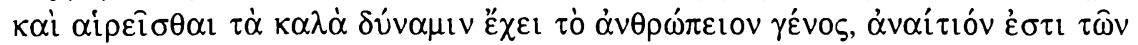

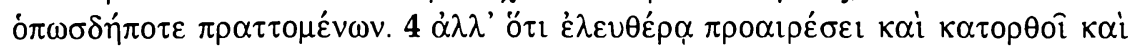

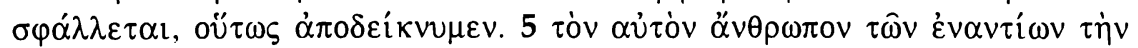

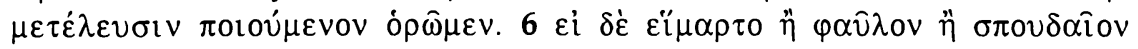

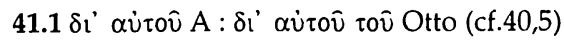

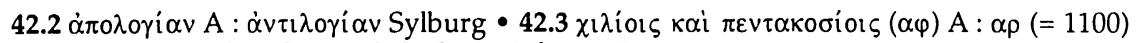
uel $\alpha v(=1050)$ Schmid 135 (cf. Grabius, Ashton...)

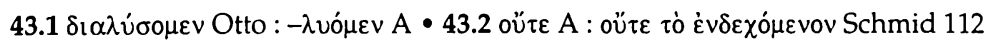


41.1 Derechef, dans une autre prophétie, l'Esprit prophétique annonce par le même David qu'après avoir été crucifié le Christ régnera; il s'exprime ainsi: "Chantez au Seigneur, terre entière; de jour en jour annoncez son salut, car grand est le Seigneur et très digne de louange, redoutable plus que tous les dieux. Car tous les dieux des nations sont simulacres de démons mais c'est Dieu qui a fait les cieux. 2 Gloire et louange sont devant lui, force et splendeur dans le lieu de sa sainteté. Rendez gloire au Seigneur, le Père des siècles. 3 Apportez l'oblation, présentez-la devant lui; adorez-le dans ses saints parvis. Que la terre entière tremble devant lui, qu'elle soit affermie et ne vacille pas. 4 Que l'on exulte de joie parmi les nations; le Seigneur est devenu roi au moyen du bois.

42.1 Il est des cas où l'Esprit prophétique annonce les événements futurs comme s'ils étaient déjà arrivés, comme on peut s'en rendre compte dans les passages cités précédemment; cela aussi nous allons l'expliquer clairement, afin que nulle excuse ne soit fournie aux lecteurs. 2 Les événements futurs lui étant parfaitement connus, il les prédit comme s'ils étaient déjà arrivés; pour vous persuader que c'est bien ainsi que cela doit être compris, considérez avec attention ce que je vais dire. 3 David a fait les prophéties citées plus haut mille cinq cents ans avant que le Christ, devenu homme, ne fût crucifié. Or, aucun de ceux qui ont vécu avant lui n'a été crucifié "pour la joie des nations", ni personne après lui. 4 Mais c'est à notre époque que Jésus-Christ a été crucifié, est mort et ressuscité, et qu'il est devenu roi, après être monté au ciel; et, à cause de ce qui a été proclamé en son nom par les apôtres parmi toutes les nations, la joie règne parmi ceux qui attendent l'incorruptibilité qu'il a annoncée.

43.1 Mais pour que personne, prenant prétexte de ce qui vient d'être dit, n'aille imaginer que nous affirmons que les événements arrivent de par la nécessité du destin, étant donné que nous avons dit qu'ils sont connus par avance, nous voulons aussi résoudre cette difficulté. 2 Chacun, selon ses œuvres, reçoit des châtiments, des punitions ou des récompenses; nous avons appris cette doctrine des prophètes et nous la tenons pour vraie; en effet, s'il n'en est pas ainsi mais si tout arrive de par le destin, alors absolument plus rien ne dépend de nous: si c'est le destin qui fait que celui-ci est bon et celui-là mauvais, le premier n'est pas digne d'éloge ni le second de blâme. 3 Pareillement, si le genre humain n'a pas le pouvoir de fuir le mal et de choisir le bien par une libre décision, il ne peut être tenu pour responsable de ses actions, quelles qu'elles soient. 4 Mais, en réalité, c'est bien par libre choix que l'homme fait le bien et qu'il fait le mal; voici comment nous le prouvons. 5 Nous voyons le même homme se mettre à la recherche de choses contraires. 6 Or, s'il était décidé par le 


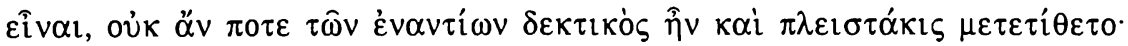

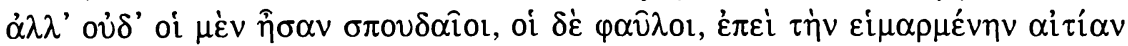

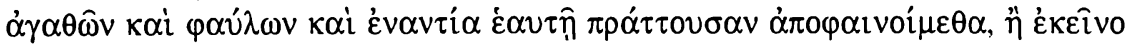

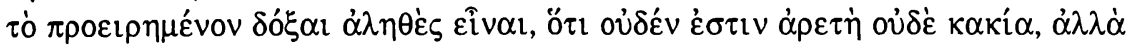

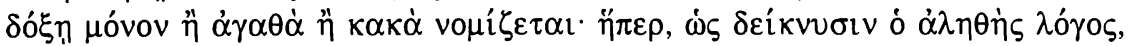

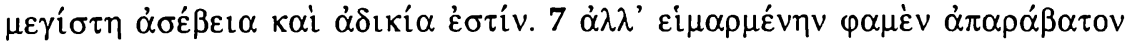

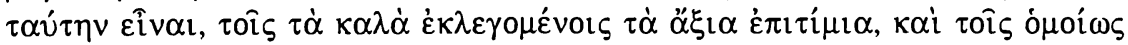

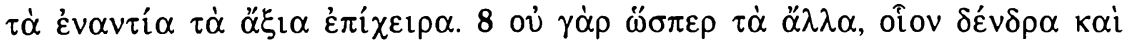

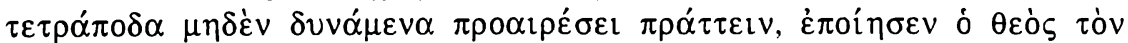

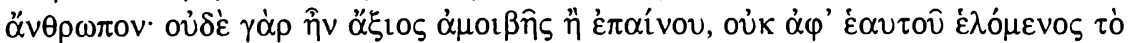

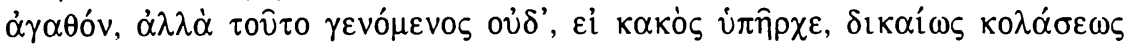

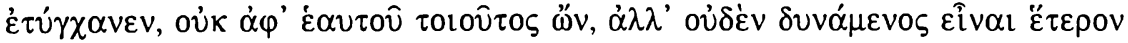

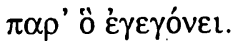

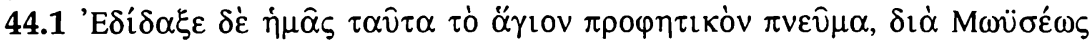

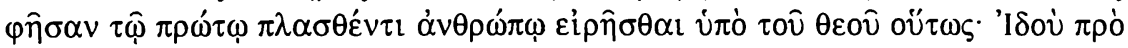

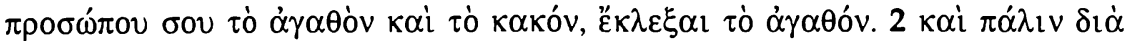

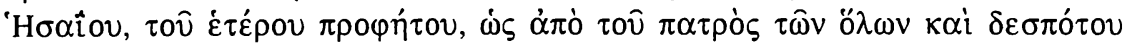

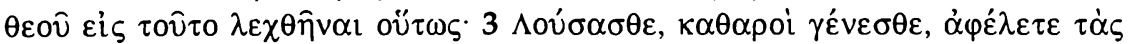

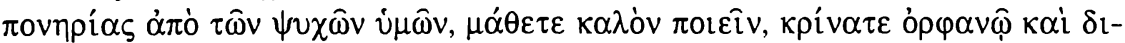

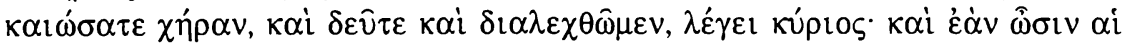

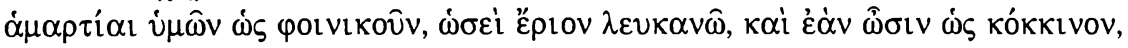

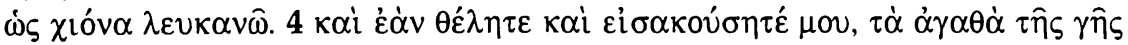

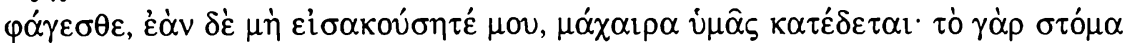

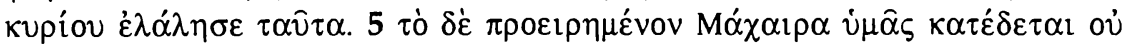

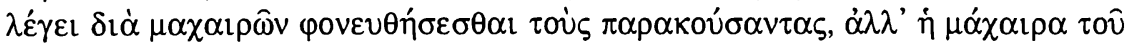

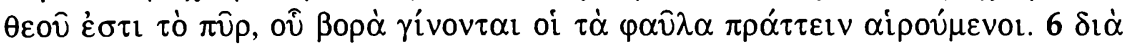

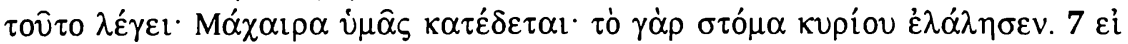

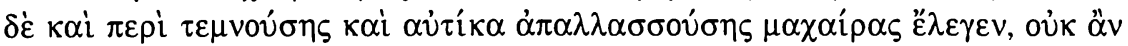

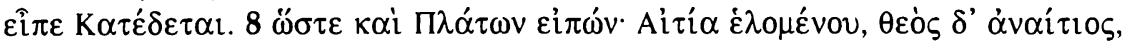

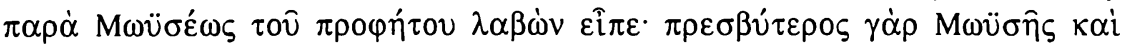

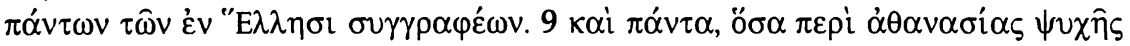

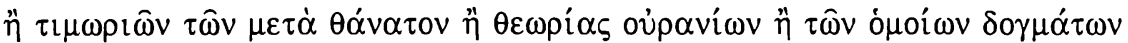

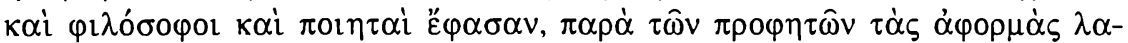

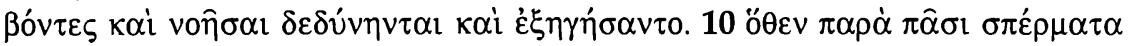

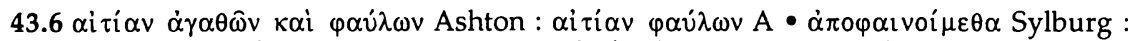

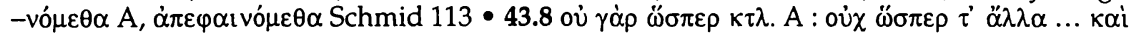

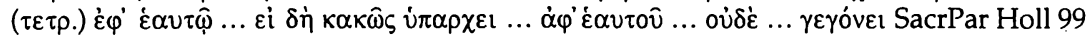

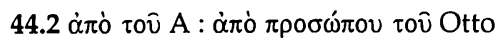

43.6 Platon, Resp. X,617E; u. infra, 44,8 
destin qu'il soit ou mauvais ou bon, il ne serait pas susceptible de choses contraires et il ne changerait pas si souvent de conduite. Et même il n'y aurait pas d'hommes bons ni d'hommes mauvais, puisqu'il nous faudrait affirmer que le destin est cause et du bien et du mal et qu'il se contredit dans son action, ou bien encore ce que nous avons dit plus haut apparaîtrat comme vrai, à savoir que la vertu et le vice n'ont aucune consistance, mais que cette distinction est seulement affaire d'opinion; or, c'est là, comme le montre la saine raison, le comble de l'impiété et de l'iniquité. 7 Tout au contraire nous affirmons que le destin inéluctable consiste en ce que, pour ceux qui choisissent le bien, il y aura des récompenses appropriées et que, pareillement, pour ceux qui font un choix contraire, il y aura des châtiments appropriés. 8 Car Dieu n'a pas créé l'homme comme les autres êtres, arbres ou quadrupèdes, incapables de rien faire par libre décision; de fait l'homme ne serait digne ni de louange ni de récompense si, au lieu de choisir de lui-même le bien, il était bon par nature et il ne pourrait pas non plus être frappé d'une juste punition, s'il était méchant, puisqu'il ne le serait pas en vertu d'une décision personnelle, mais ne pourrait être rien d'autre que ce que la nature l'a fait.

44.1 Ces enseignements, c'est l'Esprit prophétique qui nous les donne quand, par Moïse, il fait dire à Dieu au premier homme qu'il avait façonné: "Voici devant toi le bien et le mal; choisis le bien". 2 Et encore quand, par la bouche d'Isaïe, l'autre prophète, parlant au nom du Père et maître de l'univers, lui fait dire: 3 "Lavez-vous, purifiez-vous, ôtez le mal de vos âmes, apprenez à faire le bien, jugez en faveur de l'orphelin et rendez justice à la veuve, puis venez et faisons les comptes, dit les Seigneur. Et si vos péchés sont comme la pourpre, je les rendrai blancs comme laine; s'ils sont comme l'écarlate, je les rendrai blancs comme neige. $4 \mathrm{Et} \mathrm{si}$ vous le voulez et si vous m'écoutez, vous serez nourris des biens de la terre, mais si vous ne m'écoutez pas, c'est l'épée qui vous dévorera, car la bouche du Seigneur a parlé." 5 Ces mots: "L'épée vous dévorera", ne signifient pas que ceux qui refusent d'écouter, seront tués par l'épée, mais l'épée du Seigneur, c'est le feu, dont deviennent la proie ceux qui choisissent de faire le mal. 6 C'est pourquoi il dit: "L'épée vous dévorera, car la bouche du Seigneur a parlé". 7 S'il avait voulu parler de l'épée qui tranche et tue en un instant, il n'aurait pas dit: "vous dévorera". 8 Ainsi, quand Platon a dit: "La responsabilité appartient à celui qui choisit, Dieu n'en est pas responsable", il a repris cette parole au prophète Moïse, car Moïse est plus ancien que tous les écrivains grecs. 9 Et tout ce que philosophes et poètes ont dit de l'immortalité de l'âme, des châtiments après la mort, de la contemplation des choses célestes et des doctrines semblables, c'est pour en avoir repris les principes chez les prophètes qu'ils ont pu le concevoir et l'exposer. 10 De là vient que chez tous, appare-

44.1 Dt 30,$15 ; 30,19 \bullet 44.3$ Is $1,16-20 \bullet 44.5$ Is 1,20 


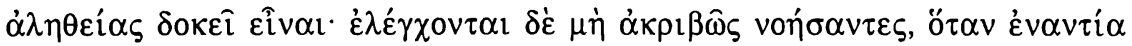

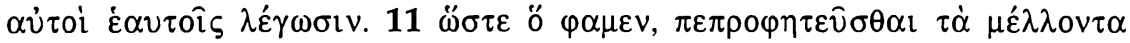

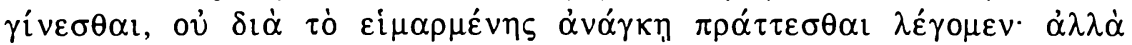

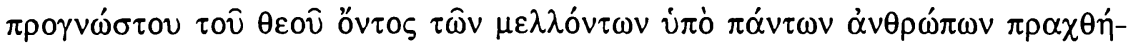

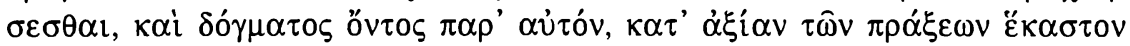

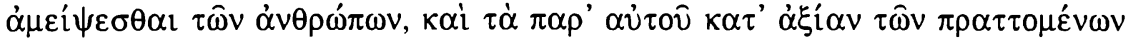

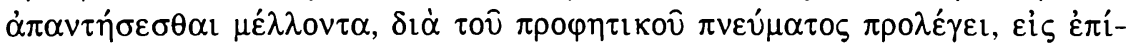

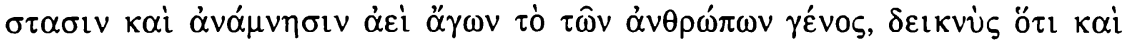

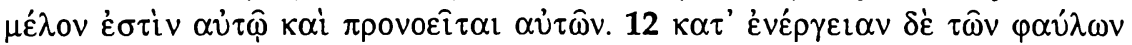

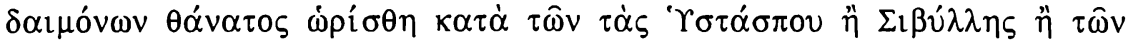

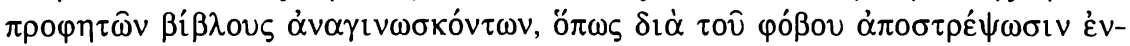

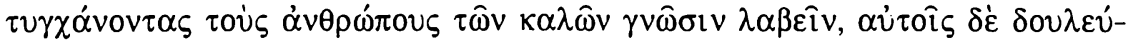

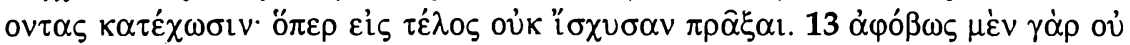

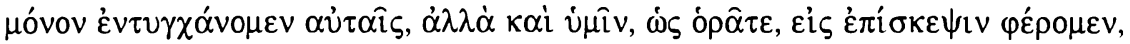

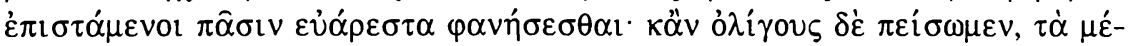

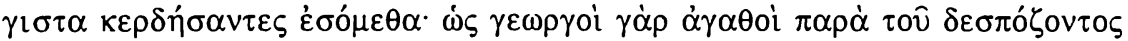

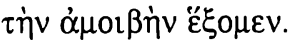

45.1 "O

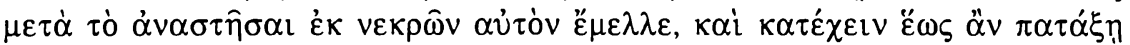

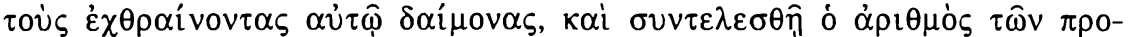

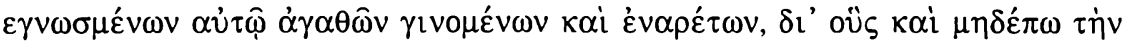

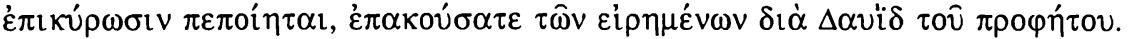

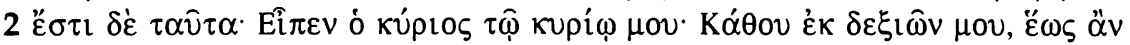

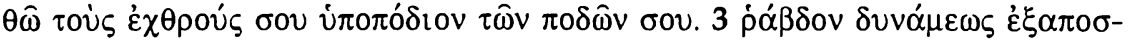

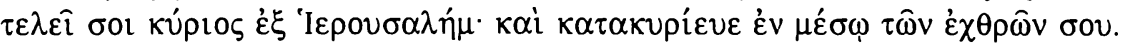

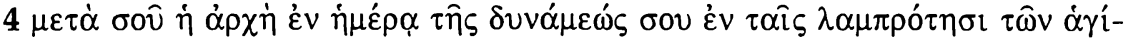

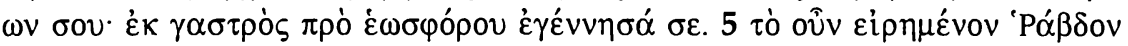

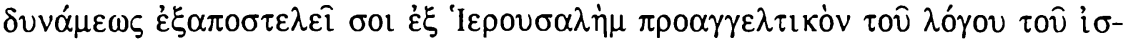

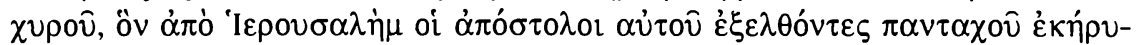

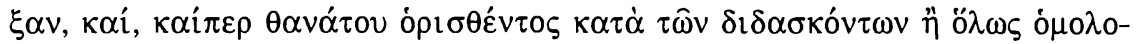

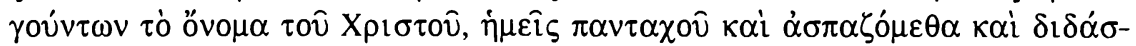

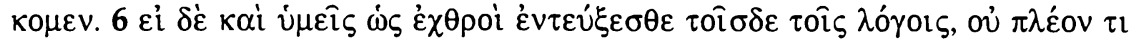

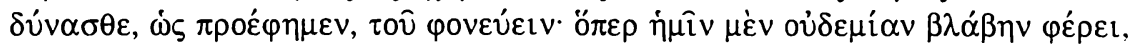

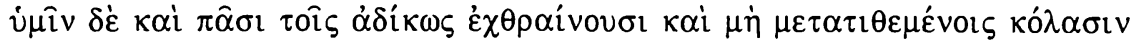

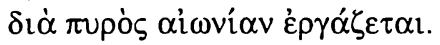

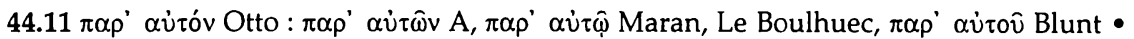

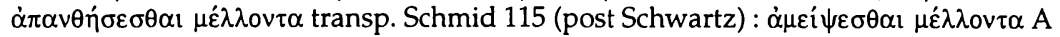

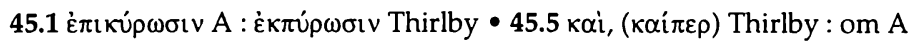

44.12 Tacite, Ann. II,32; VI,22; XII,22; Hist. I,22; II,62; Dion Cassius, Hist.rom. 57,15; 61,2 
ment, il y a des semences de vérité, mais on peut leur reprocher de n'avoir pas mené une réflexion rigoureuse, dès lors qu'ils se contredisent euxmêmes. 11 Ainsi quand nous disons que l'avenir a été prédit, nous prétendons pas que les événements se produisent de par la nécessité du destin, mais étant donné que Dieu sait d'avance ce que feront tous les hommes et qu'il a pour principe de rétribuer chacun selon ses œuvres, il annonce par l'esprit prophétique les sanctions qu'il infligera en retour, selon la gravité des actions qui auront été commises, et ainsi il amène sans cesse les hommes à comprendre et à se souvenir, leur montrant par là qu'ils sont l'objet de sa sollicitude et de sa providence. 12 Or, à l'instigation des mauvais démons, la peine de mort a été décrétée contre ceux qui liraient les ouvrages d'Hystaspe, de la Sibylle ou des prophètes, afin de détourner par la crainte les hommes de chercher dans cette lecture la connaissance du bien et de les maintenir dans leur esclavage. Mais cela ils n'ont pu le réaliser complètement. 13 En effet, non seulement nous lisons ces ouvrages sans crainte mais, comme vous le voyez, nous les offrons à votre examen, convaincus que leurs paroles seront agréables à tous. Et même si nous ne parvenons à persuader qu'un petit nombre de gens, nous aurons réalisé un bénéfice considérable car, comme de bons laboureurs, nous recevrons de notre maître notre récompense.

45.1 Dieu le Père de l'univers devait enlever le Christ au ciel, après l'avoir ressuscité des morts et il doit l'y garder jusqu'à ce qu'il ait frappé les démons, ses ennemis, et que soit complété le nombre de ceux dont il a connu d'avance qu'ils seraient bons et vertueux, à cause desquels il n'a pas encore détruit le monde par le feu; écoutez ce que le prophète David a dit à ce sujet. 2 Voici ses paroles: "Le Seigneur a dit à mon Seigneur: Assieds-toi à ma droite, jusqu'à ce que j'aie fait de tes ennemis l'escabeau de tes pieds. 3 Le Seigneur fera sortir de Jérusalem le sceptre de ta puissance; domine au milieu de tes ennemis. $4 \mathrm{~A}$ toi le commandement au jour de ta puissance, dans la splendeur de tes saints; du sein je t'ai engendré, avant l'étoile du matin". 5 Ces mots donc: "Il fera sortir de Jérusalem le sceptre de ta puissance", annoncent la parole puissante que ses apôtres, sortis de Jérusalem, ont proclamée en tout lieu; et bien que la peine de mort ait été décrétée contre ceux qui enseignent ou seulement confessent le nom du Christ, partout nous recevons cette parole et nous l'enseignons. 6 Quant à vous, si vous lisez cet ouvrage en ennemis, vous ne pouvez rien faire de plus que de nous livrer à la mort, comme nous l'avons dit précédemment; ceci ne nous apporte aucun dommage, mais vous prépare, à vous et à tous ceux qui nous haïssent injustement et ne changent pas d'attitude, un châtiment éternel par le feu. 


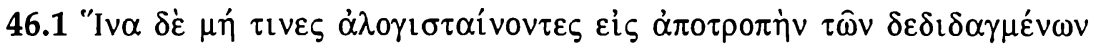

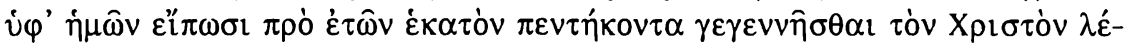

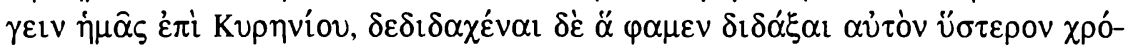

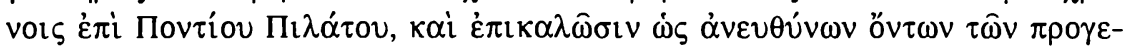

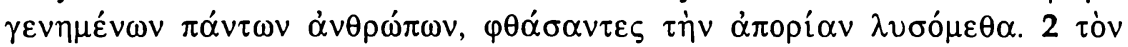

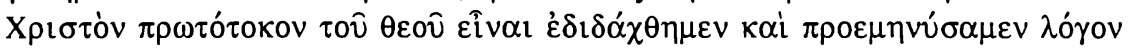

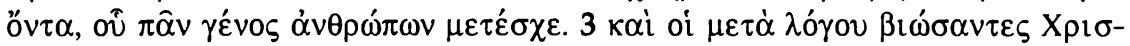

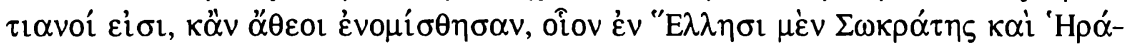

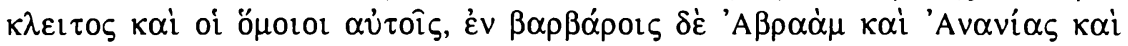

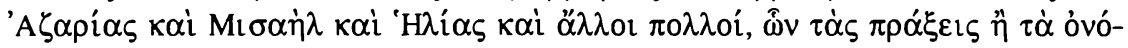

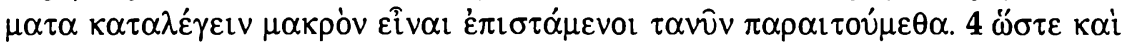

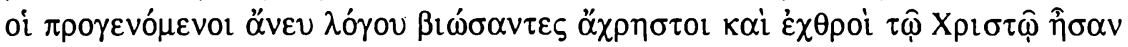

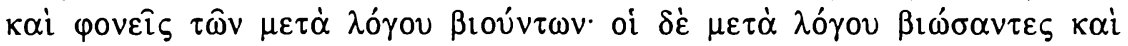

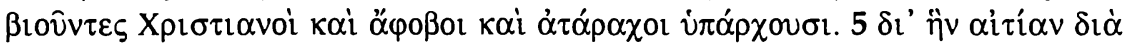

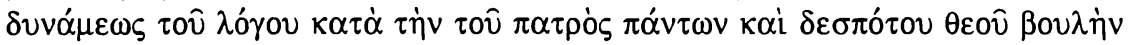

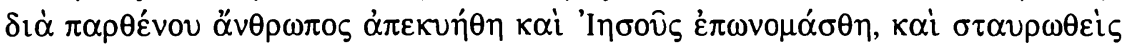

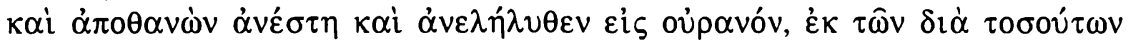

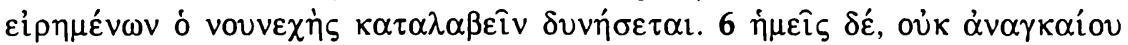

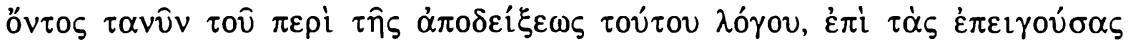

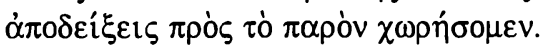

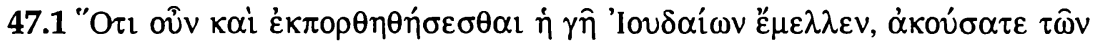

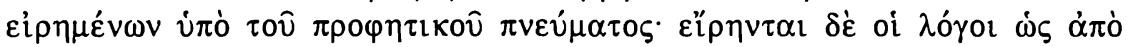

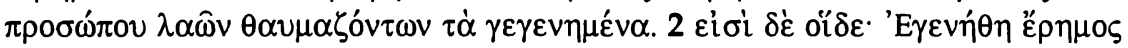

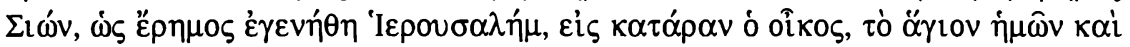

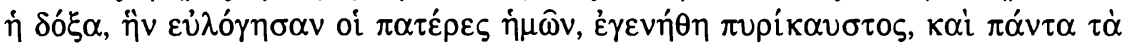

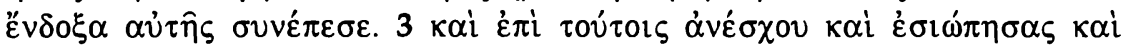

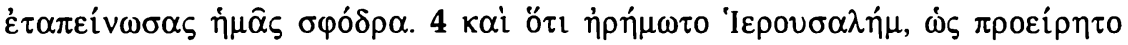

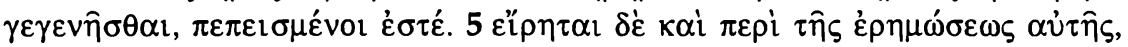

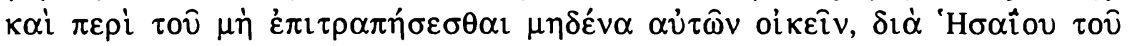

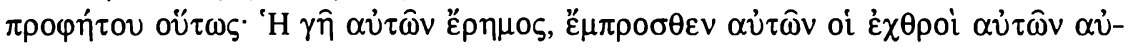

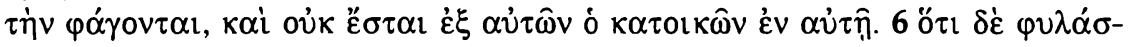

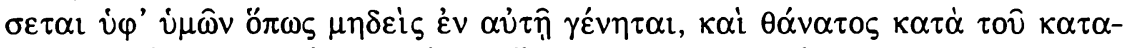

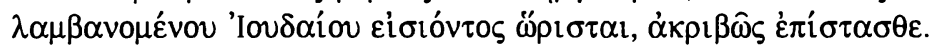

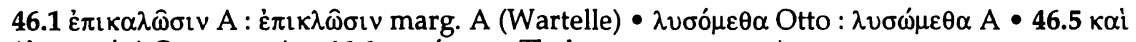

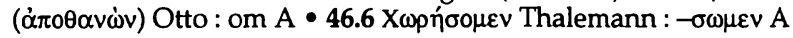

47.6 cf. Eusèbe, H.E. IV,6,3 
46.1 Certains, pour pouvoir récuser notre doctrine, objecteront peutêtre inconsidérément que, si nous affirmons que le Christ est né il y a cent cinquante ans sous Quirinius et qu'il a enseigné plus tard (encore) sous Ponce-Pilate la doctrine que nous lui prêtons, il s'ensuit que tous les hommes qui ont vécu antérieurement ne sont pas coupables; nous allons résoudre cette difficulté en la prévenant. 2 Nous avons appris que le Christ est le Premier-né de Dieu, et nous avons suggéré plus haut qu'il est son Logos, duquel le genre humain tout entier a reçu participation. 3 Ceux qui ont vécu selon le Logos sont chrétiens, même s'ils ont été tenus pour athées, comme par exemple, chez les Grecs, Socrate, Héraclite et d'autres leurs pareils et, chez les Barbares, Abraham, Ananias, Azarias, Misaël, Elie et quantité d'autres, dont nous renonçons pour l'instant à énumérer les œuvres et les noms, sachant qu'il serait trop long de le faire. 4 Dès lors aussi, ceux qui, parmi les hommes des temps passés, ont vécu loin du Logos, furent mauvais, ennemis du Christ, meurtriers de ceux qui vivaient selon le Logos, tandis que ceux qui ont vécu et qui vivent encore selon le Logos sont chrétiens, sans crainte et sans inquiétude. 5 Quant à savoir pourquoi, par la puissance du Logos, selon le dessein de Dieu, le Père et le maître de l'univers, le Christ est devenu homme, en naissant d'une vierge, a été appelé Jésus, pourquoi il a été crucifié, est mort, est ressuscité et est monté au ciel, tout homme intelligent pourra le comprendre d'après ce que nous avons exposé si longuement. 6 Quant à nous, puisque la démonstration de cet argument n'est pas nécessaire pour l'instant, nous allons passer aux démonstrations qui pressent.

47.1 Ecoutez donc ce qui a été annoncé par l'Esprit prophétique au sujet de la dévastation du pays des Juifs; ces paroles sont censées être prononcées par des nations stupéfaites par ce qui est arrivé. 2 Les voici: "Sion est devenue un désert, Jérusalem est devenue comme un désert; le temple est voué à la malédiction; notre sanctuaire et sa gloire, que les pères avaient célébrée, sont devenus la proie des flammes et tout ce qui faisait sa gloire s'est écroulé. 3 Devant cela tu es resté impassible, tu as gardé le silence et tu nous as humiliés à l'extrême". 4 Or, vous savez bien que, selon la prophétie, Jérusalem a été réduite en désert. 5 Sur cette dévastation et sur l'interdiction faite à tous les juifs de revenir l'habiter, le prophète Isaïe s'exprime en ces termes: "Leur terre est déserte, devant eux leurs ennemis la dévorent, et pas un seul d'entre eux n'y habitera." 6 Vous veillez à ce qu'aucun Juif n'y demeure et vous avez décrété la peine de mort contre tout Juif qui serait pris à vouloir y revenir; vous le savez parfaitement. 
48.1 "O

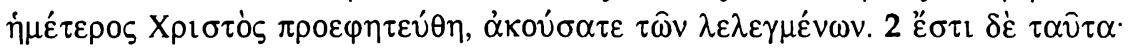

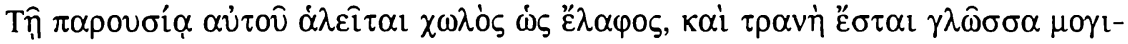

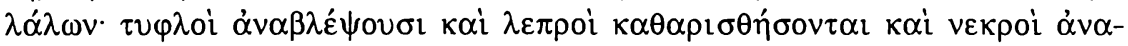

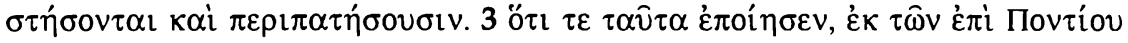

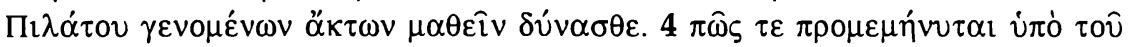

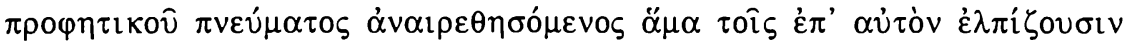

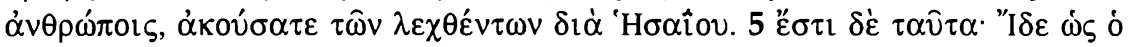

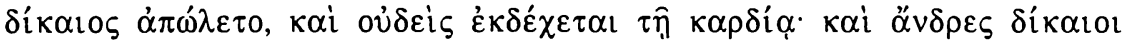

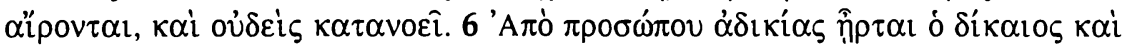

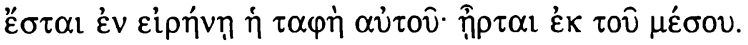

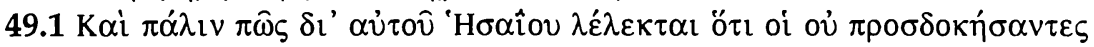

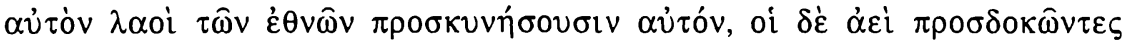

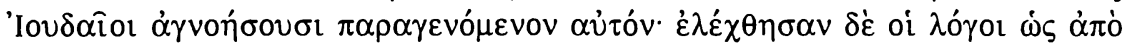

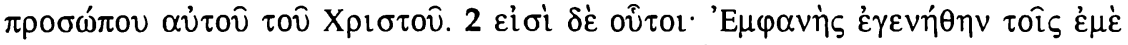

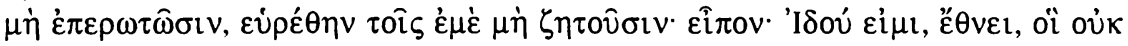

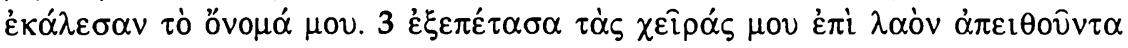

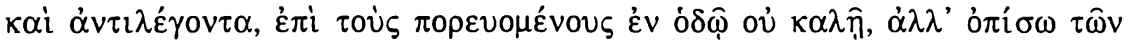

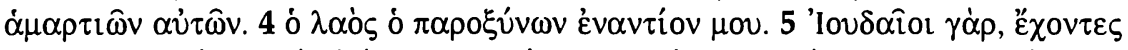

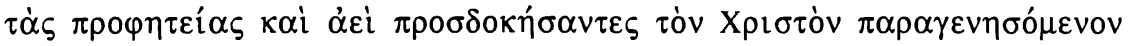

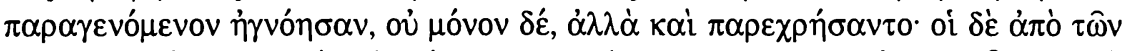

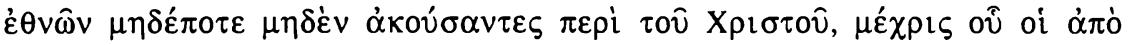

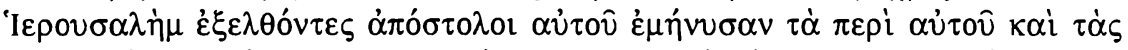

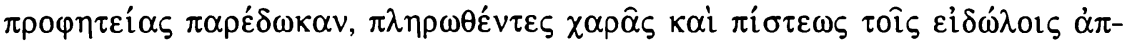

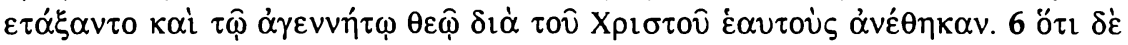

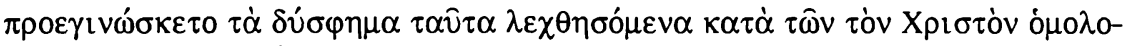

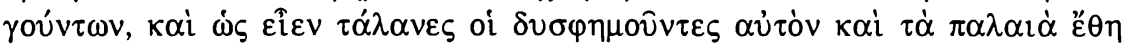

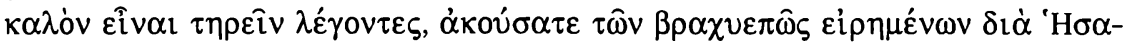

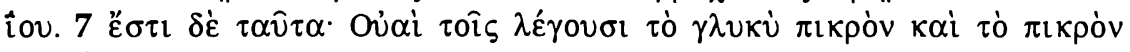

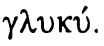

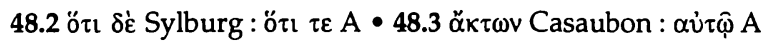

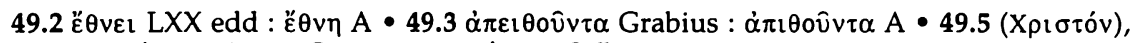
$\pi \alpha p \alpha \gamma \varepsilon v \eta \sigma o ́ p \varepsilon v o v$ A : om Otto $\bullet \pi \alpha p \alpha \gamma \varepsilon v o ́ p \varepsilon v o v$ Sylburg : om A 
48.1 Ecoutez encore comment il a été prédit que notre Christ devait guérir toute maladie et ressusciter les morts. 2 Telles sont les paroles de la prophétie: "A sa venue le boîteux bondira comme un cerf et la langue des muets parlera distinctement; les aveugles verront, les lépreux seront purifiés, les morts se lèveront et se promèneront. $3 \mathrm{Il}$ a réellement accompli ces prodiges, vous pouvez vous en assurer par les Actes de Ponce-Pilate. 4 Ecoutez aussi comment l'Esprit prophétique, par la bouche d'Isaïe, a prédit qu'il serait mis à mort, de même que ceux qui espèrent en lui. 5 Voici ses paroles: "Voilà comment est mort le juste et personne ne prend la chose à cœur; des hommes justes sont emportés et personne n'y prête attention. $6 \mathrm{~A}$ la face de l'iniquité le juste a été emporté, et sa sépulture sera en paix. Il a été enlevé du milieu des hommes".

49.1 Et encore comment le même Isaïe a dit que les peuples des nations, qui ne l'attendaient pas, devaient l'adorer, tandis que les Juifs, qui l'avaient toujours attendu, ne le reconnaîtraient pas lors de sa venue. 2 Voici ses paroles: "Je me suis manifesté à ceux qui ne me demandaient pas, j'ai été trouvé par ceux qui ne me cherchaient pas. J'ai dit: Me voici, à une nation qui n'avait pas invoqué mon nom. 3 J'ai étendu mes mains vers un peuple incrédule et contradicteur, vers ceux qui marchaient sur un mauvais chemin à la suite de leurs péchés. 4 C'est un peuple qui en face suscite ma colère". 5 En effet, les Juifs, qui avaient les prophéties et qui avaient toujours attendu le Christ à venir, non seulement ne le reconnurent pas lors de sa venue, mais ils le rejetèrent. Au contraire les Gentils n'avaient jamais entendu parler du Christ jusqu'à ce que les apôtres, partis de Jérusalem, vinrent leur révéler ce qui le concerne et leur transmettre les prophéties; pleins de joie et de foi, ils se détournèrent de leurs idoles et se consacrèrent, par le Christ, au Dieu inengendré. 6 Il a été prévu aussi que ces calomnies devaient se répandre contre les confesseurs du Christ et que le malheur frapperait ceux qui le maudissent en prétendant qu'il est beau de conserver les antiques traditions; écoutez à ce propos une brève sentence d'Isaïe: 7 Il s'exprime ainsi: "Malheur à ceux qui appellent doux ce qui est amer et amer ce qui est doux".

48.2 Is $35,5-6 ; 29,18 ;$ Mt $11,5 \bullet 48.5$ Is $57,1-2 \bullet 49.2$ Is $65,1-3 \bullet 49.5$ Ac $13,27-28 ; 13,48 \bullet$ 49.7 Is 5,20 
50.1 "O

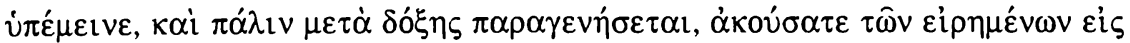

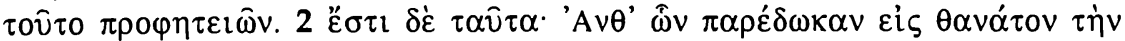

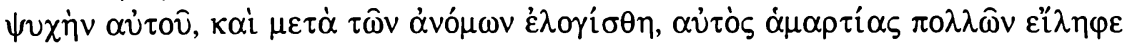

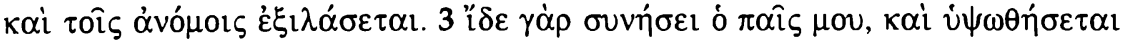

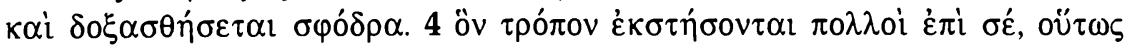

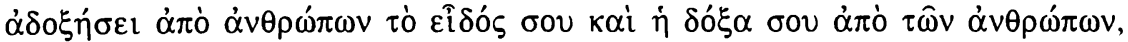

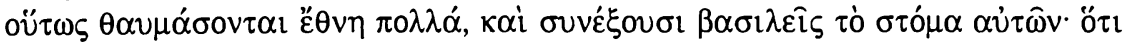

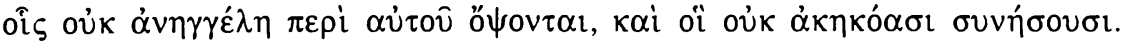

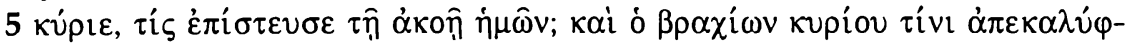

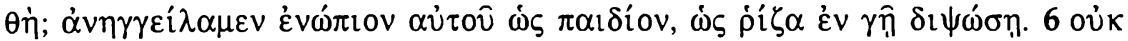

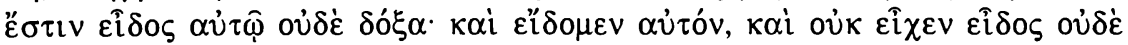

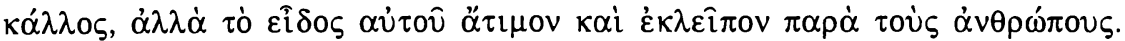

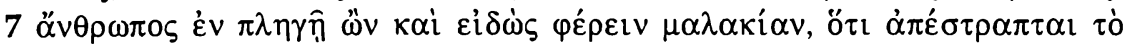

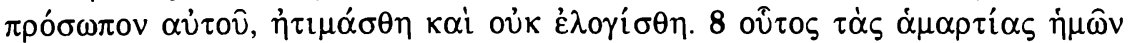

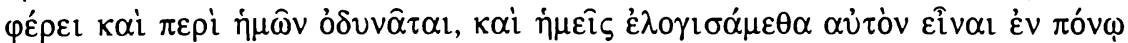

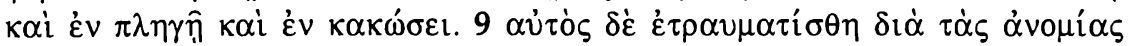

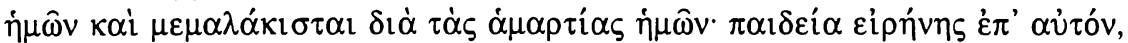

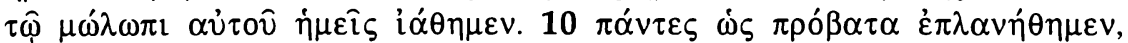

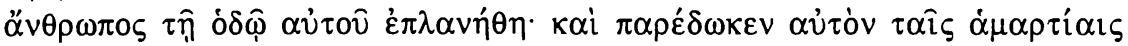

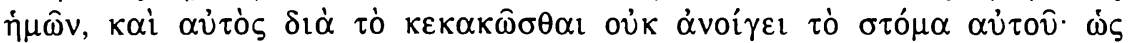

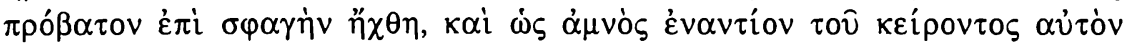

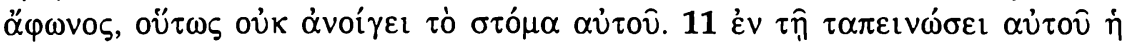

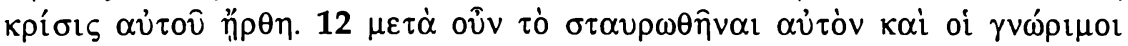

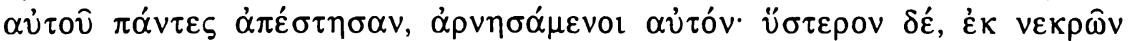

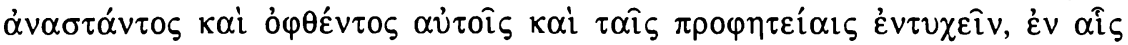

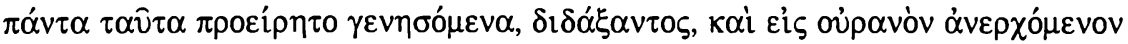

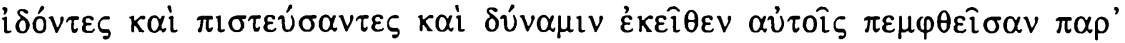

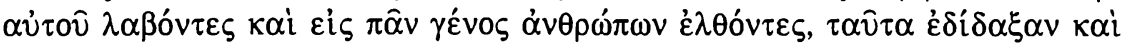

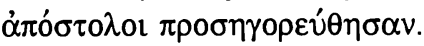

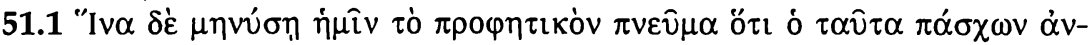

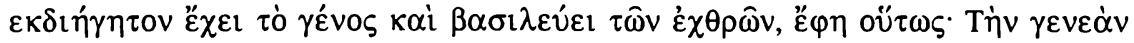

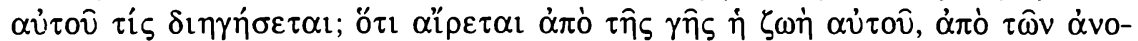

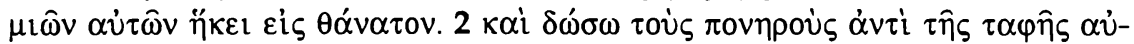

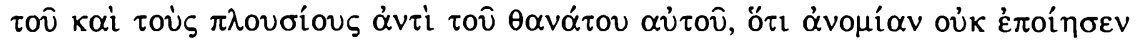

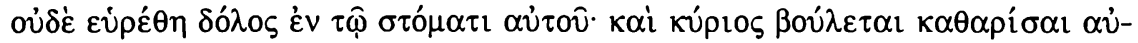

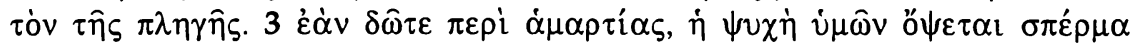

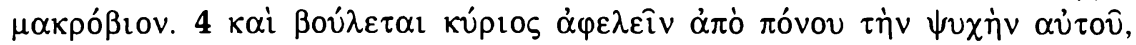

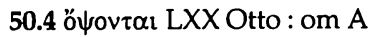

50.2 Evangile de Pierre 26-27 
50.1 Devenu homme, il a accepté de souffrir et d'être méprisé pour nous, mais il reviendra de nouveau avec gloire, écoutez les prophéties faites à ce sujet. 2 Les voici: "Parce qu'ils ont livré son âme à la mort et qu'il a été compté au rang des coupables, il a enlevé les péchés de beaucoup et il obtiendra miséricorde pour les coupables. 3 Voici que mon serviteur comprendra; il s'élèvera et il sera glorifié à l'extrême. 4 De même que beaucoup seront frappés de stupeur à ton sujet - tant ton aspect et ta gloire seront objet de mépris pour les hommes - de même beaucoup de nations s'étonneront et les rois resteront muets, parce que ceux à qui rien n'avait été annoncé de lui verront, et ceux qui n'avaient pas entendu parler de lui comprendront. 5 Seigneur, qui a prêté foi à notre parole, à qui le bras du Seigneur a-t-il été révélé? En sa présence nous avons annoncé la nouvelle, comme un petit enfant, comme une racine dans une terre desséchée. 6 Il n'a ni apparence ni gloire, nous l'avons vu: il n'avait ni apparence ni beauté, mais son apparence était sans honneur, délaissée parmi les hommes. 7 C'est un homme livré aux coups et qui sait supporter la souffrance; on se détourne de son visage, il est méprisé et compté pour rien. 8 Or, ce sont nos fautes qu'il porte et nos douleurs dont il est chargé, mais nous, nous avons vu qu'il était dans la peine, les souffrances et l'affliction. 9 Il a souffert à cause de nos forfaits, il a été dans les supplices à cause de nos fautes. Le châtiment qui nous donne la paix est sur lui; c'est par sa meurtrissure que nous avons été guéris. 10 Tous, comme des brebis, nous étions errants; chacun s'égarait dans sa voie. Il l'a livré à cause de nos fautes et lui, durant son affliction, il n'ouvre pas la bouche; comme une brebis qu'on mène à l'abattoir, comme un agneau muet devant celui qui le tond, il n'ouvre pas la bouche. 11 Dans son humiliation, son jugement a été consommé". 12 Or, après qu'il eut été crucifié, tous ses disciples l'abandonnèrent, et le renièrent; mais plus tard il ressuscita des morts et, se montrant à eux, il leur apprit à lire les prophéties, dans lesquelles il avait été prédit que tout cela devait arriver. Ils le virent monter au ciel, crurent, reçurent la force qu'il leur envoya d'enhaut, s'en allèrent vers les hommes de toute race pour leur enseigner cette doctrine, et reçurent le nom d'apôtres.

51.1 Pour nous indiquer que celui qui a connu ces souffrances a une origine ineffable et qu'il règne sur ses ennemis, l'Esprit prophétique a parlé en ces termes: "Qui racontera sa génération? Sa vie est retranchée de la terre; à cause de leurs forfaits il est allé à la mort. 2 Je livrerai les méchants contre sa sépulture et les riches contre sa mort, car il n'a pas commis le mal et l'on n'a pas trouvé de fraude dans sa bouche, le Seigneur veut le libérer de la souffrance. $3 \mathrm{Si}$ vous faites une offrande pour le péché, votre âme verra une semence de longue vie. 4 Le Seigneur veut retirer 


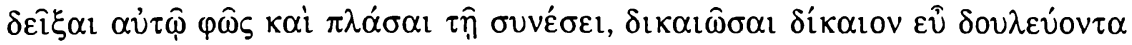

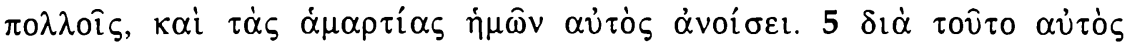

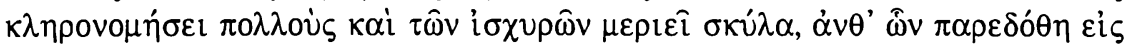

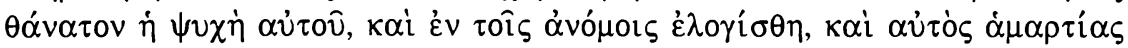

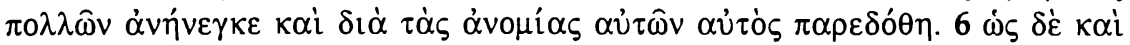

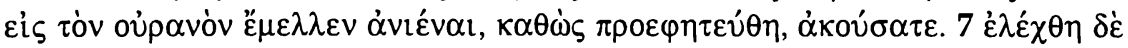

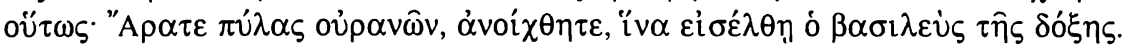

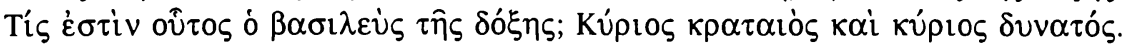

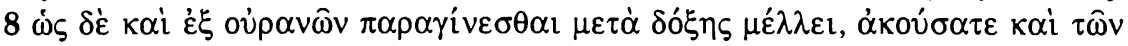

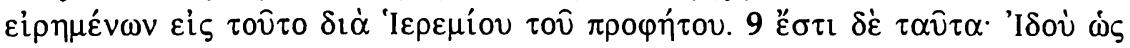

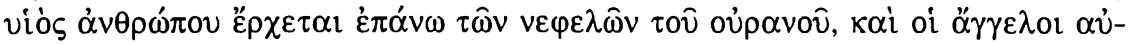

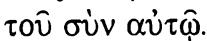

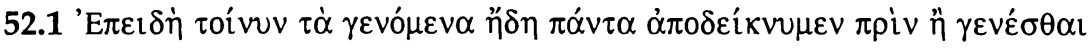

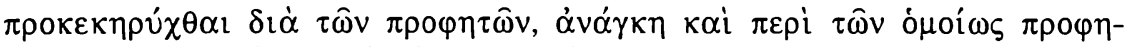

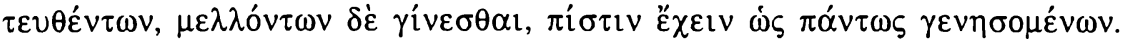

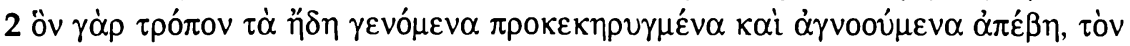

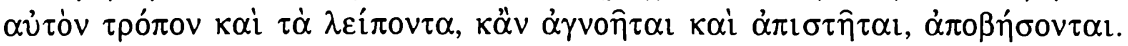

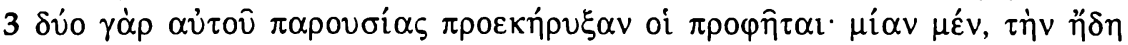

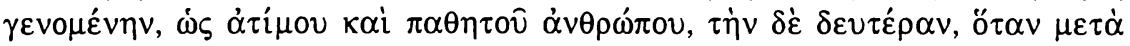

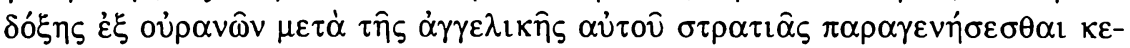

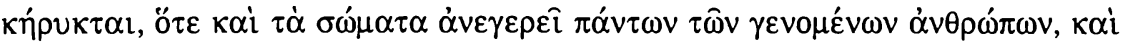

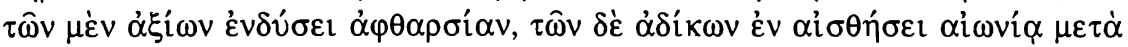

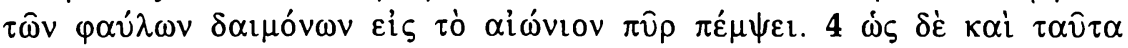

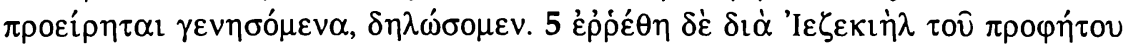

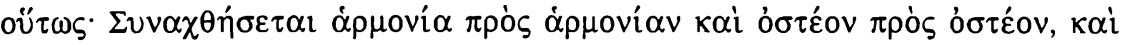

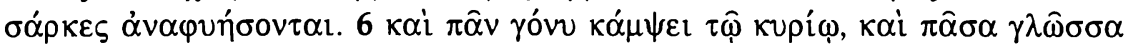

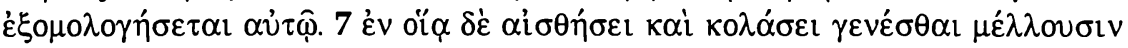

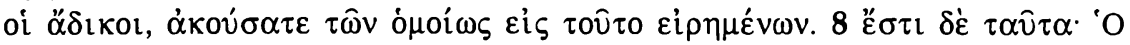

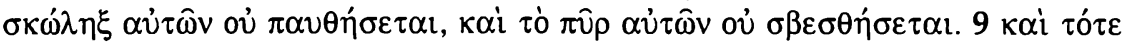

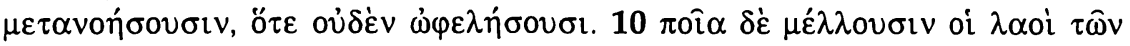

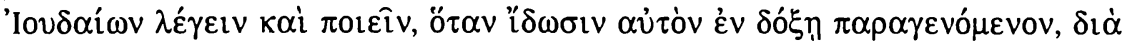

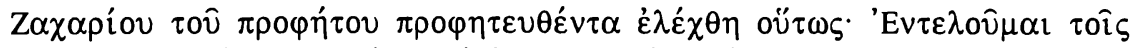

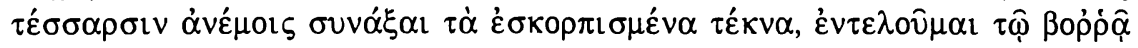

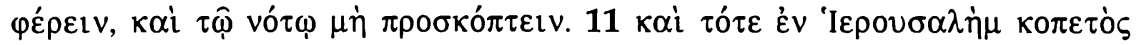

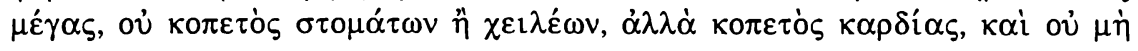

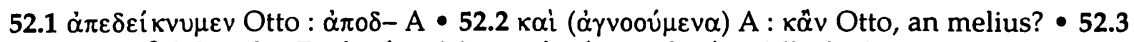

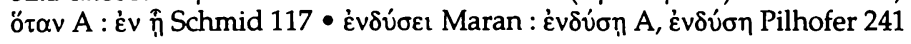


son âme de la douleur, lui montrer la lumière, lui donner l'intelligence, pour justifier ce juste, qui s'est fait l'esclave de beaucoup. Il portera luimême nos péchés. 5 C'est pourquoi il recevra en héritage beaucoup de peuples et il partagera les dépouilles des forts, car son âme a été livrée à la mort et il a été compté parmi les coupables; il a porté les péchés d'un grand nombre et a été livré à cause de leurs forfaits". 6 Écoutez encore comment, d'après les prophéties, il devait monter au ciel. $7 \mathrm{Il}$ a été dit: "Élevez les portes des cieux, qu'elles s'ouvrent pour que fasse son entrée le roi de gloire. Quel est ce roi de gloire? C'est le Seigneur fort, le Seigneur puissant". 8 Il doit aussi revenir des cieux avec gloire, écoutez ce qu'a dit à ce sujet le prophète Jérémie. 9 Telles sont ses paroles: "Voici qu'il vient sur les nuées du ciel comme un fils d'homme, et ses anges sont avec lui".

52.1 Puisque nous avons montré que tous les événements accomplis dans le passé avaient été prédits par les prophètes avant même leur réalisation, il faut croire aussi que ceux qui ont été prophétisés comme devant encore arriver se réaliseront intégralement. 2 De même, en effet, que les événements du passé, annoncés d'avance, se sont accomplis, bien qu'ils n'aient pas été compris, ainsi ceux qui restent encore en suspens s'accompliront aussi, même si on ne les comprend pas et qu'on refuse d'y croire. 3 De fait les prophètes ont annoncé deux avènements du Christ: le premier, qui a déjà eu lieu, comme d'un homme méprisé et soumis à la douleur, l'autre, qui doit avoir lieu, ainsi qu'il les prédit, quand il reviendra des cieux, dans la gloire, avec l'armée de ses anges. Alors il ressuscitera les corps de tous les hommes qui ont existé et il revêtira les justes d'incorruptibilité, mais il enverra les méchants au feu éternel, avec les mauvais démons, pour une souffrance éternelle. 4 Ces événements à venir ont été prédits eux-aussi, nous allons le montrer. 5 Voici ce qui a été dit par le prophète Ezéchiel: "L'articulation se réunira à l'articulation, l'os à l'os, et les chairs repousseront. 6 Tout genou fléchira devant le Seigneur et toute langue le célébrera". 7. Dans quelle souffrance et dans quel châtiment doivent être les méchants, écoutez une sentence analogue qui concerne ce sujet. 8 En voici les paroles: "Leur ver ne cessera pas et leur feu ne s'éteindra pas". 9 Cest alors qu'ils se repentiront, quand cela ne servira plus à rien. 10 Mais ce que diront et feront les tribus des juifs, quand elles verront le Christ revenir dans la gloire, le prophète Zacharie l'a annoncé en ces termes: "Je commanderai au vent du nord de les porter et au vent du sud de ne pas les arrêter. 11 Et alors, à Jérusalem, il y aura une grand lamentation, non pas de la bouche et des lèvres, mais une lamentation du cœur; ils ne déchireront pas leurs vêtements mais leurs

51.7 Ps 24,7-8 • 51.9 Da 7,13; Za 14,5; Mt 25,31 - 52.3 Is 53,2; Da 7,13-14 • 52.5 Ez 37,

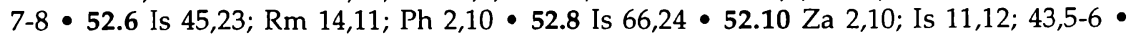
52.11 Za 12,10-12; Jl 2,13 


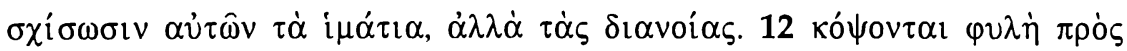

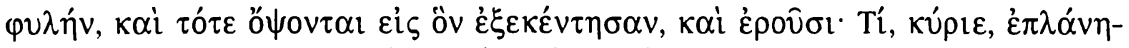

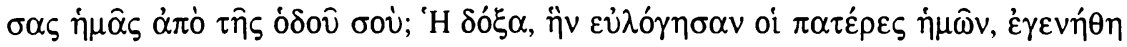

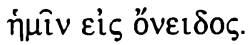

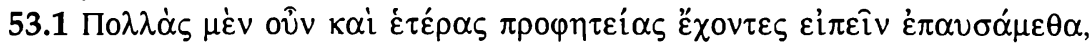

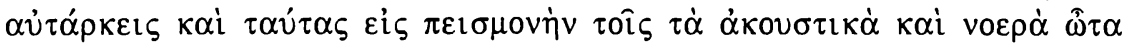

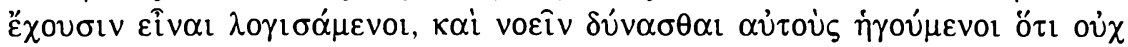

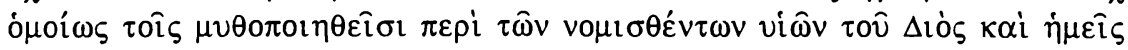

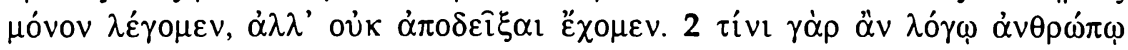

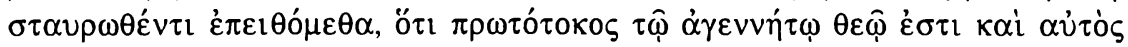

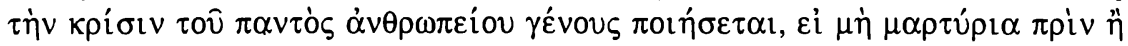

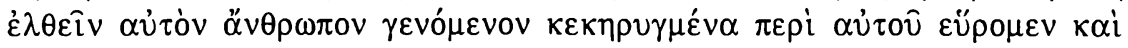

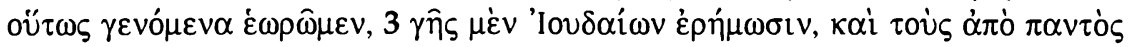

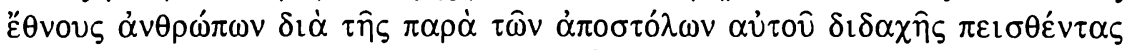

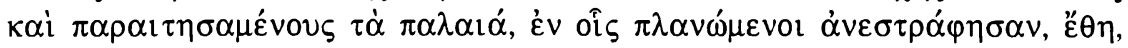

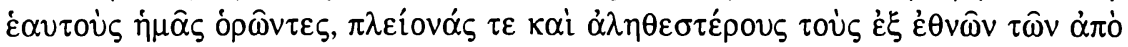

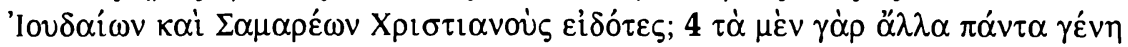
$\dot{\alpha} v \theta \rho \omega ́ \pi \varepsilon l \alpha$ vं

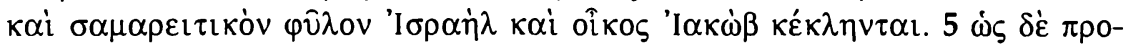

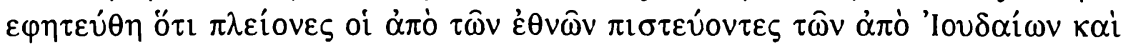

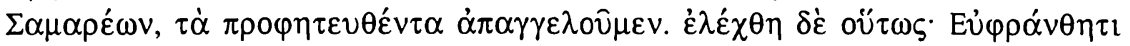

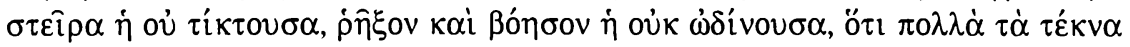

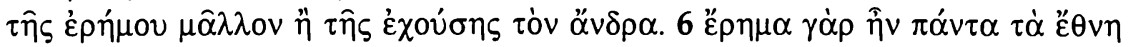

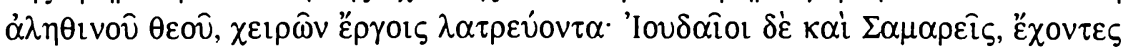

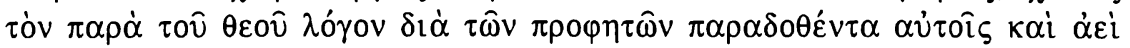

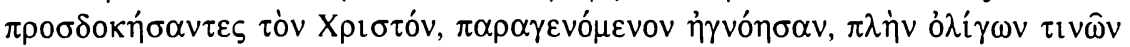

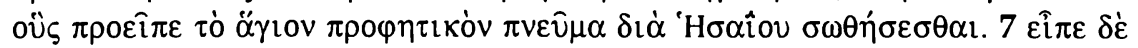

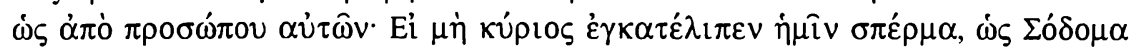

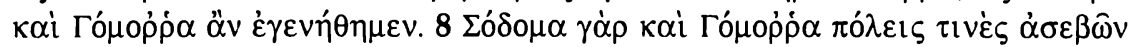

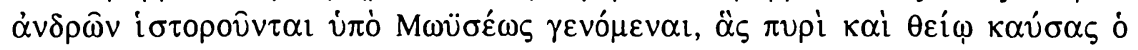

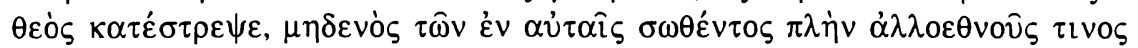

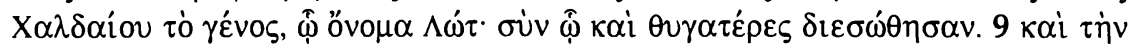

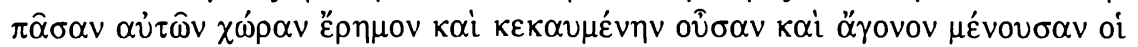

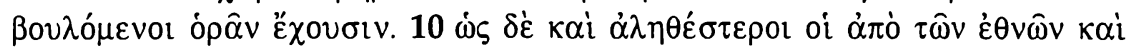

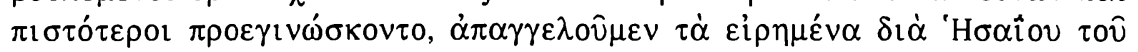

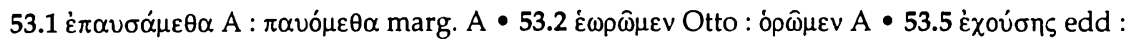

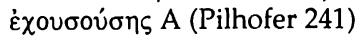


consciences. 12 Ils se lamenteront tribu à tribu; et alors ils regarderont vers celui qu'ils ont transpercé et ils diront: Pourquoi, Seigneur, nous as-tu fait errer loin de ton chemin? La gloire que nos pères bénissaient est devenue pour nous un opprobre".

53.1 Bien que nous ayons encore beaucoup d'autres prophéties à citer, nous nous en tiendrons là, persuadés que celles que nous avons alléguées suffisent à convaincre ceux qui ont des oreilles pour entendre et comprendre: ils peuvent comprendre, croyons-nous, qu'à la différence des fables inventées sur les prétendus fils de Zeus, nous ne nous contentons pas d'affirmer, sans pouvoir apporter de preuves. 2 Pour quelle raison, en effet, croirions-nous d'un homme crucifié qu'il est le premier-né du Dieu inengendré et qu'il jugera le genre humain tout entier, si nous ne trouvions les témoignages qui le concernent proclamés d'avance, avant même qu'il ne fût devenu homme, et si nous ne les voyions réalisés de la sorte: 3 la dévastation du pays des Juifs, les hommes de toutes les nations accédant à la foi après avoir reçu la doctrine des apôtres et rejetant les antiques traditions dans lesquelles ils vivaient égarés, et si nous ne voyions pas que nous-mêmes, issus de la Gentilité, nous sommes devenus chrétiens, plus nombreux et plus sincères que ceux qui sont d'origine juive ou samaritaine. 4 Car les autres races d'hommes sont appelées "Gentils" par l'Esprit prophétique, par opposition aux tribus de Judée et de Samarie, qui sont appelées "Israël" et "maison de Jacob". 5 Comme il fut annoncé que les croyants de la Gentilité seraient plus nombreux que ceux d'origine juive et samaritaine, nous rapporterons cette prophétie. Elle est conçue en ces termes: "Réjouis-toi, stérile, toi qui n'as pas d'enfants; éclate en cris de joie, toi qui ne connais pas les douleurs, car les enfants de la femme délaissée sont plus nombreux que ceux de la femme qui a un époux". $6 \mathrm{De}$ fait, délaissées étaient toutes les nations qui, loin du vrai Dieu, adoraient des ouvrages faits de main d'homme, mais les Juifs et les Samaritains, qui possédaient la parole de Dieu que leur avaient transmise les prophètes, et qui attendaient le Christ depuis toujours, ne surent pas les reconnaître, à sa venue, sauf un petit nombre, dont le saint Esprit prophétique a annoncé le salut par la bouche d'Isaïe. 7 Celui-ci, parlant en leur nom, s'est exprimé en ces termes: "Si le Seigneur ne nous avait laissé une semence, nous serions devenus comme Sodome et Gomorrhe". 8 Sodome et Gomorrhe sont deux villes de gens impies, dont Moïse raconte l'histoire et que Dieu ruina par le feu et le soufre. Aucun de ses habitants ne fut sauvé, excepté un étranger, d'origine chaldéenne, nommé Loth qui échappa avec ses filles. 9 Toute cette contrée, déserte, brûlée, demeure stérile: ceux qui le désirent peuvent le constater de visu. 10 Comment enfin il avait été prévu que ceux qui viendraient de la Gentilité seraient plus sincères et plus

52.12 Za 12,12; Is 63,17; 64,10 - 53.1 Mt 13,9; Mc 4,9; Lc 8,8 • 53.5 Is 54,$1 ;$ Ga 4,27 • 53.7 Is $1,9 \cdot \mathbf{5 3 . 7 - 8}$ Gn 19 


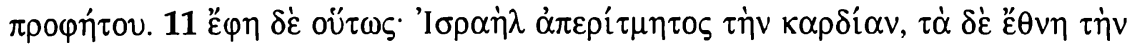

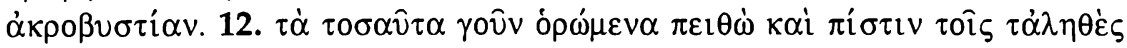

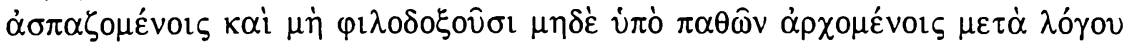
$\dot{\varepsilon} \mu \varphi \circ \rho \hat{\jmath} \sigma \alpha \mathrm{l} \delta \dot{v} \alpha \tau \alpha \mathrm{l}$.

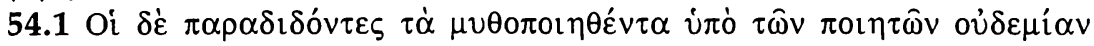

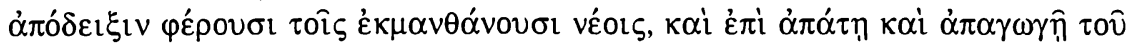

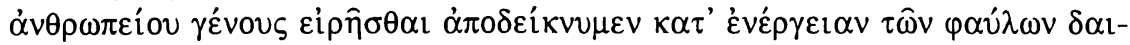

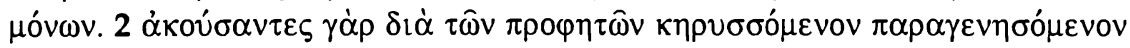

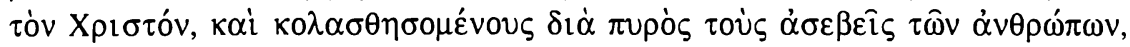

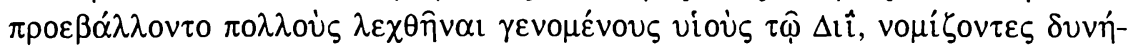

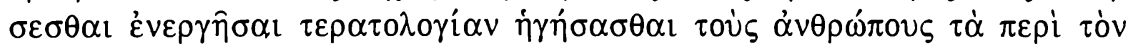

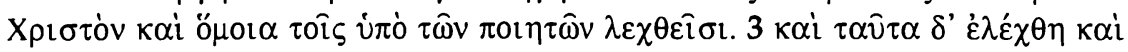

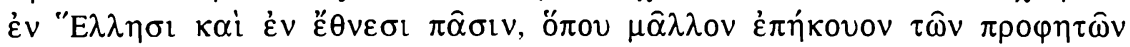

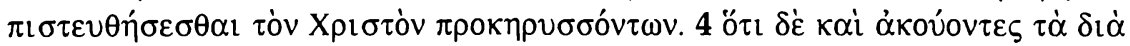

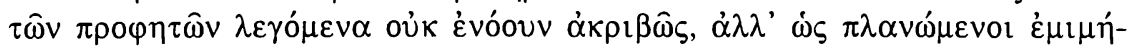

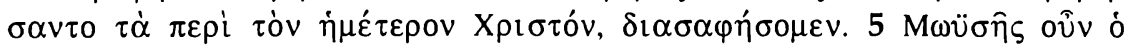

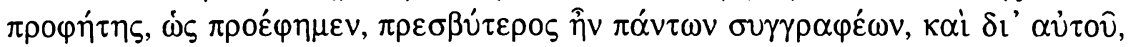

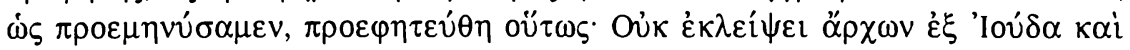

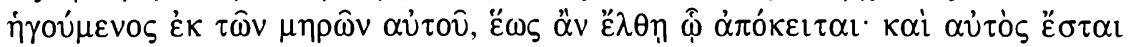

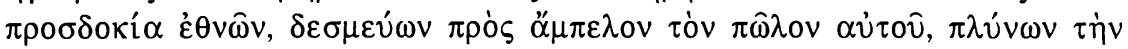

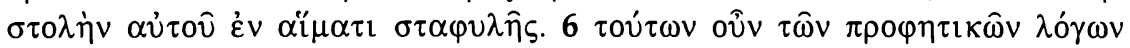

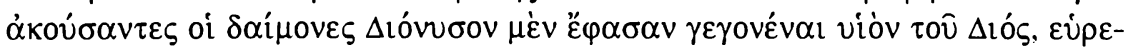

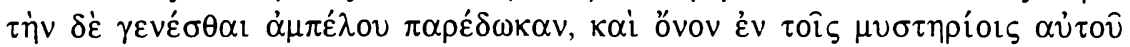

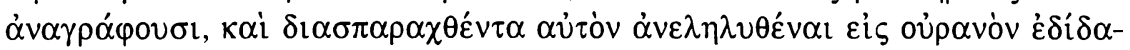

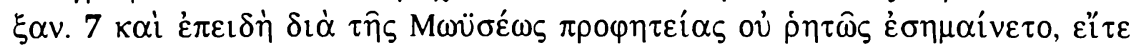

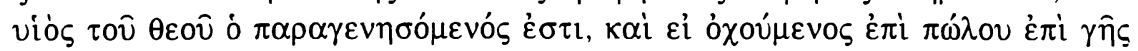

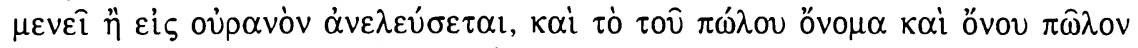

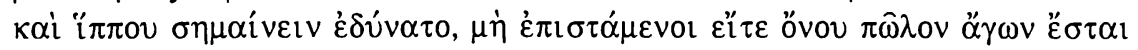

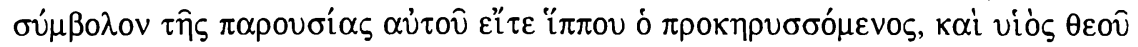

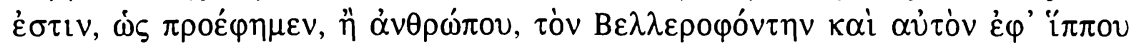

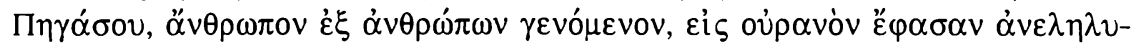

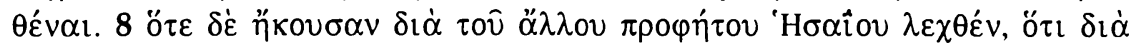

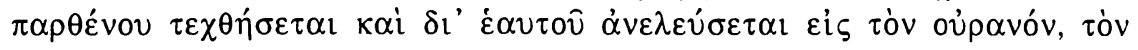

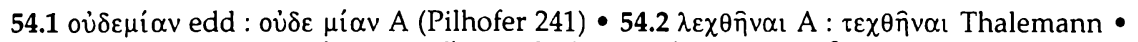

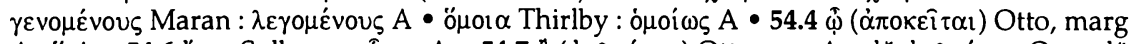

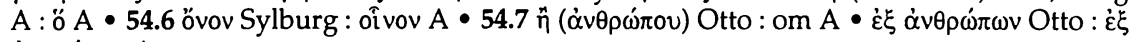
$\dot{\alpha} \vee \theta \rho \omega ́ \pi \circ 0 v \mathrm{~A}$

54.6 Pline, Hist.nat. 24,1 
fidèles, nous allons le montrer en citant les paroles du prophète Isaïe à ce sujet. 11 Les voici: "Israël est incirconcis dans son cœur, les Gentils ne le sont que dans leur chair". Tous ces témoignages visibles peuvent certainement, avec l'aide de la raison, faire naître persuasion et foi chez ceux qui s'attachent à la vérité, ne se laissent pas diriger par l'opinion et ne sont pas esclaves de leurs passions.

54.1 Ceux qui enseignent les fables inventées par les poètes n'apportent aucune preuve à l'appui de leurs dires aux jeunes gens qui les apprennent, tandis que nous prouvons qu'elles ont été composées, à l'instigation des mauvais démons, en vue de tromper et d'égarer le genre humain. 2 Ceuxci, en effet, sachant par les prophètes que le Christ devait venir et que les impies seraient punis par le feu, entreprirent de faire attribuer à Zeus un grand nombre de fils, car ils comptaient bien pouvoir obtenir ainsi que les hommes considèrent tout ce qui concerne le Christ comme une invention mensongère et du même acabit que les fables racontées par les poètes. 3 Ces récits ont été répandus chez les grecs et dans toutes les nations, là surtout où les démons savaient, grâce aux prédictions des prophètes, que leurs habitants croiraient au Christ. 4 Mais s'ils connaissaient les paroles des prophètes, les démons n'en comprenaient pas exactement le sens; nous alons montrer qu'il imitèrent ce qui concerne notre Christ à contresens, comme des gens qui marchent à l'aveuglette. 5 Ainsi donc le prophète Moïse comme nous l'avons dit plus haut, vivait avant tous les écrivains en question et, comme nous l'avons indiqué plus haut, il avait fait la prophétie suivante: "Il ne manquera pas de prince de la descendance de Juda ni de chef de sa race jusqu'à ce que vienne celui à qui il est réservé; il sera l'attente des nations, il attachera son poulain à la vigne et il lavera sa robe dans le sang de la grappe". 6 Comme ils avaient eu connaissance de ces paroles prophétiques, les démons racontèrent donc que Dionysios était né fils de Zeus et transmirent qu'il avait découvert la vigne; ils inscrivirent un âne dans ses mystères et enseignèrent qu'il est monté au ciel après avoir été mis en pièces. 7 Comme la prophétie de Moïse n'indiquait pas expressément si celui qui devait venir était fils de Dieu ni si, assis sur un poulain, il devait rester sur terre ou monter au ciel, - de plus, le nom de poulain pouvait signifier le petit d'un âne aussi bien que celui d'un cheval -, ne sachant pas si celui qui était annoncé devait, en signe de son avènement, être assis sur le petit d'un âne ou sur celui d'un cheval, ne sachant pas non plus s'il serait fils de Dieu, comme nous l'avons dit plus haut, ou fils d'un homme, ils racontèrent que Bellérophon, qui était un homme et un fils des hommes, était monté au ciel sur le cheval Pégase. 8 Lorsque'ils apprirent, par la bouche d'Isaïe, l'autre prophète, que le Christ devait naître d'une vierge et remonter au ciel par sa propre

53.11 Jr $9,24-25 \bullet 54.5$ Gn $49,10-11 \bullet 54.8$ Is 7,14 


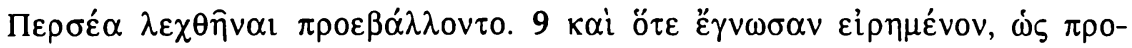

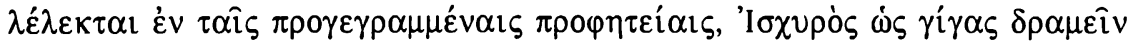

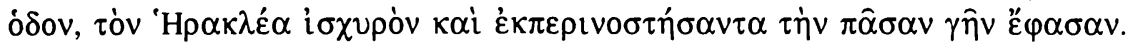

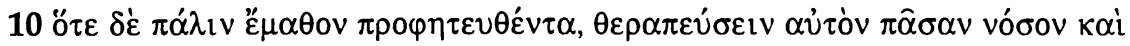

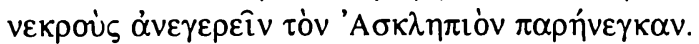

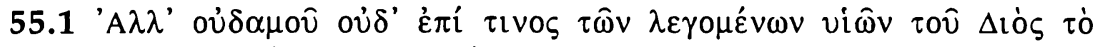

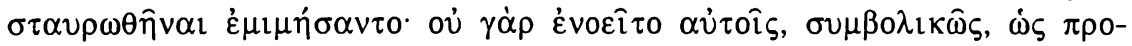

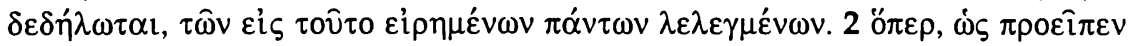

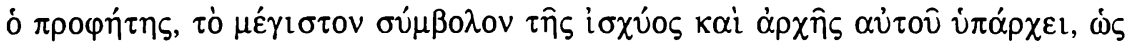

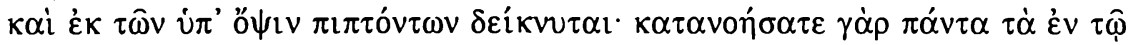

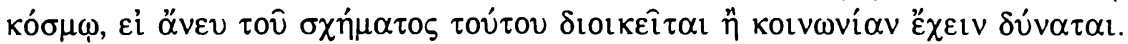

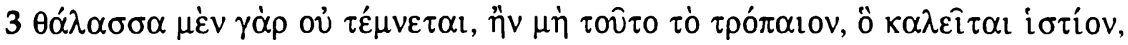

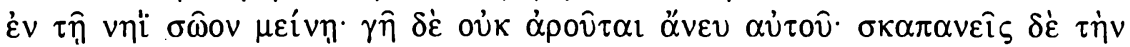

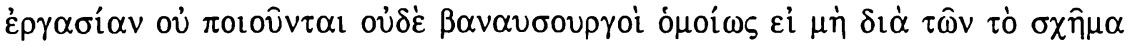

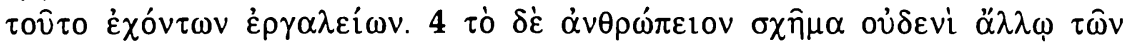

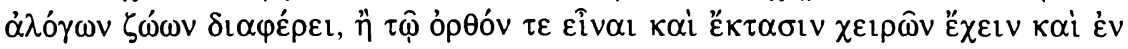

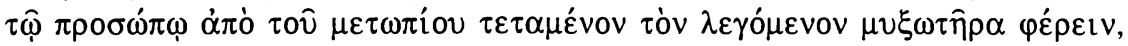

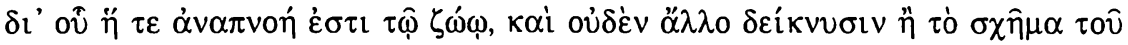

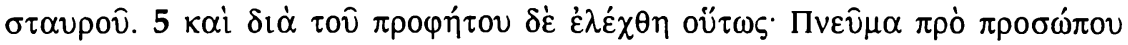

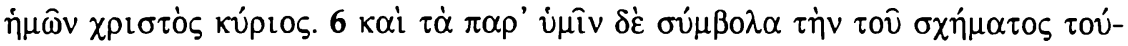

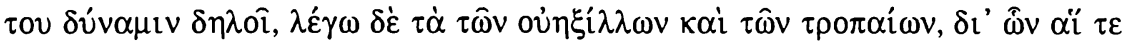

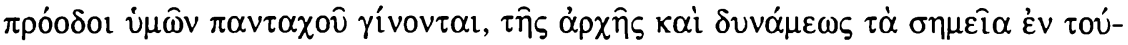

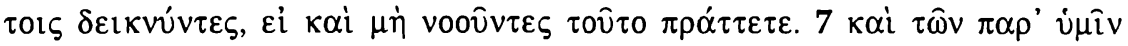

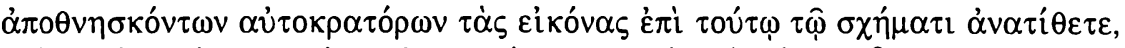

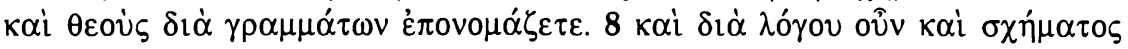

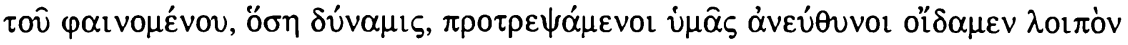

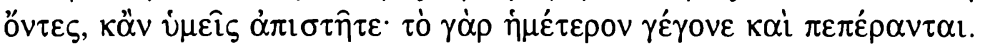

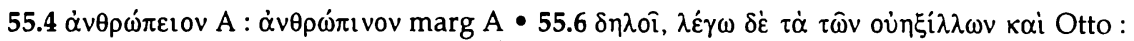

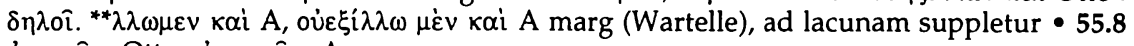

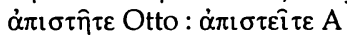


puissance, ils produisirent la légende de Persée. 9 Et quand ils apprirent qu'il était dit, dans les prophéties mentionnées plus haut: "Fort comme un géant, pour parcourir sa carrière", ils déclarèrent qu'Hercule était ce géant et qu'il avait parcouru la terre entière. $10 \mathrm{Et}$ encore, lorsqu'ils surent qu'il était prédit que le Christ devait guérir toute maladie et ressusciter les morts, ils mirent en avant Asclépios.

55.1 Mais jamais et pour aucun des prétendus fils de Zeus ils n'ont proposé une imitation de la mise en croix; de fait, cela ne leur vint pas à l'esprit, parce que tout ce qui avait été dit à ce sujet l'avait été sous forme de symbole, comme on l'a indiqué plus haut. 2 Et pourtant, comme l'avait prédit le prophète, c'est précisément en cela que consiste le symbole majeur de la force du Christ et de son autorité, comme on le voit aussi d'après les objets qui tombent sous les sens: considérez, en effet, toutes les choses qui existent dans le monde, et demandez-vous s'il en est une seule qui puisse exister ou avoir sa consistance, si elle est dépourvue de cette forme. 3 La mer ne peut être fendue, si ce signe de victoire, appelé ici le mât, ne se dresse intact sur le navire; la terre ne peut être labourée sans lui; les défricheurs, tout comme les manœuvres, ne peuvent accomplir leur travail qu'avec des instruments qui présentent cette forme. 4 Quant à l'aspect de l'être humain, le seul point qui les distingue de celui des animaux dépourvus de raison, c'est qu'il se tient droit et peut étendre les mains et encore que, sur son visage, à partir du front, la proéminence du nez, l'organe de la respiration du vivant, dessine précisément le signe de la croix. 5 Aussi bien le prophète a-t-il déclaré: "Le souffle de notre visage, c'est le Christ, le Seigneur". 6 Les symboles en usage chez vous manifestent aussi la puissance de ce signe, je veux parler des étendards et des trophées, qui vous précèdent partout dans vos déplacements et par lesquels vous produisez les preuves de votre autorité et de votre puissance, même si vous le faites sans en avoir conscience. 7 Et quand vos empereurs viennent à mourir, vous consacrez leurs images sous cette forme et vous les divinisez dans les inscriptions. 8 En faisant appel au raisonnement et à un signe manifeste nous avons cherché à vous convaincre, autant que nous le pouvions; nous savons que désormais nous n'avons rien à nous reprocher, même si vous demeurez dans l'incrédulité, car nous avons fait notre devoir et notre tâche est achevée. 


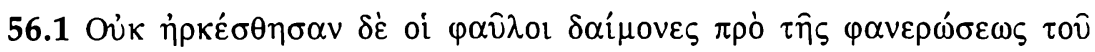

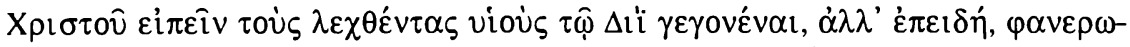

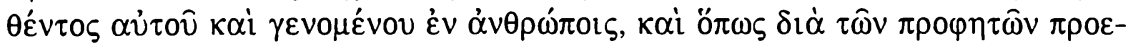

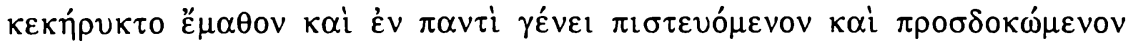

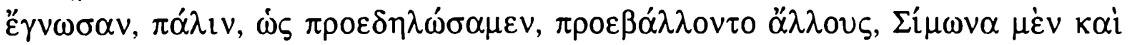

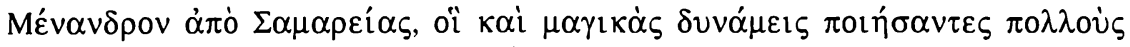

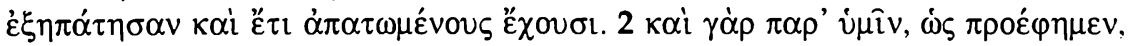

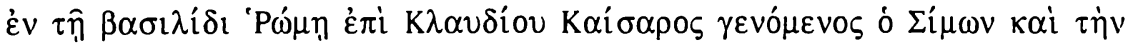

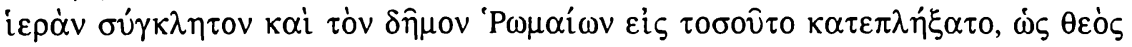

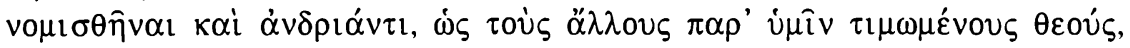

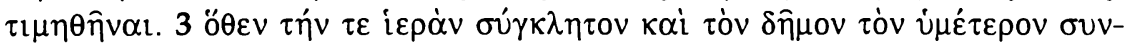

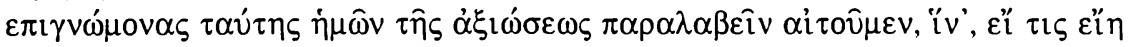

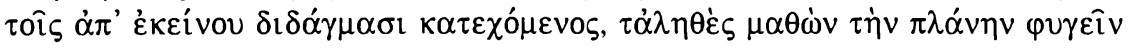

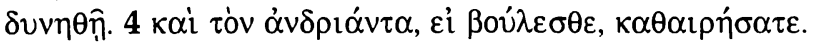

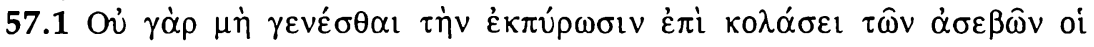

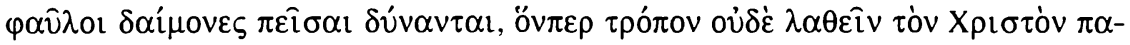

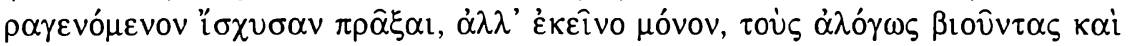

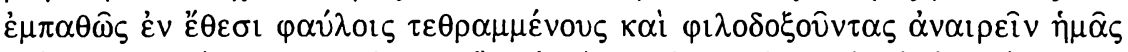

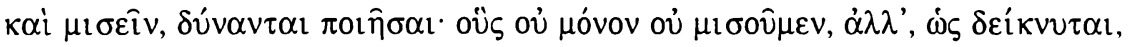

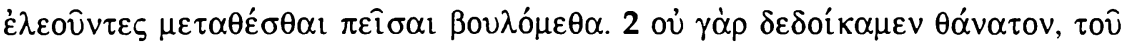

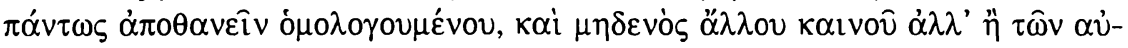
$\tau \hat{\omega} v \dot{\varepsilon} v \tau$ ๆ

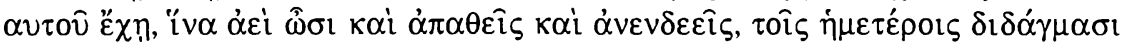

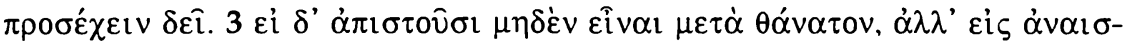

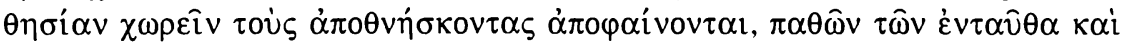

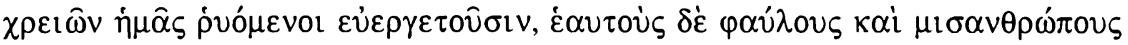

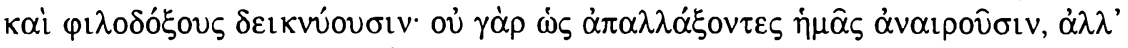

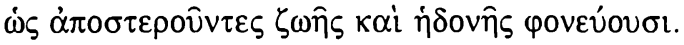

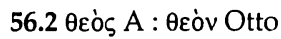

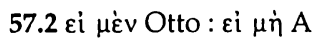

57.2 Marc-Aurèle, 11,3; Epictète, Dissert. IV,7,6; Lucien, Peregr. 13 • 57.3 Platon, Apol. $41 \mathrm{D}$ 
56.1 Les mauvais démons ne se sont pas contentés, avant la manifestation de Christ, de répandre les légendes relatives aux prétendus fils de Zeus, mais après sa manifestation et son avènement parmi les hommes, sachant comment il avait été annoncé par les prophètes et comprenant qu'il était la foi et l'attente de toutes les nations, ils suscitèrent d'autres personnages, comme nous l'avons indiqué plus haut, Simon et Ménandre de Samarie qui, par des opérations de magie ont séduit beaucoup de gens, qu'ils maintiennent encore dans l'erreur. 2 En effet, quand Simon vint chez vous, dans votre cité impériale de Rome sous Claude César, comme nous l'avons dit plus haut, il fit une telle impression sur le vénérable Sénat et sur le peuple romain, qu'il fut considéré comme un dieu et qu'on éleva une statue en son honneur, comme on le fait pour ceux qui sont honorés chez vous comme des dieux. 3 C'est pourquoi nous vous demandons de faire connaître aussi au vénérable Sénat et à votre peuple la requête que nous vous adressons, afin que, si quelqu'un se trouvait encore impliqué dans les doctrines de cet homme, il apprenne la vérité et puisse échapper à l'erreur. 4 Quant à la statue, faites-la détruire, s'il vous plaît.

57.1 Les mauvais démons sont incapables de persuader que la destruction du monde par le feu n'est pas réservée au châtiment des impies, tout comme ils n'ont pu faire en sorte que la venue du Christ demeurât cachée. Tout ce qu'ils peuvent faire, c'est de pousser des gens qui vivent contrairement à la raison, selon leurs passions, pour avoir été élévés en des habitudes mauvaises, et qui se laissent guider par l'opinion, à nous mettre à mort, à nous haïr; ceux-là non seulement nous ne les haïssons pas mais, comme il est manifeste, nous avons pitié d'eux et nous désirons les persuader de se convertir. 2 Car nous ne craignons pas la mort, tout le monde reconnaît que de toute façon il faut mourir, et il n'y a rien de nouveau dans la marche du monde, mais les choses sont toujours les mêmes. Si le dégoût s'empare de ceux qui en ont joui, ne fût-ce que pendant un an, il leur faut, pour vivre à jamais exempts de souffrance et de besoin, s'attacher à notre doctrine. 3 Mais s'ils croient qu'il n'y a plus rien après la mort, et prétendent que ceux qui meurent parviennent à un état d'insensibilité, ils nous rendent service en nous arrachant aux souffrances et aux besoins de cette vie, mais ils se révèlent eux-mêmes méchants, ennemis de l'humanité et amis des apparences, car ce n'est pas pour nous délivrer qu'ils nous suppriment, mais ils nous font mourir en croyant nous priver ainsi de la vie et du bonheur. 


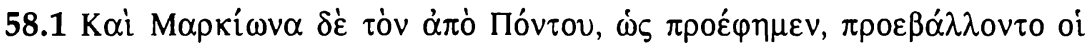

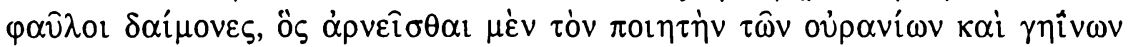

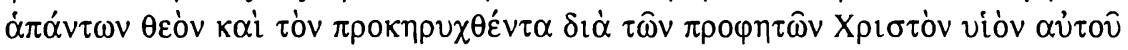

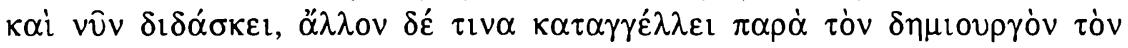

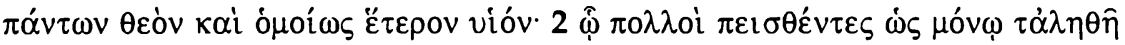

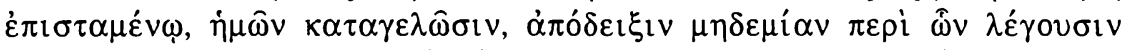

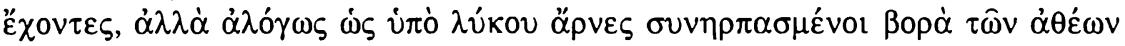

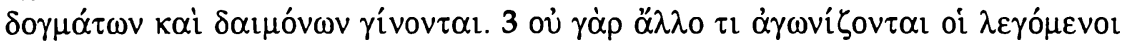

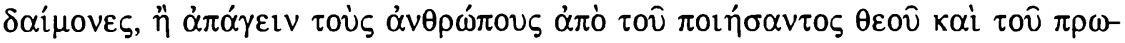

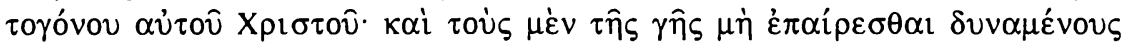

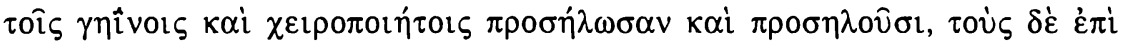

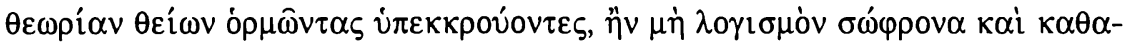

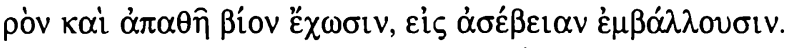

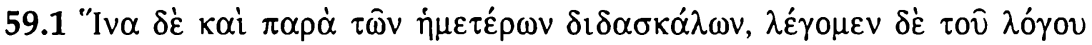

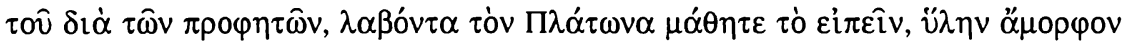

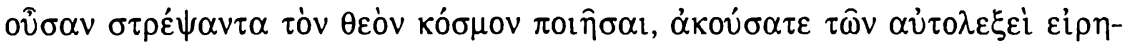

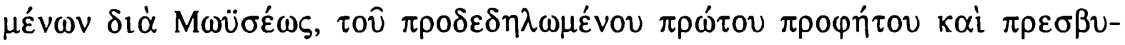

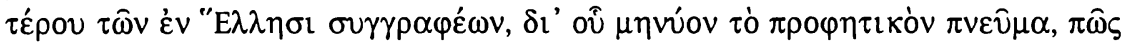

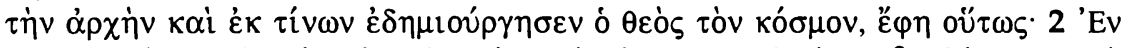

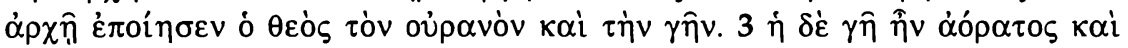

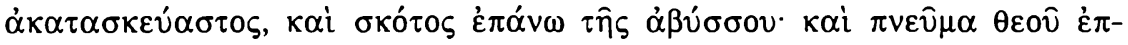

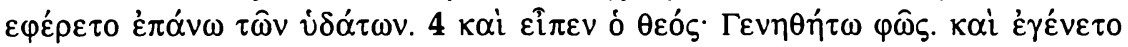

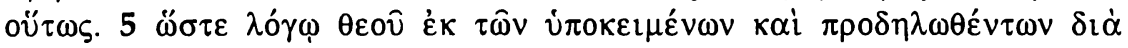

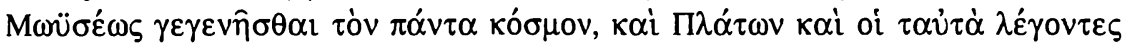

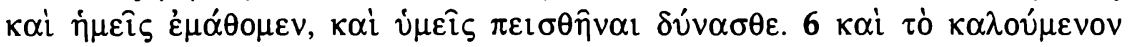

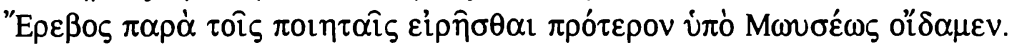

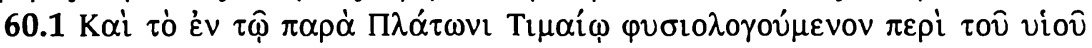

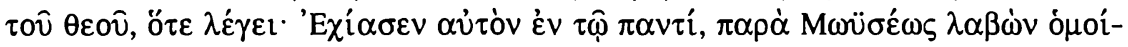

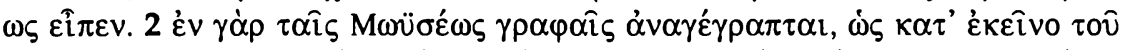

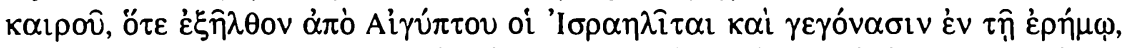

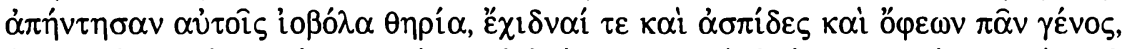

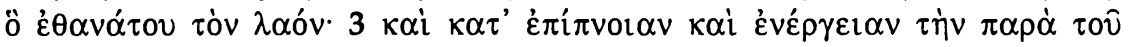

$58.1 \tau \dot{\jmath} v(\pi \dot{\alpha} v \tau \omega v) \mathrm{A}: \tau \hat{\omega} v$ Otto

$59.5 \tau \alpha u \dot{\alpha} \dot{\alpha}$ Thirlby : $\tau \alpha \hat{\tau} \alpha \mathrm{A}$

59.1 Platon, Tim. 29E-30B; 55A-B; 69BC $\bullet 59.6$ Hésiode, Theog. $123 \bullet 60.1$ Platon, Tim. 36BC 
58.1 Les mauvais démons ont suscité aussi Marcion, originaire du Pont, comme nous l'avons dit plus haut, qui maintenant encore enseigne à nier que Dieu soit le créateur de tout ce qui existe au ciel et sur la terre et que celui qui a été annoncé par les prophètes soit le Christ, son Fils; il prêche un autre Dieu à côté du Dieu créateur de l'univers, et pareillement un autre fils. 2 Beaucoup ont cru en lui, comme s'il était le seul à connaître la vérité, et ils se moquent de nous bien qu'ils n'aient aucune preuve à l'appui de ce qu'ils affirment; mais, stupidement, comme des brebis emportées par un loup, ils deviennent la proie des doctrines athées et des démons. 3 Car les démons en question ne déploient leurs efforts qu'en vue de détourner les hommes du Dieu créateur, et de son premier-né, le Christ. Ceux qui ne peuvent pas s'élever au-dessus de la terre, ils les ont cloués et les clouent aux choses terrestres et faites de la main de l'homme, mais ceux qui cherchent à s'élever jusqu'à la contemplation des choses divines, ils les harcèlent et, s'ils ne gardent un jugement sain et ne mènent une vie pure et exempte de passions, ils les précipitent dans l'impiété.

59.1 Pour que vous compreniez que c'est à nos maîtres, je veux dire à l'enseignement transmis selon laquelle Dieu a créé l'univers en façonnant une matière informe, écoutez les paroles expresses de Moïse, mentionné plus haut, qui fut le premier des prophètes, antérieur aux écrivains de la Grèce: par son intermédiaire l'Esprit prophétique a indiqué comment et à partir de quoi Dieu, au commencement, a façonné l'univers. Il s'est exprimé en ces termes: "Au commencement Dieu créa le ciel et la terre. 3 Or la terre était invisible et informe et les ténèbres étaient au-dessus de l'abîme; et l'Esprit de Dieu était porté au-dessus des eaux. 4 Et Dieu dit: Que la lumière soit, et il en fut ainsi". 5 Ainsi donc, c'est par une parole de Dieu que tout l'univers est venu à l'existence à partir des éléments mentionnés d'abord par Moïse; Platon et les tenants de la même doctrine l'ont appris de lui, ainsi que nous-mêmes, et vous pouvez vous laisser persuader à votre tour. 6 Nous savons aussi que l'Erèbe, dont parlent les poètes, a été mentionné auparavant par Moïse.

60.1 Lorsque, dans le Timée, dissertant des choses de la nature, Platon dit à propos du fils de Dieu: "Il l'a imprimé dans l'univers comme un X", c'est encore à Moïse qu'il a emprunté cette notion. 2 Il est rapporté, en effet, dans les écrits de Moïse, qu'à l'époque où les enfants d'Israël sortirent d'Egypte et furent au désert, ils furent assaillis par des animaux venimeux, vipères, aspics, serpents de toute espèce, qui semaient la mort parmi le peuple. 3 Sous l'inspiration et la motion de Dieu, Moïse

$59.2 \mathrm{Gn} 1,1-3 \cdot 60.2 \mathrm{Nb} 21,6-9$ 


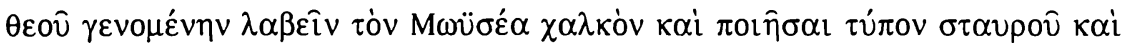

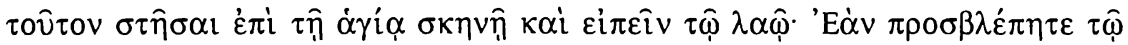

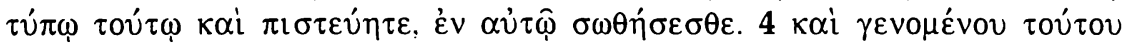

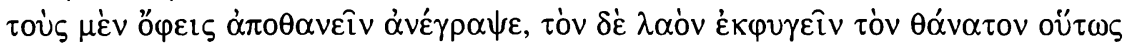

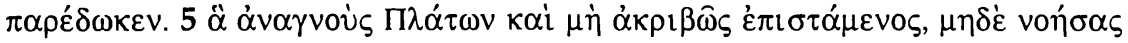

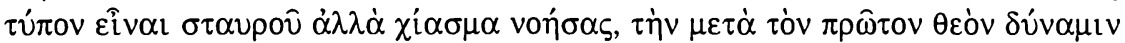

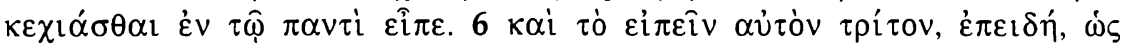

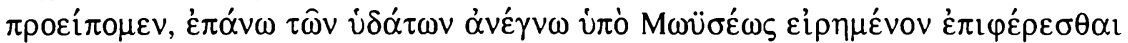

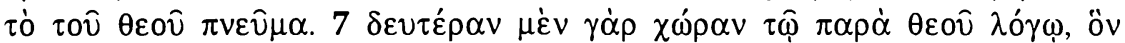

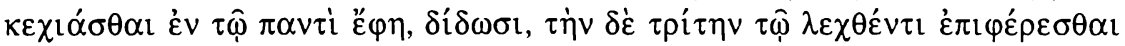

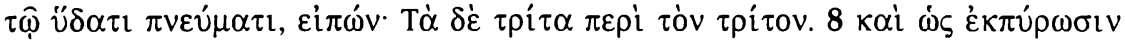

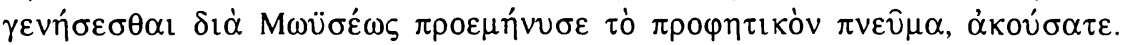

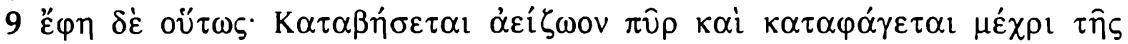

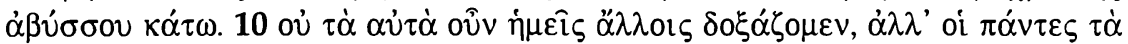

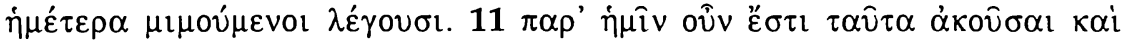

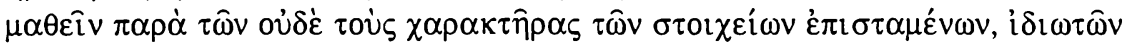

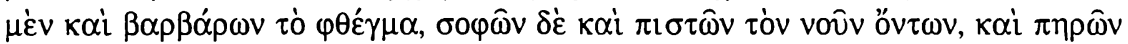

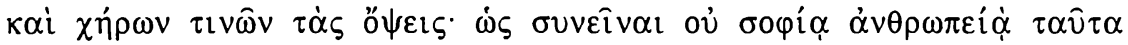

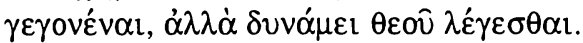

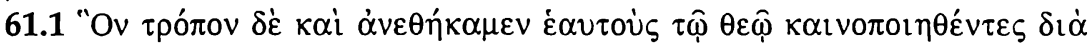

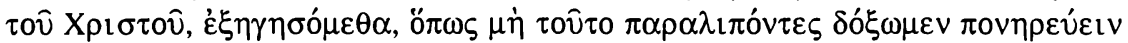

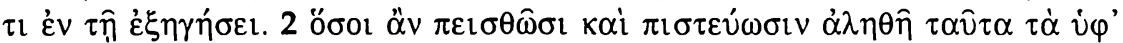

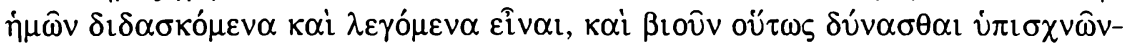

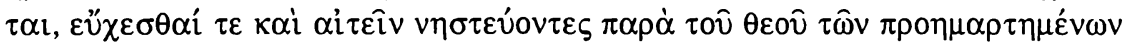

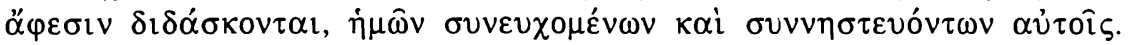

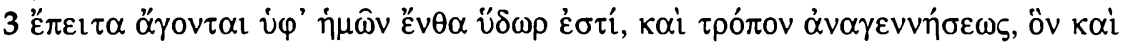

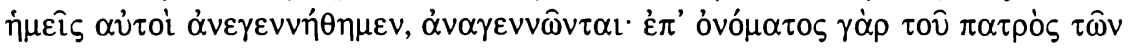

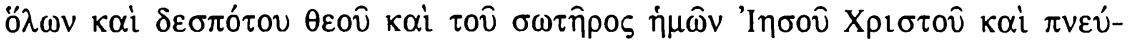

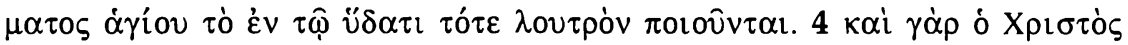

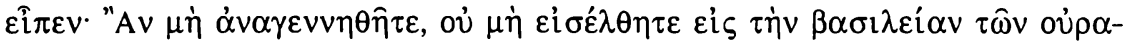

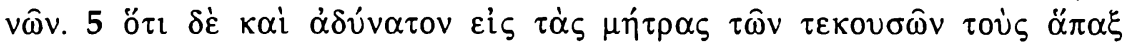

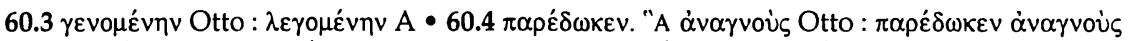

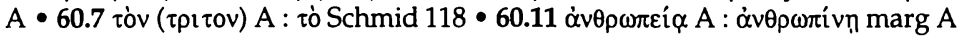

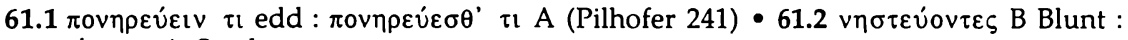

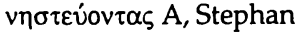

60.7 Ps.Platon, ep. II,312E; Proclus, Theol.Platon. II,11 
prit de l'airain et en fit une figure en forme de croix, qu'il dressa sur le saint tabernacle, et il dit au peuple: "Si vous regardez vers cette figure et si vous croyez, vous trouverez en elle votre salut". 4 A la suite de cela, écrit-il, les serpents périrent et c'est ainsi que le peuple échappa à la mort, rapporte-t-il. 5 Platon lut ce récit, mais ne l'ayant pas exactement compris et n'ayant pas reconnu qu'il s'agissait de la forme d'une croix (érigée), mais, ayant cru qu'il s'agissait d'une disposition en chiasme (X), il dit qu'après Dieu, le premier principe, la seconde puissance est imprimée dans l'univers sous la forme d'un X. 6 Et s'il parle d'une troisième puissance, c'est parce que, comme nous l'avons dit plus haut, il avait lu les paroles de Moïse, selon lesquelles l'Esprit de Dieu était porté audessus des eaux. 7 Car il assigne la deuxième place au Logos venu de Dieu, dont il affirme qu'il est imprimé dans l'univers sous la forme d'un $X$, et il assigne la troisième place à l'Esprit, dont il a été dit qu'il était porté au-dessus des eaux, quand il dit: "Les troisièmes sont autour du troisième". 8 Écoutez encore comment l'Esprit prophétique a annoncé par la bouche de Moïse que doit survenir une conflagration universelle. 9. Il s'est exprimé en ces termes: "Un feu toujours vivant descendra et dévorera jusqu'au fond de l'abîme". 10 Ainsi donc ce n'est pas nous qui avons les mêmes opinions que les autres, mais tous ne font qu'imiter et répéter les nôtres. $11 \mathrm{Chez}$ nous, du reste, on peut les entendre et les apprendre auprès de gens qui ne connaissent pas même les caractères de l'écriture, gens ignorants et barbares par leur langage, mais sages et dignes de foi pour ce qui est de la pensée, même si certains d'entre eux sont infirmes ou aveugles, si bien que l'on peut comprendre par là que ce n'est pas l'œuvre d'une sagesse humaine mais l'expression de la puissance de Dieu.

61.1 Nous allons vous exposer aussi de quelle façon, renouvelés par le Christ, nous nous sommes consacrés à Dieu, de peur que, si nous omettions ce point, nous ne paraissions présenter un exposé en partie défectueux. 2 Tous ceux qui se laissent convaincre et croient à la vérité de nos enseignements et de notre doctrine, et qui déclarent pouvoir y conformer leur vie, nous leur apprenons à prier et à demander à Dieu dans le jeûne la rémission de leurs péchés antérieurs, et nous-mêmes nous prions et nous jeûnons avec eux. 3 Ensuite ils sont conduits par nous dans un endroit où il y a de l'eau, et ils sont régénérés selon le mode de régénération que nous avons connu nous-mêmes: car c'est au nom de Dieu, le Père et souverain de l'univers, de notre Sauveur Jésus Christ, et de l'Esprit saint, qu'ils prennent alors dans l'eau le bain purificateur. 4 Car le Christ a dit: "Si vous n'êtes pas régénérés, vous n'entrerez pas dans le royaume des cieux". 5 Or, il est bien évident pour tout le monde qu'il est impossible,

60.3 Nb 21,8 • 60.6 Gn 1,2 60.9 Dt 32,22? $\bullet 60.111$ Cor 2,5 61.3 Mt 28,19 61.4 Jn 3,3; Mt 18,$3 ;$ Jn 3,5 


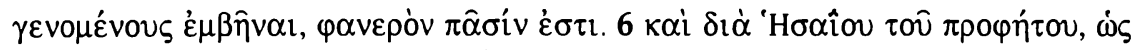

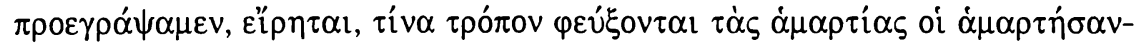

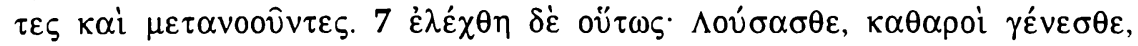

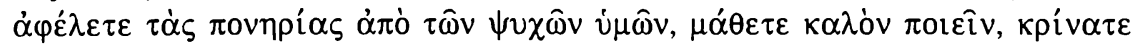

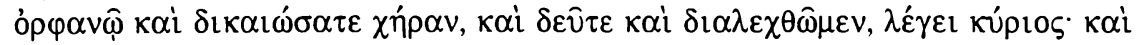

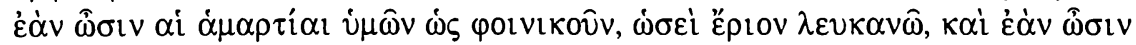

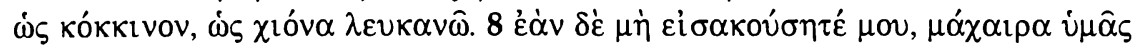

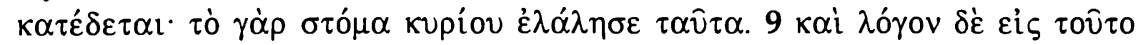

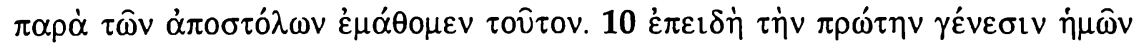

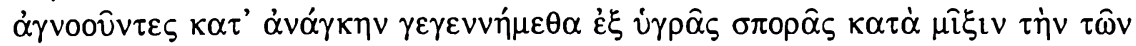

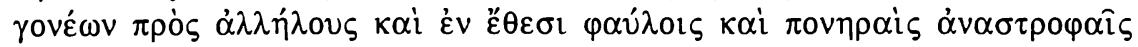

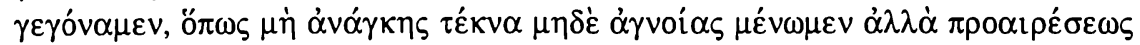

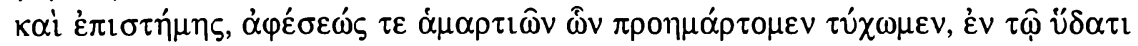

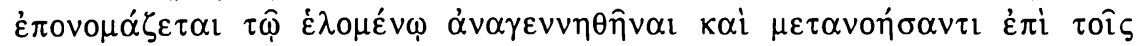

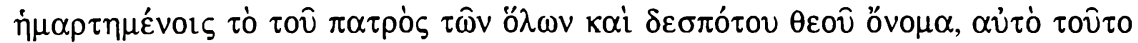

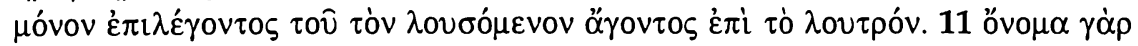

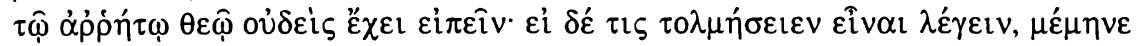

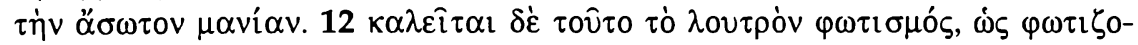

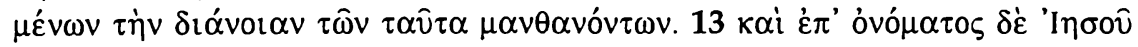

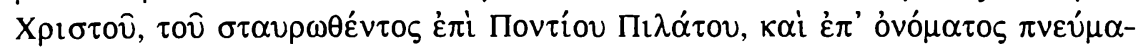

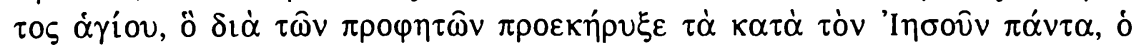

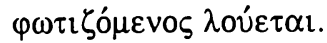

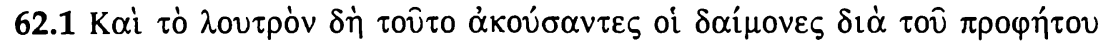

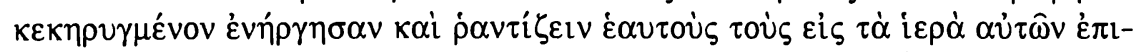

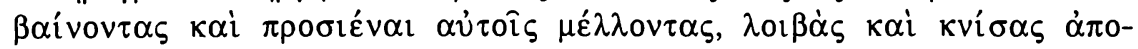

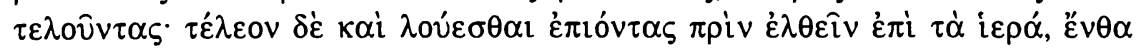

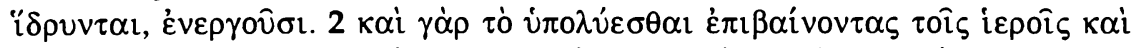

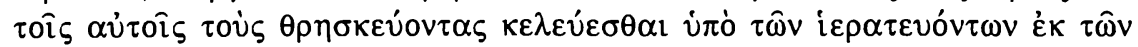

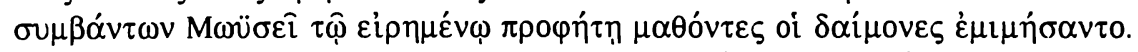

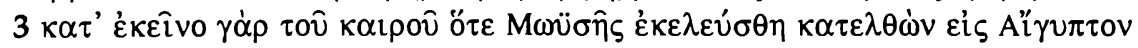

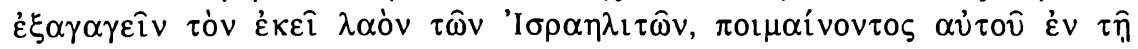

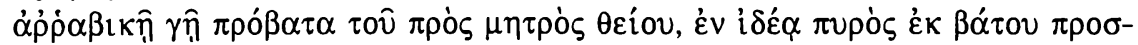

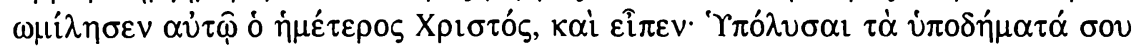

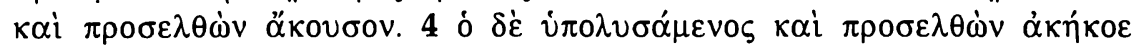

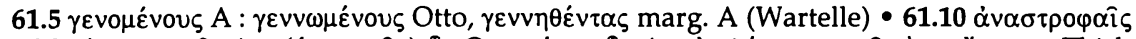

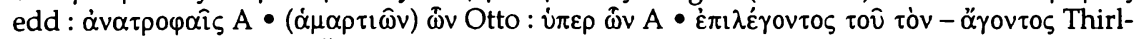

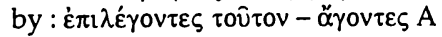

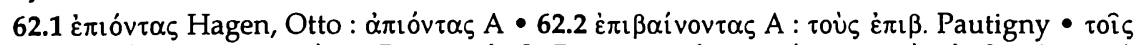

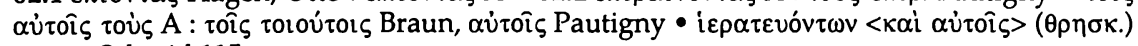
transp Schmid 115 
pour ceux qui sont nés une fois pour toutes, de rentrer dans le sein de leur mère. 6 Comme nous l'avons écrit plus haut, le prophète Isaïe a expliqué de quelle manière ceux qui ont péché et qui font pénitence peuvent échapper à leurs péchés. 7 Voici ses paroles: "Lavez-vous, devenez purs, chassez les méchancetés de vos âmes, apprenez à faire le bien, jugez en faveur de l'orphelin, et rendez justice à la veuve, puis venez, et faisons les comptes, dit le Seigneur. Et si vos péchés sont comme la pourpre, je les rendrai blancs comme laine, et s'ils sont comme l'écarlate, je les rendrai blancs comme neige. 8 Mais si vous ne m'écoutez pas, le glaive vous dévorera car la bouche du Seigneur a parlé". 9 Pour agir ainsi, nous avons reçu des apôtres l'enseignement suivant. 10 Etant donné que, lors de notre première génération, nous avons été engendrés sans le savoir, selon la loi de la nécesssité, d'une semence liquide, du fait de l'union mutuelle de nos parents, et que nous sommes nés avec des habitudes mauvaises et des penchants pervers, pour que nous ne demeurions pas enfants de la nécessité et de l'ignorance, mais que nous devenions, au contraire, enfants de la liberté et de la science, pour obtenir la rémission de nos péchés antérieurs, on invoque, dans l'eau, sur celui qui a choisi librement d'être régénéré et qui a fait pénitence de ses péchés, le nom de Dieu, le Père et souverain de l'univers, et c'est ce nom seul qui est invoqué, par celui qui le conduit au bain, sur celui qui doit le prendre. 11 Personne, en effet, ne peut donner un nom au Dieu ineffable, et si quelqu'un avait l'audace de dire qu'il en existe un, c'est qu'il aurait sombré dans une folie inguérissable. 12 Ce bain est appelé illumination, parce que ceux qui comprennent ces choses, ont l'esprit inondé de lumière. 13 C'est aussi au nom de Jésus-Christ, qui a été crucifié sous Ponce-Pilate, et au nom de l'Esprit saint qui, par la bouche des prophètes, a prédit tout ce qui concerne Jésus, que celui qui est illuminé est lavé.

62.1 Comme ils avaient eu connaissance aussi de ce bain purificateur, annoncé par les prophètes, les démons voulurent que s'aspergent euxmêmes ceux qui entrent dans leurs temples et se présentent devant eux, pour offrir des libations et des sacrifices; de plus ils exigent qu'on prenne un bain avant de pénétrer dans les sanctuaires où ils résident. 2 Quant à l'usage selon lequel les prêtres ordonnent de se déchausser à ceux qui entrent dans les temples pour y rendre un culte aux démons, ceux-ci l'ont imité pour l'avoir appris de ce qui est arrrivé au prophète Moïse, dont il a été question. 3 En effet, à l'époque où Moïse reçut l'ordre de descendre en Égypte et d'en faire sortir le peuple d'Israël, - il gardait alors en Arabie les troupeaux de son oncle maternel -, notre Christ, sous l'apparence d'un feu sortant d'un buisson, lui adressa la parole et lui dit: "Enlève tes chaussures, approche et écoute". 4 Il se déchaussa, s'approcha et reçut 


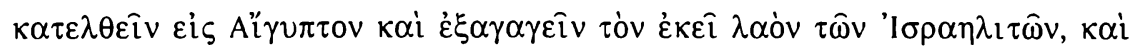

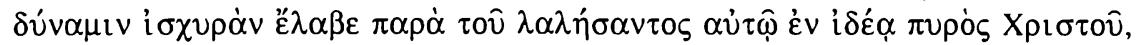

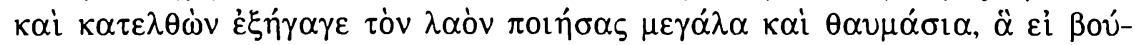

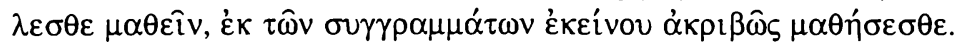

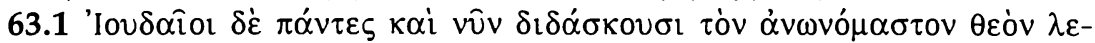

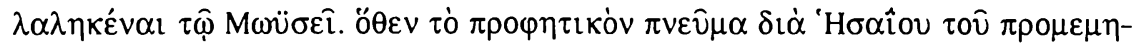

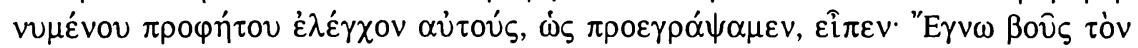

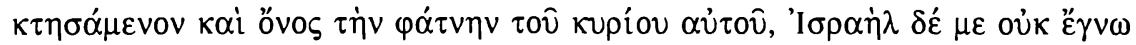

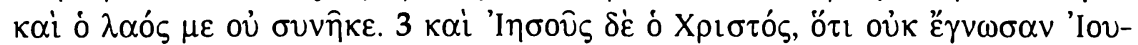

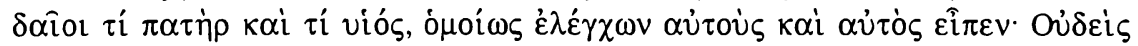

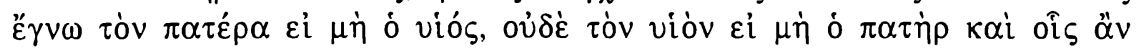

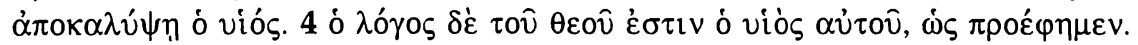

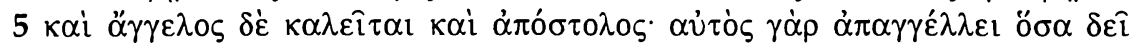

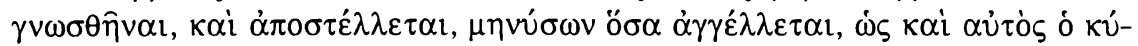

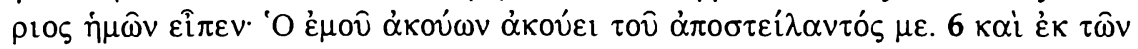

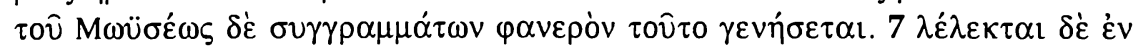

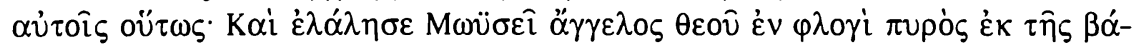

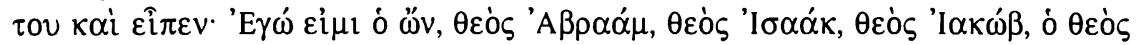

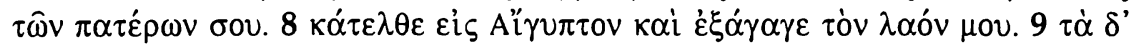

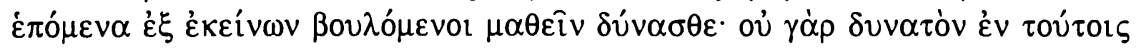

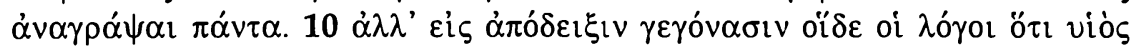

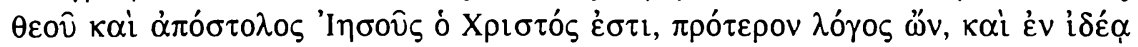

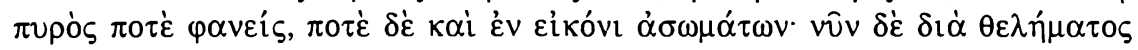

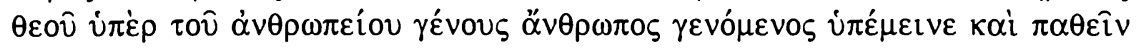

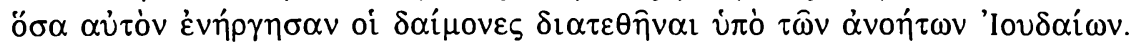

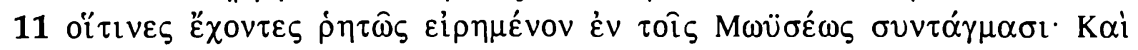

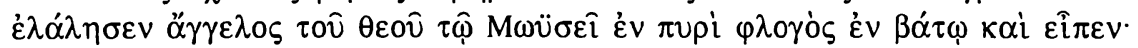

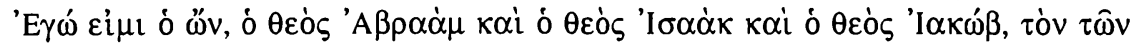

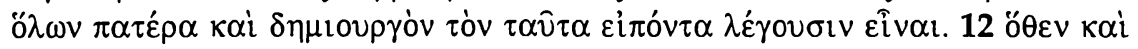

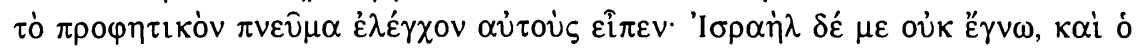

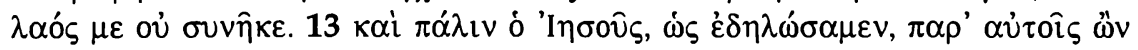

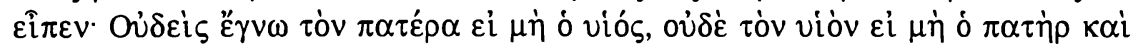

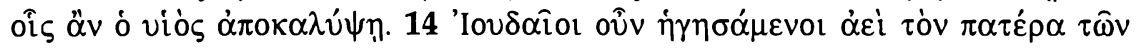

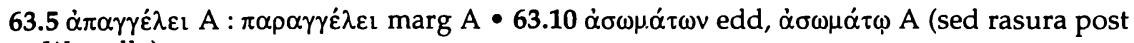
$\omega:$ Wartelle) 
l'ordre de descendre en Égypte et d'en faire sortir le peuple d'Israël; il reçut une puissance considérable de la part du Christ qui lui avait parlé sous l'apparence d'un feu; il descendit et fit sortir le peuple, après avoir accompli de grands et merveilleux prodiges, si vous voulez les connaître, vous pourrez en apprendre le détail dans ses écrits.

63.1 Tous les Juifs aujourd'hui encore enseignent que c'est le Dieu qu'on ne peut nommer qui a parlé à Moïse. 2 C'est pourquoi, comme nous l'avons écrit plus haut, l'Esprit prophétique les réprimande en ces termes par la bouche du prophète Isaiie, déjà mentionné: "Un bœuf connaît son possesseur et un âne la crèche de son maître, mais Israël ne m'a pas connu et mon peuple ne m'a pas compris". 3 Jésus le Christ réprimande lui aussi les Juifs, parce qu'ils n'ont pas connu ce qu'est le Père ni ce qu'est le Fils, et il leur dit: "Nul ne connaît le Père si ce n'est le Fils, et nul ne connaît le Fils si ce n'est le Père et ceux à qui le Fils l'a révélé". 4 Or, le Logos de Dieu est son Fils, comme nous l'avons dit. 5 Il est appelé aussi Ange (messager) et Apôtre (envoyé), car il est messager de tout ce qu'il faut connaître et envoyé pour révéler tout le message, comme l'a dit notre Seigneur lui-même: "Celui qui m'écoute écoute celui qui m'a envoyé". 6 Cela apparaîtra à l'évidence d'après les écrits de Moïse. 7 Voici ce qui y est dit: "Un ange de Dieu parla à Moïse dans une flamme de feu du sein du buisson et lui dit: je suis celui qui est, le Dieu d'Abraham, le Dieu d'Isaac, le Dieu de Jacob, le Dieu de tes pères. 8 Descends en Égypte et fais-en sortir mon peuple". 9 La suite, vous pouvez la connaître, si vous le désirez, en lisant ces écrits, car il n'est pas possible de tout rapporter ici. 10 Mais ces textes ont été cités en vue de démontrer que Jésus le Christ est le Fils de Dieu et son Envoyé, parce qu'il est d'abord son Logos et il s'est manifesté tantôt sous l'apparence d'un feu, tantôt sous une figure incorporelle, mais à notre époque il est devenu homme par la volonté de Dieu, pour sauver le genre humain, et il a accepté de souffrir tous les tourments que les démons avaient entrepris de lui faire subir par l'intermédiaire des Juifs en leur déraison. 11 Ceux-ci avaient pourtant ces paroles expresses consignées dans les écrits de Moïse: "Un ange de Dieu parla à Moïse dans une flamme de feu au sein du buisson et lui dit: Je suis celui qui est, le Dieu d'Abraham, le Dieu d'Isaac, le Dieu de Jacob", mais ils prétendent que celui qui a parlé ainsi est le Père et le créateur de l'univers. 12 C'est pourquoi l'Esprit prophétique les réprimande en ces termes: "Israël ne m'a pas connu et mon peuple ne m'a pas compris". $13 \mathrm{~A}$ son tour Jésus, comme nous l'avons montré, a dit, quand il était au milieu d'eux: "Nul n'a connu le Père si ce n'est le Fils et nul n'a connu le Fils si ce n'est le Père et ceux à qui le Fils l'a révélé". 14 Les Juifs donc,

63.2 Is $1,3 \bullet 63.3$ Mt 11,27; Jn 7,29; 8,19; 16,3; 10,15; Lc 10,22 • 63.5 Lc 10,16; Mt 10,40 • 63.7 Ex 3,2; 3,14-15; 3,10 • 63.11 Ex 3,2; 3,14; 3,6 • 63.12 Is 1,3 • 63.13 Mt 11,27; Lc 10,22; Jn 7,$29 ; 8,19 ; 16,3 ; 10,15$ 


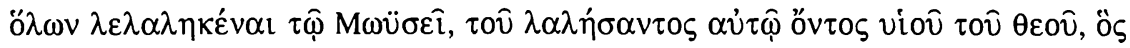

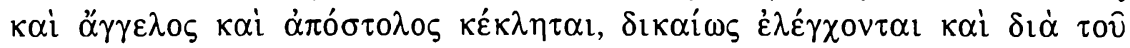

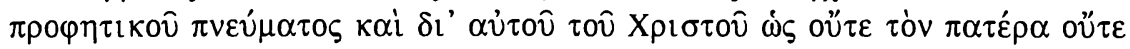

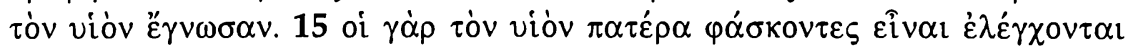

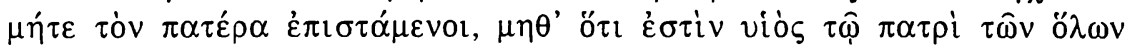

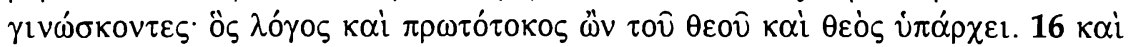

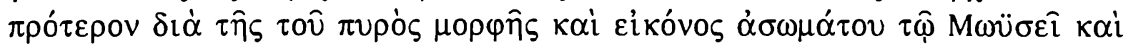

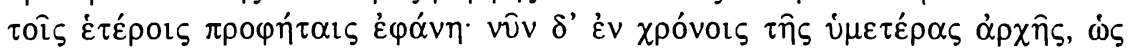

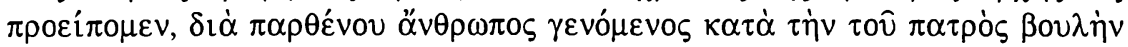

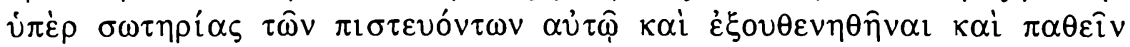

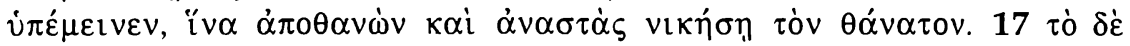

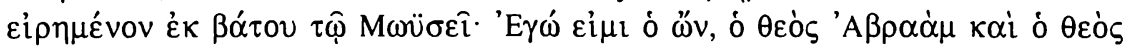

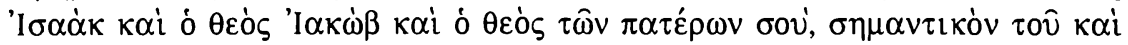

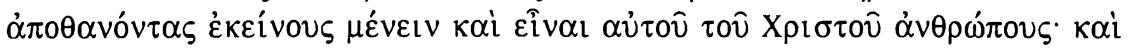

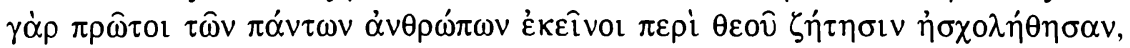

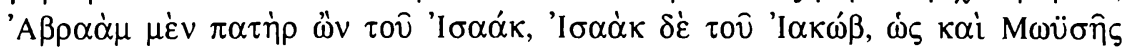
$\dot{\alpha} v \varepsilon \varepsilon_{\gamma} \alpha \psi \varepsilon$.

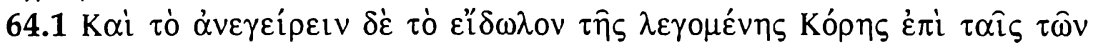

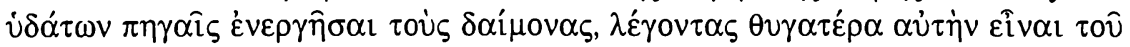

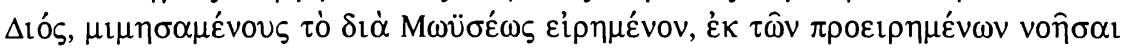

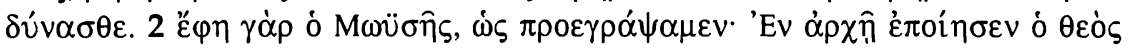

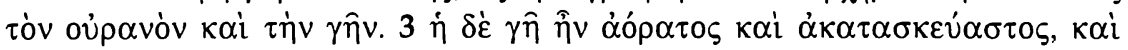

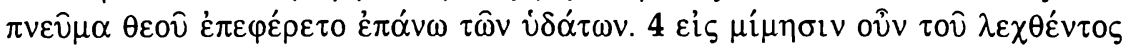

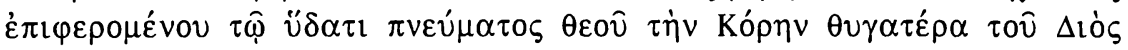

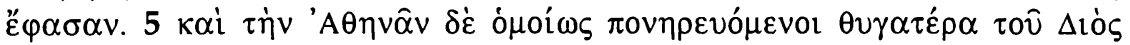

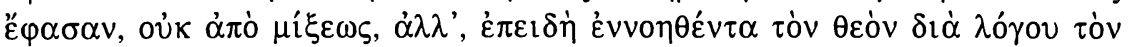

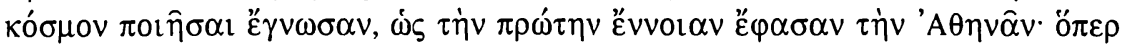

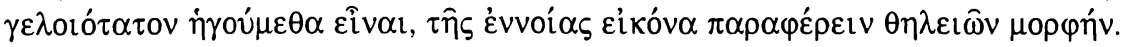

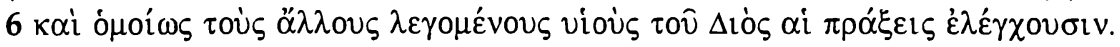

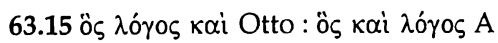

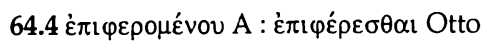

64.1 Diodore de Sicile, Bibl.Hist. 5,4; Pausanias, Perieg. IV,33,4 $\bullet 64.5$ Hésiode, Theog. 886s., Pindare, Olymp. VII,32 
parce qu'ils pensent toujours que c'est le Père de l'univers qui a parlé à Moïse, alors que c'est le Fils, qui est appelé aussi son Ange et son Envoyé, sont réprimandés à juste titre par l'Esprit prophétique et par le Christ lui même, pour n'avoir connu ni le Père ni le Fils. 15 De fait, ceux qui déclarent que le Fils est le Père encourent le reproche de ne pas connaître le Père et d'ignorer que le Père de l'univers a un fils: celui-ci, étant le Logos et le premier-né de Dieu, est Dieu également. 16 Il s'est manifesté en premier lieu, sous la forme du feu et sous une figure incorporelle, à Moïse et aux autres prophètes, et maintenant, au temps de votre empire, comme nous l'avons dit, né d'une vierge, il est devenu homme, selon la volonté du Père, pour le salut de ceux qui croient en lui, et il a accepté d'être compté pour rien et de souffrir, afin de vaincre la mort par sa mort et sa résurrection. 17 Les paroles que Moïse entendit sortir du buisson: "Je suis celui qui est, le Dieu d'Abraham, le Dieu d'Isaac, le Dieu de Jacob, le Dieu de tes pères", signifient que, même après leur mort, ces hommes demeurent, et sont les hommes du Christ lui-même. De fait, les premiers de tous les hommes, ils se sont employés à chercher Dieu: Abraham, qui fut le père d'Isaac, et Isaac, le père de Jacob, ainsi que Moïse l'a écrit.

64.1 Si l'on élève auprès des sources l'image de celle que l'on appelle Corè, c'est encore à l'instigation des démons, qui prétendent qu'elle est fille de Zeus, et qui imitent à ce qui a été dit par Moïse; vous pouvez le comprendre d'après ce que nous avons dit plus haut. 2 De fait, comme nous l'avons écrit, Moïse a dit: "Au commencement Dieu créa le ciel et la terre. 3 La terre était invisible et informe, et l'Esprit de Dieu était porté au-dessus des eaux". 4 C'est donc pour imiter ce qui est dit de l'Esprit de Dieu porté au-dessus des eaux, que les démons ont fait de Corè une fille de Zeus. 5 Pareillement leur malice leur a fait prétendre qu'Athéna était une fille de Zeus, née sans union charnelle; au contraire comme ils savaient que Dieu a créé par son Logos le monde, qu'il avait d'abord conçu dans sa pensée, ils prétendirent qu'Athéna était en quelque sorte cette première pensée. C'est là, croyons-nous, le comble du ridicule, que de proposer une figure féminine comme image de la pensée. 6 Il en est de même des autres prétendus fils de Zeus; leurs actions les confondent. 


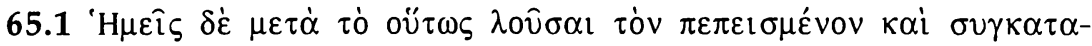

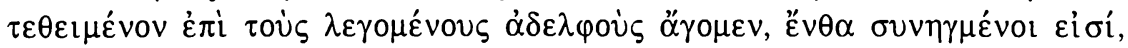

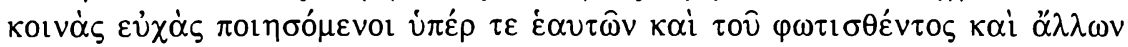

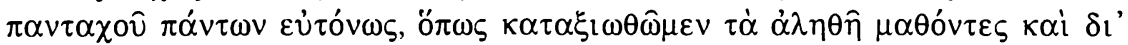

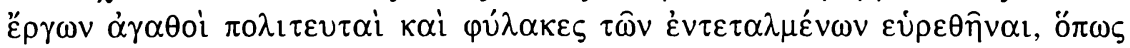

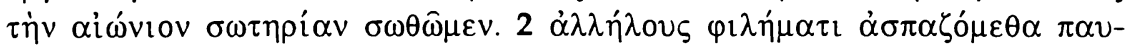

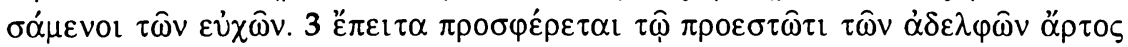

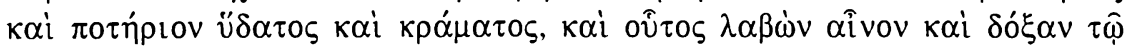

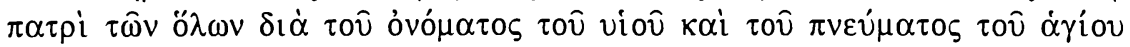

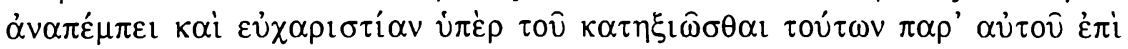

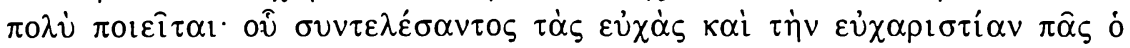

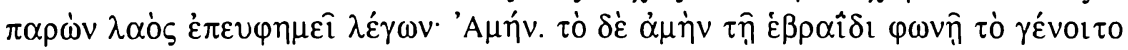

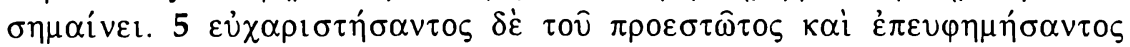

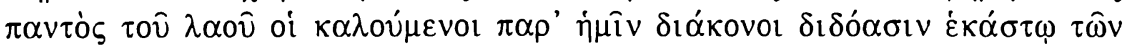

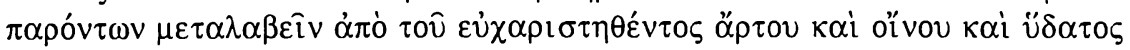

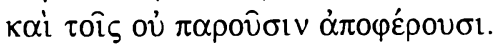

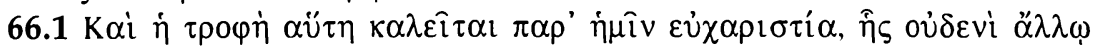

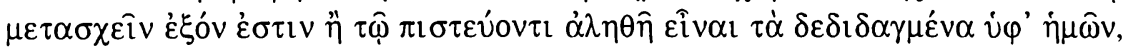

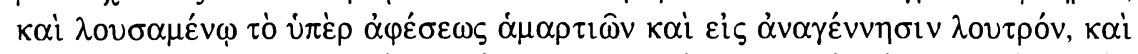

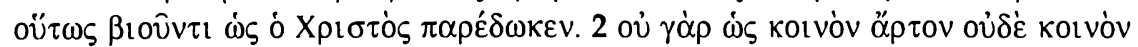

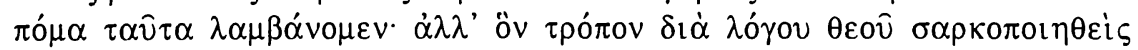
'I

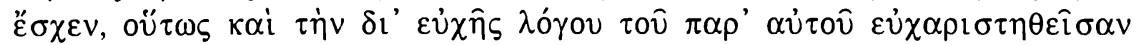

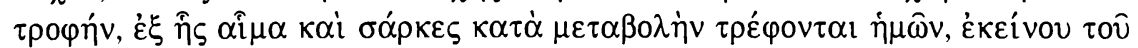

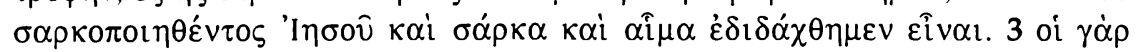

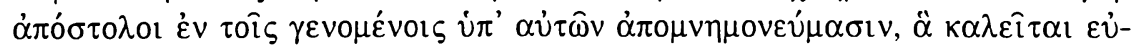

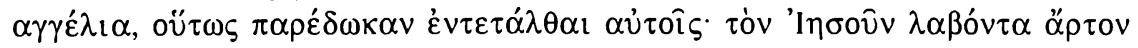

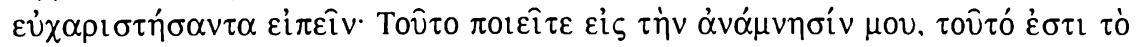

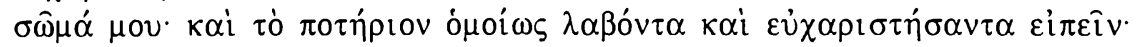

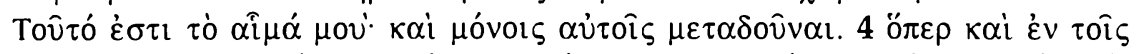

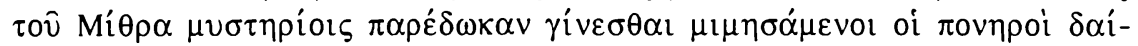

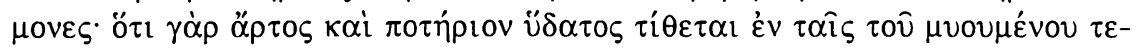

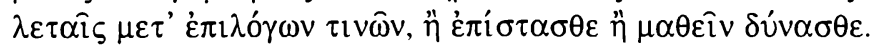

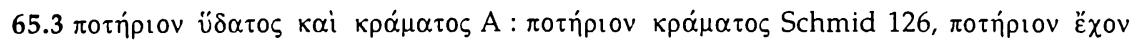

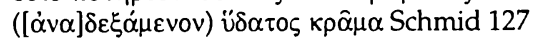

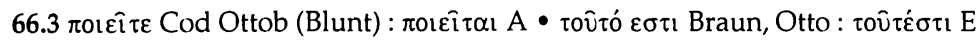

65.1 Pline le Jeune, ep. X,96,7 • 66.2 cf. Irénée, A.H. IV, 18,5 • 66.4 cf. Tertullien, Praesc. 40,4 ; Bapt. 5 
65.1 Quant à nous, après avoir ainsi lavé celui qui a embrassé la foi et donné son assentiment (à la doctrine), nous le menons après de ceux que nous appelons "les frères", au lieu où ils sont assemblés, afin de faire ensemble des prières ferventes pour nous-mêmes, pour celui qui a été illuminé, et pour tous les autres, où qu'ils se trouvent, afin qu'après avoir connu la vérité, nous méritions aussi, par nos actions, d'être reconnus comme gens de bonne conduite et bons observateurs des préceptes reçus, afin de parvenir ainsi au salut éternel. 2 Quand les prières sont terminées, nous nous saluons mutuellement par un baiser. 3 Ensuite on apporte à celui qui préside l'assemblée des frères du pain et une coupe d'eau et de vin trempé, il les prend et adresse louange et gloire au Père de l'univers, par le nom du Fils et de l'Esprit saint, et il fait une longue action de grâces pour tous les biens qu'il a daigné nous accorder. Quand il a terminé les prières et l'action de grâces, tout le peuple présent exprime son accord par des acclamations, en disant: Amen. 4 Amen est un mot hébreu, qui signifie: Ainsi soit-il. 5 Quand le président de l'assemblée a achevé la prière de l'eucharistie et que tout le peuple a exprimé son accord, ceux que nous appelons les diacres distribuent à chacun des assistants du pain et du vin mélangé d'eau, sur lesquels a été prononcée la prière de l'action de grâces, et ils en portent aussi aux absents.

66.1 Cette nourriture reçoit chez nous le nom d'eucharistie, et il n'est permis à personne d'y prendre part, s'il ne croit à la vérité de notre doctrine, s'il n'a reçu le bain pour la rémission des péchés et en vue de la régénération, et s'il ne vit selon les préceptes donnés par le Christ. 2 Car nous ne prenons pas cette nourriture comme du pain ni comme une boisson ordinaires mais, de même que Jésus Christ notre sauveur, fait chair par la vertu du Logos de Dieu, eut chair et sang pour notre salut, de même la nourriture "eucharistiée" par un discours de prière qui vient de lui - nourriture dont notre sang et nos chairs sont nourris par assimilation - est précisément, d'après ce que nous avons appris, la chair et le sang de ce Jésus fait chair. 3 En effet, les apôtres, dans leurs Mémoires, que l'on appelle Évangiles, rapportent qu'ils ont reçu les instructions suivantes: Jésus prit du pain, rendit grâces et dit: "Faites ceci en mémoire de moi; ceci est mon corps"; de même, il prit la coupe, rendit grâces et dit: "Ceci est mon sang", et c'est à eux seuls qu'il donna ces instructions. 4 Cet usage, précisément, les mauvais démons l'ont imité aussi dans la tradition des mystères de Mithra; en effet dans les cérémonies d'initiation, on présente du pain et une coupe d'eau, et on prononce en même temps certaines formules; vous le savez ou bien vous pouvez vous en assurer. 


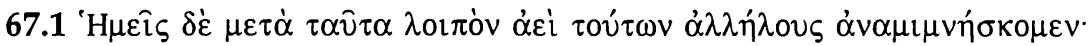

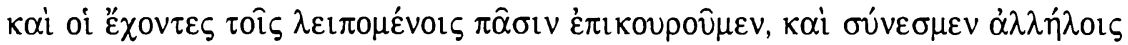

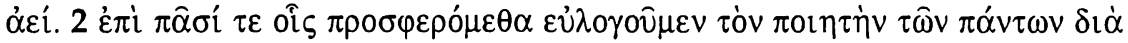

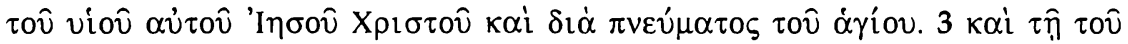

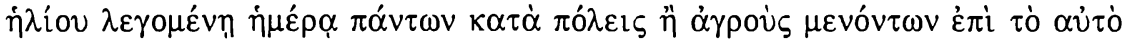

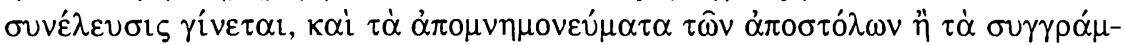

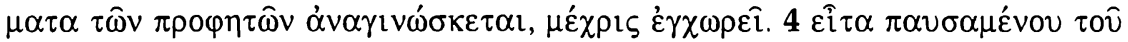

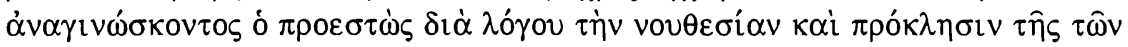

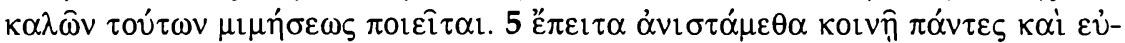

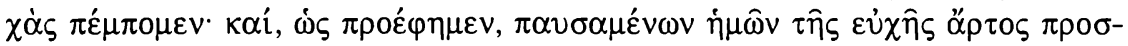

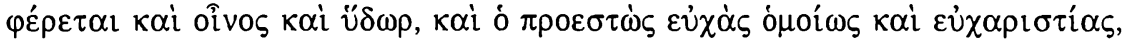

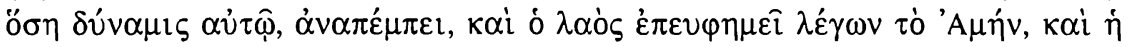

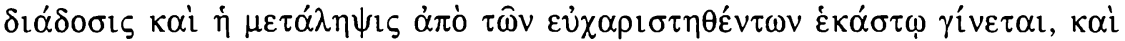

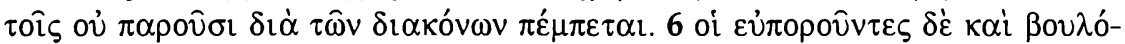

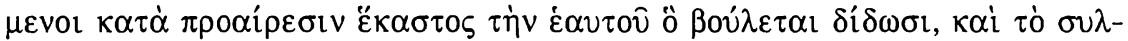

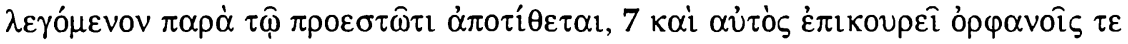

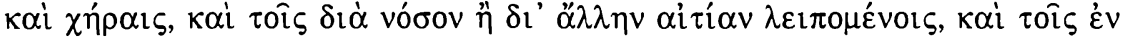

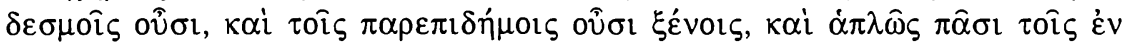

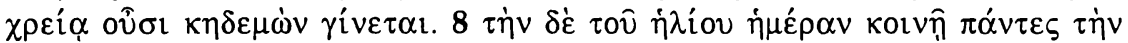

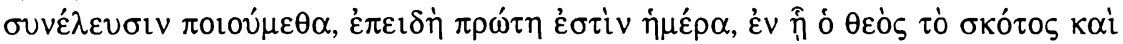

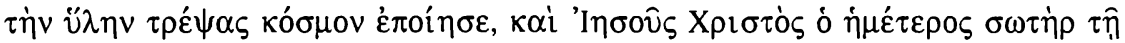

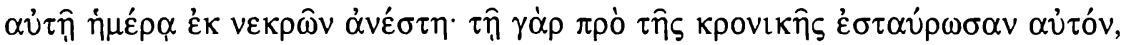

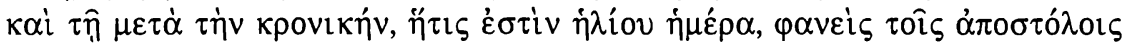

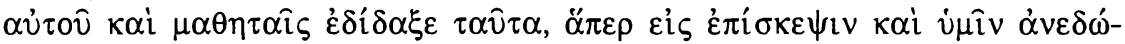
$\kappa \alpha \mu \varepsilon v$.

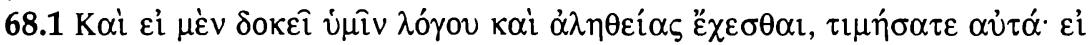

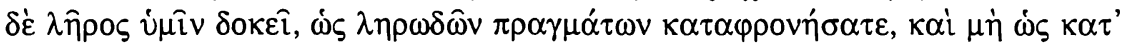

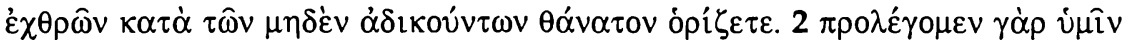

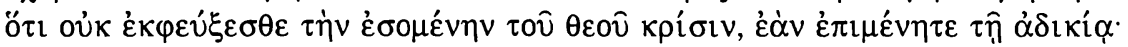

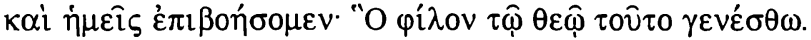

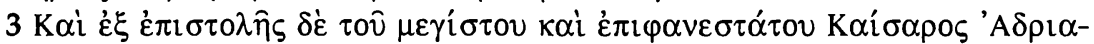

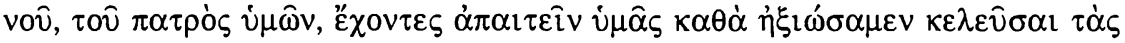

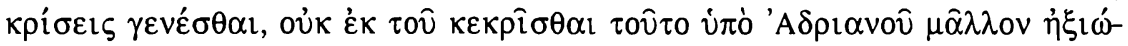

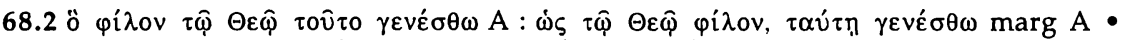

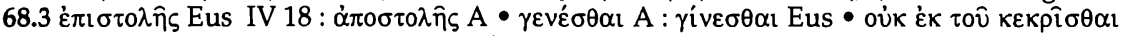

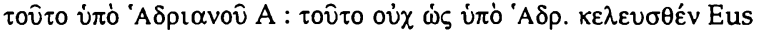

67.5 cf. Const.Apost. VIII,12 • 68.2 Platon, Apol. 19A; Crit. 43D; Phaedr. 246D; Phil. 12C; Leg. X,886D; Epictète, Enchir. 50(79) • 68.3-10 cf. Eusèbe, H.E. IV,8,7; 9,1-3 
67.1 Quant à nous, désormais nous renouvelons sans cesse entre nous le souvenir de ces choses; ceux parmi nous qui possèdent viennent en aide à tous ceux qui sont dans le besoin, et nous nous prêtons toujours une mutuelle assistance. 2 Pour toute la nourriture que nous prenons, nous bénissons le Créateur de l'univers par son Fils Jésus Christ et par l'Esprit saint. $3 \mathrm{Au}$ jour qu'on appelle le jour du soleil se tient une réunion de tous ceux qui habitent dans un même lieu, dans les villes et à la campagne; on y lit les Mémoires des apôtres et les écrits des prophètes, autant que le temps le permet. 4 Puis, quand le lecteur a fini, le président de l'assemblée prend la parole pour nous adresser des avertissements et nous exhorter à l'imitation de ces beaux enseignements. 5 Ensuite nous nous levons tous ensemble et nous prions à haute voix; et, comme nous l'avons dit plus haut, lorsque nous avons achevé notre prière, on apporte du pain, ainsi que du vin et de l'eau, et le président fait monter vers le ciel prières et actions de grâces, autant qu'il le peut, et le peuple exprime son accord par l'acclamation: Amen. Puis a lieu la distribution et le partage, et chacun reçoit une part de l'eucharistie; on envoie aussi leur part aux absents par le ministère des diacres. 6 Ceux qui le peuvent et qui veulent donner donnent librement ce qu'ils veulent, chacun ce qu'il veut, et ce qui est recueilli est déposé auprès du président; c'est lui qui assure des secours aux orphelins et aux veuves, à ceux qui sont dans le besoin du fait de la maladie ou de quelque autre cause, ainsi qu'aux prisonniers, aux hôtes étrangers; en un mot, il est le "secouriste" de tous ceux qui sont dans le besoin. 8 C'est le jour du soleil que nous nous réunissons tous ensemble, parce que ce jour est le premier, où Dieu, transformant la ténèbre et la matière, fit le monde, et où Jésus Christ notre sauveur est ressuscité des morts: il avait été crucifié la veille du jour de Saturne et, le lendemain de ce jour, c'est-à-dire le jour du soleil, il apparut à ses apôtres et à ses disciples et il leur enseigna ce que nous venons d'exposer, pour le soumettre aussi à votre examen.

68.1 Si cela vous paraît être conforme à la raison et à la vérité, prenezle en considération, mais si cela vous paraît être une ineptie, traitez-le avec mépris, comme on traite des inepties, mais ne prononcez pas la peine de mort, comme on le fait contre des ennemis, contre des hommes qui ne sont coupables d'aucun délit. 2 Car nous vous le prédisons: vous n'échapperez pas au jugement futur de Dieu, si vous persévérez dans l'injustice; quant à nous, nous nous écrierons: "Qu'il en soit comme il plaira à Dieu".

3 Alors que nous pourrions, en vertu d'une lettre de très grand et très illustre César Hadrien, votre père, vous demander d'ordonner que les procès nous concernant soient menés comme nous vous l'avons demandé, nous n'avons pas voulu formuler notre requête en nous appuyant sur le 


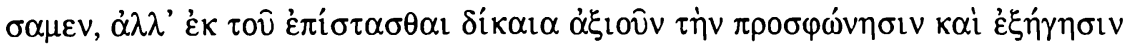

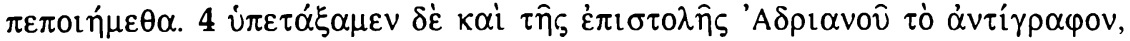

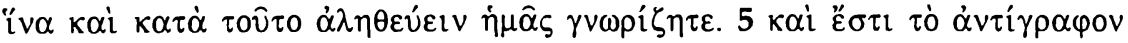

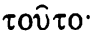

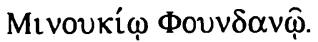

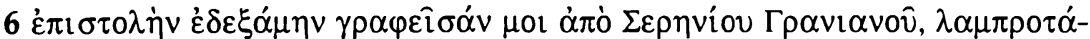

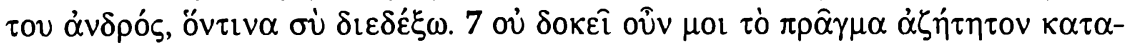

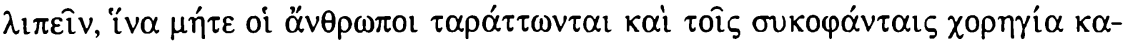

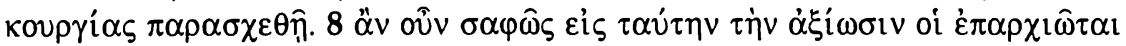

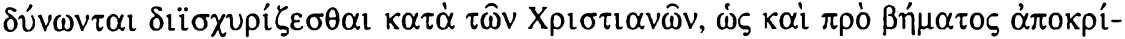

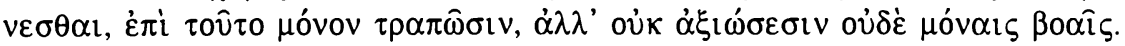

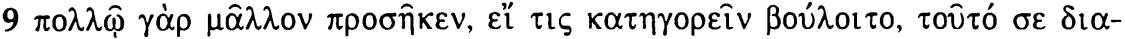

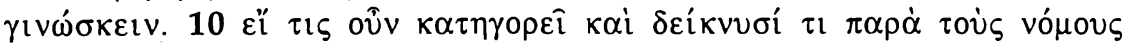

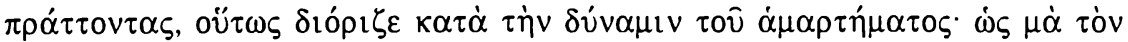

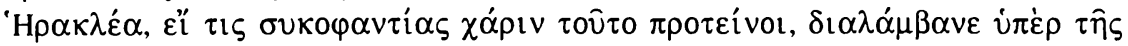

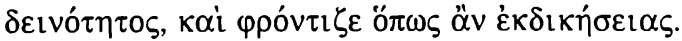

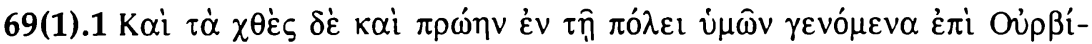

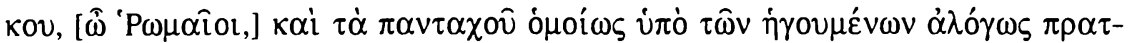

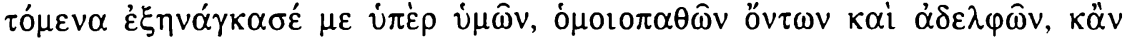

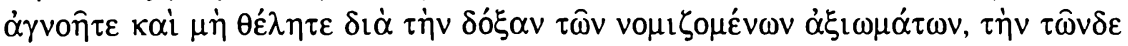

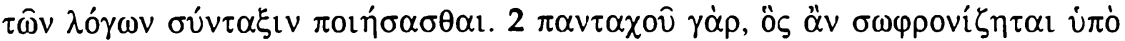

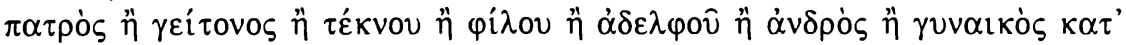

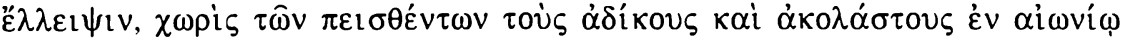

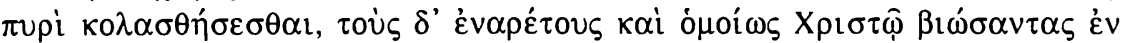

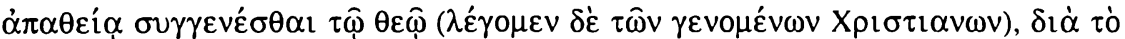

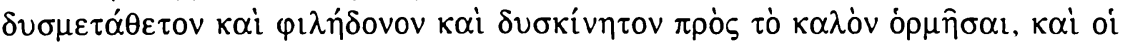

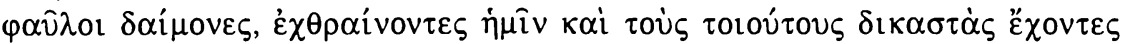

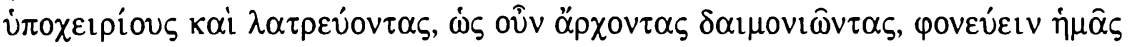

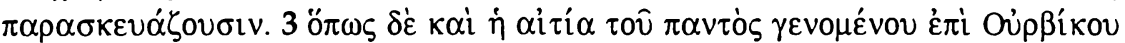
$\varphi \alpha v \varepsilon \rho \dot{\alpha} \dot{v} \mu \hat{\imath} v \gamma \varepsilon \dot{\varepsilon} v \eta \tau \alpha$, $\tau \dot{\alpha} \pi \varepsilon \pi \rho \alpha \gamma \mu \varepsilon \dot{\varepsilon} v \alpha \dot{\alpha} \pi \alpha \gamma \gamma \varepsilon \lambda \hat{\omega}$.

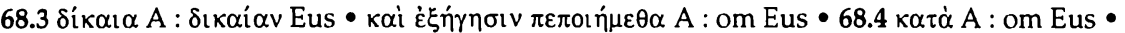

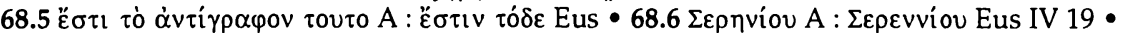

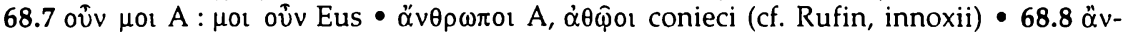

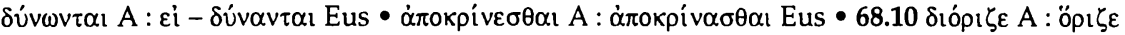
Eus

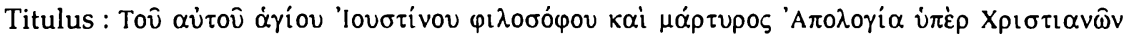

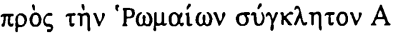

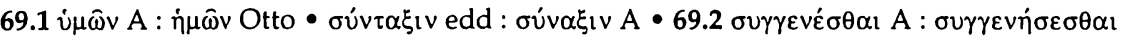
Otto 
fait qu'Hadrien en a décidé ainsi mais, parce que nous savons qu'est juste ce que nous demandons, nous vous avons adressé cet appel et cet exposé. Cependant nous joignons une copie de la lettre d'Hadrien, afin que vous puissiez reconnaître que, sur ce point aussi, nous disons la vérité. 5 Voici cette copie.

\section{A Minucius Fundanus}

6 J'ai reçu une lettre, qui m'a été écrite par Serenius Graianus, clarissime, à qui tu as succédé. $7 \mathrm{Il}$ ne me semble pas indiqué de laisser cette affaire sans examen, pour éviter que les innocents ne soient inquiétés et que ne soit fournie aux calomniateurs une aide dans leur méchanceté. $8 \mathrm{Si}$ donc les habitants de ta province sont en mesure, à l'appui de leur requête, de soutenir ouvertement leurs accusations contre les chrétiens, au point d'en répondre aussi devant le tribunal, qu'ils aient recours à cette seule voie, mais non point à de simples pétitions ni à des clameurs. 9 Il est bien plus convenable, en effet, si quelqu'un veut intenter une accusation, que tu en connaisses toi-même. $10 \mathrm{Si}$ donc un accusateur se présente et apporte la preuve qu'ils font quelque chose à l'encontre des lois, prononce un jugement approprié, selon la gravité de la faute. Mais, par Hercule, si quelqu'un devait avancer une telle allégation par pure calomnie, coupe court à cette méchanceté et aie le souci de la punir.

69(1).1 Les événements qui se sont produits récemment dans votre ville, sous Urbicus, et pareillement les actes déraisonnables que vos magistrats commettent en tout lieu m'ont contraint à composer ces discours, dans votre intérêt, car vous êtes susceptibles des mêmes impressions que nous et vous êtes nos frères, quand bien même vous ne le sauriez pas et que vous refuseriez de l'admettre à cause de la fausse opinion que vous avez de vos prétendues "dignités". 2 Partout, en effet, si l'on excepte ceux qui croient que les méchants et les intempérants seront punis dans un feu éternel, tandis que les bons, qui ont vécu selon le Christ, seront avec Dieu dans une condition d'impassibilité, nous voulons parler de ceux qui sont devenus chrétiens, partout donc, quiconque est repris par un père, un voisin, un fils, un ami, un frère, un mari, une épouse, pour une faute quelconque, fomente notre mort, à cause de son obstination dans le mal, de son attachement aux plaisirs, de son allergie au bien; les mauvais démons en font autant, eux qui nous haïssent et qui ont en leur pouvoir et à leur service de tels juges, qui se conduisent comme si les démons avaient égaré l'esprit de ces magistrats. 3 Mais pour que vous apparaisse clairement la cause de tout ce qui s'est passé sous Urbicus, je vais raconter les faits. 


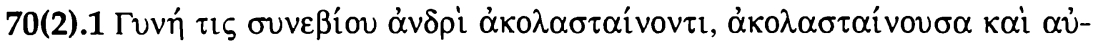

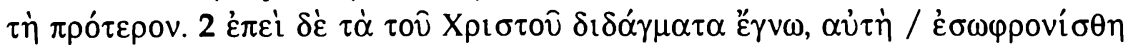

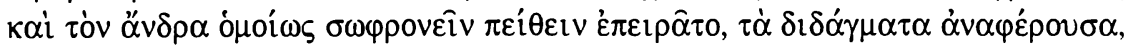

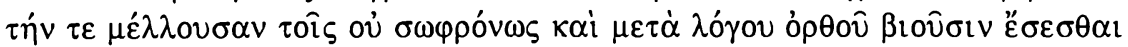

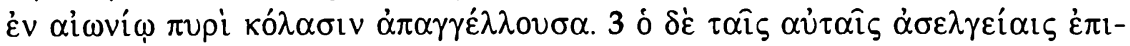

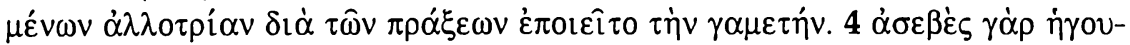

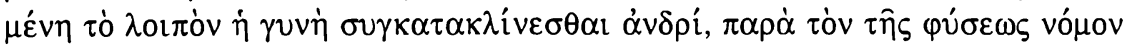

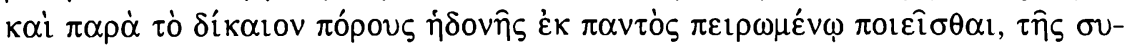

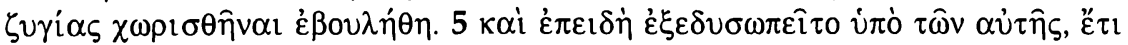

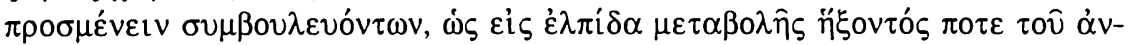

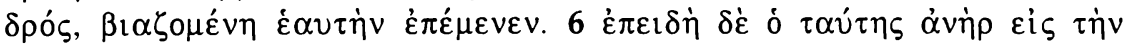

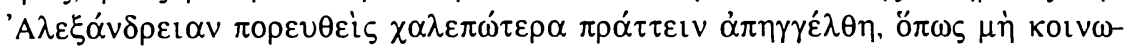

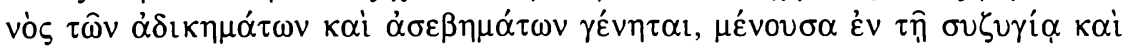

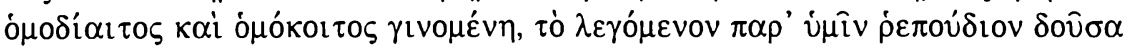

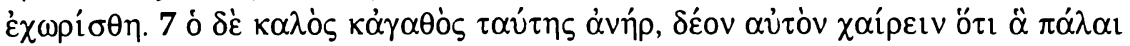

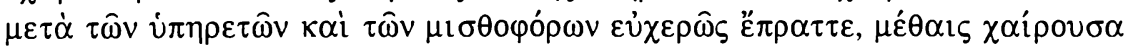

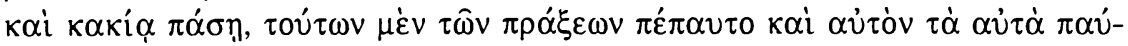

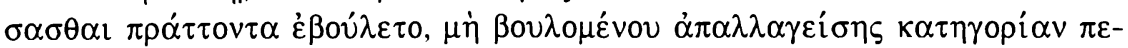

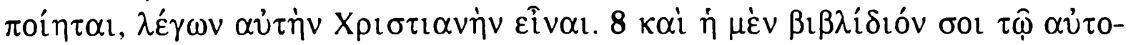

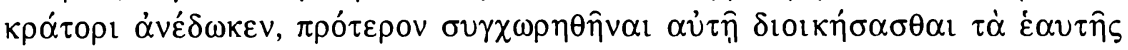

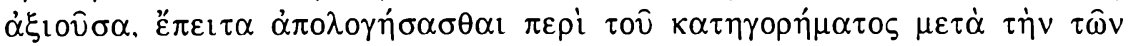

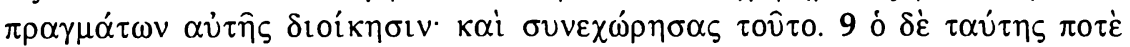

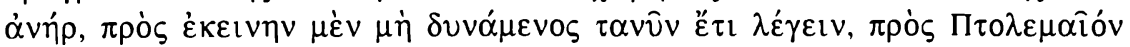

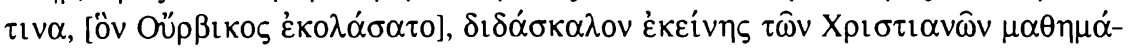

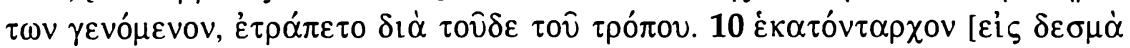

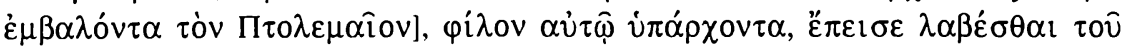

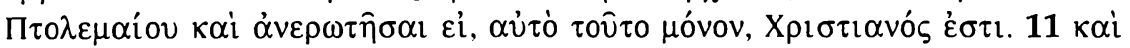

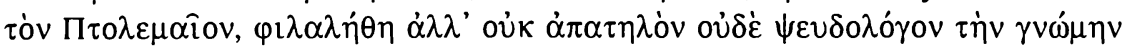

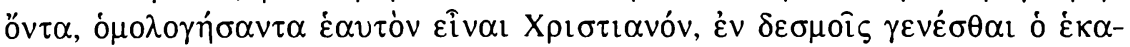

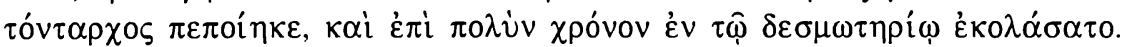

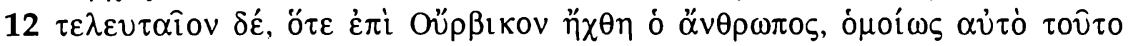

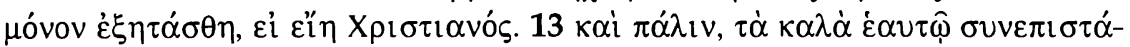

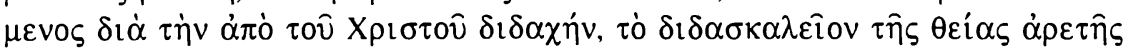

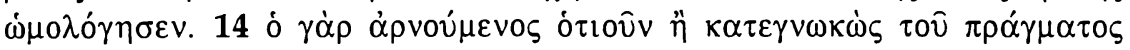

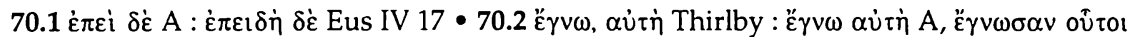
marg A (Wartelle) • //غं $\sigma \omega \varphi p o v i \sigma \theta \eta-\dot{\varepsilon} \lambda \varepsilon \gamma \chi \dot{\mu} \mu \varepsilon v o v / /$ (2.16) lacuna codd, ex Eus IV 17,2-12

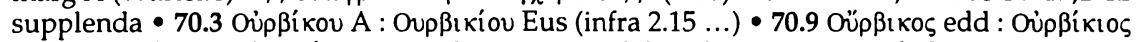

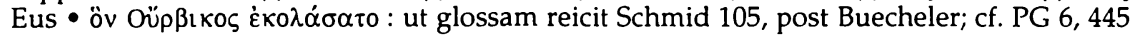

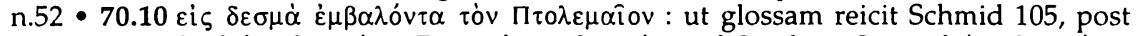

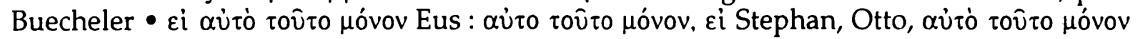
del Schmid 105

70.1-16 cf. Eusèbe, H.E. IV,17 
70(2).1 Une femme vivait avec un mari débauché à l'extrême; elle-même avait vécu dans le désordre dans un premier temps. 2 Mais lorsqu'elle fut instruite des enseignements du Christ, elle embrassa la chasteté et elle s'efforça de persuader son mari de mener lui aussi une vie chaste, en lui exposant cette doctrine et l'avertissant du châtiment dans le feu éternel, réservé à ceux qui ne vivent pas chastement, selon la droite raison. 3 Mais lui persévéra dans les mêmes désordres et, par sa conduite, s'aliéna le cœur de sa femme. 4 Elle crut, en effet, que ce serait une impiété de continuer à partager la couche d'un homme qui cherchait à se procurer du plaisir par tous les moyens, au mépris de la loi naturelle et de la justice, et elle résolut de mettre fin à la vie commune. 5 Cependant, sur les instances des siens, qui lui conseillaient de demeurer encore, dans l'espoir d'un changement éventuel du mari, elle se fit violence et resta. 6 Mais lorsqu'elle eut appris que son mari, parti pour Alexandrie, se conduisait encore plus mal, pour n'être point complice de ses méfaits et de ses impiétés, elle lui signifia le repudium, comme vous dites, et se sépara de lui. 7 Cet excellent mari, qui aurait dû se réjouir de voir sa femme renoncer à la vie relâchée qu'elle avait menée jadis en compagnie de serviteurs et de mercenaires, adonnée aux beuveries et à tous les vices, et vouloir lui faire cesser à son tour pareille conduite, refusa de s'amender et, parce qu'elle l'avait quitté pour ce motif, il intenta contre elle une accusation, en disant qu'elle était chrétienne. 8 Mais elle vous présenta une requête, à vous, l'empereur, sollicitant la faveur de pouvoir d'abord régler ses affaires et de répondre ensuite sur le chef de l'accusation, une fois ses affaires réglées; vous le lui avez accordé. 9 Comme son mari ne pouvait plus rien alléguer contre elle pour le moment, il se retourna contre un certain Ptolémée, qui l'avait instruite de la doctrine chrétienne; voici comment il s'y prit. 10 Il persuada un centurion de ses amis, de prendre au piège Ptolémée, après l'avoir jeté en prison, et de ne l'interroger que sur ce seul point, à savoir s'il était chrétien. 11 Le centurion obtint que Ptolémée, parce qu'il était un ami de la vérité, étranger à la ruse et au mensonge, reconnût qu'il était chrétien, et il le maltraita longtemps dans la prison. 12 Finalement, lorsque notre homme fut conduit devant Urbicus, pareillement il ne fut interrogé que sur le seul point de savoir s'il était chrétien. 13 Encore une fois, pleinement conscient des biens qu'il devait à l'enseignement qui vient du Christ, il confessa l'école de la vertu divine. 14 En effet, celui qui renie 


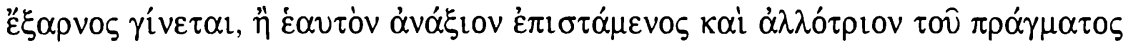

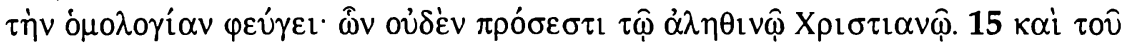

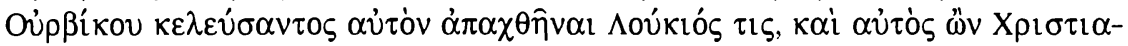

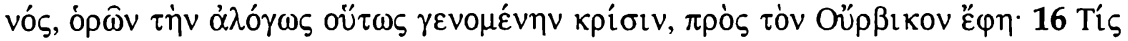

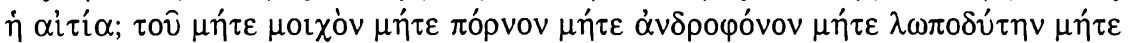

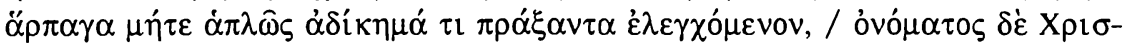

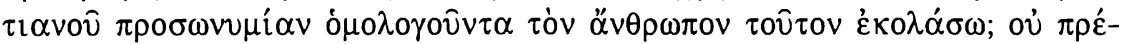

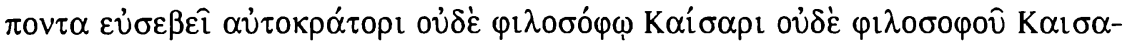

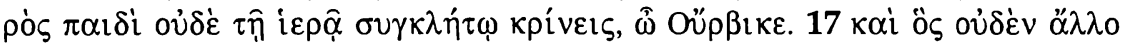

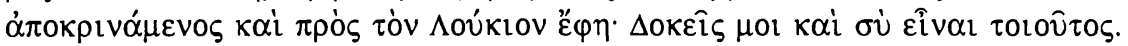

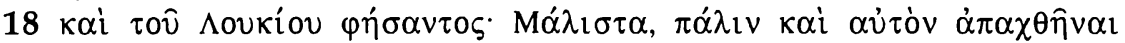

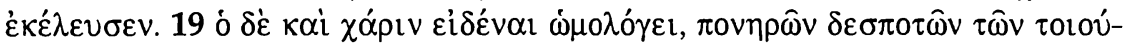

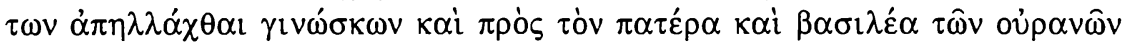

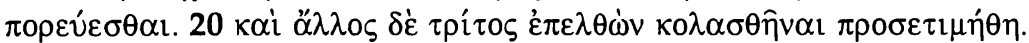

71(3[4]).1 "O

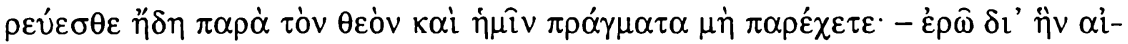

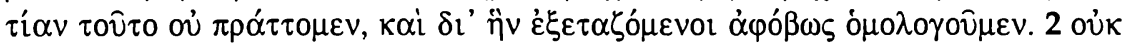

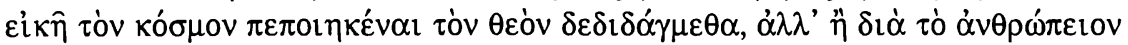

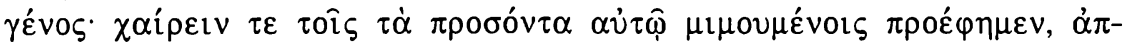

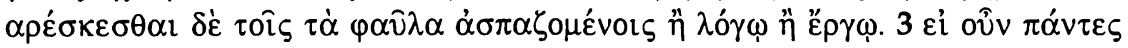

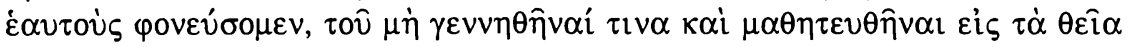

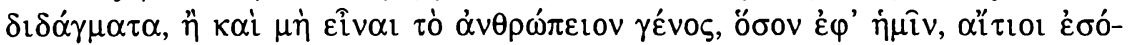

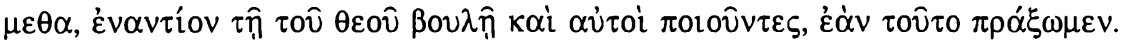

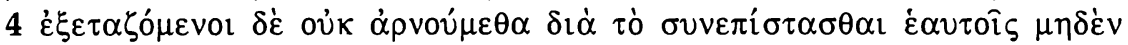

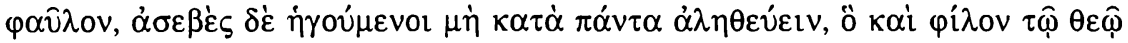

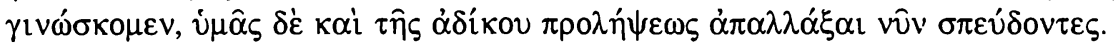

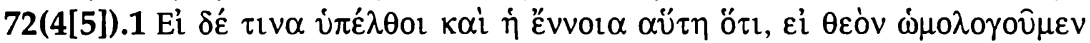

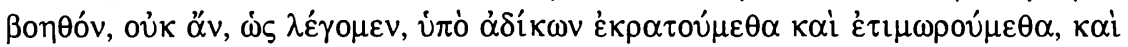

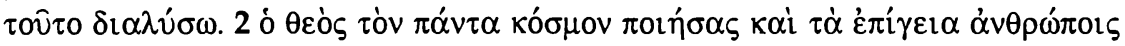

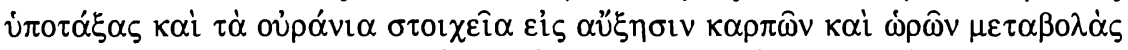

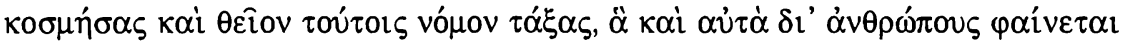

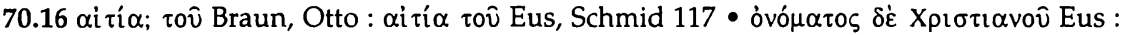
$\pi \alpha \theta \dot{\mu} \mu \alpha \tau o \zeta ~ \delta \dot{\varepsilon}$ X

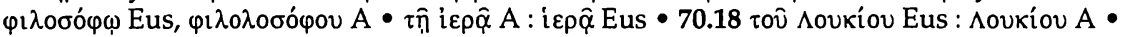

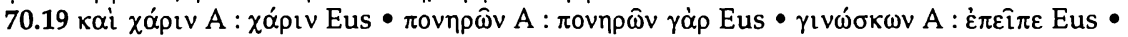

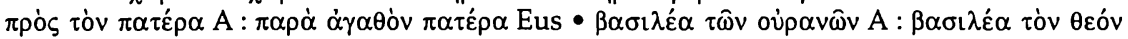
Eus • $70.20 \dot{\varepsilon} \pi \varepsilon \lambda \theta \dot{\omega} v$ Eus : $\dot{\alpha} \pi \varepsilon \lambda \theta \dot{\omega} v \mathrm{~A}$

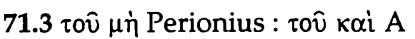

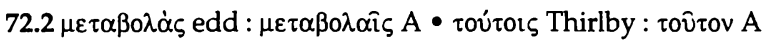

70.14 Pline le Jeune, ep. $X, 96,5$ 
quoi que ce soit, ou bien le fait parce qu'il condamne la chose elle-même, ou bien il refuse de la confesser parce qu'il a conscience d'en être indigne ou de lui être étranger, mais ni l'une ni l'autre de ces attitudes n'est le fait d'un vrai chrétien. 15 Comme Urbicus avait donné l'ordre de l'emmener (au supplice), un certain Lucius, chrétien lui aussi, au vu du jugement rendu ainsi au mépris de la raison, dit à Urbicus: 16 "Quel est le motif (de la condamnation)? Alors qu'il n'a été convaincu ni d'adultère, ni de débauche, ni de meurtre, ni de vol, ni de rapt, ni d'avoir commis le moindre délit, mais qu'il a avoué seulement répondre au nom de chrétien, tu as condamné cet homme à mort? Ton jugement, Urbicus, ne s'accorde ni avec le pieux empereur ni avec le César philosophe, ni avec le fils de César philosophe, ni avec le vénérable Sénat. 17 Mais lui, pour toute réponse, s'adressa à Lucius et lui dit: "Il me semble que toi aussi tu es de ces gens-là". 18 Et comme Lucius répondit: "Parfaitement", il ordonna de l'emmener lui aussi (au supplice). 19 Mais Lucius proclamait qu'il lui en savait gré, conscient d'être délivré de ces maîtres pervers et de s'en aller auprès du Père et du Roi des cieux. 20 Un troisième encore, qui se présenta, fut condamné à être supplicié.

71(4).1 Afin que personne ne dise: "Donnez-vous donc tous la mort à vous-mêmes et allez-vous-en auprès de votre Dieu, sans nous causer d'embarras, je dirai pour quelle raison nous n'agissons pas ainsi et pourquoi, lorsque nous sommes soumis à l'interrogatoire, nous confessons sans crainte notre foi. 2 Nous avons appris que Dieu n'a pas créé le monde au hasard mais pour le genre humain; il se plaît, nous l'avons dit plus haut, à ceux qui s'efforcent d'imiter ses perfections, mais il déteste ceux qui aiment le mal en parole ou en acte. 3 Si nous nous donnions tous la mort, nous serions responsables, pour ce qui nous concerne, de ce que plus personne ne naîtrait et ne serait plus instruit dans les enseignements divins, et même que le genre humain cesserait d'exister; et si nous agissions ainsi, nous irions nous aussi à l'encontre de la volonté de Dieu. 4 Mais quand on nous interroge, nous ne nions pas, car nous avons pleine conscience de ne rien faire de mal, tandis que nous considérons comme une impiété de ne pas dire en tout la vérité; car c'est là, croyons nous, ce qui plaît à Dieu; enfin parce que nous voudrions aussi, à cette occasion, vous détourner de vos injustes préjugés.

72(5).1 Mais pour le cas où il viendrait à l'esprit de quelqu'un de penser que, si nous confessions un Dieu secourable, nous ne serions pas, comme nous le prétendons, asservis à des méchants et maltraités par eux, je vais aussi résoudre cette difficulté. 2 Après avoir créé l'univers et soumis à l'homme tout ce qui est sur terre, après avoir disposé les corps célestes en vue de la croissance des fruits et de la succession des saisons, après avoir imposé une loi divine à ces éléments que, de toute évidence, il a créés 


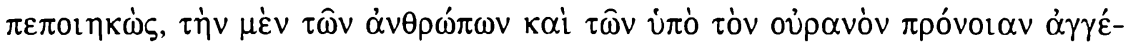

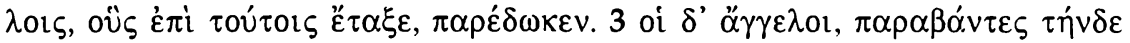

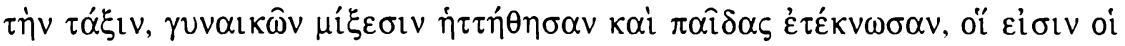

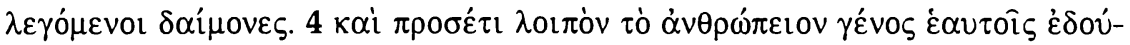

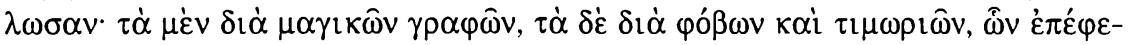

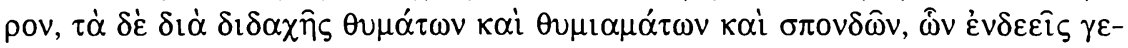

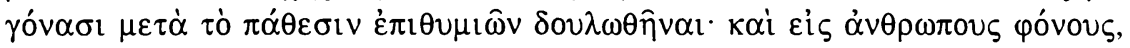

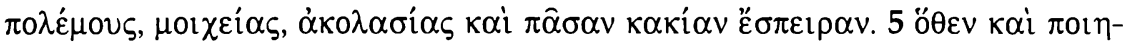

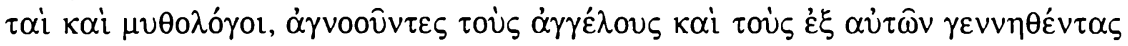

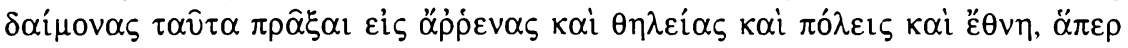

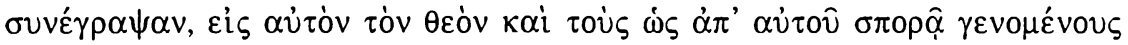

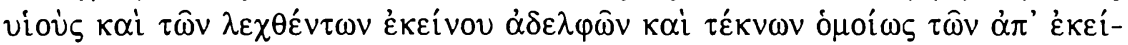

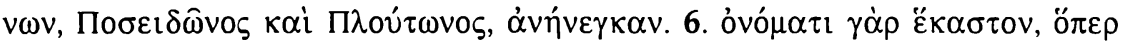

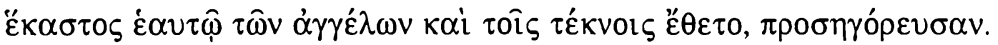

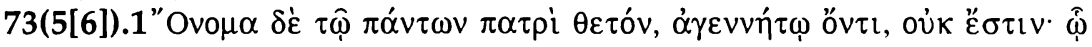

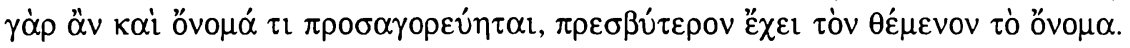

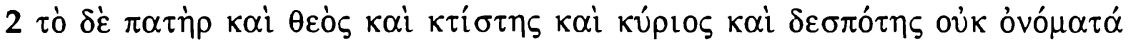

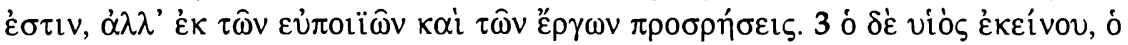

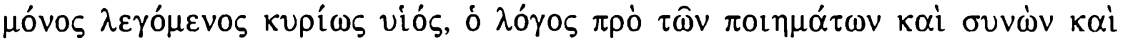

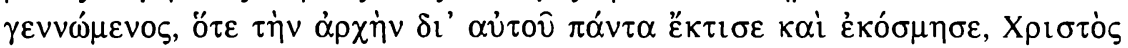

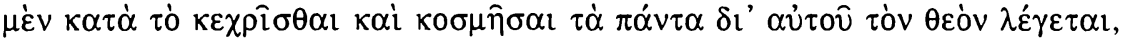

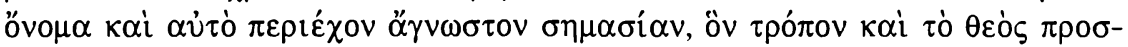

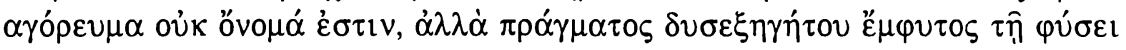

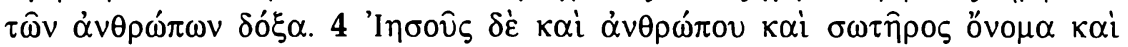

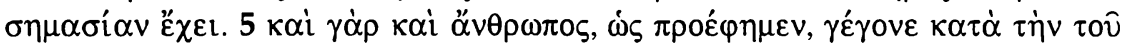

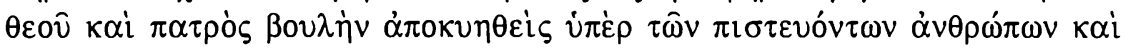

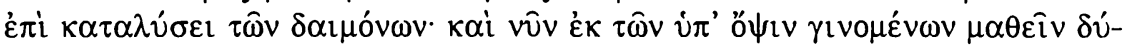

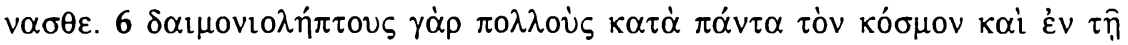

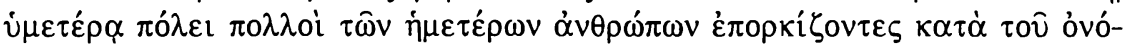
$\mu \alpha \tau o \zeta$ 'I

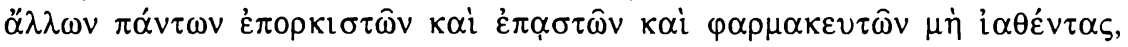

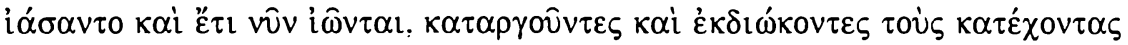

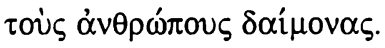

$72.4 \hat{\omega} \vee \dot{\varepsilon} \pi \dot{\varepsilon} \varphi \varepsilon \rho \circ$ Thirlby : $\dot{\varepsilon} \pi \varepsilon ́ \varphi \varepsilon \rho \circ \mathrm{A}$

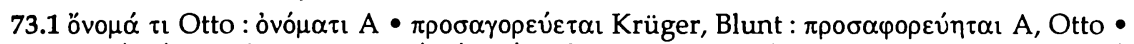

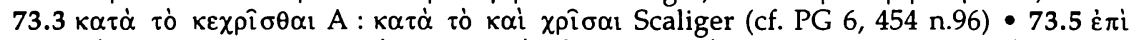

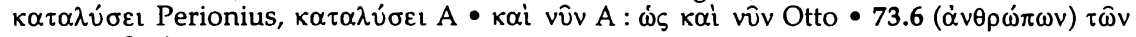

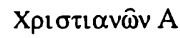

73.1 Platon, Tim. 28C; Cicéron, nat.deor. I,12; Sénèque, benef. 4,7... 
à cause des hommes, Dieu a confié le soin de veiller sur les hommes et sur les êtres qui sont sous les ciel aux anges, qu'il a mis à leur tête. 3 Mais les anges, transgressant cette ordonnance, s'abaissèrent à s'unir à des femmes et engendrèrent des enfants, qui sont ce qu'on appelle les démons. $4 \mathrm{De}$ plus, ils se sont par la suite asservi le genre humain, soit par des écrits magiques, soit par la crainte et les tourments qu'ils faisaient subir, soit en enseignant à leur offrir sacrifices, encens et libations, dont ils étaient devenus avides, après s'être laissé asservir par la passion des désirs, et ils ont semé parmi les hommes meurtres, guerres, adultères, dérèglements et vices de toute espèce. 5 Voilà pourquoi les poètes et les mythologues, ne sachant pas que les anges et leurs fils, les démons, avaient commis au détriment d'hommes, de femmes, de cités et de nations, les forfaits qu'ils racontaient, les ont attribués à Zeus lui-même et aux fils prétendument issus de sa descendance charnelle, ainsi qu'à ses prétendus frères, Poseidon et Pluton et à leurs enfants. 6 De fait ils ont donné à chacun d'eux le nom que chacun des anges avait choisi pour lui-même et pour ses enfants.

73(6).1 Mais le Père de l'univers, parce qu'il est inengendré, n'a pas de nom qui lui ait été imposé, car celui à qui un nom est imposé le doit à quelqu'un de plus ancien, qui le lui impose. 2 Les termes: Père, Dieu, Créateur, Seigneur, Maître, ne sont pas des noms mais des désignations tirées de ses bienfaits et de ses œuvres. 3 Mais son fils, celui qui seul est appelé "Fils" au sens propre du terme, le Logos qui, avant les créatures, était avec lui et fut engendré, lorsque, au commencement, il fit et ordonna par lui l'univers, on l'appelle "Christ", parce qu'il a reçu l'onction et que, par lui, Dieu a ordonné l'univers; ce nom même comporte une signification qui échappe à la connaissance, de la même manière que l'appellation "Dieu" n'est pas un nom, mais une notion innée à la nature humaine, pour désigner une réalité difficile à expliquer. 4 Mais "Jésus" renferme et le nom et la notion d'un homme qui est aussi sauveur. 5 En effet, comme nous l'avons dit antérieurement, il est devenu homme selon la volonté de Dieu, le Père, enfanté pour le salut des hommes croyants et pour la ruine des démons; vous pouvez vous en convaincre maintenant encore par ce qui se passe sous vos yeux. 6 En effet, beaucoup de possédés des démons, dans le monde entier et dans votre cité, qui n'avaient pas été guéris par tous les autres exorcistes, faiseurs d'adjurations et de potions magiques, nombre des nôtres les ont guéris et ils les guérissent encore présentement, en les exorcisant au nom de Jésus-Christ, crucifié sous Ponce-Pilate, cependant qu'ils réduisent à l'impuissance et expulsent les démons, qui exercent leur pouvoir sur les hommes. 
74(6[7]).1 "O

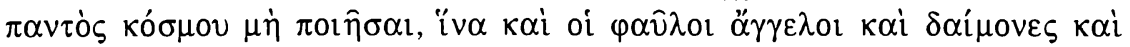

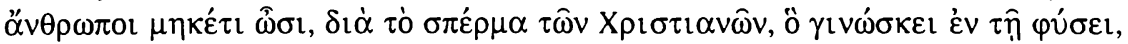

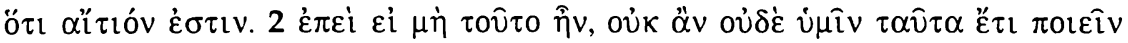

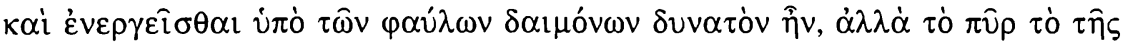

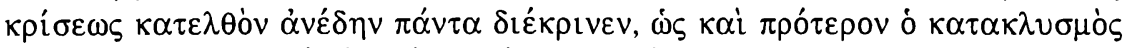

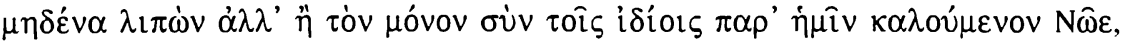

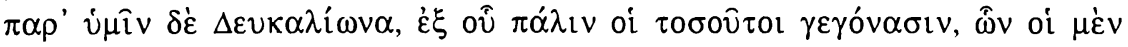

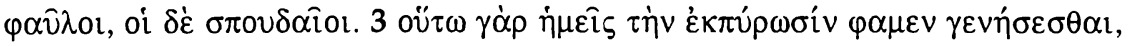

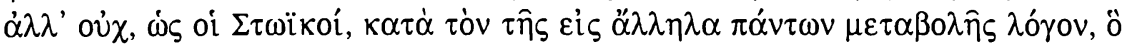

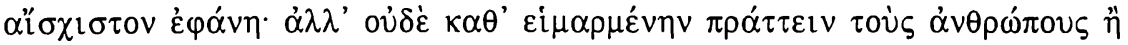

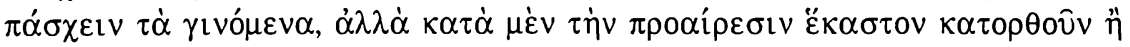

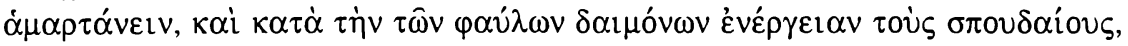

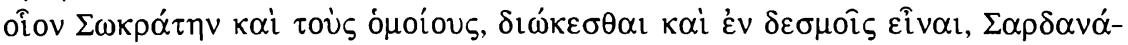

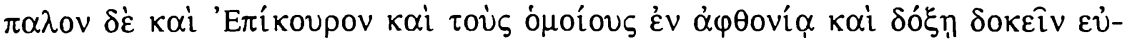

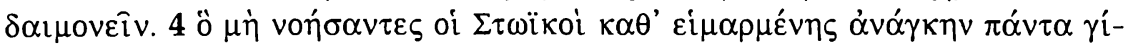

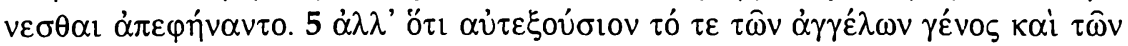

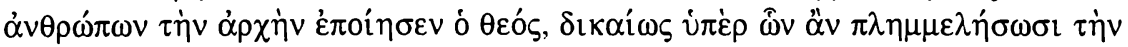

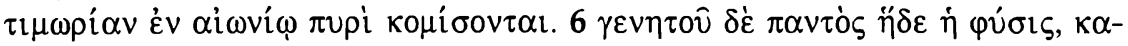

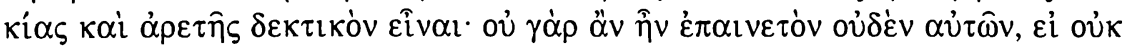

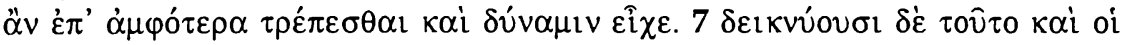

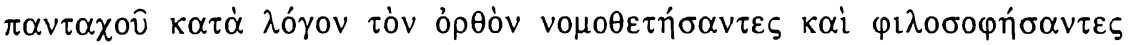

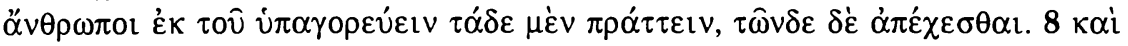

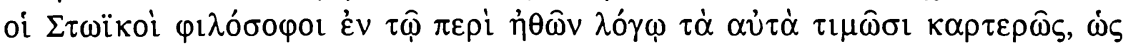

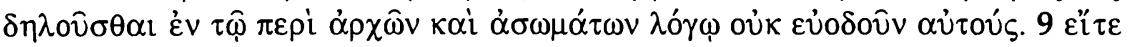

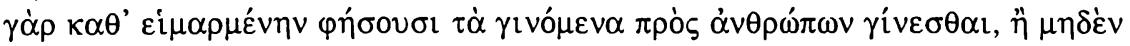

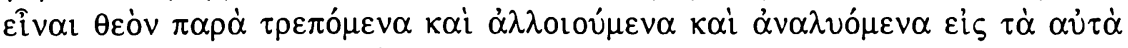

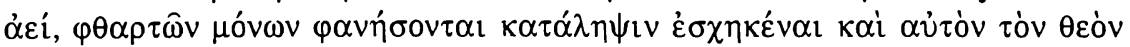

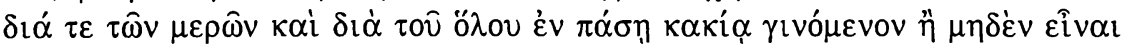

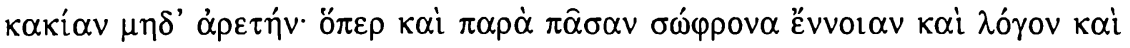

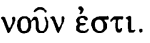

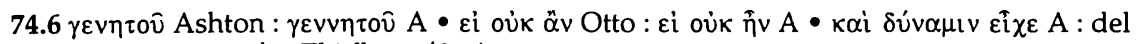

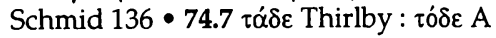

74.3 Fusion: cf. Tatien, Or. 3,2; 6,1; 9,1; Athénagore, Leg. 19,3; 22,6 - Sardanapale: cf. Hérodote, II,150; Aristote, Eth.Nic. I,3; Eth.Eud. 5; Plutarque, Alex.fort. 1,2 - 74.8 Etres incorporels: cf. Plutarque, Plac.Phil. I,28; Laert. VII,134.149; Eusèbe, Praep.euang. XV,1415 
74(7).1 C'est pourquoi, si Dieu retarde le bouleversement et la destruction du monde entier, qui doit mettre fin à l'existence des mauvais anges, des mauvais démons et des hommes pervers, c'est à cause de la semence des chrétiens, en qui il reconnaît un motif (de conserver le monde). 2 S'il n'en était pas ainsi, il ne vous serait plus possible, à vous non plus, d'agir comme vous le faites et de vous laisser manœuvrer par les mauvais démons, mais le feu du jugement descendrait et détruirait l'univers de fond en comble, comme autrefois aussi le déluge n'a épargné personne, excepté, avec les siens, un seul homme, celui que nous appelons Noé, et vous Deucalion, dont est née la nouvelle génération des hommes, immense, faite de bons et de méchants. 3 Car c'est ainsi, nous l'affirmons, qu'aura lieu la destruction du monde par le feu, et non pas, comme le pensent les Stö̈ciens, selon la théorie de la fusion mutuelle de tous les êtres, ce qui est, de toute évidence, une opinion des plus indécentes; mais ce n'est pas non plus selon un destin fatal que les hommes accomplissent ou subissent ce qui arrive, mais chacun fait le bien ou le mal par libre décision et c'est par l'influence des mauvais démons que les hommes de bien, comme Socrate et ceux qui lui ressemblent, sont persécutés et jetés aux fers, tandis que Sardanapale, Épicure et leurs semblables paraissent jouir du bonheur, dans l'abondance et dans la gloire. 4 Mais parce qu'ils ne l'avaient pas compris, les Stoïciens ont déclaré que tout arrive selon la nécessité d'un destin fatal. $5 \mathrm{Au}$ contraire, parce que Dieu, au commencement, a créé libres la race des anges et celle des hommes, c'est à juste titre qu'ils auront à subir dans un feu éternel le châtiment pour les fautes qu'ils auront commises. 6 Toute créature est, de par sa nature, susceptible de mal et de bien; nulle d'entre elles, en effet, ne serait digne de louange, si elle n'avait le capacité et le pouvoir de se tourner vers l'un ou vers l'autre. 7 Ceci est prouvé par le fait que les hommes qui, en tout lieu, ont établi des lois et fait des réfléxions philosophiques en accord avec la saine raison, ordonnent de faire ceci et d'éviter cela. 8 Même les philosophes stoïciens dans leur doctrine morale tiennent fermement le même axiome, ce qui montre bien qu'ils font fausse route dans leur doctrine relative aux principes et aux êtres incorporels. 9 En effet, s'ils déclarent que tout ce qui arrive aux hommes se produit selon la fatalité du destin, ou que Dieu n'est rien en dehors de ce qui, toujours, change, se transforme et se résout dans les mêmes éléments, il apparaîtra qu'ils n'ont de compréhension que pour les choses corruptibles et que, d'après eux, Dieu lui-même se trouve impliqué dans le mal sous toutes ses formes, d'une manière générale et en particulier, ou bien (il leur faudra dire) que ni le mal ni la vertu ne sont rien: ce qui est contraire à toute saine réflexion et va contre la raison et l'intelligence. 


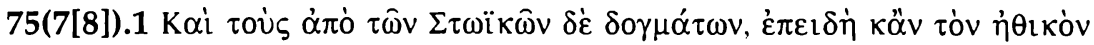

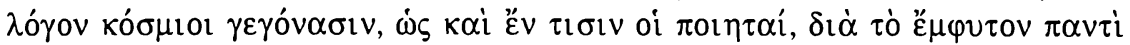

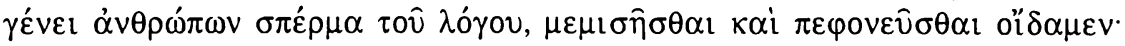

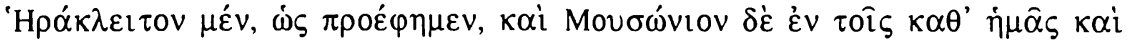

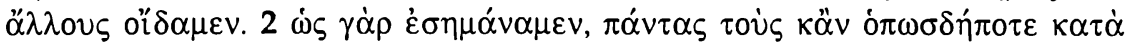

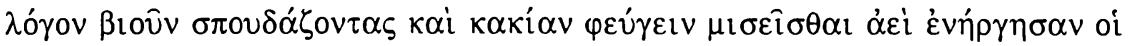

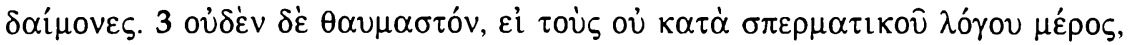

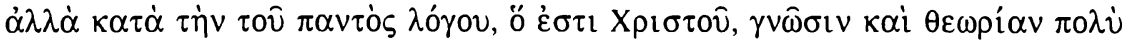

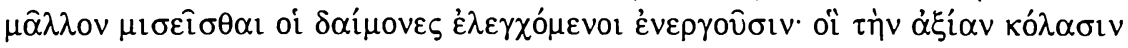

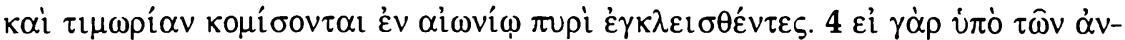

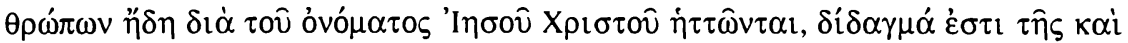

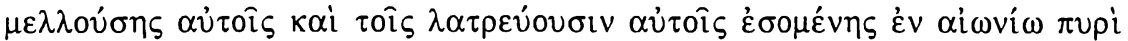

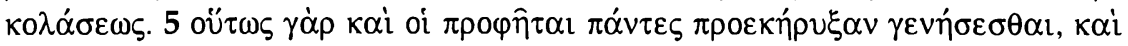

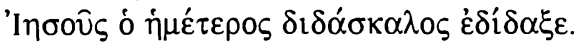

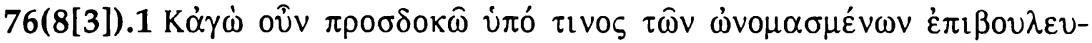

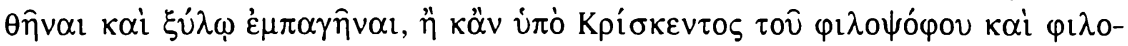

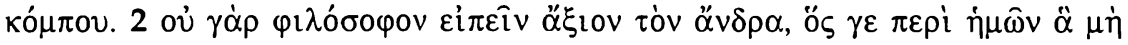

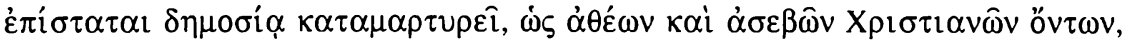

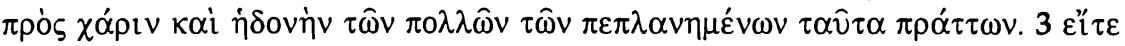

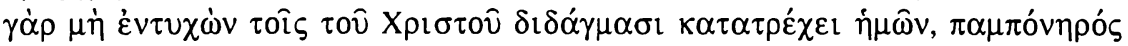

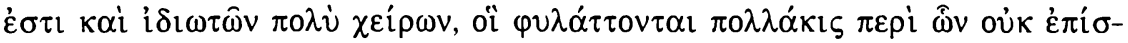

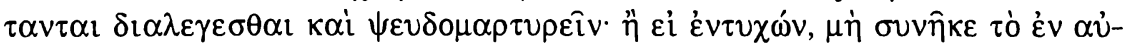

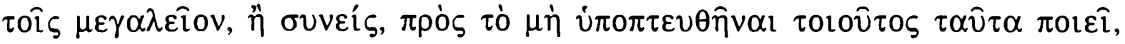

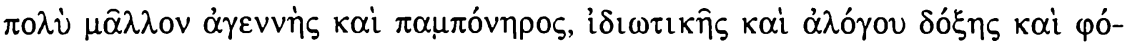

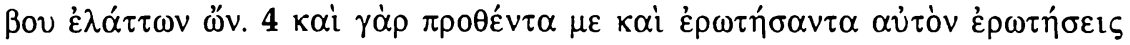

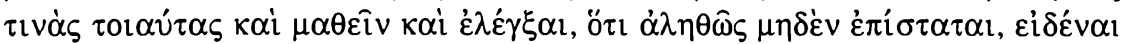

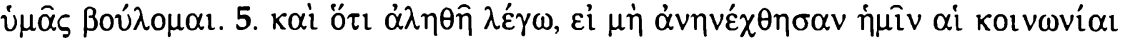

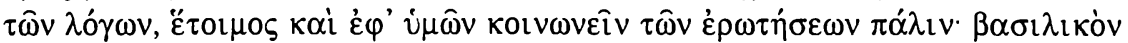

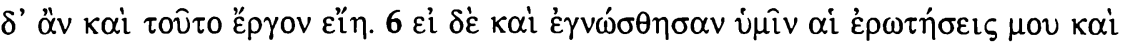

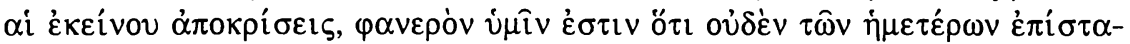

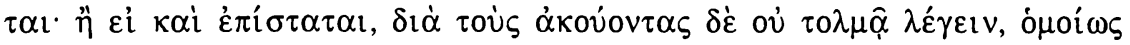

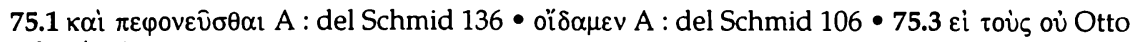

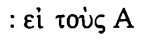

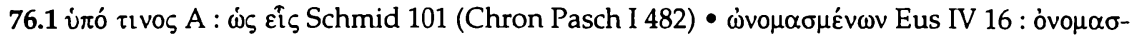

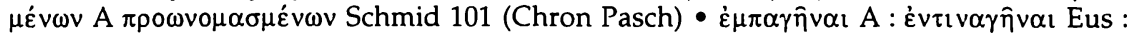

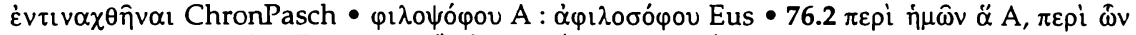

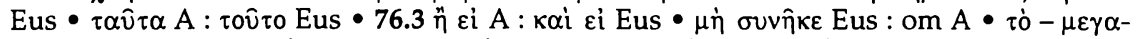

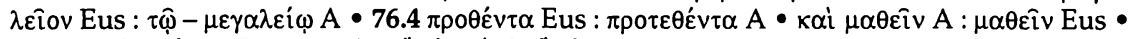

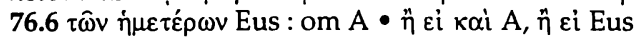

75.1 Héraclite: Marc-Aurèle, VII,3; Athénagore, Leg. 3,2; Arnobe, C.Gent. I,40. - Musonius Rufus: Tacite, Ann. XIV,59,1; XV,71,4; Hist. III,81; IV,10; 40; Pline le Jeune, ep. III,11; Dion Cassius, Hist.rom. 66,13,2 • 76.1 cf. Eusèbe, H.E. IV,16,3-6; cf. Tatien, Or. 19 
75(8).1 De plus, ceux qui ont suivi les enseignements des Stoïciens, parce qu'ils ont été honnêtes au moins dans leur doctrine morale, comme aussi, par endroits, les poètes, en vertu de la semence du Logos implanté dans tout le genre humain, nous savons qu'ils ont été en butte à la haine et mis à mort: Héraclite, comme nous l'avons dit plus haut, Musonius parmi nos contemporains, d'autres encore. 2 Comme nous l'avons expliqué, les démons ont toujous travaillé à faire haïr tous ceux qui, de quelque manière que ce soit, s'efforcent de vivre selon la raison et d'éviter le mal. 3 Rien d'étonnant, dès lors, si les démons, convaincus de fourberie, travaillent à faire haïr encore davantage ceux qui s'efforcent de vivre non point selon une partie seulement du Logos séminal, mais selon la connaissance et la contemplation du Logos tout entier, c'est-à-dire du Christ; ils subiront le châtiment et les tourments qu'ils méritent, après avoir été renfermés dans le feu éternel. 4 Car s'ils sont d'ores et déjà vaincus par les hommes au nom de Jésus Christ, c'est là une indication du châtiment qui les attend dans le feu éternel, eux et ceux qui sont à leur service. 5 Car tous les prophètes ont prédit qu'il en serait ainsi, et Jésus notre maître l'a enseigné.

76(3).1 Moi aussi je m'attends donc à être l'objet d'une machination et à être attaché au bois du supplice, à l'instigation de l'un de ceux que j'ai nommés, ne serait-ce que Crescent, cet ami du bruit (philopsophe) et de l'emphase. 2 Car il ne convient pas d'appeler philosophe un homme qui témoigne publiquement contre nous de choses qu'il ne connaît pas, à savoir que nous sommes athées et impies, mais il agit de la sorte afin de gagner la faveur de la multitude égarée et de lui faire plaisir. 3 Car s'il nous attaque sans avoir lu les enseignements du Christ, il est un scélérat accompli, bien pire que les gens sans éducation, car ceux-ci le plus souvent se gardent de discuter et de porter des affirmations fausses sur les choses qu'ils ne connaissent pas. Mais s'il les a lus, sans comprendre la grandeur qui est en eux, ou bien s'il l'a comprise et agit de la sorte, afin qu'on ne le soupçonne pas d'être de ces gens-là, alors il est d'autant plus abject et plus scélérat qu'il se laisse dominer par une opinion ignorante et déraisonnable et par la crainte. 4 Je lui ai posé quelques questions à ce sujet et je l'ai interrogé et j'ai pu me rendre compte par moi-même et lui prouver que, vraiment, il n'y connaît rien; je voudrais que vous le sachiez. $5 \mathrm{Et}$ pour vous prouver que je dis vrai, je suis prêt, si l'ensemble de ces discussions ne vous ont pas été rapportées, à lui faire part de mes questions, une nouvelle fois, en votre présence même; ce serait là aussi une tâche impériale. 6 Mais si vous avez eu connaissance de mes questions et de ses réponses, vous avez la preuve évidente qu'il ne connaît rien de notre doctrine; ou bien, s'il la connaît, mais, par crainte des auditeurs, n'ose pas 


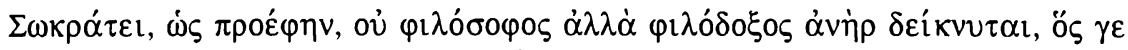

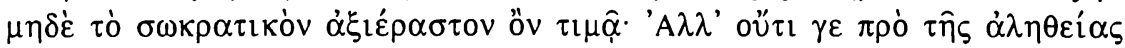

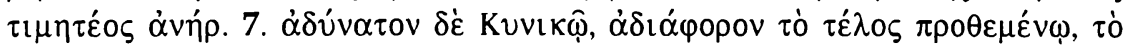

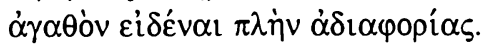

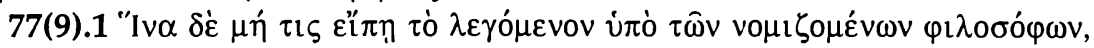

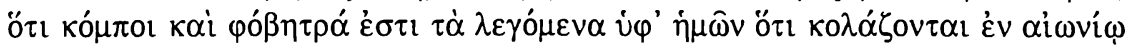
$\pi v p i$ oi $\ddot{\alpha} \delta$ เ

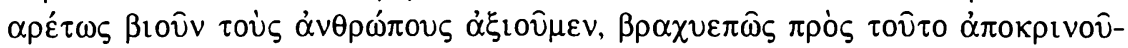

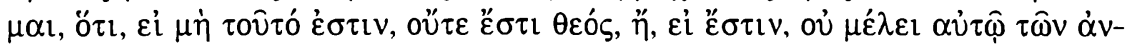

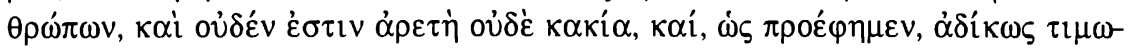

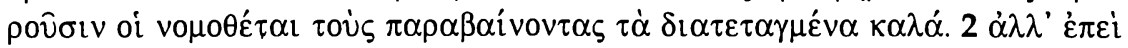

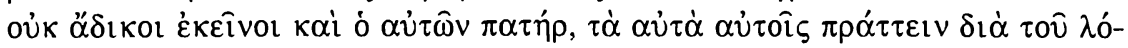

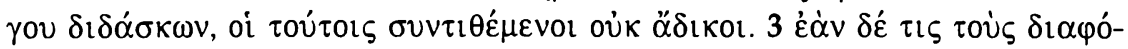

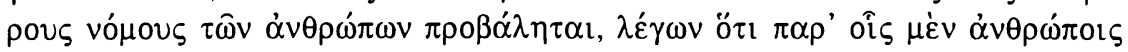

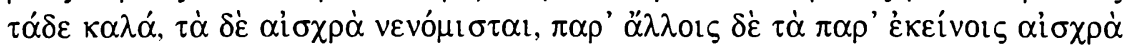

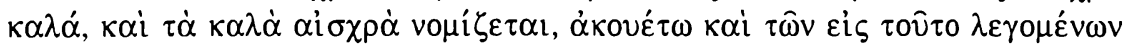

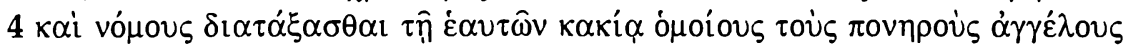

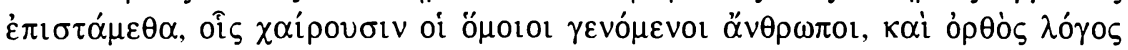

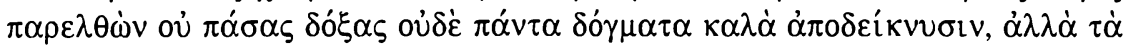

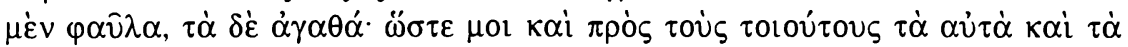

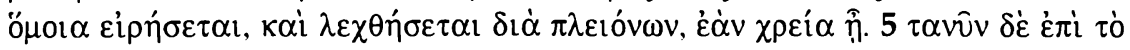

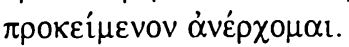

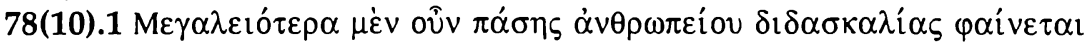

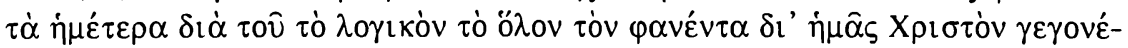

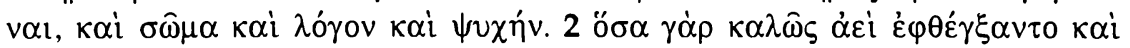

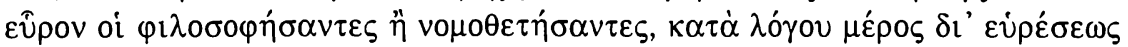

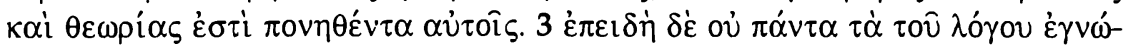

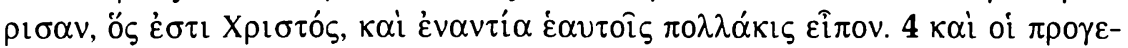

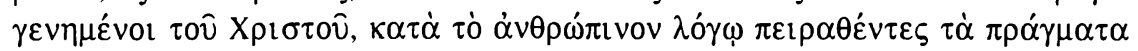

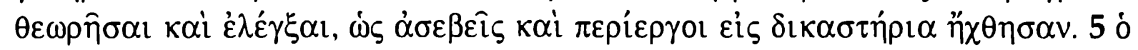

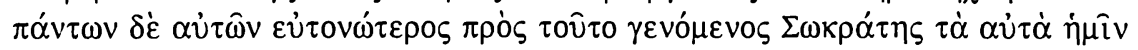

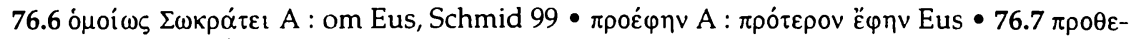
$\mu \dot{\varepsilon} v \omega$ Otto : $\pi \rho \circ \varepsilon \mu \dot{\varepsilon} v \omega \mathrm{A}$

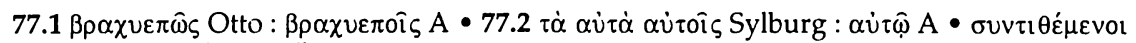

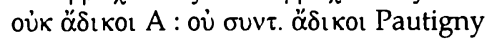

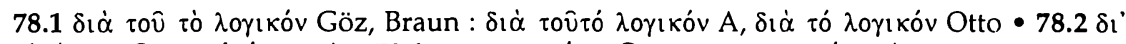

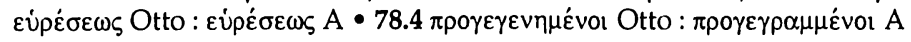

76.6 Platon, Resp. X,595C; 607C • 76.7 Cicéron, Acad.Pr. 42,130; Eusèbe, Praep.euang. XV ,4,16 (Atticus) • 77.2 Platon, Leg. II,662DE; Philon, Sacr.Abel. 131 • 77.3 Platon, Leg. II,661D; Phaedo 73A; Aristote, Eth.Nic. I,1 • 78.5 Platon, Apol. 24B 
parler comme Socrate, il se montre, comme je l'ai dit plus haut, non pas un ami de la sagesse (philosophe) mais un ami de l'opinion, lui qui ne respecte même pas l'admirable maxime de Socrate: "En aucun cas il ne faut honorer un homme plus que la vérité". 7 Mais il est impossible à un cynique, qui s'est assigné l'indifférence comme fin, de connaître le bien ailleurs que dans l'indifférence.

77(9).1 Afin que personne ne vienne dire, comme les prétendus philosophes que, quand nous affirmons que les méchants sont punis dans un feu éternel, ce ne sont là que paroles en l'air et épouvantails et que nous voulons amener les hommes à la vertu au moyen de la crainte et non point parce qu'il est beau et agréable de vivre dans la vertu, je vais répondre brièvement à cette objection; je dirai donc: s'il n'est est pas ainsi, Dieu n'existe pas, ou bien s'il existe, il ne se soucie pas des hommes et rien n'est ni bien ni mal et, comme nous l'avons dit plus haut, c'est injustement que les législateurs punissent ceux qui transgressent leurs sages prescriptions. 2 Tout au contraire puisqu'ils ne sont pas injustes, ni eux, ni leur Père, qui nous enseigne par le Logos à l'imiter dans notre conduite, ceux qui leur obéissent ne sont pas non plus injustes. 3 Mais si quelqu'un nous objecte la diversité des lois humaines, en disant que chez les uns ceci est considéré comme bien et cela comme mal, tandis que chez d'autres est considéré comme bien ce qui passait pour mal chez les premiers et comme mal ce qui passait pour bien, écoutez encore ce que nous répondons à cela. 4 D'une part, nous savons que les mauvais anges ont institué, à l'image de leur perversité, des lois auxquelles se complaisent les hommes qui leur ressemblent; d'autre part, quand elle intervient, la droite raison démontre que toutes les opinions et tous les principes ne sont pas bons, mais qu'il y en a de mauvais et de bons. A ceux qui font de telles objections, je répondrai de même ou de manière analogue et je pourrai le faire plus explicitement, s'il en est besoin. 5 Mais pour le moment, je reviens à mon propos.

78(10).1 Il est donc évident, disais-je, que notre doctrine est supérieure à toute doctrine humaine du fait que l'intégralité du Logos, le Christ, qui a paru pour nous, est devenu corps, raison et âme. 2 En effet, tout ce que depuis toujours les philosophes et les législateurs ont dit et découvert d'excellent, ils l'ont élaboré grâce à leur recherche et à leur réflexion touchant partiellement le Logos. 3 Mais parce qu'ils n'ont pas connu l'intégralité du Logos, qui est le Christ, ils ont exprimé souvent des opinions contradictoires. 4 De plus, les hommes qui ont vécu avant le Christ, quand ils se sont efforcés, autant que le permet la nature humaine, de considérer et d'interroger le réel à la lumière de la raison, ont été traînés devant les tribunaux comme impies et magiciens. 5 Celui qui s'y appliqua avec le plus de vigueur, Socrate, fut l'objet des mêmes accusations que 


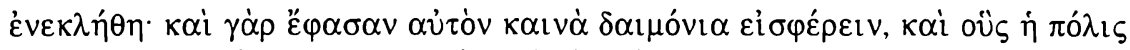

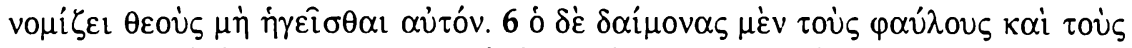

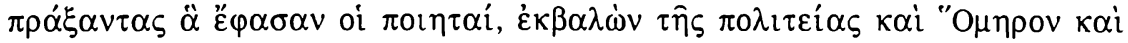

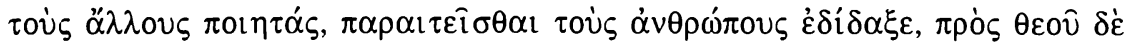

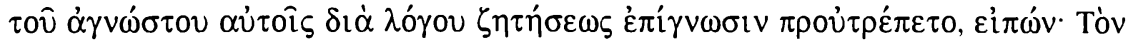

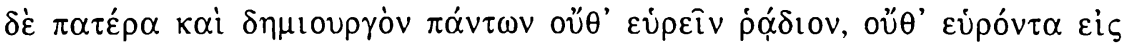

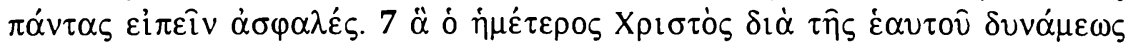

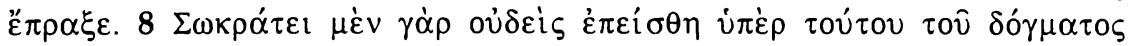

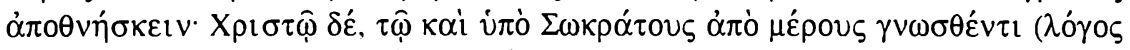

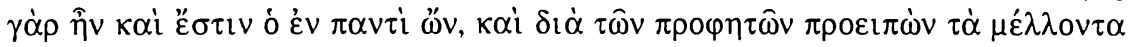

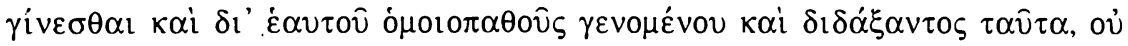

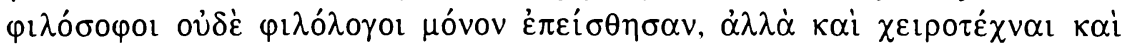

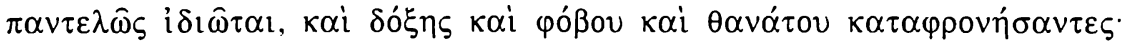

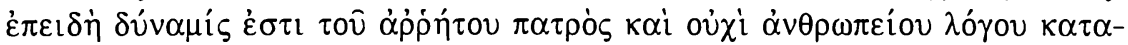

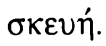

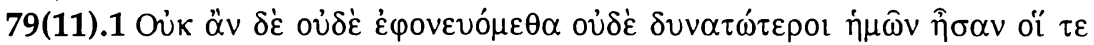

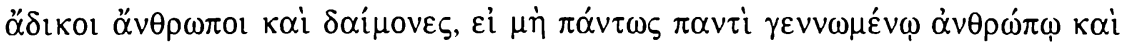

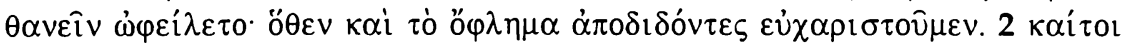

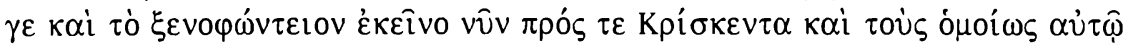

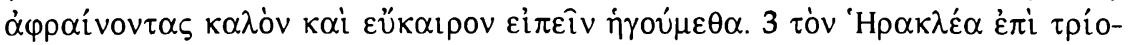

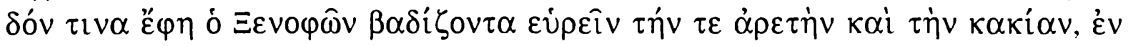

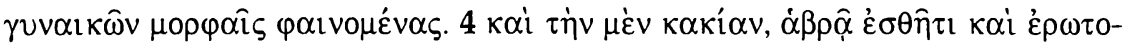

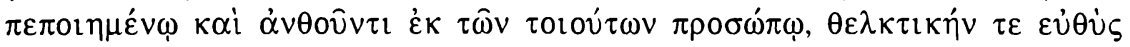

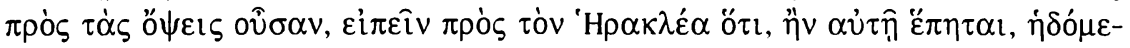

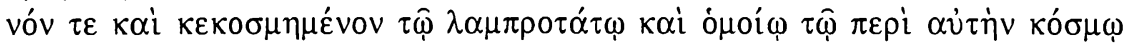

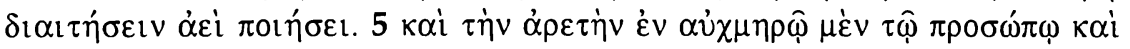

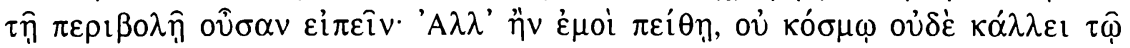

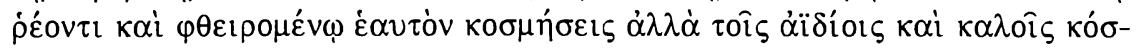

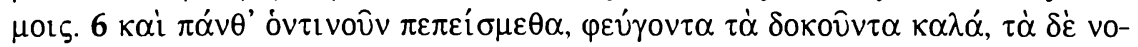

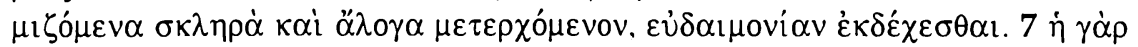

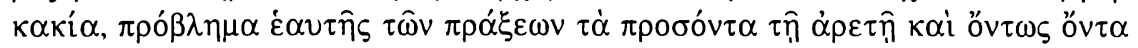

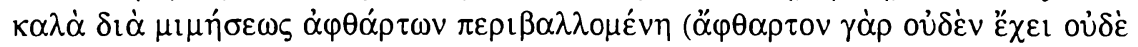

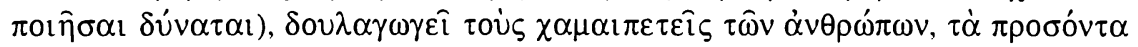

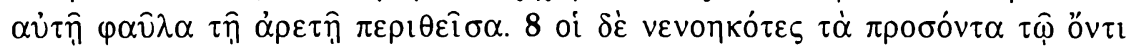

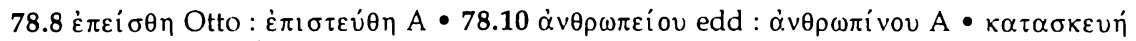

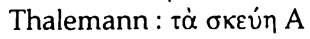

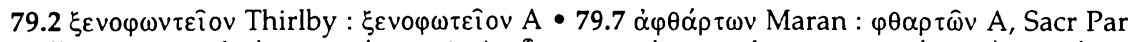

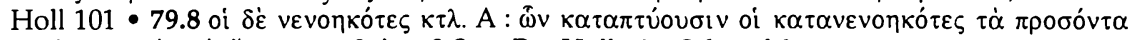

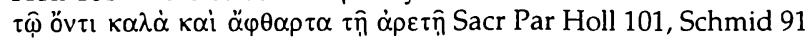

78.6 Platon, Tim. 28C; Resp. II; X • 79.2-8 Xénophon, Mem. II,1 • 79.6 Platon, Resp. II,361; IX,591 
nous: on lui reprochait d'introduire des divinités nouvelles et de ne pas croire aux dieux que reconnaît la cité. 6 Mais lui, en expulsant de sa République Homère et les autres poètes, enseignait aux hommes à se détourner des mauvais démons et des divinités qui commettent ce que les poètes ont raconté, et il les exhortait à acquérir par une recherche fondée en raison la connaissance du Dieu qui leur était inconnu. "Il n'est pas facile, disait-il, de trouver le Père et créateur de l'univers et, quand on l'a trouvé, il n'est pas sans risque d'en parler à tous". 7 Cela, notre Christ l'a réalisé par sa propre puissance. 8 En effet, personne ne s'est laissé convaincre par Socrate de mourir pour sa doctrine, mais le Christ, que Socrate avait connu partiellement (car il était et il est le Logos présent en tout homme, qui a prédit l'avenir par les prophètes et par lui-même, lui qui est devenu passible comme nous et qui nous a donné cet enseignement), ce ne sont pas seulement des philosophes et des lettrés, mais aussi des artisans et des gens sans aucune instruction, qui se sont laissé persuader par lui de mépriser l'opinion, la crainte et la mort, parce qu'il est la puissance du Père ineffable et non pas une production de la raison humaine.

79(11).1 Nous ne serions pas mis à mort, les méchants et les démons n'auraient pas de pouvoir sur nous, si la mort n'était une dette dont doit s'acquitter tout homme né en ce monde; c'est pourquoi nous sommes heureux de payer notre dette. 2 Cependant nous estimons qu'il est beau et opportun de citer maintenant, à l'attention de Crescent et de ceux qui partagent son égarement, le fameux mythe de Xénophon. 3 Héraclès, ditil, arriva un jour à un carrefour, où il rencontra la Vertu et le Vice, qui se présentèrent à lui sous la figure de deux femmes. 4 Le Vice, qui portait un vêtement somptueux et présentait un visage florissant grâce aux artifices habituels, de nature à charmer au premier regard, promit à Héraclès, s'il s'attachait à sa suite, de le faire jouir sans fin de tous les plaisirs de la vie, revêtu de la gloire la plus éclatante, comme celle dont il était luimême paré. 5 Quant à la Vertu, qui avait un visage et un vêtement sévères, elle lui dit: "Au contraire, si tu te laisses persuader par moi, tu ne chercheras pas à te parer d'ornements ni d'une beauté fugitive et périssable, mais de la beauté éternelle et véritable". 6 Or, nous sommes fermement convaincus que quiconque fuit la beauté apparente, pour s'attacher à ce qui est considéré comme pénible et déraisonnable, aura part à la béatitude. 7 Pour voiler ses propres actions, le Vice s'affuble des propriétés de la Vertu, qui sont réellement bonnes du fait qu'elles imitent les êtres incorruptibles (car lui ne possède rien d'incorruptible et ne peut rien réaliser de tel), asservit les hommes attachés au terrestre, et impose à la Vertu ses propriétés, qui sont mauvaises. 8 Mais ceux qui ont compris 


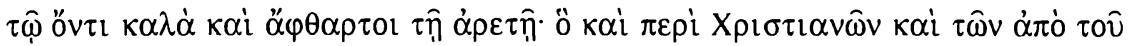

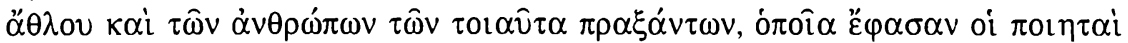

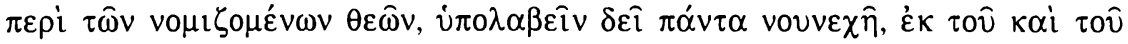


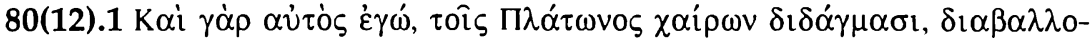

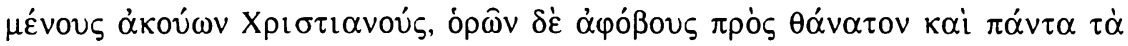

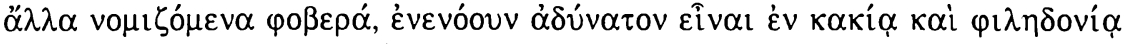

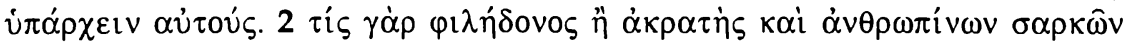

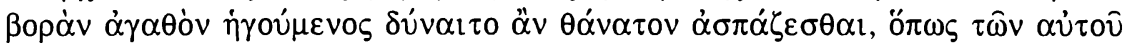

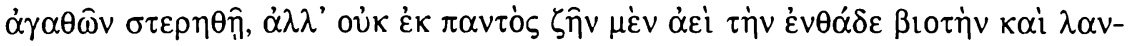

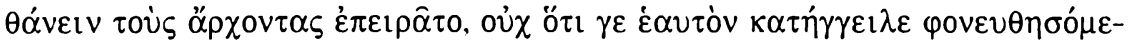

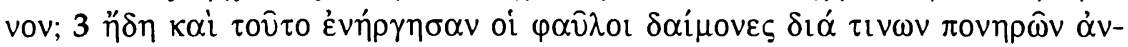

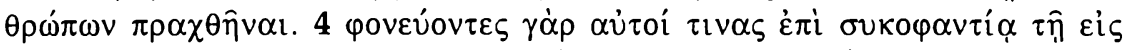

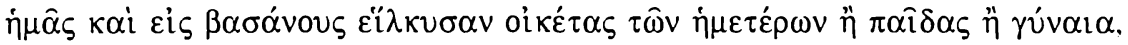

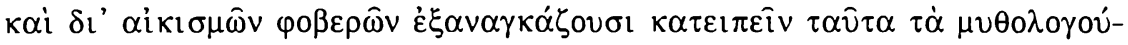

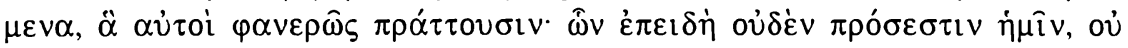

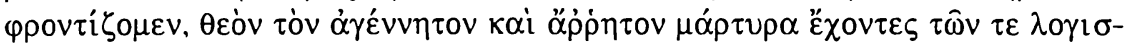

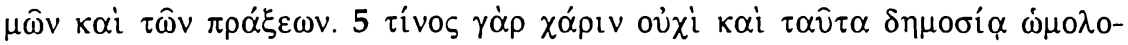

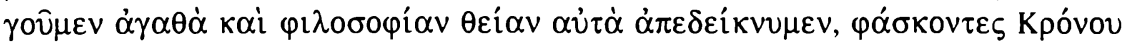

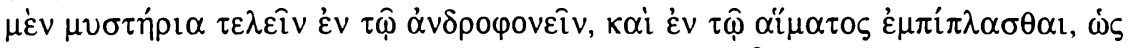

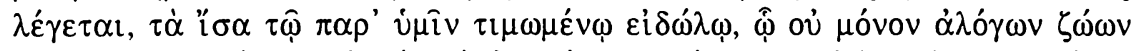

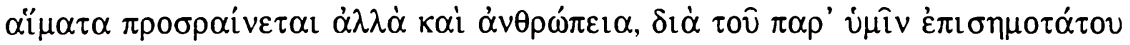

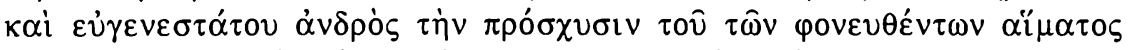

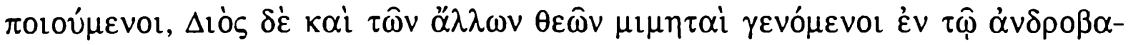

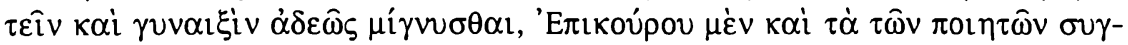

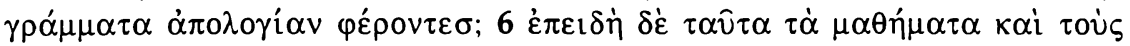

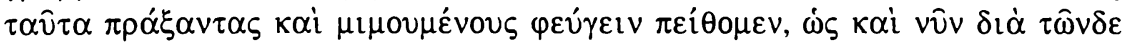

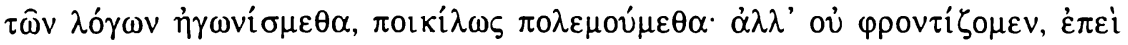

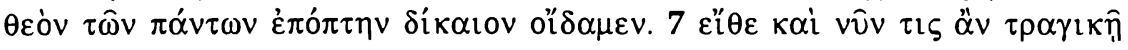

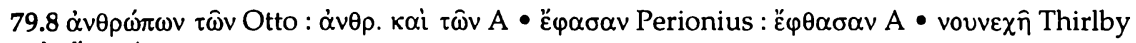

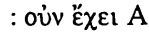

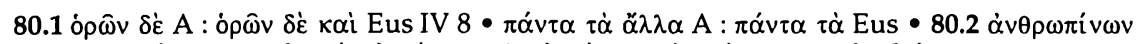

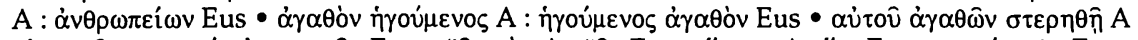

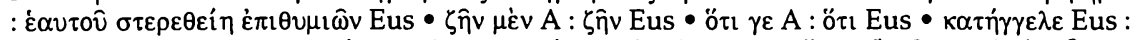

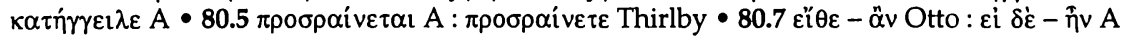

80.1-2 cf. Eusèbe, H.E. IV,8,5 • 80.5 Cronos: cf. Tertullien Apol. 9; Minucius Felix, Oct. 30,3; Origène, Cels, V,27; Porphyre, Abstin. II,56. - Libation: cf. Tertullien, Apol. 9,5 
les beautés véritables qui appartiennent à la Vertu, sont eux aussi incorruptibles grâce à elle. Cela, tout homme sensé doit le concevoir à propos des chrétiens, des athlètes et des hommes qui accomplissent des actions du genre de celles que les poètes racontent au sujet de leurs prétendues divinités, pour peu qu'il veuille prendre en compte le fait que nous méprisons la mort, alors que nous pourrions l'éviter.

80(12).1 Moi-même, à l'époque où je prenais plaisir aux enseignements de Platon, en entendant les accusations portées contre les chrétiens et en les voyant intrépides en face de la mort et de tout ce qui passe pour être effrayant, je concluais qu'il était impossible qu'ils vécussent dans le vice et la recherche du plaisir. 2 Quel homme, en effet, avide du plaisir et de la débauche, ou qui ferait ses délices d'un repas de chair humaine, pourrait saluer avec empressement la mort qui le prive de ses biens? ne chercherait-il pas, au contraire, par tous les moyens, à jouir toujours de la vie présente et à échapper aux magistrats, bien loin de se dénoncer lui-même, pour être mis à mort. 3 Voici encore ce que les mauvais démons viennent de manigancer avec la complicité de certains personnages pervers. 4 Voulant faire condamner à mort plusieurs personnes sur ces calomnies répandues contre nous, ils ont mis à la question nos serviteurs, des adolescents ou de jeunes servantes et, au prix d'effroyables tortures, ils les ont forcés à nous imputer ces crimes, inventés de toutes pièces, qu'ils commettent eux-mêmes ouvertement. Mais puisque rien de tout cela ne nous concerne, nous ne nous en inquiétons pas, car comme témoin de nos pensées et de nos actions nous avons le Dieu inengendré et ineffable. 5 Pourquoi, en effet, ne pas reconnaître publiquement que ces pratiques sont bonnes et déclarer que c'est là une philosophie divine? Pourquoi ne pas dire que, par l'homicide, nous célébrons les mystères de Cronos; qu'en nous abreuvant de sang, nous célébrons un culte semblable à celui que vous rendez à l'idole que vous honorez par des aspersions, non seulement de sang des animaux sans raison, mais même de sang humain, quand, par la main du plus illustre et du plus noble d'entre vous, vous offrez la libation du sang des hommes qui ont été mis à mort; que nous imitons Zeus et les autres dieux en nous livrant à des débauches sans retenue avec des hommes et des femmes? Ne pourrions-nous pas justifier notre conduite en alléguant les écrits d'Épicure et des poètes? 6 Or, parce que nous cherchons à inspirer l'horreur de ces maximes, de ceux qui les mettent en pratique, et de leurs imitateurs - et c'est maintenant encore ce que nous avons tâché de faire par ces discours -, on nous fait la guerre par tous les moyens, mais cela ne nous préoccupe pas, car nous savons que Dieu est un juste observateur de toutes choses. $7 \mathrm{Ah}$, si seulement, de nos jours 



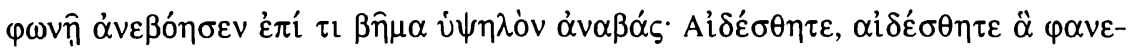

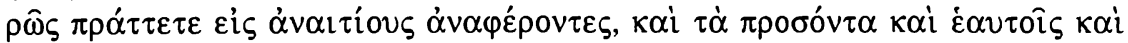

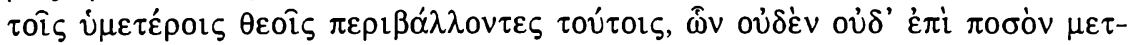

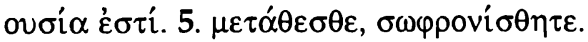

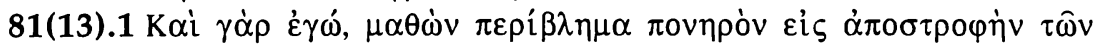

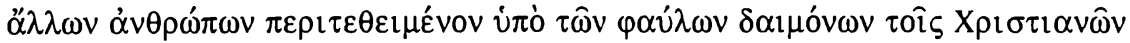

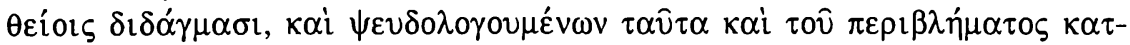

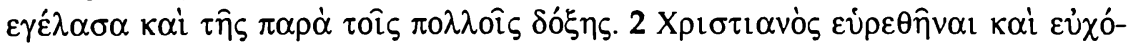

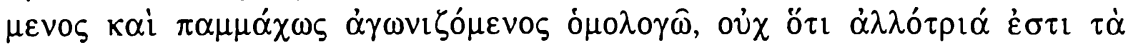

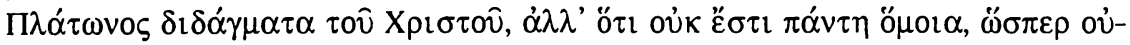

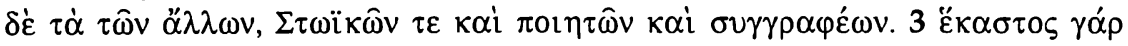

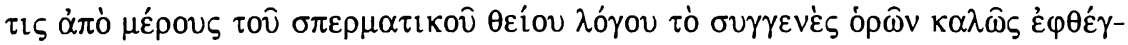

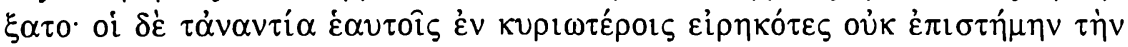

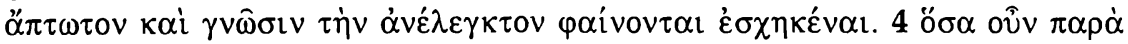

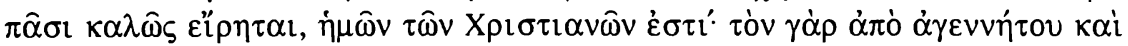

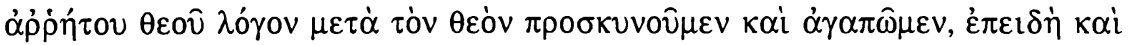

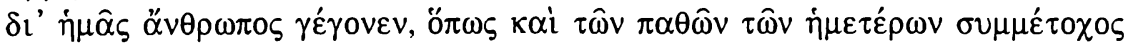

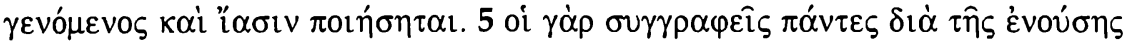

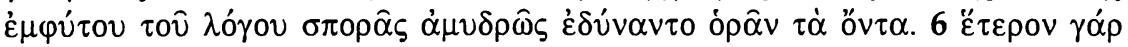

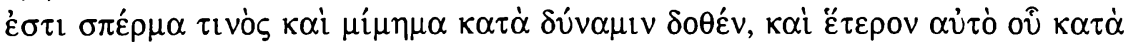

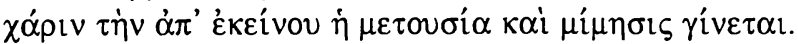

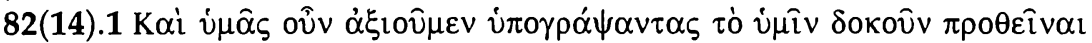

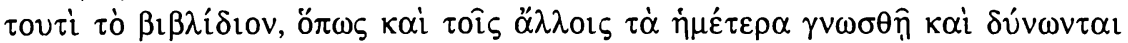

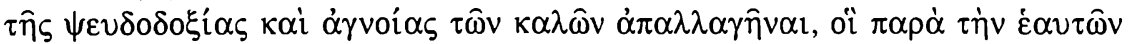

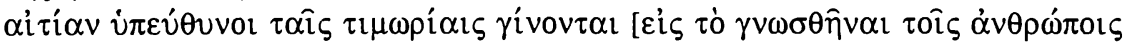

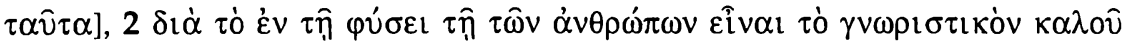

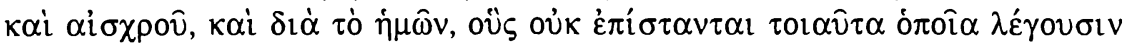

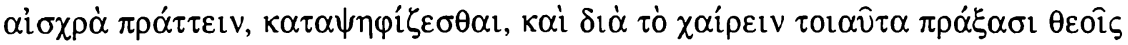

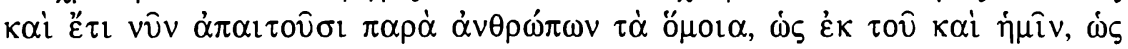

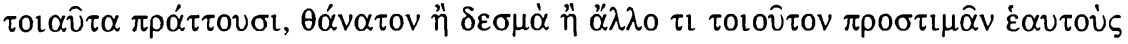

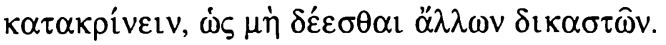

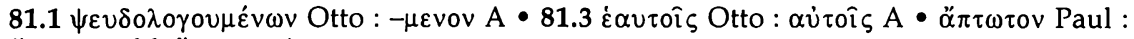

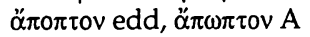

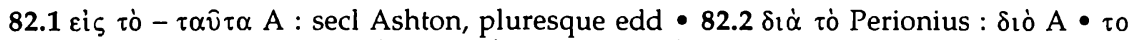

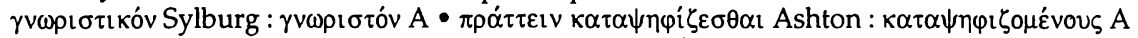

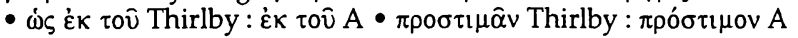

80.7 Platon, Clitoph. 407A 
encore quelqu'un pouvait, du haut d'une tribune élevée, faire retentir ce cri tragique: "Honte à vous, honte à vous, qui rejetez sur des innocents ce que vous commettez au grand jour et qui imputez à des hommes qui n'y ont aucune part, si minime soit-elle, les crimes qui vous appartiennent, à vous et à vos dieux. 8 Changez de conduite, venez à résipiscence".

81(13).1 De fait, moi aussi, quand j'eus compris que les mauvais démons avaient jeté un vêtement d'infamie sur les divins enseignements des chrétiens, je me suis moqué de ceux qui débitent ces calomnies, de ce vêtement et de l'opinion de la foule. 2 Être reconnu comme chrétien est l'objet de ma prière et de tous mes efforts, je le confesse; ce n'est pas que les enseignements de Platon soient complètement étrangers à ceux du Christ, mais ils ne lui sont pas absolument identiques, non plus que ceux des autres, Stoïciens, poètes et prosateurs. 3 En effet, dans la mesure où chacun, en vertu d'une participation au divin Logos séminal, a contemplé ce qui lui était connaturel, il en a parlé excellemment, mais ceux qui se sont contredits eux-mêmes sur des points essentiels montrent bien qu'ils ne possèdent ni une science infaillible ni une connaissance irréfutable. 4 Or, donc, ce qui a été dit excellemment par tous, nous appartient à nous chrétiens; en effet, après Dieu, nous adorons et nous aimons le Logos, né du Dieu inengendré et ineffable, puisqu'il est devenu homme pour nous, afin de prendre part aussi à nos misères, pour nous en guérir. 5 Tous les écrivains pouvaient, grâce à la semence du Logos implantée en eux, voir la réalité, d'une manière indistincte. 6 Mais autre chose est une semence et une ressemblance d'un être, accordées aux hommes à la mesure de leur capacité, autre chose l'être même dont la participation et l'imitation se réalisent en vertu de la grâce qui vient de lui.

82(14).1 Or donc nous vous demandons de faire connaître votre décision par votre souscription apposée à ce libelle et de le faire publier, afin que notre doctrine soit connue aussi des autres hommes et qu'ils puissent être libérés des préjugés et de l'ignorance du bien, eux qui, par leur propre faute, s'exposent au châtiment. 2 Dans la nature humaine se trouve, en effet, le pouvoir de connaître le bien et le mal et, du fait qu'ils nous condamnent pour des abominations, dont ils ne savent pas si nous accomplissons celles qu'ils nous imputent, tandis qu'ils se plaisent à des divinités qui commettent de tels actes et qui maintenant encore demandent aux hommes d'en commettre de semblables, lorsqu'ils nous infligent la mort, la prison ou quelque autre peine, comme si nous étions coupables de tels actes, ils prononcent contre eux-mêmes la sentence de condamnation, de sorte qu'il n'est pas besoin d'autres juges. 


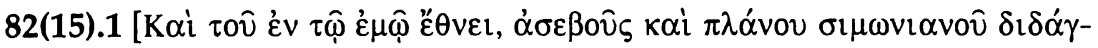

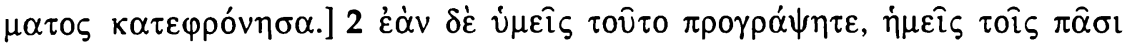

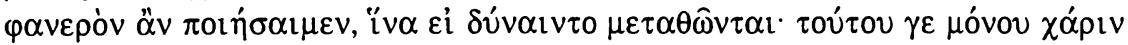

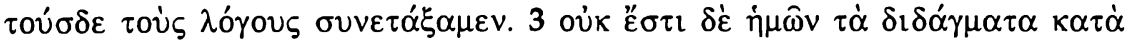

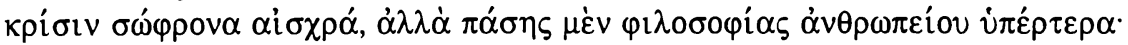

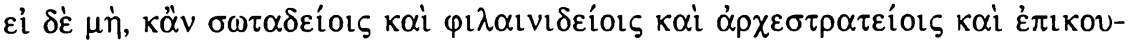

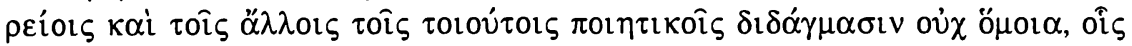

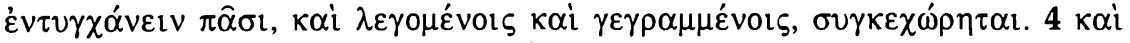

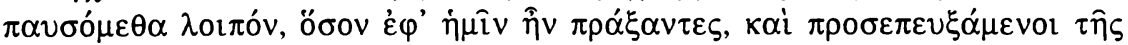

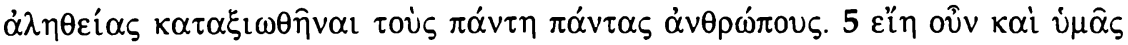

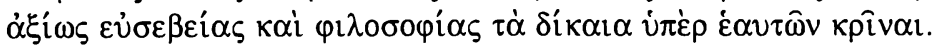

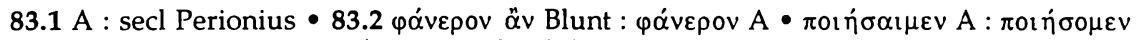

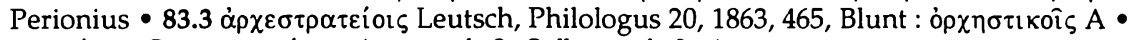

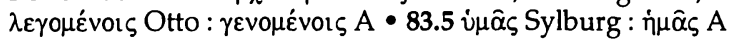

83.3 Sotadès: Plutarque, Ed.puer. 14; Strabon, XIV,1,41. - Philaenis: Athénée, VIII,p.335BE; X,457 DE; Tatien, Or.34. - Archestratos: Athénée, VIII, p.101F; 104B; 278E • 83.5 cf. Tertullien, Scap. 2,16 
83(15).1 [J'ai méprisé aussi la doctrine impie et erronée de Simon (répandue) dans ma nation.] 2 Si vous approuviez la publication de cet écrit, nous le ferions connaître à tous, afin que tous, s'il est possible, changent d'avis: du moins est-ce dans ce seul but que nous avons composé ces discours. 3 A en juger sainement, nos enseignements ne comportent rien d'infamant; ils sont, au contraire, supérieurs à toute philosophie humaine. Si l'on n'en convient pas, (on accordera), du moins, (qu')ils ne ressemblent pas à ceux de Sotadès, Philaenis, Archestrate, Épicure et des autres poètes du même genre, dont tout le monde peut prendre connaissance, soit en lecture publique, soit par écrit. 4 Nous allons conclure maintenant, après avoir fait ce qui dépendait de nous et après avoir prié afin que tous les hommes, en tout lieu, soient jugés dignes de la vérité. 5 Puissiez-vous donc, vous aussi, comme il convient à votre piété et à votre philosophie, dans votre propre intérêt, prononcer un juste jugement. 



\section{INDEX SCRIPTURAIRE}

\section{Ancien Testament}

$\begin{array}{ll}\text { Genèse } & \\ 1,1-2 & 64,2 \\ 1,1-3 & 59,2-4 \\ 1,2 & 60,6 \\ 1,3 & 60,6 \\ 6,1-5 & 5,2 ; 72,3 \\ 6,9-12 & 5,2 \\ 19, & 53,7-8 \\ 49,10 & 32,2.4 .5 .7 \\ 49,10-11 & 32,1 ; 54,5 \\ & \\ \text { Exode } & \\ 3,2 & 63,7.11 .17 \\ 3,5 & 62,3 \\ 3,6 & 63,7.11 .17 \\ 3,10 & 63,7.11 .17 \\ 3,14 & 63,7.11 .17 \\ 3,15 & 63,7\end{array}$

Nombres

$\begin{array}{ll}21,6-9 & 60,2-4 \\ 21,6 & 60,3 \\ 24,17 & 32,12\end{array}$

\section{Deutéronome}

$\begin{array}{ll}6,5 & 16,6 \\ 30,15 & 44,1 \\ 30,19 & 44,1 \\ 32,22 & 60,9\end{array}$

\section{Chroniques}

$\begin{array}{ll}16,23 & 41,1 \\ 16,25-31 & 41,1-4\end{array}$

\section{Psaumes}

$\begin{array}{ll}1,1-6 & 40,7-10 \\ 2,1-12 & 40,11-19 \\ 3,6 & 38,5 \\ 19,3-6 & 40,1-4 \\ 19,6 & 54,9 \\ 22,8-9 & 38,6 \\ 22,17-19 & 35,5 ; 38,4-5 \\ 22,19 & 35,8 \\ 24,7-8 & 51,7 \\ 96,1-2 & 41,1 \\ 96,4-10 & 41,1-4 \\ 110,1-3 & 45,2-4 \\ 110,2 & 45,5 \\ 135,15-18 & 9,1\end{array}$

Isaïe

1,3

$63,2-12$

\begin{tabular}{|c|c|}
\hline $1,3-4$ & $37,1-2$ \\
\hline 1,7 & 47,5 \\
\hline 1,9 & 53,7 \\
\hline $1,11-15$ & 13,$1 ; 37,5$ \\
\hline $1,16-20$ & $44,3-4 ; 61,7-8$ \\
\hline 1,20 & 44,5 \\
\hline $2,3-4$ & 39,1 \\
\hline 5,20 & 49,7 \\
\hline 7,14 & $33,1.4 ; 54,8$ \\
\hline 9,5 & 35,2 \\
\hline 11,1 & 32,12 \\
\hline 11,10 & 32,10 \\
\hline 11,12 & 52,10 \\
\hline 29,18 & 22,$6 ; 48,2$ \\
\hline $35,5-6$ & 48,2 \\
\hline $43,5-6$ & 52,10 \\
\hline $45,23-24$ & 52,6 \\
\hline $50,6-8$ & $38,2-3$ \\
\hline 51,1 & 32,12 \\
\hline $52,13-15$ & $50,3-4$ \\
\hline $53,1-8$ & $50,5-11$ \\
\hline 53,2 & 52,3 \\
\hline $53,8-12$ & $51,1-5$ \\
\hline 53,12 & 50,2 \\
\hline 54,1 & 53,5 \\
\hline $57,1-2$ & $48,5-6$ \\
\hline 58,2 & $35,3-4 ; 38,1$ \\
\hline $58,6-7$ & 37,8 \\
\hline 63,17 & 52,12 \\
\hline $64,9-11$ & $47,2-3$ \\
\hline 64,10 & 52,12 \\
\hline $65,1-3$ & $49,2-3$ \\
\hline 65,2 & $35,3-4 ; 38,1$ \\
\hline 66,1 & 37,4 \\
\hline 66,24 & 52,$8 ; 75,5$ \\
\hline Jérémie & \\
\hline 2,15 & 47,5 \\
\hline $9,24-25$ & 53,11 \\
\hline $17,9-10$ & 43,2 \\
\hline 50,3 & 47,5 \\
\hline Lamentatic & \\
\hline 4,20 & 55,5 \\
\hline Ezéchiel & \\
\hline 18,23 & 15,8 \\
\hline 33,11 & 15,8 \\
\hline $37,7-8$ & $52,5-6$ \\
\hline $\begin{array}{l}\text { Daniel } \\
7,13\end{array}$ & 51,9 \\
\hline
\end{tabular}


Jö̈l

Zacharie

2,3

52,11

2,10

52,10

9,9

35,11

Michée

$\begin{array}{ll}4,2-3 & 39,1 \\ 5,1 & 34,1\end{array}$

$12,10-12 \quad 52,11$

$12,12 \quad 52,12$

$14,5 \quad 51,9$

Nouveau Testament

Matthieu

1,21

1,23

$1,31-32$

2,6

4,23

5,1

5,16

5,22

5,28

5,29

5,32

5,34

5,37

$5,39-40$

5,41

5,42

5,44

$5,44-45$

5,45

5,46

5,48

6,1

6,10

6,19-20

6,20

6,21

6,25-26

6,31-33

7,15-16

7,19

7,21

$7,22-23$

7,24

9,13

9,35

10,1

10,28

10,40

11,5

11,27

13,9

$13,42-43$

16,26

18,3
$33,5.8$

33,1

33,5

34,1

31,7

34,1

16,2

16,2

15,1

15,2

15,3

16,5

16,5

16,1

16,2

15,10

14,3

15,9

15,13

$15,10.13$

15,13

15,17

68,2

15,11

15,12

15,16

15,14

$15,15-16$

16,13

16,13

16,9

16,11

16,10

15,8

31,7

31,7

19,7

16,$10 ; 63,5$

22,$6 ; 48,2$

$63,3.13$

53,1

16,12

15,12

61,4
18,9

19,11-12 15,

19,17

19,26

$21,1 \mathrm{~s}$.

22, 17-21

22,31-32

$22,37-38 \quad 16,6$

23,8

24,5

25,31

25,41

26,27-28

26,31

26,32

$27,39-42$

28,19

16,7

19,6

32,6

17,2

63,17

65,1

16,13

51,9

28,$1 ; 75,5$

66,3

50,12

68,2

38,8

61,3

Marc

2,17

4,9

15,8

8,36

9,47

10,11

$10,17-18$

10,27

11,1

12,14-17

$12,29-30$

13,6

14,22

15,29-32

Luc

1,31-32

1,35

5,32

6,27

$6,27-28$

6,28

6,29

6,30

6,32

6,34

$6,35-36$
53,1

15,12

15,2

15,3

16,7

19,6

32,6

17,2

16,6

16,13

66,3

38,8

33,5

32,$10 ; 33,4$

15,8

15,9

14,3

15,9

16,1

$15,10.13$

15,9

$15,10.16$

15,13 


\begin{tabular}{|c|c|c|c|}
\hline $6,43-44$ & 16,13 & \multicolumn{2}{|c|}{ Actes des Apôtres } \\
\hline 6,46 & 16,9 & $1,8-9$ & 50,12 \\
\hline 6,47 & 16,10 & 4,13 & 39,3 \\
\hline 8,8 & 53,1 & 4,27 & 40,6 \\
\hline 9,25 & 15,12 & $8,9-11$ & 26,2 \\
\hline 10,6 & 16,$10 ; 63,5$ & $13,27-28$ & 49,5 \\
\hline 10,22 & $63,3.13$ & 13,48 & 49,5 \\
\hline 10,27 & 16,6 & 17,23 & 78,6 \\
\hline $12,4-5$ & 19,7 & 17,25 & 10,1 \\
\hline 12,22 & 15,14 & & \\
\hline $12,22-24$ & 15,16 & Romains & \\
\hline 12,24 & 15,14 & $1,10-23$ & 28,3 \\
\hline $12,29-30$ & 15,15 & 14,11 & 52,6 \\
\hline 12,31 & 16,16 & & \\
\hline 12,33 & 15,11 & I Corinthiens & \\
\hline 12,34 & 15,16 & 2,5 & 60,11 \\
\hline 12,48 & 17,4 & $11,23-25$ & 66,3 \\
\hline $13,26-28$ & 16,11 & 14,16 & 65,3 \\
\hline 16,18 & 15,3 & 15,53 & 19,4 \\
\hline $18,18-19$ & 16,7 & & \\
\hline 18,27 & 19,6 & Galates & \\
\hline $20,22-25$ & 17,2 & 4,27 & 53,5 \\
\hline $20,36-37$ & 63,17 & & \\
\hline 21,8 & 16,13 & Philippiens & \\
\hline $22,19-20$ & 66,3 & 2,10 & 52,6 \\
\hline $23,35-37$ & 63,17 & & \\
\hline $24,25-27$ & 50,12 & I Timothée & \\
\hline $24,44-46$ & 50,12 & 5,17 & 65,3 \\
\hline Jean & & II Timothée & \\
\hline 1,1 & 63,15 & 2,12 & 10,2 \\
\hline 1,3 & 73,3 & & \\
\hline 3,3 & 61,$4 ; 73,3$ & Hébreux & \\
\hline 4,24 & 61,4 & 3,1 & 12,9 \\
\hline 7,29 & $63,3.13$ & 10,32 & 61,12 \\
\hline 8,19 & $63,3.13$ & & \\
\hline 10,15 & $63,3.13$ & Jacques & \\
\hline 14,29 & 33,2 & 5,12 & 16,5 \\
\hline 16,3 & $63,3.13$ & & \\
\hline & & $\begin{array}{l}\text { Apocalypse } \\
20,2\end{array}$ & 28,1 \\
\hline
\end{tabular}




\section{AUTEURS MODERNES}

Les chiffres renvoient aux paragraphes de l'introduction.

\begin{tabular}{|c|c|c|c|}
\hline L. Abramowski & 15 & R. Freudenberger & $6 ; 8$ \\
\hline L. Alfonsi & $9 ; 10$ & & \\
\hline C. Andresen & 10 & G.I. Gargano & 14 \\
\hline D.E. Aune & 12 & $\begin{array}{l}\text { J. Geffcken } \\
\text { J. Gervais }\end{array}$ & $\begin{array}{l}1 \\
12\end{array}$ \\
\hline H. Bacht & 12 & G. Glockmann & 10 \\
\hline G. Bardy & $1 ; 2 ; 10 ; 16 ; 18$ & E.R. Goodenough & $13 ; 17 ; 18$ \\
\hline L.W. Barnard & $\begin{array}{l}2 ; 6 ; 11 ; 12 ; \\
13 ; 15,17 ; 18\end{array}$ & $\begin{array}{l}\text { R.M. Grant } \\
\text { P. Grech }\end{array}$ & $\begin{array}{l}1 \\
14 ; 15\end{array}$ \\
\hline D. Barthélémy & 13 & & \\
\hline W. Bauer & 16 & A. Hamman & 17 \\
\hline T. Baumeister & 9 & R.P.C. Hanson & $9 ; 12 ; 14$ \\
\hline E. Baumgartner & 17 & A. von Harnack & $3 ; 9 ; 16$ \\
\hline A. Bellinzoni & 15 & R. Heard & 15 \\
\hline A. Benoît & 17 & O. Heggelbacher & 17 \\
\hline E. Benz & 9 & A. Henrichs & 8 \\
\hline J. Betz & 17 & A. Hermann & 6 \\
\hline A.W.F. Blunt & 5 & H.H. Holfelder & $4 ; 20$ \\
\hline D. Bourgeois & 10 & P. Hofrichter & 15 \\
\hline W. Bousset & $10 ; 15$ & R. Holte & 10 \\
\hline E.R. Buckley & 15 & K. Hubik & 20 \\
\hline J. Buffière & 10 & $\begin{array}{l}\text { U. Hüntemann } \\
\text { W. Hüttl }\end{array}$ & $\begin{array}{l}20 \\
4 ; 5\end{array}$ \\
\hline C. Callewaert & 7 & N. Hyldahl & 2 \\
\hline H. von Campenhausen & 11 & & \\
\hline H. Cancik & 16 & G. Iguno & 8 \\
\hline B. Capelle & 7 & J. Irmscher & 14 \\
\hline M. Carena & 9 & & \\
\hline Ph. Carrington & 14 & R. Joly & 10 \\
\hline L. Cerfaux & 6 & G. Jossa & 11 \\
\hline H. Chadwick & $10 ; 11 ; 13$ & M. Jourjon & 17 \\
\hline A. Chavasse & 16 & & \\
\hline B.S. Childs & 15 & Ch. Kannengiesser & 2 \\
\hline J. Colin & 6 & P. Katz & 13 \\
\hline O. Cullmann & 14 & P. Keresztes & $7 ; 8 ; 20$ \\
\hline W.A. Curtis & 14 & $\begin{array}{l}\text { D. Kienast } \\
\text { B. Kleinheyer }\end{array}$ & $\begin{array}{l}5 \\
17\end{array}$ \\
\hline J. Daniélou & 10 & L. Kline & $12 ; 15$ \\
\hline E. Dassmann & 15 & W.D. Köhler & 15 \\
\hline D. M. Davey & 15 & K. Koschorke & 16 \\
\hline A. Deneffe & 14 & H. Köster & $12 ; 13 ; 15$ \\
\hline G.E.M. de Sainte-Croix & 7 & H. Kraft & 10 \\
\hline C.H. Dodd & $6 ; 13$ & G. Kretschmar & 17 \\
\hline F.J. Dölger & 8 & W.S. Kurz & 12 \\
\hline A.J. Droge & 10 & & \\
\hline M. Dujarier & 14 & $\begin{array}{l}\text { P. de Labriolle } \\
\text { H. Langerbeck }\end{array}$ & $\begin{array}{l}1 \\
16\end{array}$ \\
\hline B.S. Eastwood & 7 & P. Lampe & $2 ; 10 ; 16$ \\
\hline M. Edwards & 16 & H. Last & 7 \\
\hline M. von Engelhardt & 18 & $\begin{array}{l}\text { A. Le Boulluec } \\
\text { R. Le Déaut }\end{array}$ & $\begin{array}{l}16 \\
13\end{array}$ \\
\hline $\begin{array}{l}\text { E. Fascher } \\
\text { E. Flesseman-van Leer }\end{array}$ & $\begin{array}{l}9 ; 14 \\
14\end{array}$ & G. Lüdemann & $2 ; 16$ \\
\hline
\end{tabular}




\begin{tabular}{|c|c|c|c|}
\hline C. Markschies & 16 & C. Scholten & 16 \\
\hline J.L. Marshall & 12 & L. Scipioni & 11 \\
\hline E. Massaux & 15 & B. Seeberg & $11 ; 18$ \\
\hline M. Mees & 15 & M.H. Shepherd & 17 \\
\hline G. Melinossi & 9 & W.A. Shotwell & 12 \\
\hline Th. Mommsen & 7 & J. Sikora & 10 \\
\hline V. Monachino & 1 & O. Sild & \\
\hline C. Mondésert & 14 & M. Simonetti & 16 \\
\hline J. Morales & & O. Skarsaune & $2 ; 12$ \\
\hline P. de Mouxy & 8 & A. Solignac & 2 \\
\hline Ch. Munier & $4 ; 7 ; 20$ & $\begin{array}{l}\text { M. Sordi } \\
\text { M. Spanneut }\end{array}$ & $\begin{array}{l}7 \\
10\end{array}$ \\
\hline W. Nestle & $8 ; 9$ & J. Speigl & $6 ; 9$ \\
\hline U. Neymeyr & $2 ; 14 ; 16$ & K. Stendahl & 13 \\
\hline F. Normann & & H.E. Stier & 6 \\
\hline E. Osborn & $2 ; 11 ; 15,18$ & $\begin{array}{l}\text { C.I.K. Story } \\
\text { A. Stötzel }\end{array}$ & $\begin{array}{l}17 \\
10\end{array}$ \\
\hline & & G. Strecker & 15 \\
\hline $\begin{array}{l}\text { L.G. Patterson } \\
\text { M. Pellegrino }\end{array}$ & $\begin{array}{l}11 \\
1 ; 10\end{array}$ & T. Stylianopoulos & 16 \\
\hline J. Pépin & $9 ; 10$ & M. Tabet & 14 \\
\hline P. Pilhofer & $10 ; 15 ; 19$ & K. Thraede & 17 \\
\hline P.A. Piper & 15 & C. Tibiletti & 16 \\
\hline E. des Places & 10 & J. Tixeront & 18 \\
\hline T.E. Pollard & 15 & & \\
\hline I. Posnoff & 12 & D. van den Eynde & $14 ; 17$ \\
\hline R. Price & 10 & J.C.M. van Winden & \\
\hline P. Prigent & $12 ; 15$ & H Veil & $5 ; 20$ \\
\hline A. Puech & $1 ; 18$ & $\begin{array}{l}\text { A. Vitale } \\
\text { J. de Vogel }\end{array}$ & $\begin{array}{l}8 \\
10\end{array}$ \\
\hline A. Quacquarelli & 11 & & \\
\hline G. Quispel & 16 & $\begin{array}{l}\text { J.P. Waltzing } \\
\text { A. Wartelle }\end{array}$ & $\begin{array}{l}8 \\
18\end{array}$ \\
\hline J. Ranft & 14 & J.H. Waszink & 10 \\
\hline E.C. Ratcliff & 17 & Th. Wehofer & 20 \\
\hline B. Reicke & 17 & H.Wey & 10 \\
\hline J. Ries & 9 & G. Widengren & 14 \\
\hline J. Roloff & 14 & U. Wilcken & 4 \\
\hline J. Romanidès & 15 & $\begin{array}{l}\text { R.L. Wilken } \\
\text { G.H. Williams }\end{array}$ & $\begin{array}{l}1 ; 16 \\
17\end{array}$ \\
\hline $\begin{array}{l}\text { V. Saxer } \\
\text { W. Schmid }\end{array}$ & $\begin{array}{l}17 \\
8 ; 10 ; 19\end{array}$ & N. Zeegers-Vander Vorst & 10 \\
\hline
\end{tabular}



XXVII. Maximus Confessor. Actes du Symposium sur Maxime le Confesseur. Fribourg, 2-5 septembre 1980. Edités par Felix Heinzer et Christoph Schönborn, 438 p. (1982).

XXVIII. Jean-Michel Poffet O.P.: La méthode exégétique d'Héracléon et d'Origène commentateurs de Jn 4: Jésus, la Samaritaine et les Samaritains.

XXX-302 p. (1985).

XXIX. Othmar Perler: Sapientia et Caritas. Gesammelte Aufsätze zum 90. Geburtstag. Herausgegeben von Dirk van Damme und Otto Wermelinger. XII-632 p. (1990).

XXX. Jean-Louis Feiertag: Les Consultationes Zacchaei et Apollonii. Etude d'histoire et de sotériologie. XLIV-380 p. (1990).

XXXI. Marie-Anne Vannier: "Creatio», "Conversio», "Formatio» chez S. Augustin. XXXVIII-240 p. (1991).

XXXII. Klaus Koschorke: Spuren der alten Liebe. Studien zum Kirchenbegriff des Basilius von Caesarea. VII-408 S. (1991).

XXXIII. Philippe Henne: La christologie chez Clément de Rome et dans le Pasteur d'Hermas. 378 p. (1992).

XXXIV. Jean-Michel Girard: La mort chez Saint Augustin. Grandes lignes de l'évolution de sa pensée, telle qu'elle apparaît dans ses traités. 256 p. (1992).

XXXV. Philippe Bruggisser: Symmaque ou le rituel épistolaire de l'amitié littéraire. Recherches sur le premier livre de la correspondance. VIII-536 p. (1993).

XXXVI. WILLY RoRdoRF: Lex orandi - Lex credendi. Gesammelte Aufsätze zum 60. Geburtstag. XVI-532 S. (1993).

XXXVII. Richard Seagraves: Pascentes cum disciplina. A Lexical Study of the Clergy in the Cyprianic Correspondence. XII-344 p. (1993).

XXXVIII. Charles Munier: L'Apologie de saint-Justin. Philosophe et martyr. XXVI-178 p. (1994). 



\section{Résumé}

La présente édition reflète fidèlement l'état des recherches concernant cette œuvre capitale du IIe siècle. Pour le texte, l'éditeur revient à l'ordre du manuscrit, malencontreusement abandonné en 1742 par Dom Prudent Maran et prend en compte les conjectures des éditions et des philologues antérieurs. Afin de souligner l'unité de l'œuvre, il propose une numérotation continue, parallèle à l'ancienne. Une ample introduction, une bibliographie abondante et sélective, des index appropriés complètent l'ouvrage, qui devient un instrument de référence.

\section{Zum vorliegenden Buch}

Die vorliegende Edition der Apologie Justins spiegelt den Stand der Forschung zu diesem Hauptwerk der Literatur des 2. Jahrhunderts wieder. Der Text wird nach Anordnung der Handschrift geboten, die von Dom Prudent Maran im Jahre 1742 abgeändert worden war. Darüberhinaus wurden die Konjekturen früherer Editoren und Bearbeiter berücksichtigt. Um die Einheit des Werkes herauszustellen, wird eine fortlaufende Numerierung, parallel zur früher üblichen, eingeführt. Eine Einführung, eine ausführliche Bibliographie sowie Indices runden das Werk ab.

\section{Abstract}

This edition takes into account the results of research concerning this most important work of the second century. The editor restores the order of the manuscript, which had been unfortunately abandoned in 1742 by Dom Prudent Maran. It also takes into account the conjectures of anterior editions and philologists. In order to stress the unity of the work, the edition proposes a continuous numbering of chapters, parallel to the old one. An ample introduction, an abundant and selective bibliography, as well as appropriate indexes make this edition a work of reference for future studies. 


